
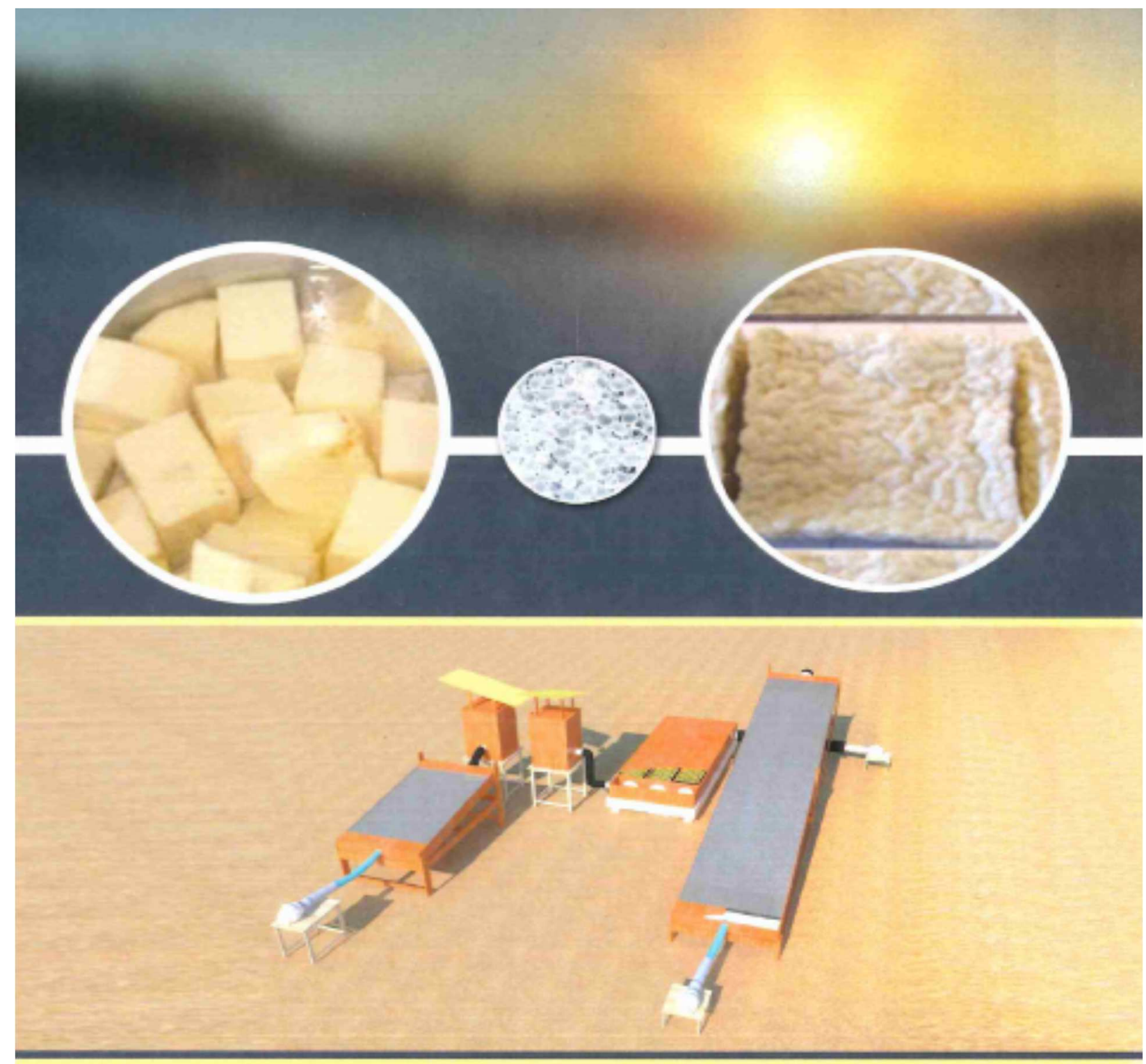

Drying of Yam with Solar Adsorption System

Emmanuel Yaw Adu Amankwah

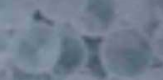




\section{Drying of yam with solar adsorption system}

Emmanuel Yaw Adu Amankwah 


\section{Thesis committee}

\section{Promotor}

Prof.Dr K.J. Keesman

Personal chair Biobased Chemistry and Technology

Wageningen University \& Research

\section{Co-promotors}

Dr A.J.B. van Boxtel

Associate professor Biobased Chemistry and Technology

Wageningen University \& Research

Prof. Dr K.A. Dzisi

Associate professor Food and Post-Harvest Engineering KNUST, Kumasi, Ghana

Prof.Dr G. van Straten

Emeritus professor Systems and Control

Wageningen University \& Research

\section{Other members}

Prof.Dr P.C. Struik, Wageningen University \& Research

Prof.Dr J. Müller, Hohenheim University, Germany

Dr M.A.I. Schutyser, Wageningen University \& Research

Dr M.A. Boon, Wageningen University \& Research

This research was conducted under the auspices of the Graduate School VLAG (Advance studies in Food Technology, Agrobiotechnology, Nutrition and Health Sciences) 


\title{
Drying of yam with solar adsorption system
}

\author{
Emmanuel Yaw Adu Amankwah
}

\section{Thesis}

submitted in fulfilment of the requirements for the degree of doctor

at Wageningen University

by the authority of the Reactor Magnificus

Prof. Dr A.P.J. Mol,

in the presence of the

Thesis Committee appointed by the Academic Board

to be defended in public

on Thursday 9 May 2019

at 11 a.m. in the Aula. 
E.Y.A. Amankwah

Drying of yam with solar adsorption system

138 Pages

$\mathrm{PhD}$ thesis, Wageningen University, Wageningen, the Netherlands (2019)

With references, with summaries in English and Twi.

ISBN: 978-94-6343-439-3

DOI $10.18174 / 471677$ 


\section{Table of Contents}

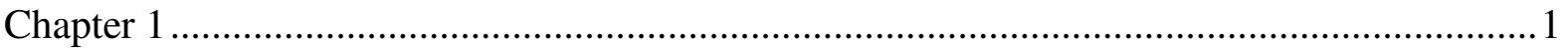

Drying of yam with solar adsorption system, ............................................................. 1

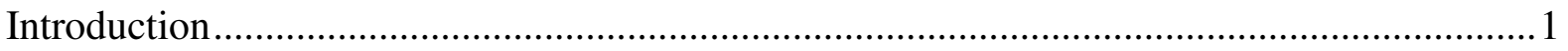

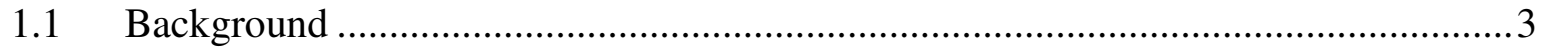

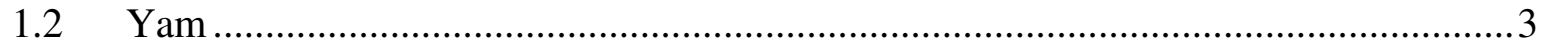

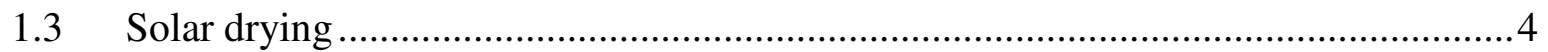

1.4 Solar Adsorption Drying (SAD) …………………………………………...6

1.5 Modeling of moisture content and sorption .......................................................

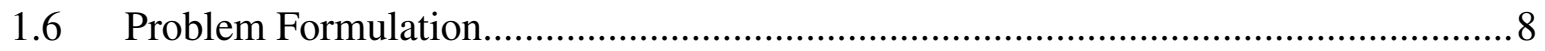

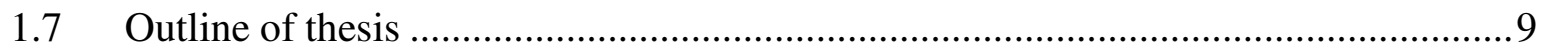

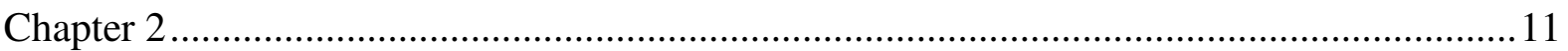

Modeling the equilibrium moisture content of desorption and adsorption of yam (Dente).11

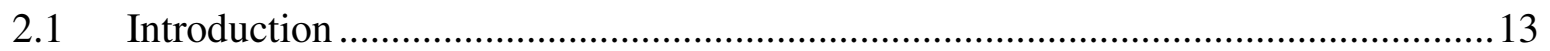

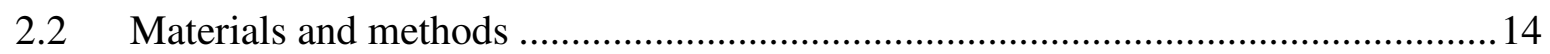

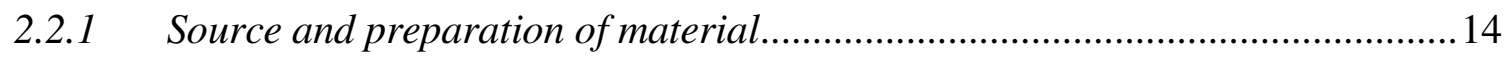

2.2.2 Procedure and measuring equipment …………….......................................... 14

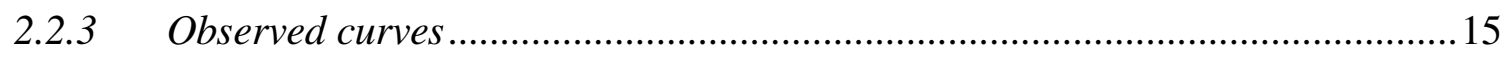

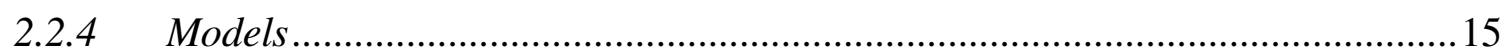

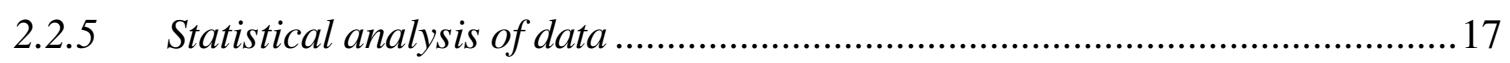

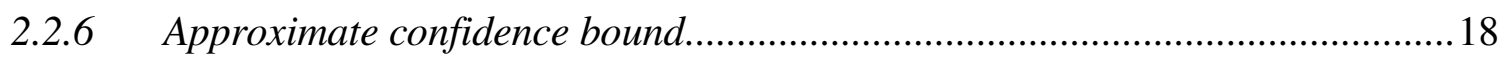

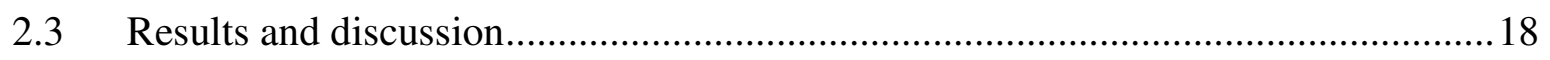

2.3.1 Desorption and adsorption isotherms measurements .......................................18

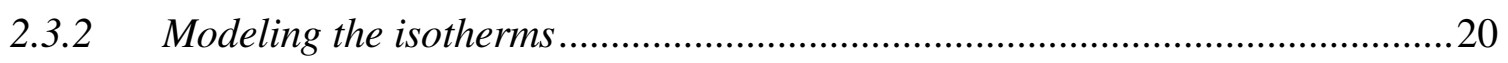

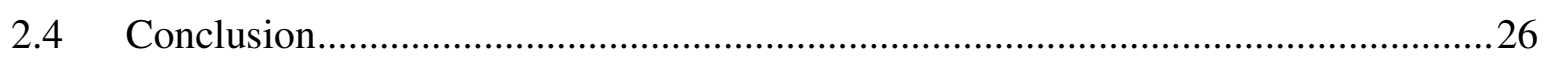

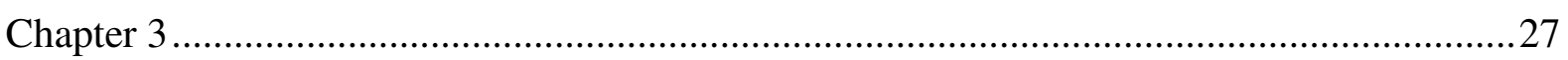

Moisture dependent diffusion and shrinkage in yam during drying ...................................27

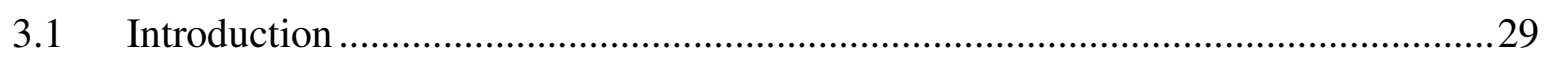

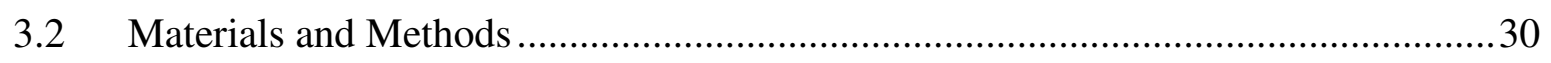

3.2.1 Yam species and sample preparation ……………………………................... 30

3.2.2 Shrinkage and moisture measurements ........................................................ 30

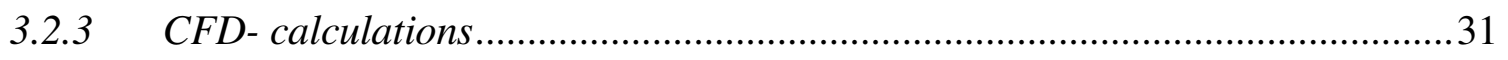

3.2.4 Drying procedure and equipment …………………......................................

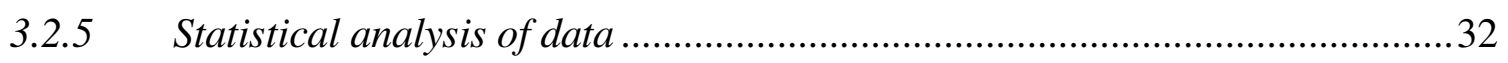


3.3 Results and discussion

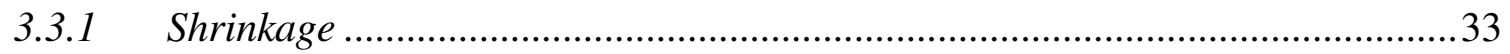

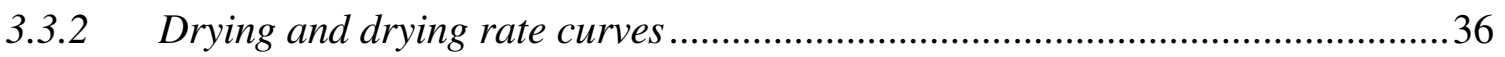

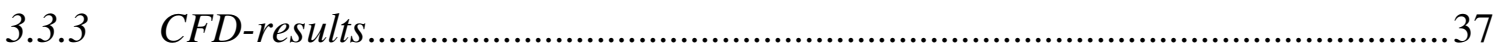

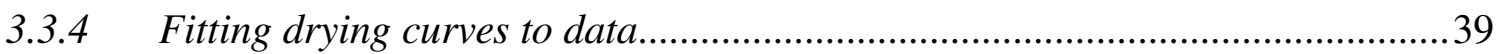

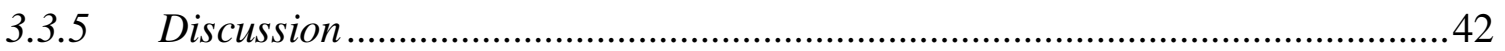

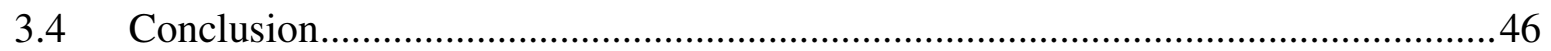

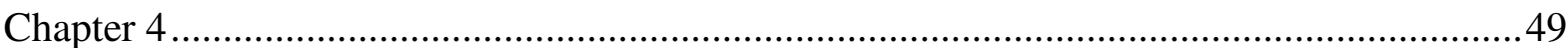

Distributed mathematical model supporting design and construction of solar collectors for

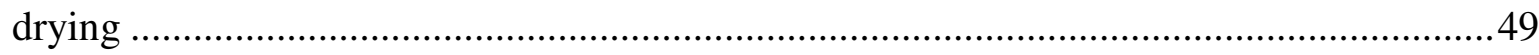

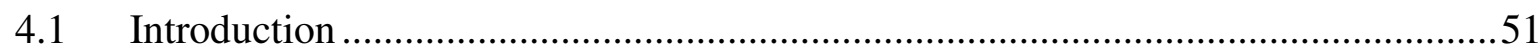

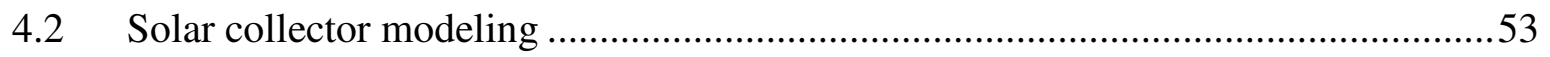

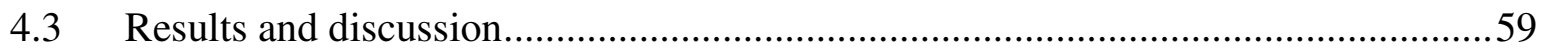

4.3.1 Model-based solar collector design and analysis...........................................59

4.3.2 Effect of absorber surface on performance .......................................................61

4.3.3 Effect of collector length on temperature .......................................................... 61

4.3.4 Construction of Collector Equipment …...........................................................63

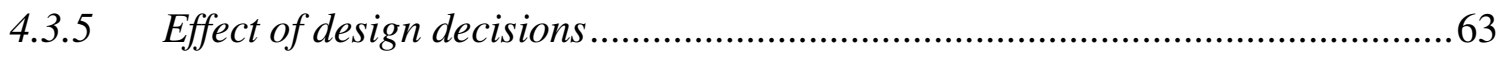

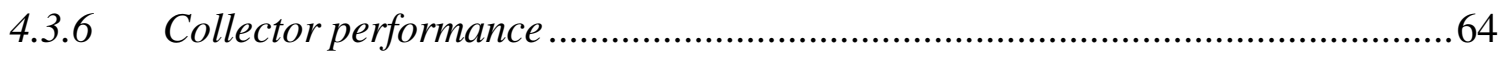

4.3.7 Effect of air speed on collector performance ..................................................65

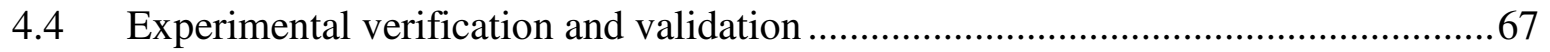

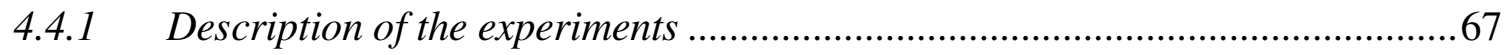

4.4.2 Model verification and parameter adjustment ...............................................67

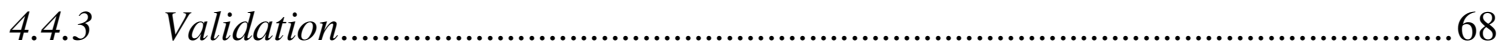

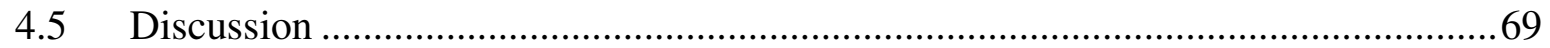

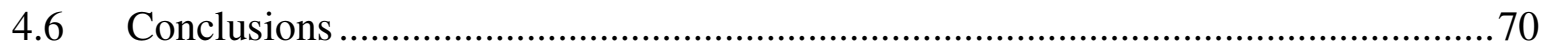

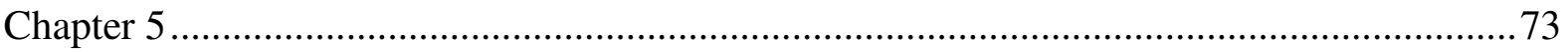

Experimental verification of yam drying with Solar Adsorption Drying ..........................73

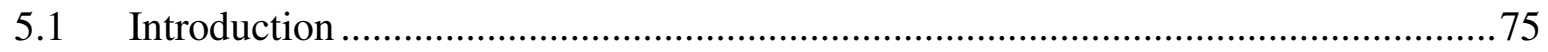

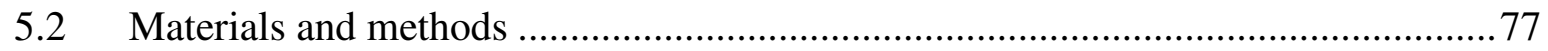

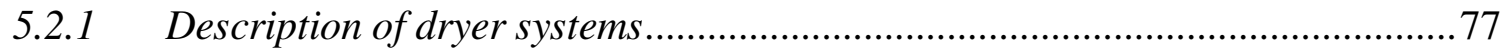

5.2.2 Temperature, air velocity and weight measurements ..................................... 78

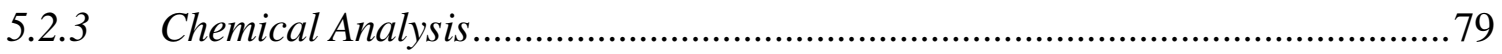

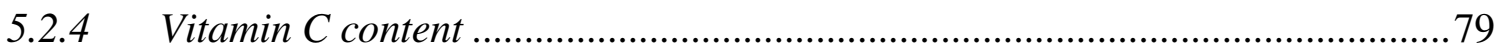

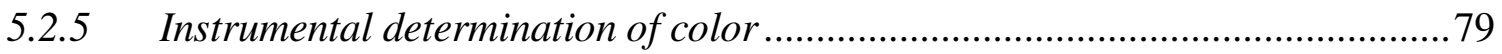




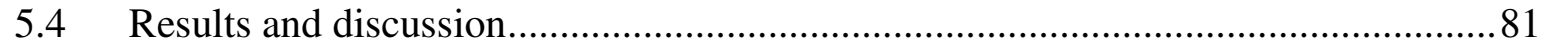

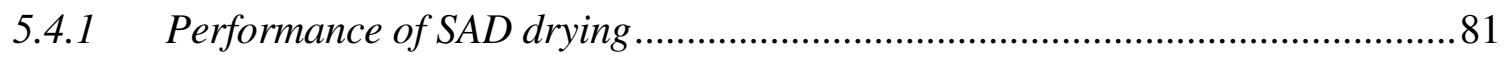

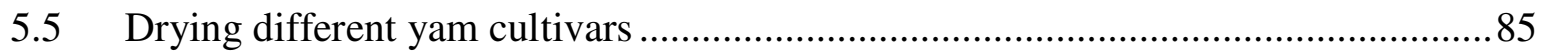

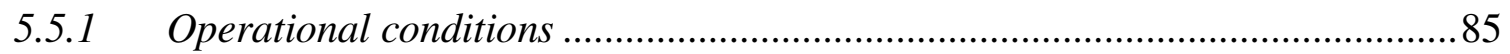

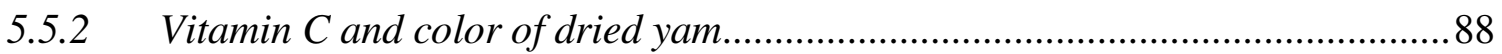

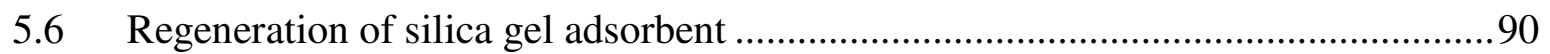

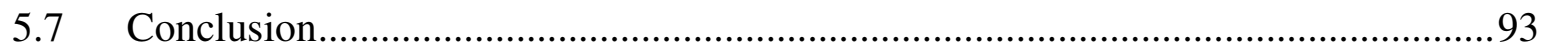

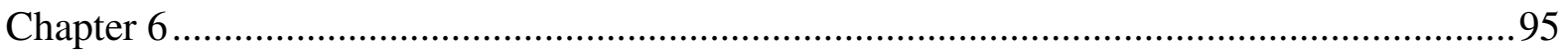

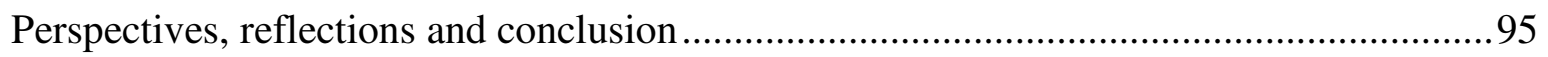

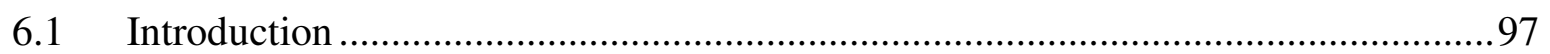

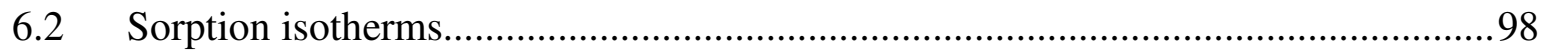

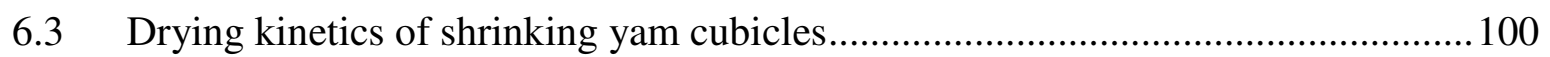

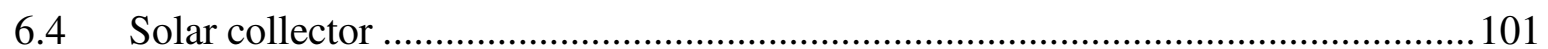

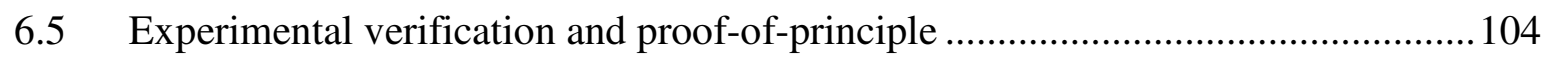

6.6 Perspectives of SADS (in Africa and elsewhere)................................................ 106

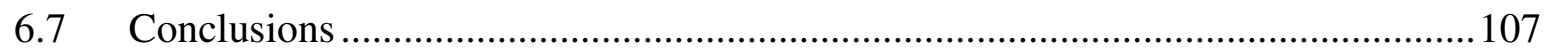

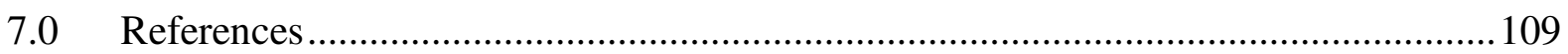

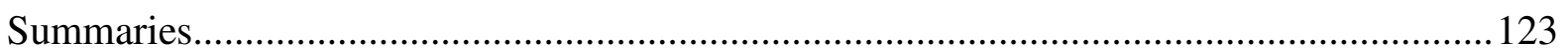

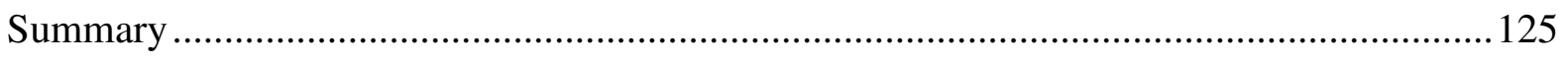

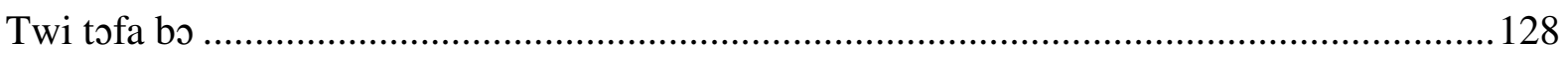

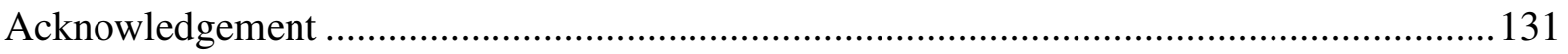

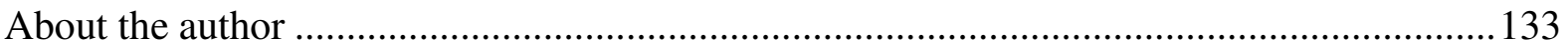

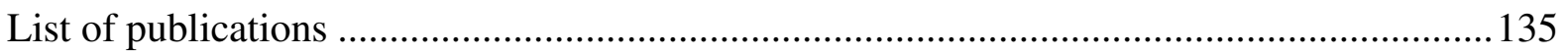

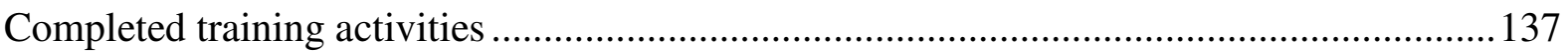


Chapter 1

Drying of yam with solar adsorption system, Introduction 


\subsection{Background}

Drying is a common but one of the most challenging unit operations in food processing. It concerns removing moisture in food to yield a solid product (Chemkhi et al., 2005; VegaMercado et al., 2001). The aims of drying vary from weight reduction to enhancing aesthetic and sensory effects of food (Brennan, 2006). However, the main goal is to reduce moisture content to levels that halt or slow the growth of spoilage organisms and incident of chemical reactions (2010; Vega-Mercado et al., 2001) in order to extent the shelf life of food (Doymaz, 2004, 2005; Oduro et al., 2007). One of the concerns of the consumer is to have a sample that closely represents the original sample. Also the dried product should potentially lead to the same variety of processed foods compared to products from the raw sample. In case of heat treatment, undesirable changes in the quality of the dried product may occur, and it is a challenge to preserve the original qualities as much as possible (Akpinar et al., 2003b).

\subsection{Yam}

Yam (see Figure 1.1) is an important food crop for many people in the yam zone of West Africa. It forms about $10 \%$ of the total roots and tubers produced in the world (FAO, 2005). It has been estimated that the world yam production would increase by $27 \%$ between 2003 and 2020. In Ghana yam production increased by $10 \%$ in 2004 (Kenyon et al., 2006). Yam is second to cassava as the most important tropical root crop, but is nutritionally better than cassava on account of their vitamin $\mathrm{C}(0.040-0.120 \mathrm{mg} / \mathrm{g}$ edible portion) and crude protein $(0.040$ $0.140 \mathrm{~g} / \mathrm{kg}$ dry matter) content (Opara, 1999). In addition to their high carbohydrate content, Eka (1985) reported that most yams are rich in phosphorus and vitamins such as thiamine, riboflavin and niacin. Yam has a moisture content of about $70 \%(\mathrm{wb})$ when harvested (Fioreze and Morini, 2000). Its high moisture content makes it susceptible to rot, thus, making it highly perishable (Osunde, 2008). Presently, Ghana is the leading exporter of raw yam in West Africa to the international market, Nigeria being the leading producer in the world. Studies have shown that post-harvest losses are estimated within the range of $40-50 \%$ in the tropics, and that between the field and final consumer, high amounts are rejected for consumption (Salunkhe et al., 1991: Kadar et al., 1985). An overall solution to prevent postharvest losses is by drying.

Therefore it is essential to develop effective methods that prolong the shelf life of yam (tubers and slices) while maintaining the nutritional and healthy components. Yam is consumed fresh when boiled, roasted or fried. The shelf life of yam ranges between 1-6 months depending on the variety (Opara, 1999) with post-harvest losses between 10-50\% (Alhassan, 1994). It is consumed when cooked or fried. The fried yam is taken with sauce, stew fried or fresh pepper. The processing of yam into other finished product varies with people of different cultural backgrounds. Much has not been done in the area of enhancing new product development such as dried yam powders incorporated in soups, making composite mixtures in bread dough or weaning foods. 


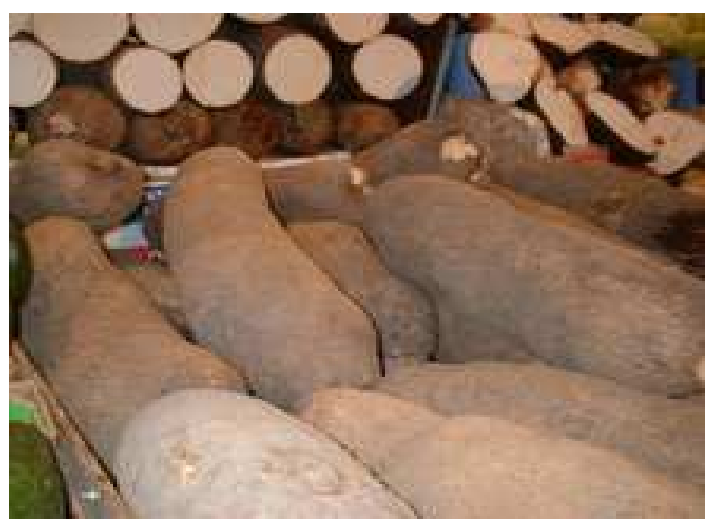

Figure 1.1 Display of yam.

The concentration of nutrients in food products, expressed per kg wet product, increases due to moisture loss during drying. Substantial amount of nutrients, however, can be lost due to both nutrient in evaporated water and temperature effect (Zanoni et al. 1999). Vitamin C, for example, is temperature sensitive and degrades during drying. Thus low and moderate temperatures are necessary for drying. However, the combination of temperature and length of exposure of air to the product is yet to be investigated. Vitamin $\mathrm{C}$ degradation during drying of tomato pulp at higher temperatures have been reported by several researchers (Amankwah et al., 2006, Giovanelli et al., 2002, Toor and Savage, 2004). Agunbiade et al. (2006) measured some physicochemical properties of dried plantain and banana and reported that some proximate composition reduced after dehydration. Effect of drying on protein is expressed in terms of decrease in digestibility and biological value and are denatured at high temperature (Rubens and Heremans, 2000). Heat does not affect total dietary fiber content, but the insoluble dietary fiber content is rather increased due to complexing of its components with protein and amino acids. As a requirement to maintain quality it important that food is dried at low temperature as possible, and at short exposure as possible.

\subsection{Solar drying}

Drying is an energy intensive operation. Conventional and fossil fuel heating are expensive and less efficient for drying and result in unwanted $\mathrm{CO}_{2}$-exhaust. Biomass heating is not a good option since it leads to desertification and erosion. Expensive sources of energy such as electricity or a combination of solar energy and some other form of energy is normally used in drying. An inexpensive option in terms of capital and operational costs is harnessing solar energy technology for heating agricultural products. Ghana is endowed with daily hour by hour mean radiation between 0-920 W/ $\mathrm{m}^{2}$ (Akuffo et al., 1991, 2003). The annual sunshine duration is between 1800-3000 hours (Edjekumhene and Atakora, 2001). This resource has not been harnessed effectively, especially for drying purposes. Solar drying, in open air is the most widely practiced agricultural operation in the world. It is simple, inexpensive and represent a low cost technique for drying agricultural products. During open air drying however, the food is at the mercy of the weather (re-wetting) and subject to microbial contamination, pest, rodents, dust and fumes from vehicles. Consumers demand processed foods that maintains its 
original characteristics, while bacterial and fungal contamination must be prevented from a food hygiene and food safety point of view (Özcan et al., 2005).

The use of solar dryers in drying to minimize or prevent the shortcomings of the open sun drying has been well researched and has proven to be a better alternative to the open sun drying in efficiency and quality of dried products. According to Oguntola et al. (2010), solar dried foods are quality products that can be stored for extended periods, easily transported at less cost while still providing excellent nutritive values. Food samples that are usually dried by direct exposure to the sun in Ghana include cocoa beans, cereals, legumes, leafy vegetables, cassava, yam, cocoyam, plantain and shrimps. Therefore any means by which samples could be dried effectively, quickly and hygienically at a lower cost to make them available during the lean season and to increase its variety of uses without compromising on quality would be very much appreciated. Improvement of design and orientations of the collector to enable it to absorb maximum radiation from the sun during the day would lead to a better performance of the dryer by reducing drying time and increasing the efficiency of the dryer (Karim and Hawlader, 2004). Many developing countries enjoy a superfluous supply of solar energy and as a result still practice the open sun method of drying as reported by Gutti et al. (2012). Solar dryers are generally classified according to the manner in which solar heat is applied and used during the drying process. Generally, dryers are categorized into two broad groups; active solar dryers (forced circulation) and passive dryers (natural circulation) (Sreekumar et al., 2008). Active dryers are systems which induce forced air circulation, while passive dryers only make use of the natural convection principle which generates movement of the heated air. The passive ones have various designs but the most common is as shown in Figure 1.2A and a tunnel one in Figure 1.2C. Figures $1.2 \mathrm{~B}$ and $\mathrm{D}$ are indirect active solar dryers with fans positioned at chimney and inlet respectively.

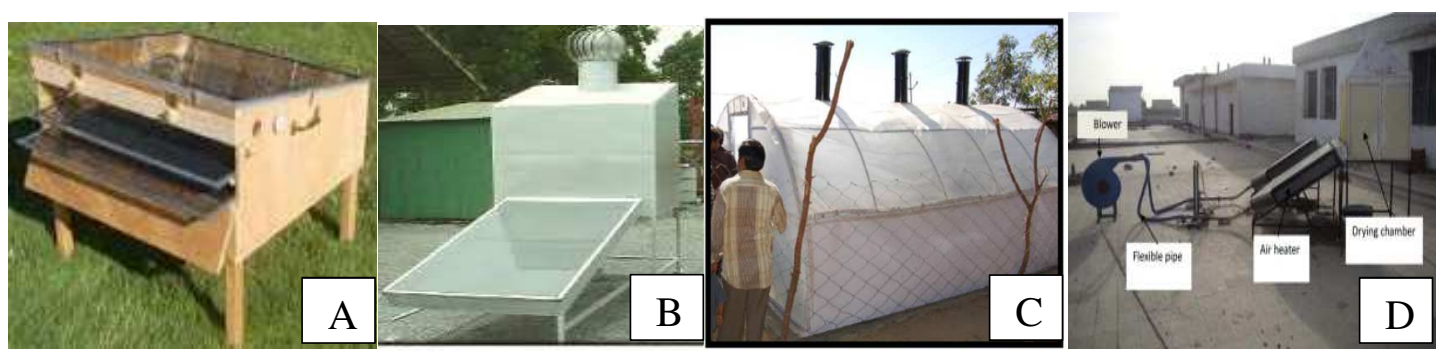

Figure 1.2 Various types of solar dryers: direct passive (A), indirect active (B), indirect passive solar dryer (C) and indirect active solar dryers (D).

Drying has a positive impact on shelf life (Esper and Muhlbauer, 1996). However, the quality of dried products can be compromised after a long exposure to the drying temperatures with adverse effect on some physical properties and nutrient content (Fellow 2000, Hofsetz et al., 2008). 


\subsection{Solar Adsorption Drying (SAD)}

Ghana is exposed to between 6-8 hours of sunshine each day, therefore it would be logical to harvest solar energy with solar collectors for drying during the day time. As mentioned by Arata and Sharma (1991), solar dryers are superior over open sun dryers, whereas it is also true that the solar radiation is not available always. It is important in drying that majority of the free water is removed within the shortest possible time to retard, prevent or halt microbial growth. Adsorption drying has the potential of continuing the drying process especially when the sun is no more. Adsorption drying has been considered lately. Djaeni et al. (2007) developed an integrated process for food drying with air dehumidified by zeolites for adsorption drying, whereby air passes over adsorbent for dehumidification. At the same time the temperature of the air is increased by the release of adsorption heat by converting water vapor to liquid. With this technology, the drying capacity of air is enhanced and drying during the night becomes a reality. Adsorption drying of flowers and herbs, giving excellent quality colour and texture, has been studied by Chua and Chou (2003). Hodali and Bougrand (2001) reduced the drying time of apricot by 8 hours after integrating adsorption into a drying system. Therefore, by combining the best of solar energy systems and adsorption drying, agricultural products can be dried continuously at temperatures with low effect on product quality and color while increasing the through-put.

Although energy is required to regenerate the adsorbent after the adsorption drying process, adsorption drying is much more energy efficient than conventional drying systems (Atuonwu et al., 2010). The challenge is to generate enough energy with the solar collector for regeneration and by so doing, cut down on input energy. Information on the effect of integrated solar and adsorption drying on the drying kinetics and quality of yam is not available.

Silica gel as adsorbent is inert and can be regenerated at low temperatures. Though some researchers have regenerated with compound parabolic concentrator (Pramuang and Exell, 2007), integrated desiccant /collector by (Saito, 1993) and Techajunta et al. (1999) the cost of producing and maintaining a solar concentrator is much higher than for a flat-plate one. Moreover, for flat plate collector the technical expertise, such as maintenance, replacement of parts, monitoring air temperature, can be met by the local farmer. The large surface to volume ratio of silica and the smaller pore spaces impedes on the air flow. This affects the drying and regeneration rate. However, one difficulty is the switch between night adsorbent drying and day regeneration of adsorbent.

A scheme of the SAD concept is shown in Figure 1.3. In this figure, ambient air flows through the collector with the aid of fan over black coated aluminum absorber plate and glass cover plate. The air heats up along the length of the collector. The heated outlet air is channeled into the drying chamber for dying during the day when the sun is available $(1 \rightarrow 2 \rightarrow 3)$. At night, humid ambient air with the aid of axial fan (blower) is blown through an adsorption chamber (silica gel as adsorbent) with compartments arranged in parallel relative to the air flow. The 
outlet air from the adsorption chamber (which is dehumidified with the release of latent heat) is channeled into the drying chamber for night drying $(4 \rightarrow 5 \rightarrow 3)$. At day time the saturated silica gel is regenerated according to the flow $(6 \rightarrow 7 \rightarrow 8)$.

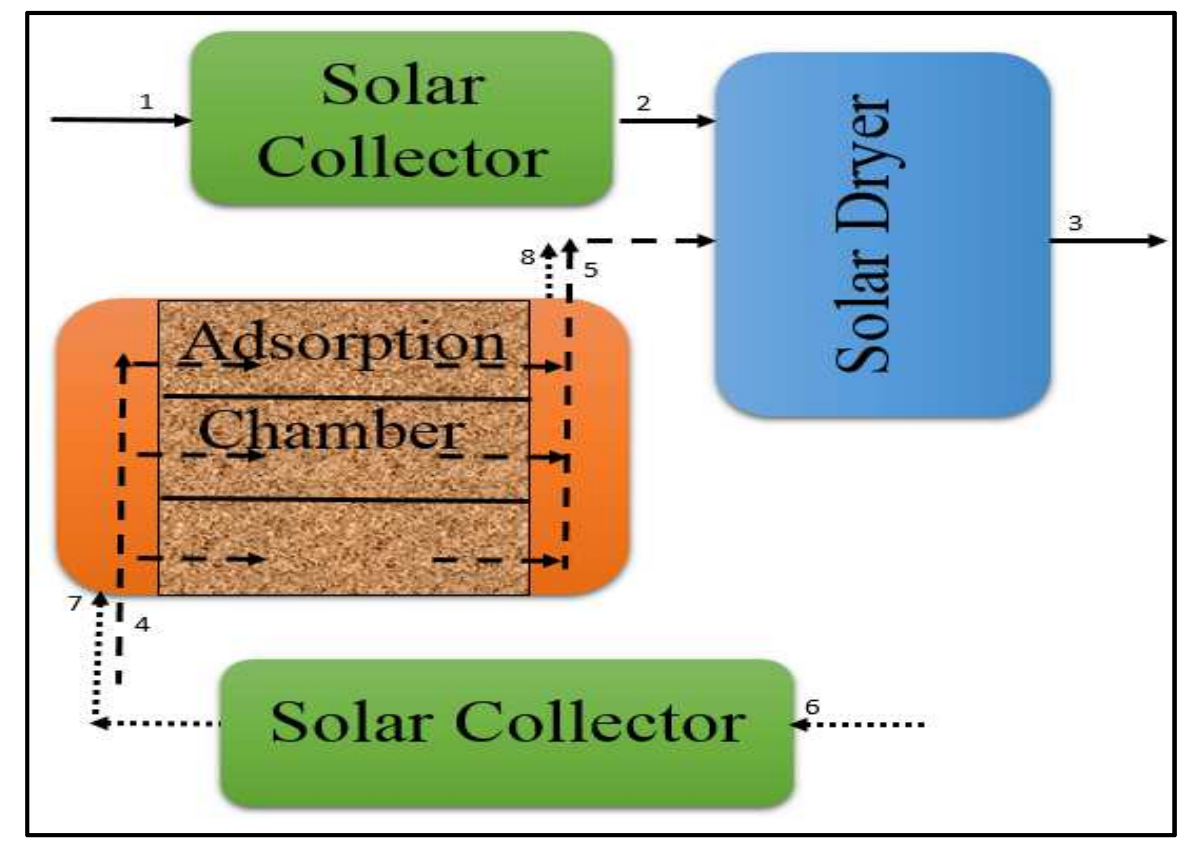

Figure 1.3 Solar-adsorbent dryer (SAD) with flow streams described as: $1 \rightarrow 2 \rightarrow 3$ : is the air flow during drying, $4 \rightarrow 5 \rightarrow 3$ : air flow during night drying, $6 \rightarrow 7 \rightarrow 8$ : air flow for regeneration during day time.

This solar adsorption dryer system (SAD) is an integrated dryer system that utilizes the sun's energy during the day and adsorption energy and dehumidified air during the night for night drying. A major advantage of the system, compared to open sun drying (OSD) and solar drying, is that drying is not interrupted for the night which results in a shorter processing time. Moreover, labor for packaging the products to avoid rewetting during the night is no-longer required.

The solar collector systems should be able for giving output air temperatures acceptable for product drying and keeping quality, and sufficient temperature for the regeneration of the adsorbent. This represents a specific new design of the collectors. Tomas et al. (2009) mentioned that virtual prototyping of solar collectors can help predict the performance of a collector before manufacturing. Following this line, the goal here is to base the solar collector design on physical state-space modeling in order to investigate the collector dimensions that give low but sufficient air output temperature for drying and which are suitable for sorbent regeneration. Literature on previous investigations on solar dryer and SAD design is rather fragmented and confusing, because a unifying picture is missing.

\subsection{Modeling of moisture content and sorption}

Moisture removal from the matrix of a food product is a mass transfer process and to predict this pass transfer models are required. Fick's diffusion equation gives the basis for the modeling 
of moisture content of products of a specified standard shape. Crank (1975) provides analytical solutions of the diffusion equation. The validity of this analytical solution for an average moisture content in an infinite sized slab holds only for uniform initial moisture concentration, negligible external resistance and time invariant diffusion coefficient. The Page equation (Saeed et al., 2006) does not reflect the diffusion behavior that occurs in many food products. It has been observed by some researchers (Sjöholm and Gekas, 1995) that a linear relationship between moisture and both shrinkage moisture diffusivity exists. Thus, a systematic deviation between an experimental data and model outputs based on the Crank equation, may exist. For a diffusion limited moisture transport system, deviations can be a result of the fact that geometry of sample cubicles may not satisfy the conditions for a homogenous flow through infinite sized slabs or moisture transport may be affected by shrinkage or the effective diffusion coefficient may not be constant. Therefore, in this thesis, fractal and non-fractal shrinkage as linear function of moisture content and diffusion coefficient were systematically investigated.

Sorption isotherms at various temperatures helps to predict the water activity which is indicative of the susceptibility of food product to spoilage by microorganisms. Much attention has been restricted to crops such as potato, carrots, green pepper, onions and dates (SamaniegoEsquerra et al., 1991; Kiranoudis et al., 1993; Myhara et al., 1998a,b). A recent work on desorption isotherms of two cultivars of yam (D. rotundata) was published by Montes et al. (2009). Models used to describe sorption isotherms of foods include: Guggenheim-Andersonde Boer (GAB), Henderson, Halsey, Oswin, Smith, Brunauer-Emmett-Teller (BET) and Peleg. Most studies are either restricted to desorption or adsorption (Andrade et al., 2011; Montes et al., 2009 and Saad et al., 2014). The method of assessing the parameters have differed from one researcher to the other, whereas limited attention has been given to the uncertainty in the parameters. Additionally, there is generally no methodological attention, with respect to the choice of the most appropriate model.

\subsection{Problem Formulation}

Apart from being a high intensity energy unit operation, drying degrades the quality of the product when subjected to high temperatures. Solar drying of agricultural products can be a solution especially when the output air temperature from the collector is designed not to exceed a certain limit. The problem then is what particular dimension of collector the system gives an output air condition in combination with an adsorption system that is most appropriate for relatively low temperature drying and is appropriate for the regeneration of adsorbent after its saturation due to night drying. What is mostly missing is the link between collector modeling and dryers (Matuska et al, 2009; Simate, 2010; Njomo, 2000; Njomo, D. and Daguenet, M., 2006; Ong and Law, 2009; Jorge and Armando, 2004). Majority of these works is based on building the solar collector to see what happens in the solar dryer. On the other hand, experimental work and the principle of proof of SAD is missing. In this thesis, the solar collector systems is studied based on systematic mass and energy balances, while the principle of proof of performance SAD is verified experimentally. Solar drying is limited to the day, 
therefore to avoid rewetting, adsorption drying at night is a possible solution. However, the adsorbent has to be regenerated after saturation. The solar collector system needs to be designed such that air temperatures are high enough to regenerate the adsorbent.

Therefore, the corresponding research questions are:

- What model (GAB, Henderson, Halsey, Oswin, Smith, BET and Peleg) best describes the equilibrium moisture isotherms for yam at $25^{\circ} \mathrm{C}$ and $50^{\circ} \mathrm{C}$, both for sorption and desorption.

- What is the effect of shrinkage and moisture diffusivity on the deviation between the experimental drying data and the Crank equation.

- What collector dimension gives an output temperature suitable for drying agricultural products and regeneration of adsorbent using spatially distributed modeling.

- What is the principle of proof of the SAD (pilot) plant and how does the operation affect the quality of dried yam.

\subsection{Outline of thesis}

In chapter 2 the equilibrium moisture content of the adsorption and desorption isotherm of yam at different temperatures is modeled, while in chapter 3, moisture dependent diffusion and shrinkage in yam during drying is modeled using Crank's solution of Fick's equation. A step-wise analysis to understand the observed deviations between the data and model outputs based on the two term analytical solution by Crank (1975), was performed. The role of shrinkage is investigated by using the concepts of volume reduction and the effect of fractal change of thickness. Chapter 4 of this thesis discusses the design of the solar collector system. The design which is based on an alternative numerical approach of the modeling work of Duffie and Beckman (1980) as their work is limited to the use of analytical expressions and approximations. The applied approach in this work eliminates the difficulty to determine the spatial mean temperature of the absorber plate which is required to obtain an overall heat loss coefficient.

In chapter 5, the performance of the solar adsorption dryer system is verified experimentally using yam as the food product. The drying performance was evaluated, while the gain in processing time due to night drying was estimated. The quality with respect to some nutrient, vitamin $\mathrm{C}$ and color were also assessed, together with the regeneration performance was also tested.

In chapter 6 new established facts and achievements in retrospective view are reflected. Further recommendations emanating from this work and conclusions are duly made. The potential of application of the solar adsorption drying method in Ghana has been discussed. The structure of the thesis is shown in Figure 1.4. 


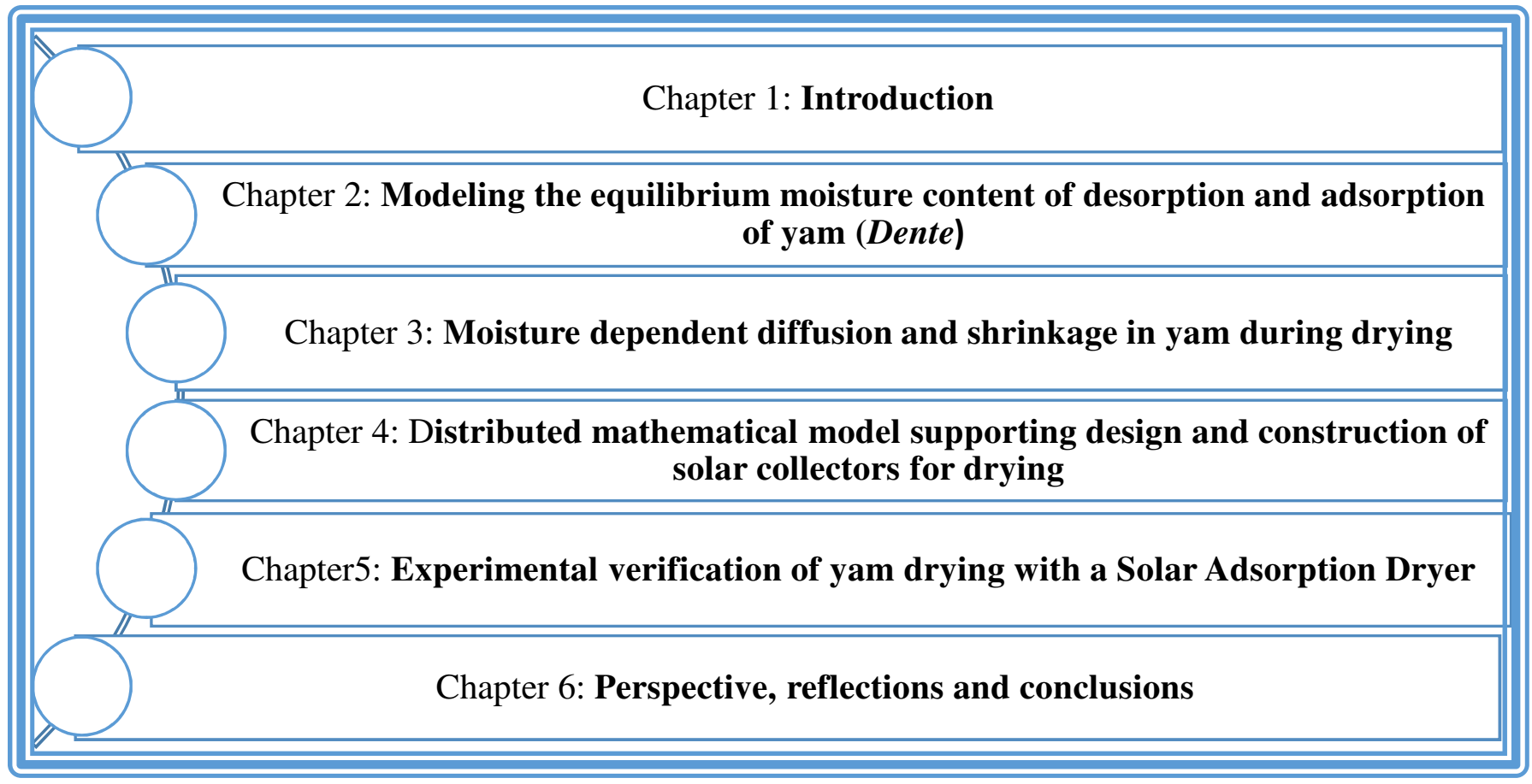

Figure 1.4 Thesis outline. 


\section{Chapter 2}

\section{Modeling the equilibrium moisture content of desorption and adsorption of yam (Dente)}

This chapter is published as:

Amankwah, E. A., K. A. Dsizi, G. van Straten, and A. J. B. van Boxtel. 2018. Modeling the equilibrium moisture content of desorption and adsorption of yam (Dente). Agricultural Engineering International: CIGR Journal, 20(1): 184-192 


\begin{abstract}
The experimental equilibrium moisture content of yam (Dioscorea rotundata; cultivar: Dente) at temperatures of $25^{\circ} \mathrm{C}$ and $50^{\circ} \mathrm{C}$ were determined at relative humidity from $0 \%$ to $95 \%$ employing the dynamic vapor sorption analyzer. Wet yam samples with about $68 \%$ initial moisture content were used, first for desorption and subsequently for sorption. Water activity decreased with increased temperature at constant equilibrium moisture content. The desorption and adsorption isotherms were fitted by the Guggenheim-Anderson-de Boer (GAB), Henderson, Halsey, Oswin, Smith, Brunauer-Emmett-Teller (BET) and Peleg models. On the basis of the fit the Peleg, GAB and Oswin models were most suitable for describing the observed data. When the focus is on drying, the GAB (3 parameters) and empirical Peleg model (4 parameters) performed best. Of these, GAB is preferable because it has fewer parameters, which, moreover, have a physical meaning.
\end{abstract}




\subsection{Introduction}

Yam is an important food crop for many people in the yam zone of West Africa. It forms about $10 \%$ of the total roots and tubers produced in the world. It has been estimated that the world yam production would increase by $27 \%$ between the years 2003-2020. In past decades, yam production in Ghana increased by $10 \%$ per year (Kenyon et al., 2006). It is second to cassava as the most important tropical root crop but is nutritionally better than cassava on account of their vitamin C (40-120 $\mathrm{mg} \mathrm{g}^{-1}$ edible portion) and crude protein (40-140 $\mathrm{g} \mathrm{kg}^{-1}$ dry matter) content (Opara, 1999). Yam has a moisture content of about $70 \%$ when harvested (Fioreze and Morini, 2000), making it highly perishable. Therefore it is essential to develop effective methods that prolong the shelf life of yam without compromising on its nutritional and healthy components. With this purpose in mind, it is imperative to obtain more information on some properties of yam that can help to reduce post-harvest losses.

Sorption isotherms give an indication of the equilibrium conditions of a food product under varying conditions of relative humidity and temperature. Information about the sorption isotherms is necessary for the optimization and design of drying equipment, predictions of quality parameters, shelf-life study, milling, mixing, packaging and storage investigations. Sorption data helps to predict the water activity which is indicative of the susceptibility of food product to spoilage microorganisms. One of the ways by which yam can be preserved to extend its shelf life is by drying, but not much is known about the parameters related to drying characteristics of yam, especially regarding desorption and sorption isotherms. Sorption isotherms of food materials have been reported by amongst others Gálvez et al. (2006), Montes (2009) and Saad et al. (2014). The majority of the work pertains to constant temperatures in the range of $15^{\circ} \mathrm{C}-60^{\circ} \mathrm{C}$ on samples from a variety of crops such as potato, carrots, green pepper, onions and dates (Samaniego-Esquerra et al., 1991; Kiranoudis et al., 1993; Myhara et al., 1998a,b). However, not much attention has been given to yam. A recent work on the desorption isotherms of two varieties of D. rotundata was studied by Montes et al. (2009). It was shown that, according the general accepted view, the equilibrium moisture content (EMC) increases with water activity of the air $\left(a_{w}\right)$ and decreases with temperature. A similar result was found by Igathinathane et al. (2005). There is also some recent work on water yam flour, which, however, is a derived product (Owo et al., 2017). Empirical and semi-empirical equations have been proposed to fit the EMC to relative humidity (RH) of food samples. Models that have been used to describe the sorption isotherms of foods include: GuggenheimAnderson-de Boer (GAB), Henderson, Halsey, Oswin, Smith, Brunauer-Emmett-Teller (BET), Peleg. These models do not all apply over the full moisture content range. The GAB equation has been applied successfully to various foods up to 0.9 water activity (Maroulis et al., 1988; Samaniego-Esquerra et al., 1991; Andrade et al., 2011) but is not suitable beyond 0.93 water activity (Andrade et al., 2011). That of Halsey is effective between $0.1-0.8$ (Rizvi, 1995). While others have reported a decrease in EMC for increased temperature at the same water activity, Montes et al. (2009) showed no temperature effect on the desorption isotherms of yam 
(Dioscorea rotundata) at temperatures $45^{\circ} \mathrm{C}$ and $55^{\circ} \mathrm{C}$. Moreover, some works were restricted to desorption or adsorption alone as reported in the work of Andrade et al. (2011), Montes et al. (2009) and Saad et al. (2014). The reported investigations also differ in the method of assessing the parameters, whereas limited attention has been given to the uncertainty in the parameters (a noteworthy exception is e.g. Quirijns (2005)). In addition, there is generally no methodological attention to the choice of the most appropriate model. The object of this research is to obtain experimental equilibrium moisture isotherms for yam at $25^{\circ} \mathrm{C}$ and $50^{\circ} \mathrm{C}$, both for sorption and desorption, to estimate the parameters and their uncertainty range for each of the models (GAB, Henderson, Halsey, Oswin, Smith, BET and Peleg), and then to use objective criteria to select the model that best describes the experimental desorption and adsorption isotherms over the relevant range of moisture contents.

\subsection{Materials and methods}

\subsubsection{Source and preparation of material}

The yam tubers of the variety, D. rotundata and cultivar (Dente) were purchased from a commercial farmer at Ejura, in the Sekyere Odumasi district of the Ashanti region of Ghana. The yam tubers were send to Wageningen, the Netherlands for the sorption measurements. For each experiment, a tuber of the yam was washed and cut into two halves. An amount of 13.36 and $31.39 \mathrm{mg}$ of fresh samples at initial moisture contents $69.87 \%$ and $65.25 \%$ w.b. for $25^{\circ} \mathrm{C}$ and $50^{\circ} \mathrm{C}$ constant temperature experiments, respectively, was scooped from the middle part of one surface of the cut yam. The sample was carefully placed in the sample pan.

\subsubsection{Procedure and measuring equipment}

The experimental technique of the dynamic method was used to determine the desorption isotherms of the fresh yam. The dynamic vapor sorption (DVS) analyzer (Surface Measurement System DVS Advantage (ET), UK) was used for the measurement. The DVS analyzer uses a microbalance to measure the weight changes of samples. Two air mass flow controllers (wet and dry) mix air in such a way that the RH of the air flow is set and controlled in the range of $95 \%$ to $0 \%$ (desorption) with an optical vapor concentration RH detector. At equilibrium between sample and air RH/100 corresponds to the water activity $a_{w}$. RH and temperature in the DVS are computer controlled and followed by a chosen procedure. The RH starts at $95 \%$ and goes down by steps of $10 \%$ to $15 \%$ and then to $0 \%$ RH. At each step the sample mass was measured every minute and equilibrium was reached when the standard deviation between three successive measurements was less than $3 \times 10^{-4} \mathrm{~g}$ (i.e. in terms of EMC $1.5 \times 10^{-5} \mathrm{~g}$ water. $\mathrm{g}^{-1}$ dry weight). The adsorption behavior was measured by the reverse procedure by stepping up from $0 \%$ through $15 \%$ to $95 \% \mathrm{RH}$. This process was repeated for temperatures $25^{\circ} \mathrm{C}$ and $50^{\circ} \mathrm{C}$. 


\subsubsection{Observed curves}

The observed data were determined for D. rotundata varieties (cultivar Dente) at $25^{\circ} \mathrm{C}$ and $50^{\circ} \mathrm{C}$ at relative humidity from $95 \%$ to $0 \%$ for desorption and $0 \%-95 \%$ for adsorption. During the $\mathrm{RH}$ ramp the micro balance $(0.0001 \mathrm{~g}$ accuracy) continuously measures the mass of the sample at intervals of 1 minute. Based on the mass of the sample as function of the $\mathrm{RH}$, the EMC was calculated in dry basis ( $\mathrm{kg}$ water. $\mathrm{kg}^{-1}$ dry weight). The equilibrium moisture content was then plotted against the water activity $(\mathrm{RH} / 100)$ of the air, to obtain equilibrium moisture curves.

\subsubsection{Models}

The most common equations for describing sorption isotherms of food products are the BET model, Oswin model, Smith model, Halsey model, Henderson model, GAB model, and Peleg model (Sahin and Sumnu, 2006). In order to make sure that parameters are dimensionally consistent across models, the models of Halsey, Henderson, Smith and Peleg were reformulated, such that the parameter $C_{1}$ in all models has the same units as $X_{e}$, and all other parameters are dimensionless (Table 2.1).

The Henderson model is often used in describing food sorption isotherms. It was originally formulated as $\left[-\frac{\ln \left(1-a_{w}\right)}{C_{1}^{\#}}\right]^{1 / n}$. The form in the table arises by redefining $C_{1}=\left[\frac{1}{C_{1}^{\#}}\right]^{\frac{1}{n}}$, which has the same units as $X_{e}$, and avoids a parameter with fractional units. The Halsey model is suitable for describing the sorption behavior of starchy foods. It expresses the condensation of multilayers at large distance from the surface of the drying product with the assumption that energy potential of a molecule varies as the inverse of the $\mathrm{n}^{\text {th }}$ power of the distance from the surface. It describes well the sorption isotherm of types I, II and III (Levine and Slade, 1991). The form in the table arises from the original form $X_{e}=\left[\frac{\left.-C_{1}^{\#}\right)}{l n a_{w}}\right]^{1 / n}$, by redefining $C_{1}=\left[C_{1}^{\#}\right]^{\frac{1}{n}}$. The Oswin equation is an empirical model that satisfies sigmoidal shaped curves (Labuza et al., 1972). The Smith model, originally formulated as $X_{e}=C_{1}+C_{2}^{\#} \ln \left(1-a_{w}\right)$ is an empirical model that describes the final curved portion of water sorption isotherm of high molecular weight biopolymers. The model is based on two fractions of water that are adsorbed onto a dry surface. The first fraction represents the quantity of water in the first sorbed fraction, while the second specifies the quantity of water in the multilayer moisture fraction. In the reformulated equation in table $1, C_{2}$ is a dimensionless parameter defined by $C_{2}^{\#} / C_{1}$. The model is suitable for various foods products of water activity 
Table 2.1 Sorption model equations as a function of water activity

Name parameter models
$\begin{aligned} & \text { Henderson } \\ & \text { (reformulated) }\end{aligned}$
Halsey (reformulated)
Oswin
Smith (reformulated)
BET
$X_{e}=C_{1}\left[\frac{-1}{\ln \left(a_{w}\right)}\right]^{\frac{1}{n}}$
$X_{e}=C_{1}\left[\frac{a_{w}}{1-a_{w}}\right]^{n}$
$X_{e}=C_{1}-\left[C_{2} \ln \left(1-a_{w}\right)\right]$
$X_{e}=C_{1} \frac{C_{2} a_{w}}{\left(1-a_{w}\right)\left(1+\left(C_{2}-1\right) a_{w}\right)}$

Three parameter models

GAB

$$
X_{e}=C_{1} \frac{C_{2} C_{3} a_{w}}{\left[\left(1-C_{3} a_{w}\right)\left(1-C_{3} a_{w}+C_{2} C_{3} a_{w}\right)\right]}
$$

Four parameters models

Peleg (reformulated)

$$
X_{e}=C_{1}\left(a_{w}{ }^{C_{3}}-C_{2} a_{w}{ }^{C_{4}}\right)
$$

Note: $X_{e}$ is the equilibrium moisture content (EMC), $a_{w}$ is the water activity, $C_{1}, C_{2}, C_{3}$ and $n$ are constants to be fitted for each equation.

within the range 0.5 to 0.95 water activity (Andrade et al., 2011). The BET model is rather qualitative, and it is linear within a limited range of water activity from 0.05 to 0.45 (Andrade et al., 2011). This limits its use to a large extent since most sorption isotherm cases of foods have wider range of water activity. The first constant is the monolayer moisture content (the moisture content at which the water attached to each polar and ionic groups starts to behave as a liquid-like phase). The second constant relates to the net heat of sorption (difference between the molecules that sorb energy of the first layer and the other remaining layers). The GAB model has successfully been applied to many foods and has been recommended by the European Project COST 90 (Oliveira et al., 2006) on physical properties of foods. It has a theoretical basis since it is an improvement of the BET model by the addition of a third parameter, so that the heat of sorption parameter is split over the first layer heat of sorption constant and the multilayer heat of sorption constant (Andrade et al., 2011; Myhara et al., 1998a). Note that the BET model is a special case of the GAB model when $C_{3}=1$. It has been found that $C_{2}>1$ and $C_{3}<1$ as reported for adsorption of corn flour at $22^{\circ} \mathrm{C}$ (Gálvez et al., 2006), dried tomato pulp at $30^{\circ} \mathrm{C}$ (Goula et al., 2008) and walnut kernels at $25^{\circ} \mathrm{C}$ (Toğrul and Arslan, 2007) while the opposite was reported by Montes et al. (2009) for the desorption of yam at $70^{\circ} \mathrm{C}$ rendering the improvement of the BET to GAB irrelevant. Peleg is a four- 
parameter model, originally given by $X_{e}=C_{1} a_{w}{ }^{C_{3}}-C_{2}^{\#} a_{w}{ }^{C_{4}}$, which is a purely empirical equation without a theoretical background. Andrade et al. (2011) mentioned that generally $\mathrm{C}_{3}<1$ while $\mathrm{C}_{4}>1$, but Montes et al. (2009) suggest the opposite which makes these parameter values inconsistent. Note that the two-parameter models deteriorate at $a_{w}=1$, as $\lim _{a_{w} \rightarrow 1} X_{e}=$ $\infty$. Hence, there is an upper limit for $a_{w}$ beyond which these models must lose their validity. It is expected in all models that $\lim _{a_{w} \rightarrow 0} X_{e}=0$.

\subsubsection{Statistical analysis of data}

The nonlinear regression method in Matlab was used for the parameter estimation of the models, by minimizing the sum of squared differences between experimental and model results of desorption and adsorption. The goodness of fit was determined with three statistical tools, that is:

the standard error $(S E)$

$$
S E=\sqrt{\frac{\sum_{i=1}^{N_{e}}(\text { Residuals })^{2}}{N_{e}-N_{p}}}
$$

the percent average relative deviation $(P R D)$

$$
P R D(\%)=\frac{100}{N_{e}} \sum_{i=1}^{N_{e}}\left(\frac{\mid \text { Residuals } \mid}{E M C_{e}}\right)
$$

and the coefficient of performance $\left(R^{2}\right)$

$$
R^{2}=1-\frac{\sum_{i=1}^{N_{e}}(\text { Residuals })^{2}}{\sum_{i=1}^{N_{e}}\left(\overline{E M C}_{e}-E M C_{m}\right)^{2}}
$$

Here, $E M C_{m}$ is the modeled value of equilibrium moisture content, $E M C_{e}$ is the experimental equilibrium moisture content value, $N_{p}$ is the number of parameters of a particular model, $N_{e}$ is the number of experimental data points, $\overline{E M C}_{e}$ is the arithmetic mean of the experimental equilibrium moisture contents, and the residuals are defined by $E M C_{e}-E M C_{m}$. All data were processed and evaluated using the Matlab software. In general, more parameters lead to a better fit, but the predictive power may be worse, unless the improvement is worthwhile. Akaike's Information Criterion (AIC) is especially suitable for comparing models with a different number of parameters (Ljung, 1987). The criterion is reformulated here as:

$$
A I C=2 N_{p}+N_{e} \ln (V(\widehat{\mathbf{p}}))
$$

The model with the lowest AIC is preferred. Here $V(\widehat{\boldsymbol{p}})$ is the sum of squared errors for the estimated parameter vector $\widehat{\boldsymbol{p}}$ i.e. $V(\widehat{\boldsymbol{p}})=\sum_{k=1}^{N}\left(M C_{m}(k, \widehat{\boldsymbol{p}})-M C_{e}(k)\right)^{2}$. Since the number of data points is small, it is better to use the small sample corrected variant $(\mathrm{Hu}, 2007)$, which is:

$$
A I C_{c}=A I C+\frac{2 N_{p}\left(N_{p}+1\right)}{N_{e}-N_{p}-1}
$$




\subsubsection{Approximate confidence bound}

The least squares method with the water activity $a_{w}$ as independent variable does not suffer from the so-called errors-in-variables problem which would occur if both the dependent and independent variable would have errors. Hence, the uncertainty of the parameter estimates can be evaluated by calculating the $2 \sigma$ confidence interval based on the Jacobian matrix. The Jacobian matrix specifies the sensitivity of each point to each of the parameters. The relationships in Table 2.1 are linear in the parameter $C_{1}$, meaning that the $2 \sigma$ bound corresponds to the $95 \%$ confidence interval, i.e. there is $5 \%$ chance that the true value is outside this range. For the other parameters, the $95 \%$ bound is only approximate. For convenience, in the tables below, the uncertainty is reported as the $1 \sigma$ coefficient of variation, i.e. as $100 \sigma p^{-1}$, where $p$ is the parameter estimate.

\subsection{Results and discussion}

\subsubsection{Desorption and adsorption isotherms measurements}

The experimental values of water activity $\left(a_{w}\right)$ and its corresponding EMC of both desorption and adsorption isotherms of yam (Dente) for $25^{\circ} \mathrm{C}$ and $50^{\circ} \mathrm{C}$ are shown in Figure 2.1. Comparing both graphs, it can be seen that the data for water adsorption has lower EMC than the data for water desorption at both $25^{\circ} \mathrm{C}$ and $50^{\circ} \mathrm{C}$. The data for adsorption and desorption crossed each other at about $0.9 a_{w}$ due to high mobility of solute and dissolved sugars at higher water activity during wetting. EMC for adsorption and desorption decreased with increased temperature between water activities of $0-0.83$ (Figure 2.2). At higher water activity a reversal is obtained where water activity levels are lower at a constant EMC, as temperatures increase.

This leads to desorption isotherms crossing at $a_{w}=0.65$ and $a_{w}=0.83$ for adsorption (Figure 2), collaborating with the work of Myhara et al. (1998a), Siripatrawan and Jantawat (2006), and Montes et al. (2009). The point of crossing depends on the amount of sugar content of the food material. Myhara et al. (1998a) reported adsorption curves of two varieties of dates crossing between $a_{w}=0.4-0.5$ and attributing it to high sugar content. Tsami et al. (1990) and Myhara et al. (1998a) have reported that the higher the sugar content the lower the $a_{w}$ of crossing. Temperature on the other hand did not show any significant effect on EMC at constant $a_{w}$ for the desorption isotherms (Myhara et al., 1998b).

This might be due to higher proportion of strongly bonded linear chain amylose molecules which are crystalline in nature. The curves show sigmoidal shape of type II and it can be observed that EMC increases with $a_{w}$ at constant temperature. This trend is in line with the work of Andrade et al. (2011) and the findings of Montes et al. (2009) who had sigmoidal type II-curves. Others such as Siripatrawan and Jatawat (2006) reported similar trend. Hysteresis is observed for both temperatures where generally the EMC of desorption are higher than that of the adsorption at constant water activity. 

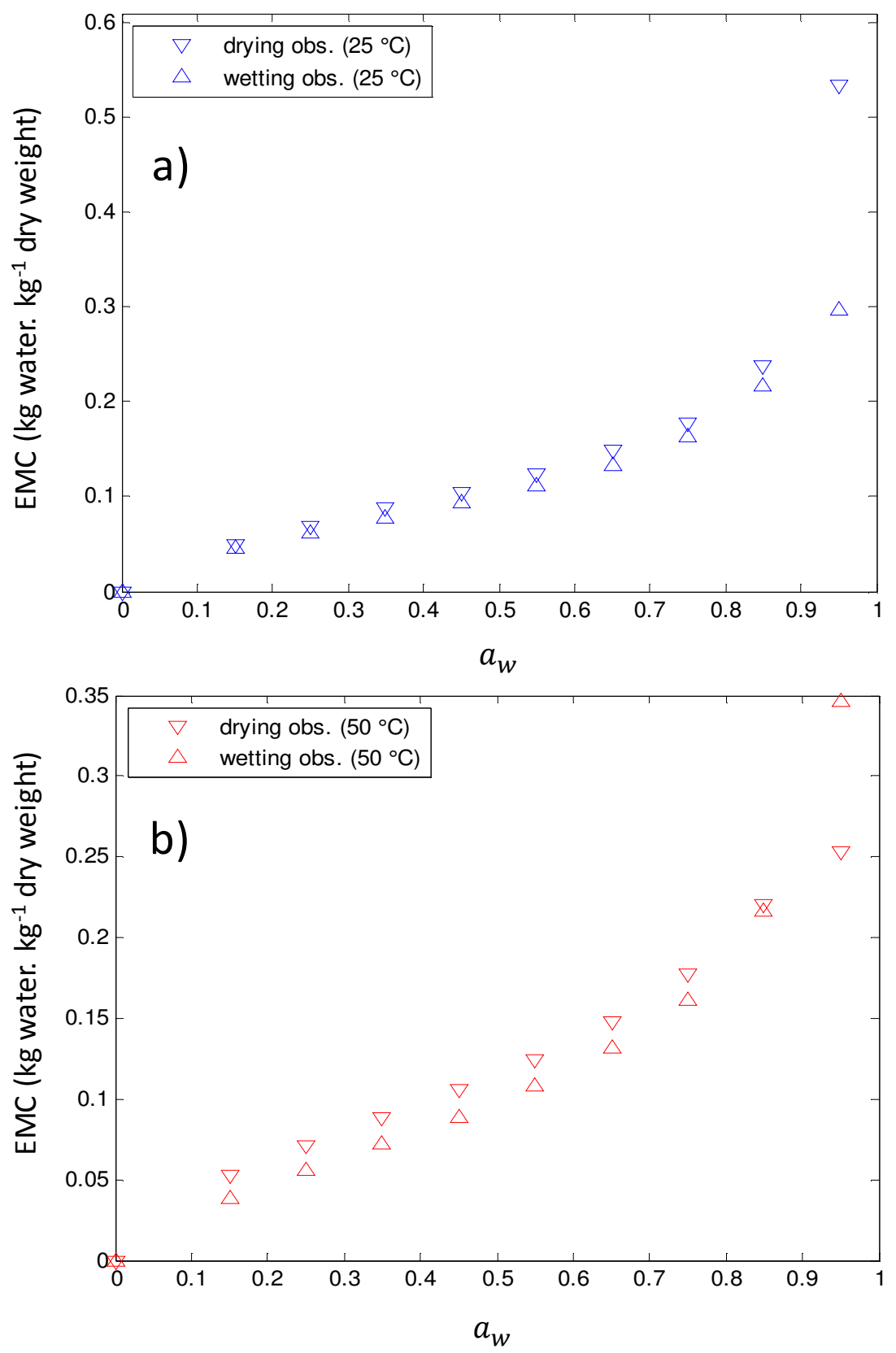

Figure 2.1 Experimental data of equilibrium moisture content (EMC) against water activity $\left(a_{w}\right)$ at $25^{\circ} \mathrm{C}$ (a) and $50^{\circ} \mathrm{C}$ (b) for water desorption and adsorption.

One reason for differences in EMC between the desorption and adsorption at constant temperature and water activity is that, during desorption, solutes may supersaturate below their crystallization water activity and therefore can hold more water, especially for products with high sugar content (Aguilera and Stanley, 1999). The other common explanation is that when dried biological material is subjected to a wetting environment, the moisture first adheres to the surface of the cells, primarily in a unimolecular layer. After a high amount of molecules adhered to the surface, the diffusional forces exceed the binding forces and allow moisture to move inside the cell. When, subsequently, the vapor pressure of the environment of the cell surface is reduced again, absorbed moisture from the cell moves out of the cells due to 
diffusional forces caused by concentration gradient leading to the hysteresis (Young and Nelson, 1967).

\subsubsection{Modeling the isotherms}

In fitting the models the data point at water activity 0.95 was ignored since according to the literature beyond $a_{w} 0.9$, most models are not able to explain well the experimental data (Samaniego-Esguerra et al., 1991). One reason could be that, according to the differences between wetting and drying behavior at high water activity, it is hard to obtain a reliable measurement point since reaching the equilibrium may require a long equilibration time. Tables 2.2 and 2.3 show the outcome of the nonlinear regression analysis of desorption and adsorption isotherms respectively, of yam (Dente) for $0 \leq \mathrm{aw} \leq 0.85$ at $25^{\circ} \mathrm{C}$ and $50^{\circ} \mathrm{C}$. The parameters of the seven models, that is, GAB, Henderson, Halsey, Oswin, Smith, BET and Peleg, fitted to the desorption and adsorption data along with SE, PRD, AIC and $\mathrm{R}^{2}$, for the temperatures $25^{\circ} \mathrm{C}$ and $50^{\circ} \mathrm{C}$. Peleg is purely empirical (it has the best combination of sores for SE, PRD, AIC of all), but the GAB and BET have a physiological background. This makes them stronger candidates. It turns out that the SE, PRD, AIC of GAB were equally low, and with fewer parameters than Peleg. On the other hand, with respect to the confidence interval of the parameters using the $2-\sigma$ bound, and in particular on the first parameter, $C_{l}$ which has the same unit as that of $X_{e}$, the GAB and Oswin recorded the least percentage coefficient of variation (1$\sigma, \% \mathrm{CV}$ ) for all the phenomena at different temperatures (Tables 2.4 and 2.5). The GAB model is subsequently considered for describing the desorption and adsorption data at temperatures $25^{\circ} \mathrm{C}$ and $50^{\circ} \mathrm{C}$. Montes et al. (2009) mentioned that the Peleg model was best for describing the desorption isotherm of two varieties of yam (D. rotundata), while Peleg and Oswin models were found suitable by Saad et al. (2014). For graphical presentation, the GAB and Peleg modeled graphs are shown in Figures 2.2 and 2.3. 


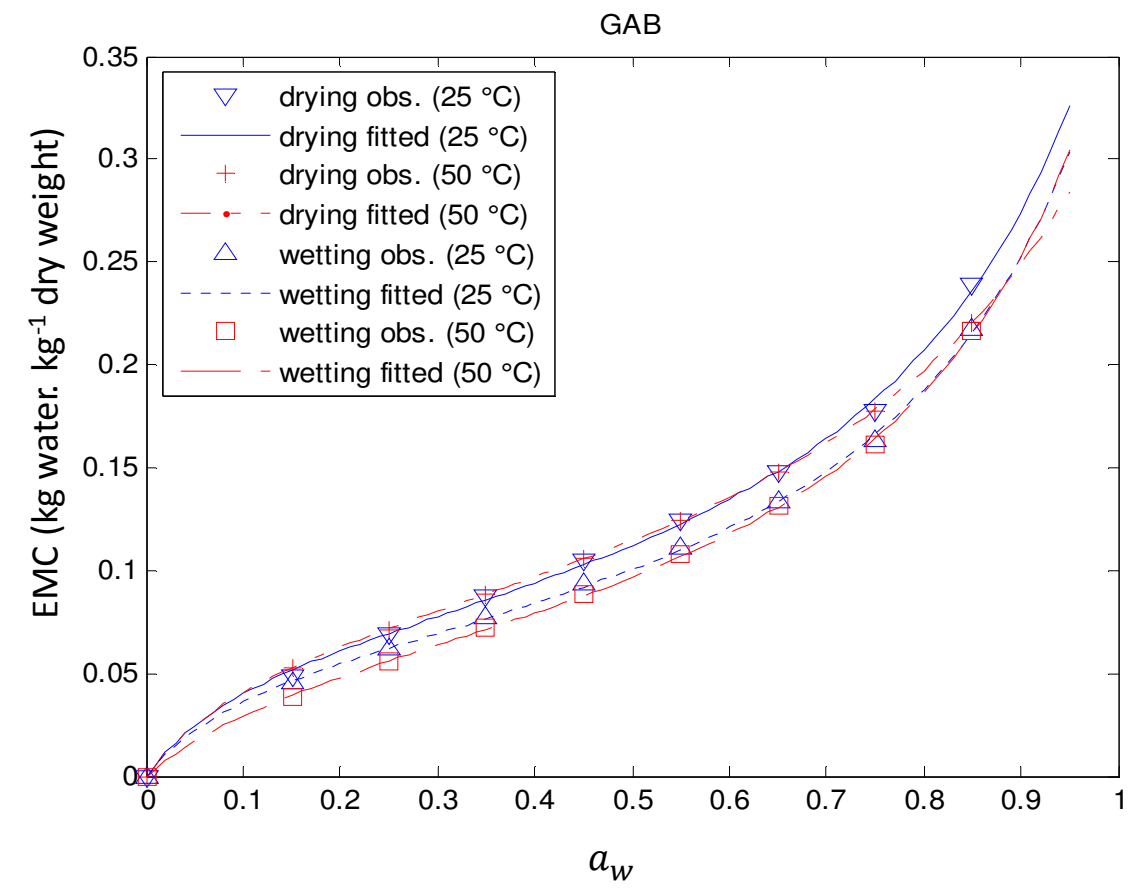

Figure 2.2 Experimental and modeled curves of equilibrium moisture content (EMC) against water activity $\left(a_{w}\right)$ for desorption (drying) and adsorption (wetting) at temperatures $25^{\circ} \mathrm{C}$ and $50^{\circ} \mathrm{C}$ using the $\mathrm{GAB}$ model.

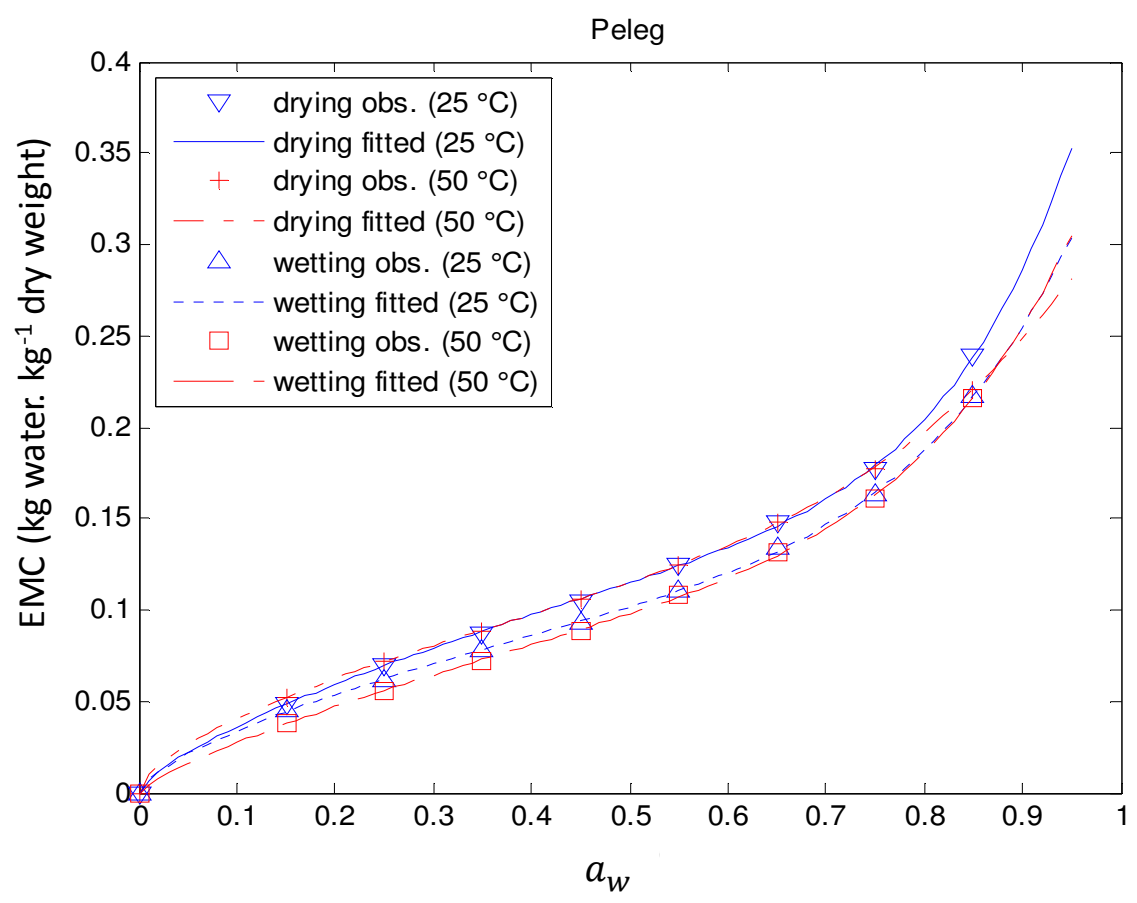

Figure 2.3 Experimental and modeled curves of equilibrium moisture content (EMC) against water activity $\left(a_{w}\right)$ for desorption (drying) and adsorption (wetting) at temperatures $25^{\circ} \mathrm{C}$ and $50^{\circ} \mathrm{C}$ using the Peleg model. 
Table 2.2 Results for desorption isotherms fitting for yam (Dente) for $0 \leq \mathbf{a}_{\mathrm{w}} \leq \mathbf{0 . 8 5}$ )

\begin{tabular}{|c|c|c|c|c|c|c|c|c|c|}
\hline & & & Parameters & & & & & & \\
\hline & Temp & $C_{1}$ & $C_{2}$ & $C_{3}$ & $C_{4}$ & SE & PRD & AIC & $\mathrm{R}^{2}$ \\
\hline \multirow[t]{2}{*}{ GAB } & 25 & 0.07551 & 10.657 & 0.8152 & - & 0.0031 & 1.64 & -77.1 & 0.9986 \\
\hline & 50 & 0.08274 & 10.126 & 0.7578 & - & 0.0005 & 0.25 & -109 & 0.9999 \\
\hline \multirow[t]{2}{*}{ Henderson } & 25 & $\begin{array}{l}0.1491 \\
\mathrm{C} 1^{\#:} 0.0588\end{array}$ & 1.4890 & - & - & 0.0061 & 4.08 & -68.3 & 0.9936 \\
\hline & 50 & $\begin{array}{l}0.1468 \\
C 1^{\#:}: 0.0426\end{array}$ & 1.6445 & - & - & 0.0031 & 2.32 & -80.6 & 0.9981 \\
\hline \multirow[t]{2}{*}{ Halsey } & 25 & $\begin{array}{l}0.0888 \\
\mathrm{C}^{\#}: \quad 0.0127\end{array}$ & 1.8044 & - & - & 0.0068 & 5.60 & -66.5 & 0.9922 \\
\hline & 50 & $\begin{array}{l}0.0913 \\
C 1^{\#:}: 0.0089\end{array}$ & 1.9762 & - & - & 0.0079 & 6.16 & -63.6 & 0.9878 \\
\hline \multirow[t]{2}{*}{ Oswin } & 25 & 0.1124 & 0.4327 & - & - & 0.0023 & 1.84 & -85.7 & 0.9991 \\
\hline & 50 & 0.1134 & 0.3938 & - & - & 0.0030 & 2.25 & -81.1 & 0.9983 \\
\hline \multirow[t]{2}{*}{ Smith } & 25 & 0.0275 & $\begin{array}{l}-4.1366 \\
C 2^{\#}:-0.1138\end{array}$ & - & - & 0.0130 & 5.90 & -54.7 & 0.9711 \\
\hline & 50 & 0.0322 & $\begin{array}{l}-3.2855 \\
\mathrm{C} 2^{\#}:-0.1059\end{array}$ & - & - & 0.0151 & 6.27 & -52.0 & 0.9556 \\
\hline \multirow[t]{2}{*}{ BET } & 25 & 0.2718 & 0.7789 & - & - & 0.0129 & 10.1 & -54.8 & 0.9713 \\
\hline & 50 & 0.2447 & 0.9898 & - & - & 0.0107 & 8.54 & -58.1 & 0.9776 \\
\hline \multirow[t]{2}{*}{ Peleg } & 25 & 0.2581 & $\begin{array}{l}0.7235 \\
\mathrm{C} 2^{\#}: 0.1867\end{array}$ & 7.8501 & 0.7142 & 0.0015 & 0.74 & -85.1 & 0.9997 \\
\hline & 50 & 0.1516 & $\begin{array}{l}1.1149 \\
\mathrm{C} 2^{\#}: 0.1690\end{array}$ & 4.9423 & 0.6195 & 0.0005 & 0.26 & -105 & 0.9999 \\
\hline
\end{tabular}


Table 2.3 Results for adsorption isotherms fitting for yam (Dente) for $0 \leq \mathbf{a}_{\mathrm{w}} \leq \mathbf{0 . 8 5}$ )

\begin{tabular}{|c|c|c|c|c|c|c|c|c|c|}
\hline & & & Parameters & & & & & & \\
\hline & Temp & $C_{1}$ & $C_{2}$ & $C_{3}$ & $C_{4}$ & SE & PRD & AIC & $\mathrm{R}^{2}$ \\
\hline \multirow[t]{2}{*}{ GAB } & 25 & 0.0666 & 10.913 & 0.8272 & & 0.0015 & 0.93 & -89.6 & 0.9996 \\
\hline & 50 & 0.0676 & 7.3021 & 0.8272 & - & 0.0015 & 0.92 & -90.4 & 0.9996 \\
\hline Henderson & 25 & $\begin{array}{l}0.1346 \\
C 1^{\#}: 0.0541\end{array}$ & 1.4545 & - & - & 0.0055 & 4.59 & -69.9 & 0.9936 \\
\hline \multirow[t]{2}{*}{ Halsey } & 25 & $\begin{array}{l}0.0795 \\
C 11^{\#}: 0.0113\end{array}$ & 1.7711 & - & - & 0.0055 & 4.98 & -70.1 & 0.9938 \\
\hline & 50 & $\begin{array}{l}0.0746 \\
C 1^{\#}: 0.0133\end{array}$ & 1.6653 & - & - & 0.0070 & 7.08 & -65.9 & 0.9903 \\
\hline \multirow[t]{2}{*}{ Smith } & 25 & 0.0238 & $\begin{array}{l}-4.3745 \\
\mathrm{C} 2^{\#}:-0.1041\end{array}$ & - & - & 0.0109 & 5.64 & -57.8 & 0.9753 \\
\hline & 50 & 0.0188 & $\begin{array}{l}-5.6389 \\
C 2^{\#}:-0.1061\end{array}$ & - & - & 0.0088 & 4.81 & -61.7 & 0.9845 \\
\hline \multirow[t]{2}{*}{ BET } & 25 & 0.2522 & 0.7286 & - & - & 0.0117 & 10.5 & -56.5 & 0.9717 \\
\hline & 50 & 0.2641 & 0.6116 & - & - & 0.0096 & 9.40 & -60.0 & 0.9814 \\
\hline Peleg & 25 & 0.2087 & $\begin{array}{l}0.7524 \\
\mathrm{C} 2^{\#}: 0.1570\end{array}$ & 6.2198 & 0.66734 & 0.0010 & 0.68 & -91.7 & 0.9998 \\
\hline
\end{tabular}


Table 2.4 The $2 \sigma$ bounds and $1 \sigma$ coefficient of variation $(C V)$ for desorption parameters $\left(0 \leq \mathbf{a}_{w} \leq \mathbf{0 . 8 5}\right)$

\begin{tabular}{|c|c|c|c|c|c|c|c|c|c|c|c|c|c|}
\hline & \multirow[b]{2}{*}{ Temp } & \multicolumn{3}{|c|}{$C_{l}$} & \multicolumn{3}{|c|}{$C_{2}$} & \multicolumn{3}{|c|}{$C_{3}$} & \multicolumn{3}{|c|}{$C_{4}$} \\
\hline & & $-2 \sigma$ & $+2 \sigma$ & $\begin{array}{l}\sigma \\
(\% \mathrm{CV})\end{array}$ & $-2 \sigma$ & $+2 \sigma$ & $\begin{array}{l}\sigma \\
(\% \mathrm{CV})\end{array}$ & $-2 \sigma$ & $+2 \sigma$ & $\begin{array}{l}1 \sigma \\
(\% \mathrm{CV})\end{array}$ & $-2 \sigma$ & $+2 \sigma$ & $\begin{array}{l}\sigma \\
(\% \mathrm{CV})\end{array}$ \\
\hline \multirow[t]{2}{*}{ GAB } & 25 & 0.0669 & 0.0841 & 5.7 & 5.7718 & 15.543 & 22.9 & 0.7761 & 0.8543 & 2.4 & & & \\
\hline & 50 & 0.0809 & 0.0846 & 1.1 & 9.3779 & 10.875 & 3.7 & 0.7491 & 0.7663 & 0.6 & & & \\
\hline \multirow[t]{2}{*}{ Henderson } & 25 & 0.1434 & 0.1548 & 1.9 & 1.3365 & 1.6416 & 5.1 & & & & & & \\
\hline & 50 & 0.1439 & 0.1497 & 1.0 & 1.5522 & 1.7368 & 2.8 & & & & & & \\
\hline \multirow[t]{2}{*}{ Halsey } & 25 & 0.0821 & 0.0955 & 3.8 & 1.6180 & 1.9909 & 5.2 & & & & & & \\
\hline & 50 & 0.0834 & 0.0992 & 4.3 & 1.7140 & 2.2384 & 6.6 & & & & & & \\
\hline \multirow[t]{2}{*}{ Oswin } & 25 & 0.1102 & 0.1147 & 1.0 & 0.4168 & 0.4486 & 1.8 & & & & & & \\
\hline & 50 & 0.1106 & 0.1163 & 1.3 & 0.3734 & 0.4143 & 2.6 & & & & & & \\
\hline \multirow[t]{2}{*}{ Smith } & 25 & 0.0111 & 0.0439 & 29.9 & -7.1362 & -1.1371 & 36.3 & & & & & & \\
\hline & 50 & 0.0131 & 0.0513 & 29.7 & -0.1262 & -0.0855 & 37.7 & & & & & & \\
\hline \multirow[t]{2}{*}{ BET } & 25 & 0.2221 & 0.3215 & 9.1 & 0.4223 & 1.1354 & 22.9 & & & & & & \\
\hline & 50 & 0.2093 & 0.2800 & 7.2 & 0.6036 & 1.3760 & 19.5 & & & & & & \\
\hline \multirow[t]{2}{*}{ Peleg } & 25 & 0.1991 & 0.3170 & 11.4 & 0.5804 & 0.8667 & 9.9 & 5.9596 & 9.7406 & 12.0 & 0.6525 & 0.7760 & 4.3 \\
\hline & 50 & 0.1449 & 0.1583 & 2.2 & 1.0502 & 1.1796 & 2.9 & 4.4409 & 5.4437 & 5.1 & 0.5905 & 0.6485 & 2.3 \\
\hline
\end{tabular}


Table 2.5 The $2 \sigma$ bounds and $1 \sigma$ coefficient of variation for adsorption parameters $\left(0 \leq \mathbf{a}_{w} \leq 0.85\right)$

\begin{tabular}{|c|c|c|c|c|c|c|c|c|c|c|c|c|c|}
\hline & \multirow[b]{2}{*}{ Temp } & \multicolumn{3}{|c|}{$C_{1}$} & \multicolumn{3}{|c|}{$C_{2}$} & \multicolumn{3}{|c|}{$C_{3}$} & \multicolumn{3}{|c|}{$C_{4}$} \\
\hline & & $-2 \sigma$ & $+2 \sigma$ & $\begin{array}{l}1 \sigma \\
(\% \mathrm{CV})\end{array}$ & $-2 \sigma$ & $+2 \sigma$ & $\begin{array}{l}1 \sigma \\
(\% \mathrm{CV})\end{array}$ & $-2 \sigma$ & $+2 \sigma$ & $\begin{array}{l}1 \sigma \\
(\% \mathrm{CV})\end{array}$ & $-2 \sigma$ & $+2 \sigma$ & $\begin{array}{l}1 \sigma \\
(\% \mathrm{CV})\end{array}$ \\
\hline \multirow[t]{2}{*}{ GAB } & 25 & 0.0625 & 0.0706 & 3.0 & 8.0991 & 13.727 & 12.9 & 0.8068 & 0.8476 & 1.2 & & & \\
\hline & 50 & 0.0629 & 0.0722 & 3.4 & 5.6763 & 8.9279 & 11.1 & 0.8055 & 0.8489 & 1.3 & & & \\
\hline \multirow[t]{2}{*}{ Henderson } & 25 & 0.1294 & 0.1399 & 1.9 & 1.3060 & 1.6029 & 5.1 & & & & & & \\
\hline & 50 & 0.1265 & 0.1346 & 1.6 & 1.2422 & 1.4497 & 3.9 & & & & & & \\
\hline \multirow[t]{2}{*}{ Halsey } & 25 & 0.0740 & 0.0850 & 3.4 & 1.6088 & 1.9335 & 4.6 & & & & & & \\
\hline & 50 & 0.0678 & 0.0815 & 4.9 & 1.4762 & 1.8544 & 5.7 & & & & & & \\
\hline \multirow[t]{2}{*}{ Oswin } & 25 & 0.1001 & 0.1019 & 0.4 & 0.4345 & 0.4486 & 0.8 & & & & & & \\
\hline & 50 & 0.0940 & 0.0982 & 1.1 & 0.4549 & 0.4895 & 1.8 & & & & & & \\
\hline \multirow[t]{2}{*}{ Smith } & 25 & 0.0099 & 0.0377 & 29.2 & -7.4380 & -4.375 & 35.0 & & & & & & \\
\hline & 50 & 0.0077 & 0.0300 & 29.6 & -9.4940 & -1.784 & 34.2 & & & & & & \\
\hline \multirow[t]{2}{*}{ BET } & 25 & 0.2049 & 0.2994 & 9.4 & 0.3943 & 1.0628 & 22.9 & & & & & & \\
\hline & 50 & 0.2200 & 0.3084 & 8.4 & 0.3745 & 0.8487 & 19.4 & & & & & & \\
\hline \multirow[t]{2}{*}{ Peleg } & 25 & 0.1860 & 0.2313 & 5.4 & 0.6764 & 0.8283 & 5.0 & 5.1718 & 7.2678 & 8.4 & 0.6110 & 0.72372 & 4.2 \\
\hline & 50 & 0.1781 & 0.2338 & 6.8 & 0.6968 & 0.8926 & 6.2 & 5.1563 & 7.8202 & 10.3 & 0.7089 & 0.8460 & 4.4 \\
\hline
\end{tabular}




\subsection{Conclusion}

Important thermodynamic characteristics for predicting the interactions between water and food components are moisture desorption and adsorption isotherms. The moisture desorption and adsorption isotherms for yam (the Dente cultivar of $D$. Rotundata) have been determined at $25^{\circ} \mathrm{C}$ and $50^{\circ} \mathrm{C}$ by the dynamic method using the DVS analyzer between $0 \%$ to $0.95 \%$ water activity. The isotherms showed a sigmoidal shape. The equilibrium moisture contents were found to increase with increasing water activity at constant temperature. While at constant EMC the water activity is higher at higher temperature under adsorption, there is no significant difference in the case of desorption. Crossing of the adsorption isotherms of $25^{\circ} \mathrm{C}$ and $50^{\circ} \mathrm{C}$, and of the adsorption and desorption isotherms at $50^{\circ} \mathrm{C}$ took place at higher water activity, which is most probable result of the low sugar content in yam compared to other products, as discussed before. Within the range $0 \leq a_{w} \leq 0.85$ all seven models tested can provide a reasonable fit, although the BET and Smith models are inferior for yam. All models require two different parameter sets to describe the hysteresis between adsorption and desorption, which is a common flaw of these equations. Based on the standard error of prediction, the Peleg, Oswin and $\mathrm{GAB}$ models were found as most suitable to describe the experimental equilibrium moisture contents of yam (Dente) of both desorption and adsorption. The parameter uncertainty of the Oswin model is low. In general, a low parameter uncertainty means that the parameters can be estimated well from experimental data. At $50^{\circ} \mathrm{C}$ the absolute error is larger for the Oswin model than for Peleg and GAB. The Oswin model has the lowest AIC for sorption, which may make it the best model when it is needed to describe wetting of a product. For drying, however, the larger number of parameters in the Peleg and GAB models is justified, as shown by the lowest AIC values at desorption. Of these two, the GAB is preferred since it has a physiological basis, and fewer parameters that can be estimated quite well from experimental data. 


\section{Chapter 3}

\section{Moisture dependent diffusion and shrinkage in yam during drying}

This chapter is published as:

Amankwah, Emmanuel A.; Dzisi, Komla Agbeko; Straten, Gerrit van; Boxtel, Anton J.B. van 2018. Moisture dependent diffusion and shrinkage in yam during drying, International Journal of Food Engineering, 14(7-8), ISSN 2194-5764 - 15 p. 


\begin{abstract}
Crank's analytical approximations for Fick's diffusion equation were used to investigate the effect of moisture dependent sample thickness and diffusivity on the drying behavior of yam (Dioscoreaceae rotundata) cubicles. Drying and shrinkage experiments were separately conducted at temperatures of 30,40 and $50^{\circ} \mathrm{C}$ in a cabinet drier. The comparative study of moisture dependent shrinkage and moisture dependent diffusivity justifies the interdependence of diffusivity and shrinkage due to water loss during drying. The behavior for yam is best explained by a combination of fractal moisture dependent shrinkage and moisture dependent diffusion, describing both the drying and rate curves better with good prediction of the high moisture regions. This assertion was reached as a result of low mean square error, standard error, percentage relative deviation, Akaike's Information Criterion and high coefficient of determination. The results may indicate a varying mobility of water in food matrix of different moisture content in the multilayer and monolayer regimes.
\end{abstract}




\subsection{Introduction}

Yam, a delicacy and a major source of food supply for many African, Asian and Latin American countries, has a moisture content of about $70 \%$ when harvested, which make yam perishable (Fioreze et al., 2000). This can be prevented by drying into powders and storage under appropriate conditions. The powders are incorporated into soups, baby foods or processed into a thick viscous diet called Amala in Nigeria or Fufu in Ghana. Yam powder is obtained from yam cubicles which are dried in a traditional way like open sun drying or by using industrial or solar dryers. During drying, shrinkage occurs. To advance drying technology, it is essential to quantify and analyze the drying characteristics of yam cubicles, not neglecting the shrinkage factor.

Torres et al. (2011) report about the drying characteristics of two yam species (Dioscoreaceae alata) by using a classical model approach. The use of the Page equation is a semi-empirical approach and does not reflect the diffusion behavior that occurs in many food products as formulated by Yadollahinia, and Jahangiri (2009), Al-Muhtaseb et al. (2004) and Hassini et al. (2007) who have shown a linear relationship between moisture and shrinkage. Sjöholm and Gekas (1995) have shown a linear relationship between $D_{\text {eff }}$ and moisture content during apple drying as a consequence of volume change with moisture content. The change of moisture content in these products is given by Fick's second law:

$$
\frac{d X(t, x)}{d t}=\frac{d}{d x} D \frac{d X(t, x)}{d x}
$$

with $X(t, x)$ the moisture content ( $\mathrm{kg}$ water $/ \mathrm{kg}$ solids) as a function of time $(t)$ and position $(x)$ in the product compared to the center. $D$ is the effective diffusion coefficient $\left(\mathrm{m}^{2} / \mathrm{s}\right)$.

Crank (1975) provided analytical solutions of the diffusion equation for standard shaped products. For a product with an uniform initial moisture concentration $\left(X_{0}\right)$, negligible external resistance and time invariant diffusion coefficient the analytical solutions for the average moisture content in an infinite sized slab is given as:

$$
M R(t)=\frac{X(t)-X_{e}}{X_{o}-X_{e}}=\frac{8}{\pi^{2}} \sum_{n=0}^{\infty} \frac{1}{(2 n+1)^{2}} \exp \left(-\frac{(2 n+1)^{2} \pi^{2} D}{L^{2}} t\right)
$$

With $M R(t)$ the moisture ratio, $X(t)$ the actual averaged moisture content, $X_{0}$ the initial moisture content, $X_{e}$ the equilibrium moisture content at the end of drying, all in $\mathrm{kg}$ water $/ \mathrm{kg}$ solids and $L(m)$ the thickness of the slab.

Equation 3.2 represents a series of terms and writing the first 3 terms out $(n=0,1$ and 2 ) gives

$$
\begin{gathered}
M R(t)=\frac{8}{\pi^{2}} \exp \left(-\frac{\pi^{2} D}{L^{2}} t\right)+\frac{8}{9 \pi^{2}} \exp \left(-\frac{9 \pi^{2} D}{L^{2}} t\right) \\
+\frac{8}{25 \pi^{2}} \exp \left(-\frac{25 \pi^{2} D}{L^{2}} t\right)+. .
\end{gathered}
$$


The time scales of the successive terms differ strongly, i.e. the time scale of the third term is very short, for the second term, longer but still fast and the expression is dominated by the time scale of the first term. Together with a decreasing pre-exponential factor for each term, in practice just one or two terms suffice ( $n=0$ and 1), leading to Equation 3.4 as a suitable basis for the interpretation of drying curves $(n=0$ and 1$)$.

$$
M R(t)=\frac{8}{\pi^{2}} \exp \left(-\frac{\pi^{2} D}{L^{2}} t\right)+\frac{8}{9 \pi^{2}} \exp \left(-\frac{9 \pi^{2} D}{L^{2}} t\right)
$$

Often only one term is used as reported by Ah-Hen et al. (2013), Ben Haj Said et al. (2015), Chayjan et al. (2012), Asiah et al. (2017) and Hassini et al. (2007). In our experiments on drying of yam cubicles with a limited size, we observed systematic deviations between the data and fitted curves based on Equation 3.4. Assuming that moisture transport for yam is diffusion limited, these deviations can be a result of the following issues: (i) the geometry of the cubicles does not satisfy the conditions for infinite sized slabs, (ii) moisture transport is affected by shrinkage Mulet (1994), or (iii) the effective diffusion coefficient is not constant (Ruiz-Lopez and Garcia-Alvarado (2007). In this work we perform a step-wise analysis to understand the observed deviations between the data and fits for Equation 3.4. To check the role of the geometry and size of the particles, an analysis with computational fluid dynamics is performed. The role of shrinkage is investigated by using the concepts of volume reduction (Sjöholm and Gekas, 1995) and the effect of fractal change of thickness (Gekas and Lamberg, 1991). RuizLopez and Garcia-Alvarado (2007) related the diffusivity of water in the product matrix to moisture content. In line with their observations a moisture dependent diffusion coefficient is evaluated in this work.

\subsection{Materials and Methods}

\subsubsection{Yam species and sample preparation}

Yam tubers, Dioscoreaceae rotundata cultivar Dente, were precisely cut into discs of $10 \mathrm{~mm}$ thickness and subsequently the discs were further cut into square dimensions of $30 \mathrm{~mm}$ by 30 $\mathrm{mm}$. The dimensions of the samples were measured using digital calipers (model: 01407A, NEIKO, USA) of $0.02 \mathrm{~mm}$ accuracy.

\subsubsection{Shrinkage and moisture measurements}

In separate experiments on shrinkage, ten fresh yam cuts $(3 \times 3 \times 1 \mathrm{~cm})$ were placed in the drying chamber and dried at 30,40 and $50^{\circ} \mathrm{C}$. Before and after drying for 2, 4, 6, and 15 hours for all temperatures, plus 19, 42 and 72 hours for 50,40 and $30^{\circ} \mathrm{C}$, respectively and, 5 samples (replicates) were randomly selected from the drying chamber. For each sample cubicle, the side thickness $\left(S_{T}\right)$ and side lengths $\left(S_{L}\right)$ were determined with the digital calipers at the four sides of the sample, while the center thickness $\left(C_{T}\right)$ was measured three times within the neighborhood of the center of the sample. The average values each of the $S_{T}, \mathrm{~S}_{\mathrm{L}}$ and $\mathrm{S}_{\mathrm{T}}$ ere calculated. After the size measurements the corresponding moisture content of the samples were determined. 
According to Gekas and Lamberg (1991) the relative sample thickness and sample volume are related to each other by an exponential relation with fractal dimensional exponent $(z)$ as shown in Equation 3.5:

$$
\frac{L_{i}}{L_{0}}=\left[\frac{V_{i}}{V_{0}}\right]^{1 / z}
$$

With $V_{0}$ and $L_{0}$ respectively the initial sample volume $\left(\mathrm{mm}^{3}\right)$ and thickness $(\mathrm{mm}), V_{i}$ and $L_{i}$ the volume and thickness of the sample at the sampling moments during drying. The thickness of the sample is the average value from the four measured side thicknesses $\left(S_{T}\right)$ and the center thickness $\left(C_{T}\right)$ :

$$
L_{i}=\left[\frac{4 S_{T}+C_{T}}{5}\right]
$$

The circular deformation from the sides to the center at the top and bottom surface of the sample is considered as a parabolic form. With symmetrical surfaces, the actual volume of the product is then the volume of a square product $V_{s q r}$ minus the volume of the parabolic indentions $V_{\text {par }}$ :

$$
V_{i}=V_{s q r}-2 V_{\text {par }}=S_{L}^{2} S_{T}-2\left(0.5 \pi r^{2} h\right)
$$

With $r=\frac{S_{L}}{2}$ the radius of parabola basis and $h=\frac{S_{T}-C_{T}}{2}$ the height of the parabola.

\subsubsection{CFD- calculations}

In COMSOL two geometries of product cubicles $(3 \times 3 \times 1 \mathrm{~cm})$ were defined and Ficks diffusion equation was applied to these geometries. Simulations were performed with a diffusion coefficient of $2.5 \times 10^{-10} \mathrm{~m}^{2} / \mathrm{s}$. The initial condition for water content throughout the geometry was set to $1.0 \mathrm{~kg} / \mathrm{m}^{3}$ and at the boundaries of the geometry at $0.0 \mathrm{~kg} / \mathrm{m}^{3}$. Drying in the first geometry corresponds to an infinite slab by blocking water transport through the side surfaces which results in water transport through only the top and bottom surface. The second geometry concerned the actual drying behavior by moisture transport through all surfaces. The results were evaluated by fitting Equation 3.4 to the simulated moisture content as a function of time.

\subsubsection{Drying procedure and equipment}

The dryer system was made up of a fan, heating element and drying chamber. Ambient air at a speed of $2.6 \mathrm{~m} / \mathrm{s}$ reaches the heating element by a fan (accuracy $\pm 0.05 \mathrm{~m} / \mathrm{s}$ ) through a controlled valve. The temperatures of the heated air and in the chamber were measured with K-type thermocouples (accuracy $\pm 0.1^{\circ} \mathrm{C}$ ). The relative humidity of the inlet air to the dryer was determined by a relative humidity sensor of accuracy $\pm 0.2 \% \mathrm{RH}$. The inlet air enters the dryer at the bottom side and leaves at the top side (See Figure 3.1). 


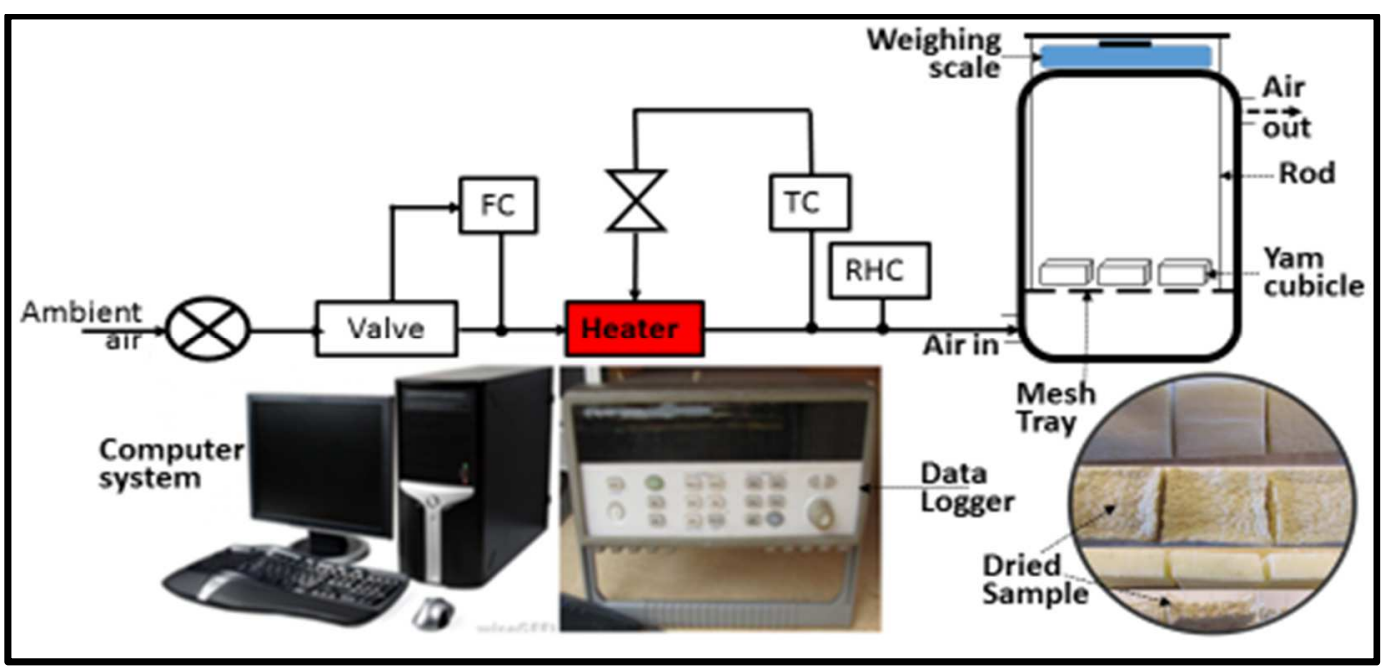

Figure 3.1 Schematic overview of the drying equipment with flow control ( $\mathrm{Fl} \mathrm{Ctl}$ ) and temperature control ( $\mathrm{T} \mathrm{Ctl})$, processor and data logger.

The air flow and air temperature were kept constant through PID controllers. At steady state of temperature and air speed, yam cuts $(3 \times 3 \times 1 \mathrm{~cm})$ weighing between $170-180 \mathrm{~g}$ were carefully placed on a wire mesh tray in the drying chamber (Figure. 3.1). The wire mesh tray is connected to a weighing scale (Mettler Toledo, PM250, Switzerland) to automatically read the changes in weight during drying. An Agilent data logger (model: 34970A, USA) logs and stores the drying air temperatures, air speed, relative humidity and changes in the sample weight by using a Labview interface. All data were recorded within intervals of 2 seconds each and repeated for drying air temperatures of 30,40 and $50^{\circ} \mathrm{C}$.

\subsubsection{Statistical analysis of data}

Nonlinear regression in Matlab was used for parameter estimation of the models to the experimental data. The extent of variation between experimental data and model was determined with the statistical performance indicators:

Standard error:

$$
S E=\sqrt{\frac{\sum_{i=1}^{N_{e}}(\text { Residuals })^{2}}{N_{e}-N_{p}}}
$$

Percent average relative deviation:

$$
\begin{aligned}
P R D(\%) & =\frac{100}{N_{e}} \sum_{i=1}^{N_{e}}\left(\frac{\mid \text { Residuals } \mid}{X}\right) \\
M S e & =\frac{\sum_{i=1}^{N_{e}}(\text { Residuals })^{2}}{N_{e}}
\end{aligned}
$$

Where the residuals are the differences between the observed and predicted data, and $X$ is the observed moisture content value. In general, a better fit is obtained with more parameters, but the improvement must be worth-while. Akaike's Information Criterion (AIC) is especially suitable for comparing models with a different number of parameters. The criterion is defined by 


$$
A I C=2 N_{p}+N_{e} \ln (V(\widehat{\mathbf{p}}))
$$

based on the likelihood function, but ignoring the constant term $-N_{e} \ln \left(N_{e}\right)-N_{e} \ln (2 \pi)-$ $N_{e}$. The model with the lowest AIC is preferred. Here $V(\widehat{\boldsymbol{p}})$ is the sum of squares errors, $N_{p}$ is the number of parameters of a particular model, and $N_{e}$ is the number of experimental data points. All data were processed and evaluated using the Matlab software.

\subsection{Results and discussion}

\subsubsection{Shrinkage}

Table 3.1 shows the mean dimensions of the yam cubicles and its corresponding moisture content in time. Shrinkage is highest in the center of the cubicle and is temperature dependent. The percentage shrinkage is between $44-64 \%$ in the center with highest shrinkage recorded at $50^{\circ} \mathrm{C}$ From the data in Table 3.1 first the thickness and volume were calculated according Equations 3.6 and 3.7 and next the results were transformed to the relative thickness $\left(L_{c}=\right.$ $\left.L_{i} / L_{0}\right)$ and relative volume $\left(V_{c}=V_{i} / V_{0}\right)$ by dividing with the initial values at start of the experiment. These results are given in Table 3.2. 
Table 3.1 Measured dimensions $\left(S_{L}, S_{T}\right.$ and $\left.C_{T}\right)$ and moisture content of yam cubicles for drying at 30,40 and $50^{\circ} \mathrm{C}$

\begin{tabular}{|c|c|c|c|c|c|c|c|c|c|c|c|c|}
\hline Time & \multicolumn{4}{|c|}{$30^{\circ} \mathrm{C}$} & \multicolumn{4}{|c|}{$40^{\circ} \mathrm{C}$} & \multicolumn{4}{|c|}{$50^{\circ} \mathrm{C}$} \\
\hline & $S_{L}(\mathrm{~cm})$ & $S_{T}(\mathrm{~cm})$ & $C_{T}(\mathrm{~cm})$ & $X(d b)$ & $S_{L}(\mathrm{~cm})$ & $S_{T}(\mathrm{~cm})$ & $C_{T}(\mathrm{~cm})$ & $\mathrm{X}(\mathrm{db})$ & $S_{L}(\mathrm{~cm})$ & $S_{T}(\mathrm{~cm})$ & $C_{T}(\mathrm{~cm})$ & $X(d b)$ \\
\hline 0 & 3.00 & 1.00 & 1.00 & 2.330 & 3.00 & 1.00 & 1.00 & 2.330 & 3.00 & 1.00 & 1.00 & 2.330 \\
\hline 2 & $\begin{array}{c}2.93 \\
(0.019)\end{array}$ & $\begin{array}{c}0.91 \\
(0.037)\end{array}$ & $\begin{array}{c}0.92 \\
(0.032)\end{array}$ & 1.758 & $\begin{array}{c}2.84 \\
(0.030)\end{array}$ & $\begin{array}{c}0.90 \\
(0.021)\end{array}$ & $\begin{array}{c}0.89 \\
(0.022)\end{array}$ & 1.390 & $\begin{array}{c}2.83 \\
(0.073)\end{array}$ & $\begin{array}{c}0.86 \\
(0.017)\end{array}$ & $\begin{array}{c}0.85 \\
(0.012)\end{array}$ & 1.12 \\
\hline 4 & $\begin{array}{c}2.85 \\
(0.065)\end{array}$ & $\begin{array}{c}0.88 \\
(0.032)\end{array}$ & $\begin{array}{c}0.87 \\
(0.043)\end{array}$ & 1.589 & $\begin{array}{c}2.76 \\
(0.04)\end{array}$ & $\begin{array}{c}0.83 \\
(0.024)\end{array}$ & $\begin{array}{c}0.78 \\
(0.035)\end{array}$ & 1.104 & $\begin{array}{c}2.7 \\
(0.053)\end{array}$ & $\begin{array}{c}0.8 \\
(0.024)\end{array}$ & $\begin{array}{c}0.64 \\
(0.011)\end{array}$ & 0.77 \\
\hline 6 & $\begin{array}{c}2.78 \\
(0.049)\end{array}$ & $\begin{array}{c}0.87 \\
(0.032)\end{array}$ & $\begin{array}{c}0.79 \\
(0.045)\end{array}$ & 1.132 & $\begin{array}{c}2.69 \\
(0.047)\end{array}$ & $\begin{array}{c}0.79 \\
(0.029)\end{array}$ & $\begin{array}{c}0.72 \\
(0.031)\end{array}$ & 1.055 & $\begin{array}{c}2.6 \\
(0.026)\end{array}$ & $\begin{array}{c}0.79 \\
(0.039)\end{array}$ & $\begin{array}{c}0.56 \\
(0.045)\end{array}$ & 0.52 \\
\hline 15 & $\begin{array}{c}2.74 \\
(0.046)\end{array}$ & $\begin{array}{c}0.84 \\
(0.031)\end{array}$ & $\begin{array}{c}0.62 \\
(0.027)\end{array}$ & 0.625 & $\begin{array}{c}2.61 \\
(0.057)\end{array}$ & $\begin{array}{c}0.74 \\
(0.029)\end{array}$ & $\begin{array}{c}0.56 \\
(0.024)\end{array}$ & 0.400 & $\begin{array}{c}2.5 \\
(0.042)\end{array}$ & $\begin{array}{c}0.7 \\
(0.020)\end{array}$ & $\begin{array}{c}0.48 \\
(0.028)\end{array}$ & 0.254 \\
\hline 19 & - & - & - & - & - & - & - & - & $\begin{array}{c}2.48 \\
(0.036)\end{array}$ & $\begin{array}{c}0.68 \\
(0.019)\end{array}$ & $\begin{array}{c}0.36 \\
(0.032)\end{array}$ & 0.045 \\
\hline 47 & - & - & - & - & $\begin{array}{c}2.58 \\
(0.029)\end{array}$ & $\begin{array}{c}0.70 \\
(0.02)\end{array}$ & $\begin{array}{c}0.50 \\
(0.035)\end{array}$ & 0.140 & - & - & - & - \\
\hline 72 & $\begin{array}{c}2.71 \\
(0.025)\end{array}$ & $\begin{array}{c}0.83 \\
(0.026)\end{array}$ & $\begin{array}{c}0.56 \\
(0.025)\end{array}$ & 0.170 & - & - & - & - & - & - & - & - \\
\hline$\% \mathrm{Shr}$ & 10 & 17 & 44 & - & 14 & 30 & 50 & - & 17 & 32 & 64 & - \\
\hline $\mathrm{Sdv}_{\mathrm{ave}}$ & 0.0408 & 0.0316 & 0.0344 & & 0.0406 & 0.0246 & 0.029 & & 0.046 & 0.0238 & 0.0272 & \\
\hline $\begin{array}{c}\text { Stdev } \\
\text { (Stdev) }\end{array}$ & 0.0187 & 0.00391 & 0.00915 & & 0.01180 & 0.00427 & 0.00660 & & 0.01799 & 0.00887 & 0.01509 & \\
\hline
\end{tabular}

()$=$ standard deviation over 5 replicates, Shr = shrinkage, Sdvave = average of standard deviation, Stdev (Stdev) = Standard deviation of the standard. 
Table 3.2 Relative volume $\left(V_{c}\right)$ and thickness $\left(L_{c}\right)$ derived from the product dimensions (Table 1) and product moisture content $(X(t))$ during drying at temperatures ranging between 30 and $50^{\circ} \mathrm{C}$

\begin{tabular}{lccc}
\hline Moisture content $\mathrm{X}(\mathrm{kg} / \mathrm{kg})$ & Relative thickness $\mathrm{L}_{\mathrm{c}}(-)$ & Relative volume $\mathrm{V}_{\mathrm{c}}(-)$ \\
\hline $30^{\circ} \mathrm{C}$ & & & \\
\hline & 2.33 & 1.00 & 1.00 \\
& 1.76 & 0.91 & 0.87 \\
& 1.59 & 0.88 & 0.79 \\
& 1.13 & 0.85 & 0.72 \\
& 0.63 & 0.80 & 0.63 \\
& 0.17 & 0.78 & 0.59 \\
\hline $40{ }^{\circ} \mathrm{C}$ & & & 1.00 \\
\hline & 2.33 & 1.00 & 0.80 \\
& 1.39 & 0.90 & 0.69 \\
& 1.10 & 0.82 & 0.61 \\
& 0.66 & 0.78 & 0.51 \\
& 0.40 & 0.70 & 0.46 \\
\hline $50{ }^{\circ} \mathrm{C}$ & 0.14 & 0.66 & 1.00 \\
\hline & 2.33 & & 0.76 \\
& 1.12 & 1.00 & 0.60 \\
& 0.77 & 0.86 & 0.52 \\
0.52 & 0.77 & 0.43 \\
& 0.25 & 0.74 & 0.38 \\
\hline 0.05 & 0.66 &
\end{tabular}

Linear regression of relative thickness $\left(L_{c}\right)$ against moisture content $(X)$ at temperatures 30, 40 and $50{ }^{\circ} \mathrm{C}$ respectively gave the combined linear equations as:

$$
L c(X, T)=(0.0033 \mathrm{~T}+0.0105) \mathrm{X}+0.8870-0.0054 \mathrm{~T}
$$

Equation 5 relates the relative thickness $\left(L_{c}\right)$ and relative volume $\left(V_{c}\right)$ through the fractal coefficient $(z)$. Figure 3.2 presents the double logarithmic plot of relative thickness and volume for all data from Table 3.2, which results in average fractal factor, $z=1.98$. This value is in the upper range of the values found by Gekas and Lamberg, (1991) and ( $\mathrm{z}=1.4-1.8)$ and indicates a relative strong contribution of the sample thickness to the volume (See Figure 3.2). 


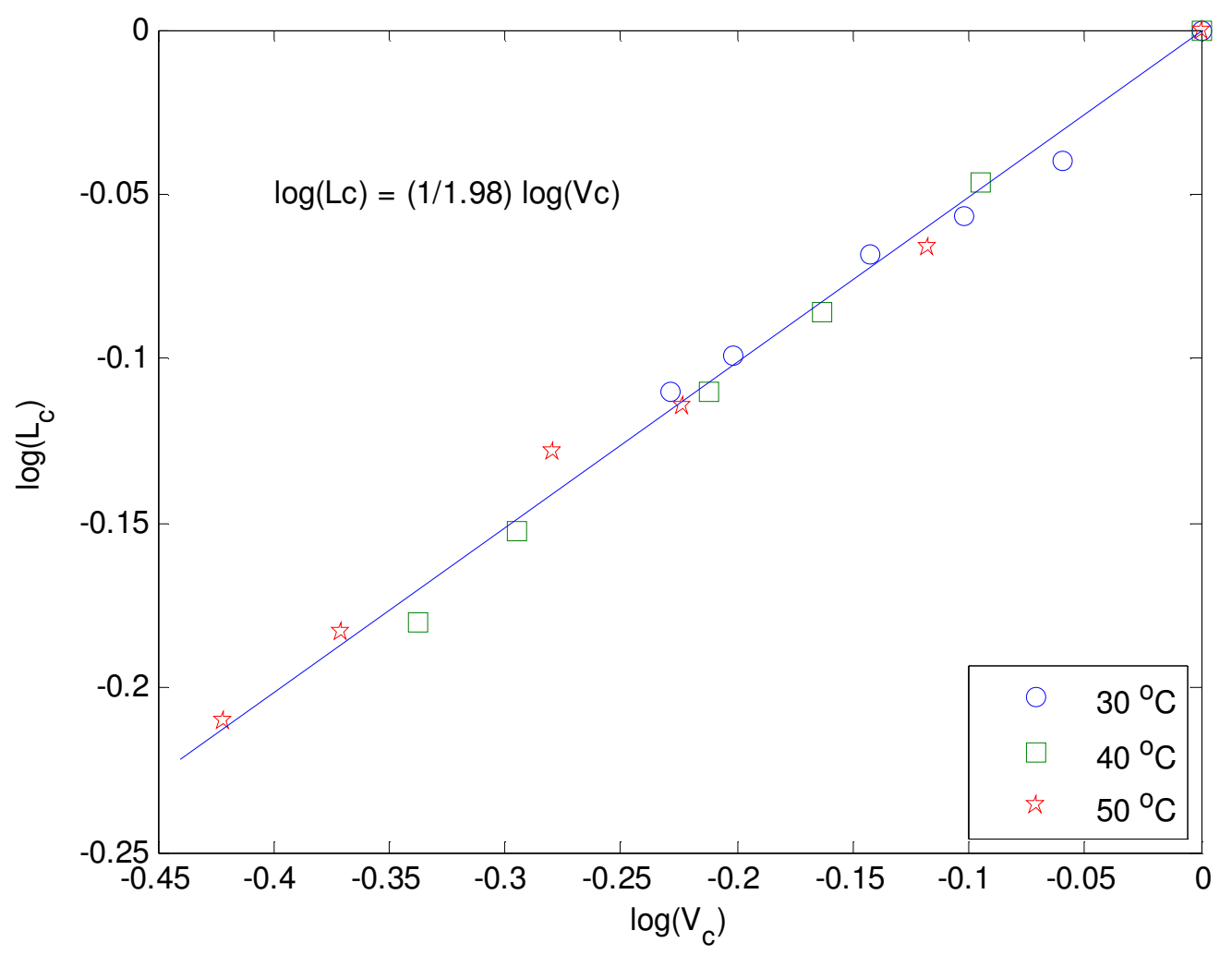

Figure 3.2 Logarithm of volume change $\left(V_{c}\right)$ against logarithm of thickness change $\left(L_{c}\right)$ for temperatures ranging between $30-50{ }^{\circ} \mathrm{C}$.

The yam cubicle dimensional reduction during drying represented by the relative volume from Table 3.2 at temperatures $30-50^{\circ} \mathrm{C}$ showed non-linear relationships with moisture content $(X)$. Regression analysis of $\log \left(V_{c}\right)$ as a function of $X-X o$ is given as:

$$
\log \left(V_{c}\right)=S X-S X_{0}
$$

Where $S$ is the slope, $X_{0}$ is the initial moisture content, $X$ is the moisture content in time, both given as $\mathrm{kg}$ water/kg dry matter. The combination gives:

$$
\log (V c)=(0.0038 \mathrm{~T}-0.0012) X-0.0065 \mathrm{~T}+0.0738
$$

The expression for the final relative thickness is then:

$$
\frac{L}{L_{0}}=L_{c}=10^{\frac{[(0.0038 \mathrm{~T}-0.0012) X-(0.0065 \mathrm{~T}+0.0738)]}{Z}}
$$

Both equations 3.12 and 3.15 give an expression for the relative thickness as a function of moisture content and temperature. The difference between both equations arises from the applied procedure to link the relative thickness to the moisture content. Equation 3.12 is based on direct regression between thickness and moisture content, while equation 3.15 is based on regression between product volume and moisture content.

\subsubsection{Drying and drying rate curves}

Figure 3.3 (top) shows the drying curves of the observed data of yam cubicles at temperatures of 30,40 and $50^{\circ} \mathrm{C}$. The figure shows the well-known trends for drying curves, with a 
decreasing moisture ratio over time and shorter drying times for higher temperatures. From the raw data the drying rate was derived and expressed as a function of the moisture ratio (Figure 3.3 (bottom)). Figure 3.3 (bottom) shows that the drying rate increases with moisture ratio and with steeper slope for higher temperatures. The plots show two main phases of rates which can, at first sight, be approximated by linear functions as: 1) a linear function for the range 0 0.5 and a linear function for the range above 0.5. Jannot et al. (2004) reported of 3 phases for banana. In the next part these phases section are analyzed by Crank's approximation for Fick's second law.
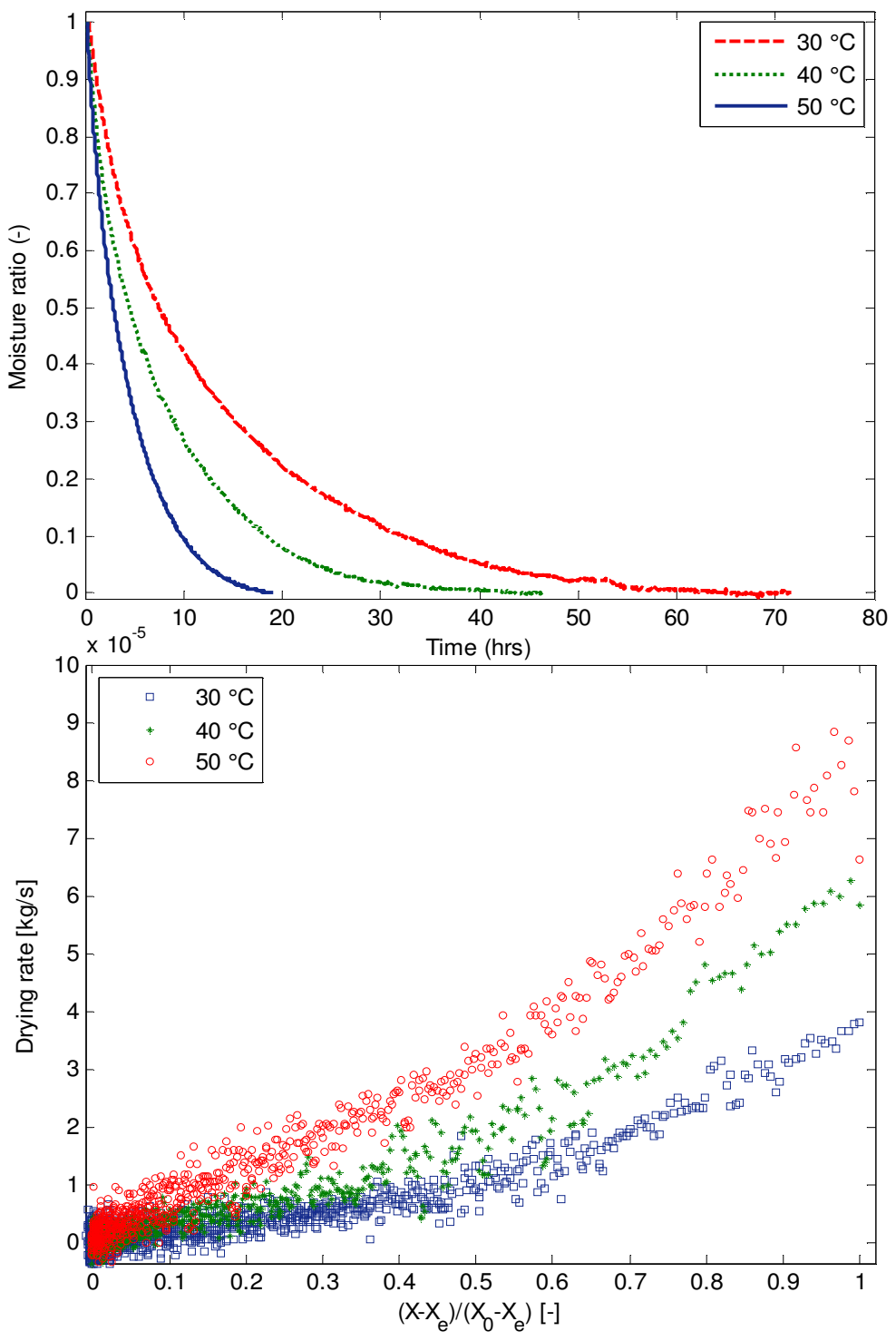

Figure. 3.3 Experimental data of moisture ratio against time (top) and drying rate against moisture (bottom) of yam at different temperatures.

\subsubsection{CFD-results}

Figure 3.4 represents the distribution for the moisture ratio in product samples with moisture transport through all product edges at 20000 and 50000 seconds. The distribution, with a gradual decrease of moisture towards the edges of the product, is a characteristic example for 
diffusional mass transport in a sample with limited dimensions. For products that behave as an infinite slab there is only a gradient towards top and bottom of the sample.
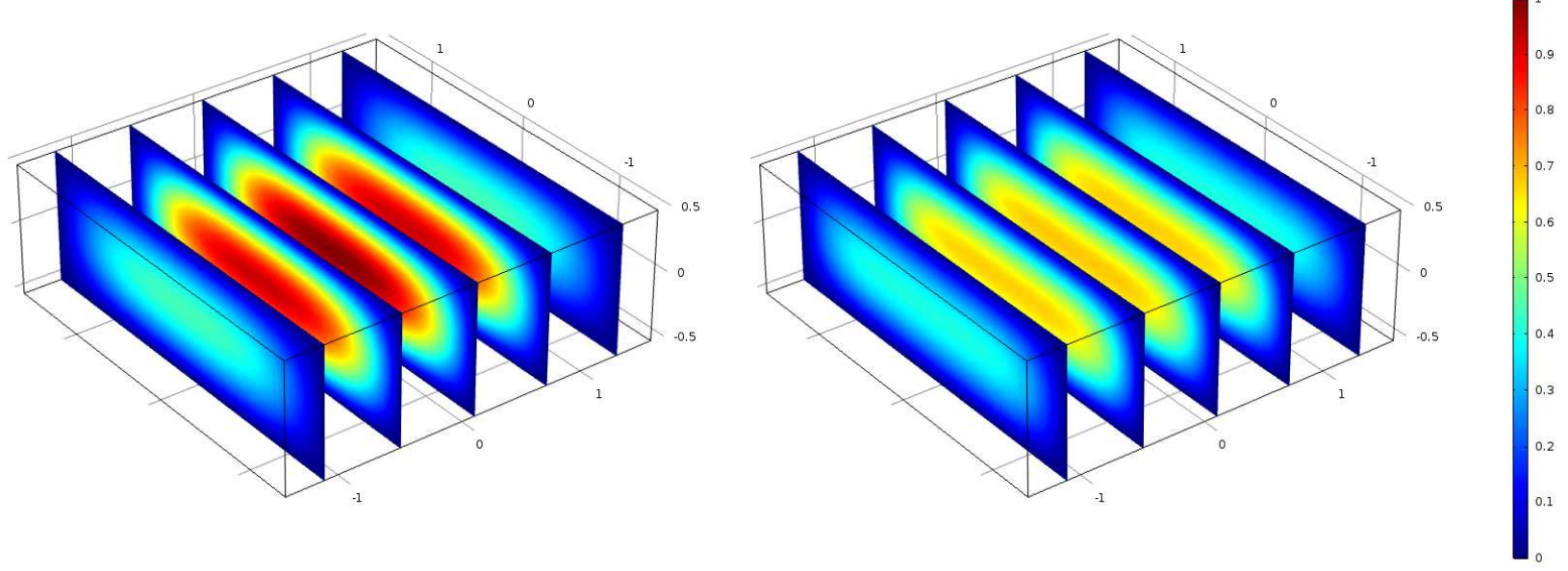

Figure 3.4 Profile of moisture ratio in the product samples with transport through all side planes at 20000 and 50000 seconds of drying.

Like in Figure 3.3, CFD generated data of the drying rate for the two geometries are plotted against the moisture ratio in Figure 3.5 (top: transport through only bottom and top and satisfying the properties of an infinite slab, bottom: moisture transport through all sides). Comparison of the results shows that the drying rate in the second geometry is above that of the first geometry, which is evident due to the larger product surface available for drying. Applying the three term model (Equation 3.3) to fit the drying curve $(X(t)$ as a function of time resulted in the dashed lines in both graphs. Overall, the drying rate from the three term model is in both cases very close to the data, the main difference is in the region of the high moisture ratio. The performance in the high moisture region could be slightly improved by adding more terms. The estimated diffusion coefficient for the first geometry corresponds to that used in the simulations to generate the data. For the second geometry the estimated diffusion coefficient is higher due to the larger drying rates that result from the extra moisture transferring surfaces. These results show that, with a higher effective diffusion coefficient, Crank's approximation can also be applied for the considered particles with moisture transport through the side surfaces. Moreover, the different phases in the drying rate in Figure 3.3 are not result of the rather small dimensions of the particles used in the experiments. 

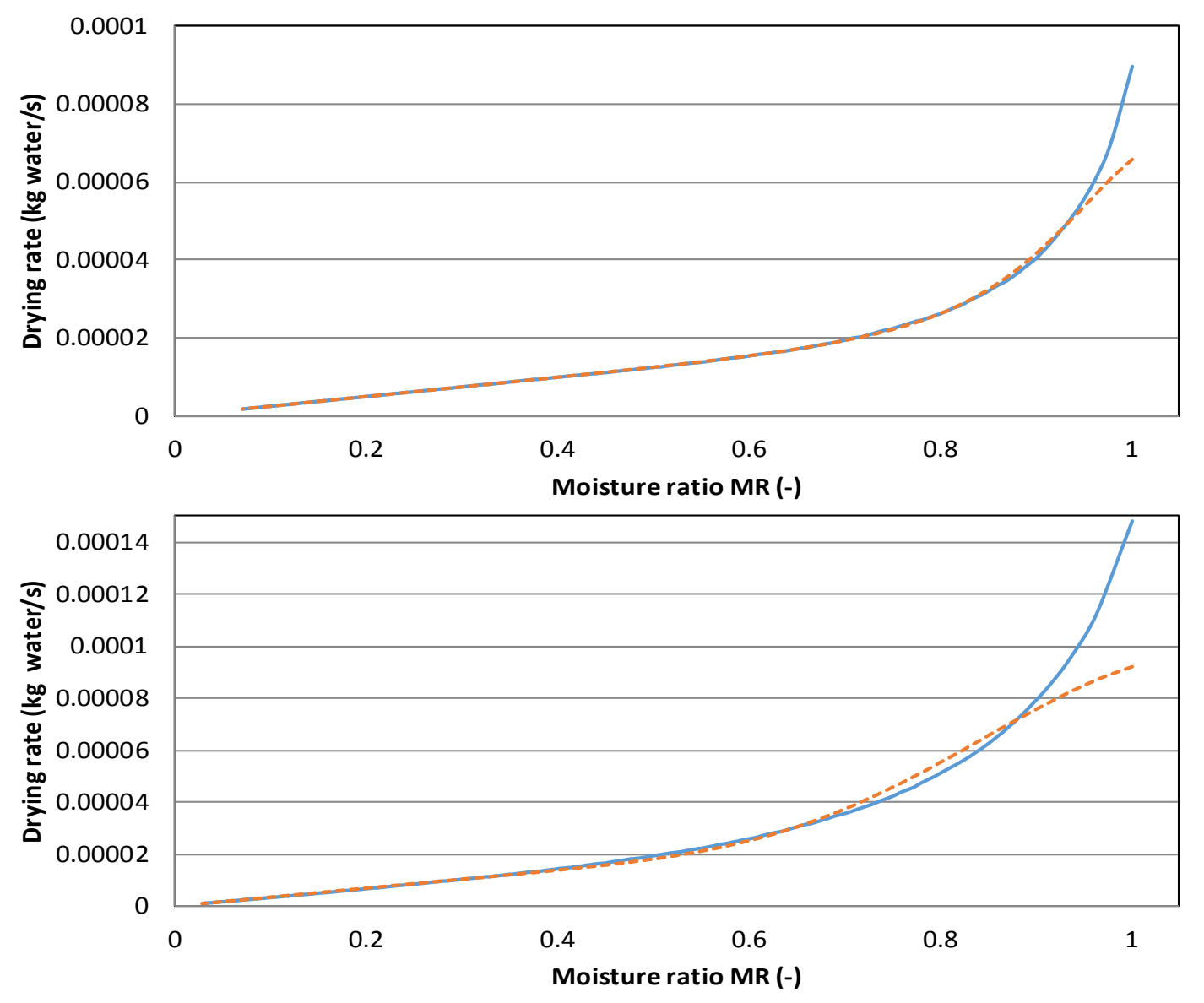

Figure 3.5. Comparing CFD generated data for a geometry with moisture transport through the top and bottom surface (top), and a geometry with moisture transport through all sides (bottom). Drawn line CFD data, dashed line approximation with the Crank's approximation with three terms.

\subsubsection{Fitting drying curves to data}

The form of the drying rate curves for the data generated by CFD and the measured data given in Figure 3.3 (bottom) have a large similarity and therefore the measured drying curves were fitted with the Equation 3.4 with 2 terms. The noise in the measured data was too high for a statistical meaningful application of 3 terms (Equation 3.3). To compensate partly for the effects of higher terms, the coefficient of the second term in the right hand side of Equation (3.4) is considered as a parameter (Equation 3.16).

Non-linear

$$
M R(t)=\frac{8}{\pi^{2}} \exp \left(-\frac{\pi^{2} D(X)}{L(X)^{2}} t\right)+p \exp \left(-\frac{9 \pi^{2} D(X)}{L(X)^{2}} t\right)
$$

At first, Equation 3.16 is fitted to the data with fixed values for the diffusion coefficient $D$ and sample thickness L. Figure 6 shows measured and model curves of the non-linear approximation for the diffusion equation. The obtained parameters and the statistics of the fit are given in Table 3.3. 
Figure 3.6 (top) represents moisture ratio as a function of time while the bottom figure represents the drying rate as a function of moisture ratio at constant slab thickness and diffusion coefficient. The figures show systematic errors in the models, while the drying rate curves reflect a drastic deviation of the models from the observed data. However, it is able to produce the two phases as observed in Figure 3.4 (bottom). The deviation of the drying rate curve (Figure 3.6, bottom) can possibly be a result from 1) product shrinkage, 2) a moisture dependent diffusion coefficient, or 3 ) a combination of these two.
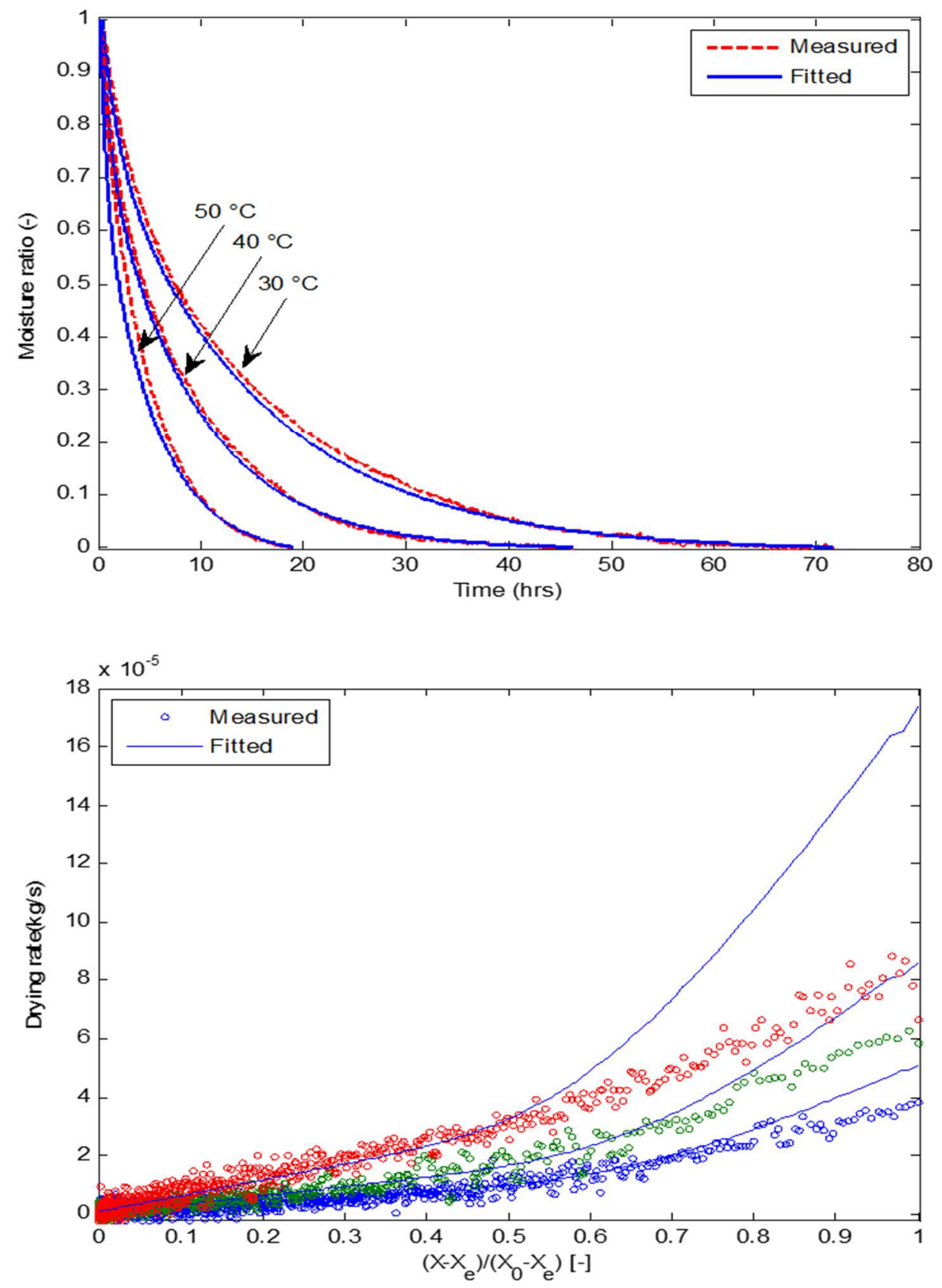

Fig 3.6. Results for the two term diffusion equation approximation. Moisture ratio as a function of time (top), drying rate as a function of moisture ratio (bottom) at constant slab thickness and diffusion coefficient. 
Table 3.3 Estimated parameters with coefficient of variation in brackets (\%) and statistical results for two-term at constant sample thickness and diffusion coefficient.

\begin{tabular}{lclll}
\hline & Temperature ${ }^{\circ} \mathrm{C}$ & 30 & 40 & 50 \\
\hline & $D \times 10^{-10} \mathrm{~m}^{2} / \mathrm{s}$ & $1.833(0.22)$ & $3.143(0.28)$ & $5.472(0.93)$ \\
& $p$ & $0.301(1.59)$ & $0.300(2.013)$ & $0.434(5.26)$ \\
$\begin{array}{l}\text { Two term equation at constant } \\
\text { slab thickness and diffusion }\end{array}$ & $M S e \times 10^{-4}$ & 0.577 & 0.553 & 0.694 \\
coefficient & $\mathrm{SE}$ & 0.007 & 0.007 & 0.0263 \\
& $\mathrm{PRD}$ & 2.987 & 3.306 & 15.707 \\
& $\mathrm{AIC}$ & -3336.810 & -2559.481 & -508.501 \\
& $R^{2}$ & 0.999 & 0.999 & 0.998 \\
\hline
\end{tabular}

Because of the systematic deviations in both the drying curve and drying rate curve the effect of the dependency of $L$ and $D$ on $X$, is studied by considering four options. The results are given in Figure 3.7 and Table 3.4.

Option one: left graphs in Figure 3.7, concern a variable slab thickness, linearly related to the moisture content $L(X)=c_{1} X(t)+c_{2}$, and based on Equation (3.12), and a constant diffusion coefficient $(D)$. The fits for the moisture ratio over time in Figure 3.7a and the drying rate in Figure $7 \mathrm{~b}$ deviate significantly from the data, especially the drying curve.

Option two: Figure 3.7c,d, middle graphs, gives the results for an effective diffusion coefficient, linearly related to the moisture content according to $D(X)=D_{0}+b X(t)$, in combination with a constant slab thickness. Compared to option 1 , the drying curve with moisture ratio over time fits better to the data, which is also reflected by a lower mean squared error and standard error etc. (see Table 3.4). Moreover, the drying rate model fits better to the data. However, the coefficient $b$ in the expression $D(X)=D_{0}+b X(t)$ is negative. This implies that the diffusion coefficient decreases with moisture content. In other words diffusive moisture transport becomes easier towards the end of drying, which is contradictory to the general experience from the literature (Janot et al., 2004).

Option three: Both sample thickness and diffusion coefficient are linearly related to the moisture content as presented in the previous options. The results are presented in Figure 3.7e,f (right graphs). In these graphs, the model results for the drying and drying rate curves are the closest to the data. The coefficient $b$ in the expression $D(X)=D_{0}+b X(t)$ is now positive which indicates a decreasing diffusion coefficient with decreasing moisture content. This result corresponds to a decline of water mobility during drying which corresponds to the general experience and which is amongst others explained by the free volume theory Jin et al. (2011). Compared with option 2, option 3 confirms the assertion by Tütüncü and Labuza (1996) that the diffusion coefficient varies during drying together with thickness. However, this option 
fails to predict well the observed data at high moisture content due to the accuracy level of the predictability of the initial relative length $(\mathrm{Lc}=1.0)$.

Option four: Instead of Equation 3.12, the fractal thickness of the sample as a function of moisture content from Equation 3.15 is applied in combination of the effective diffusion coefficient, linearly related to the moisture content (see Figure 3.8). The parameters and fitting results are summarized in Table 3.4. The drying and the drying rate curves show similar fit with that of the third option but now with good prediction of the high initial moisture content.

Statistically, for the various temperatures, options 2, 3 and 4 are close and give the lowest MSE (10 fold or more lower), SE, PRD, AIC and higher $\mathrm{R}^{2}$ compared to options 1 . However option 2 is rejected for the fact that the coefficient of $b$ is negative while option 4 is preferred over option 3 due to the good prediction of the high moisture region. Actually, options three and four are very close and differ only in the way the thickness of the sample is related to the product moisture content. In option three, the relation was direct derived from the thickness data, while in option four the expression was based on the product volume. The last approach proved to be a more suitable method when dealing with non-infinite slabs and gives a better data smoothing result.

\subsubsection{Discussion}

Mulet (1994) emphasizes the role of shrinkage and varying diffusivity for the interpretation of drying curves. Ruiz-Lopez and Garcia-Alvarado (2007) reported that a better estimation of effective diffusion coefficient can be achieved when both shrinkage and diffusivity as functions of moisture are factored in such models. In this work an additional analysis was made by examining curves of the drying rate as a function of moisture ratio. These curves show that the two-term approximation of the diffusion equation (equation 3.4) fit for the yam cubicles. The drying rate showed different stages during drying. Hassini et al. (2007) modeled the stages by determining different values for the diffusion coefficient in each stage. In contrast to the work of Hassini et al., 2007), in the current work the variation in diffusive transport is modeled by the two mechanisms: shrinkage and moisture dependent diffusion behavior. The moisture dependent diffusion behavior is attributed to the mobility of water in the product matrix, which is governed by the cell structure in yam and different water adsorption properties in mono and multilayers. Verma et al. (1985) mentioned also starch gelatinization as possible reason for the variable diffusion behavior for product for temperatures beyond $65^{\circ} \mathrm{C}$, but this level of temperature was not reached in this work.

The models with moisture dependent diffusion have one additional parameter $(b)$. According to the lower AIC (Table 3.4) for those models, the addition of this extra parameter is justified. The two equations (3.12) and (3.15) do not differ much. However, in the interest of accurate prediction of the high moisture region preference is given to inclusion of the fractal shrinkage in the model. 

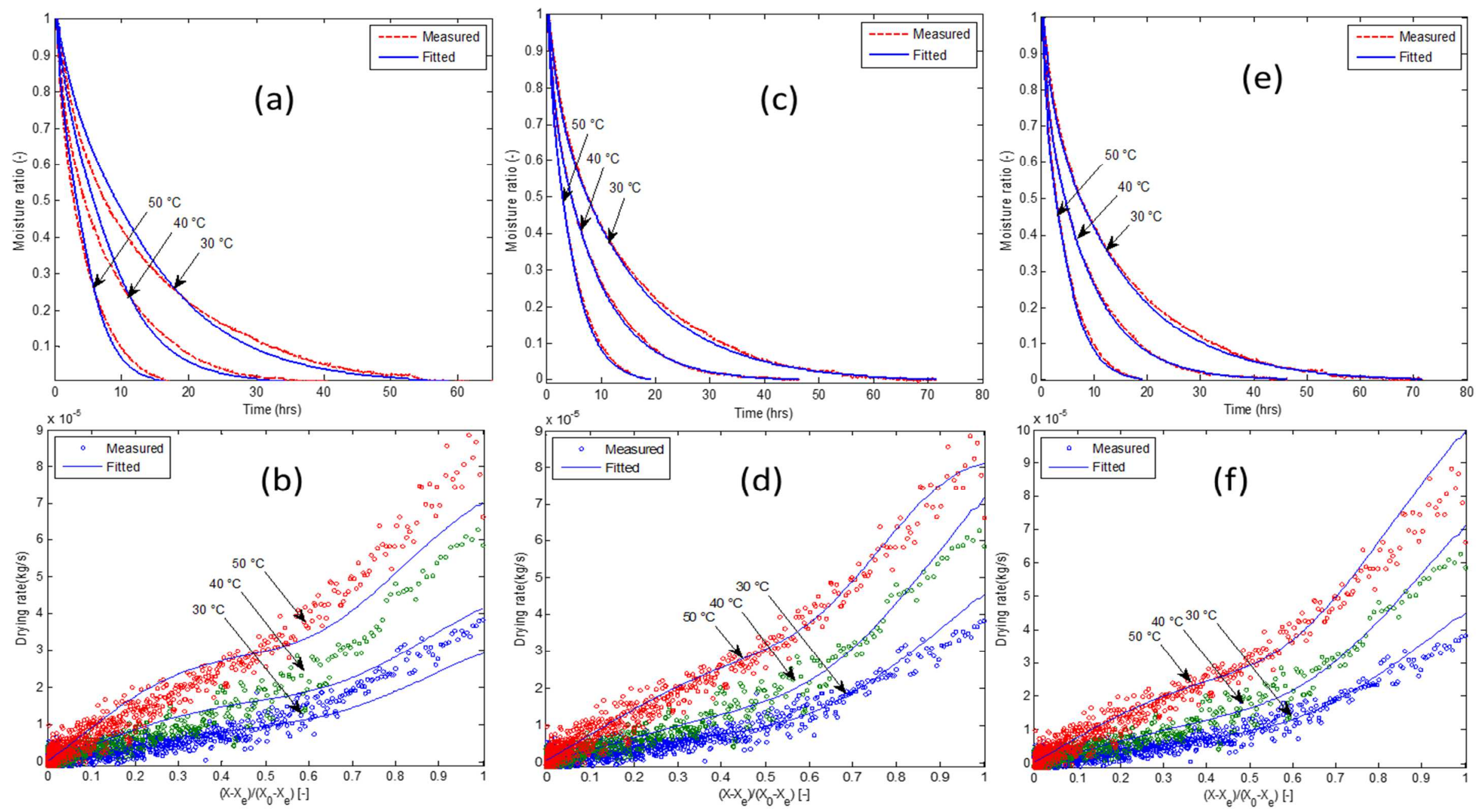

Figure 3.7 Results for the two term diffusion equation approximation (Equation 3.16). Shrinkage as linear function of moisture content and constant diffusion coefficient (a,b). No shrinkage and diffusion coefficient as a linear function of moisture content (c,d). Combined effect of shrinkage and diffusion coefficient both linearly related with moisture content $(e, f)$. 

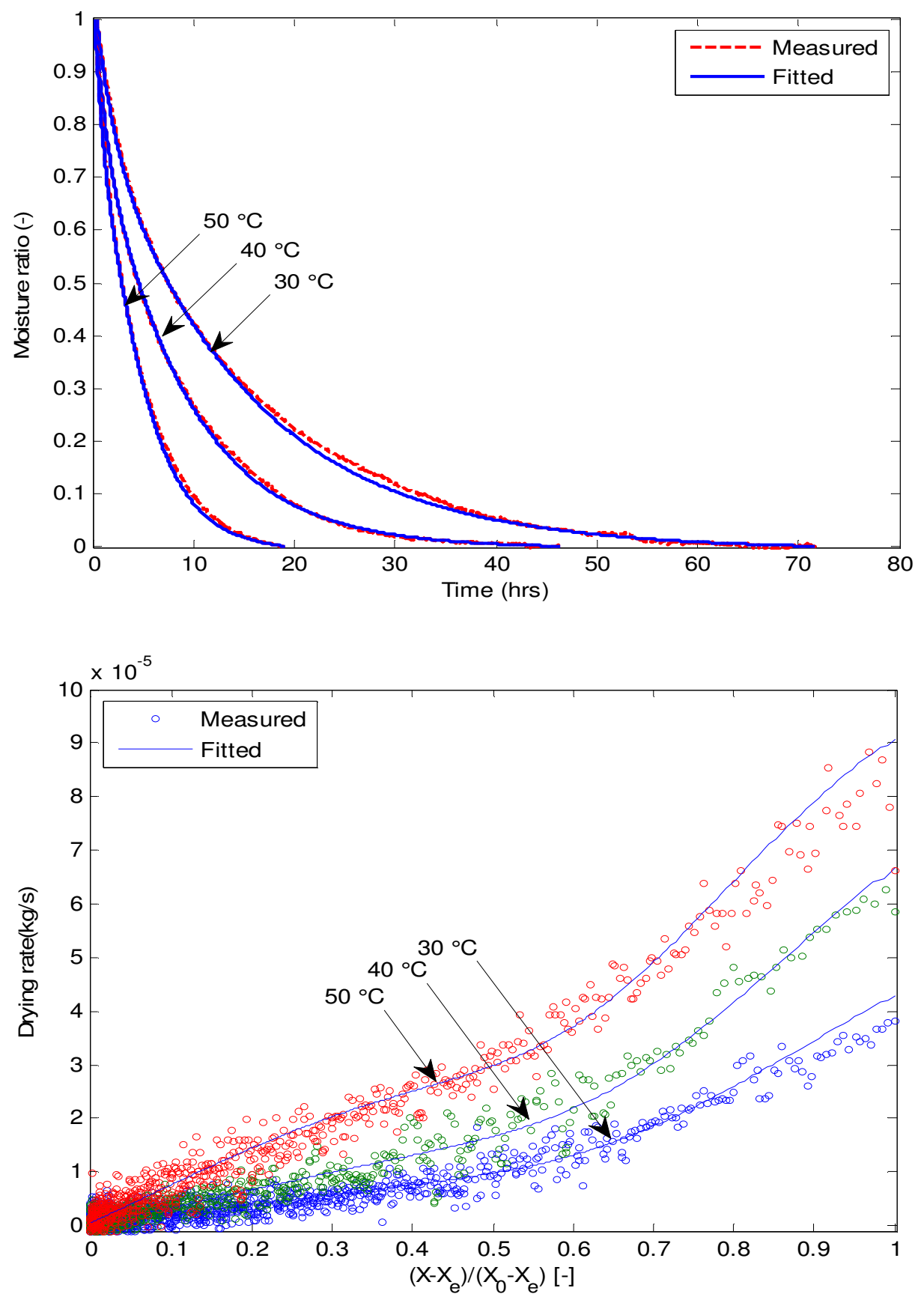

Figure 3.8 Results for the two term diffusion equation approximation (Equation 3.16). Fractal thickness shrinkage (Equation 3.13) as a linear function of moisture content and diffusion coefficient linearly elated to moisture content. Top: Moisture as a function of time; Bottom: Drying rate as function of moisture content. 
Table 3.4. Estimated parameters with coefficient of variation in brackets (\%) and statistical results for the four model options.

\begin{tabular}{|c|c|c|c|c|}
\hline & Temperature ${ }^{\circ} \mathrm{C}$ & 30 & 40 & 50 \\
\hline \multirow{7}{*}{$\begin{array}{l}\text { Moisture content related slab } \\
\text { thickness } \\
L(X)=c_{1} X(t)+c_{2} \text {, Eq } 12 \text {. }\end{array}$} & $D \times 10^{-10} \mathrm{~m}^{2} / \mathrm{s}$ & $1.12(0.55)$ & $1.85(0.76)$ & $2.91(0.55)$ \\
\hline & $p$ & $0.19(4.30)$ & $0.16(6.87)$ & $0.21(3.72)$ \\
\hline & $M S e \times 10^{-4}$ & 3.30 & 4.69 & 3.46 \\
\hline & SE & 0.018 & 0.022 & 0.018 \\
\hline & PRD & 3.22 & 4.19 & 5.33 \\
\hline & AIC & -1102 & -780 & -982 \\
\hline & $R^{2}$ & 0.999 & 0.998 & 0.999 \\
\hline \multirow{8}{*}{$\begin{array}{l}\text { Moisture content } \\
\text { diffusion coefficient } \\
D(X)=D_{0}+b X(t)\end{array}$} & $D_{o} \times 10^{-10} \mathrm{~m}^{2} / \mathrm{s}$ & $1.90(0.40)$ & $3.31(0.36)$ & $6.48(0.38)$ \\
\hline & $b \times 10^{-11}$ & $-0.90(-9.72)$ & $-2.46(-5.86)$ & $-15.07(-1.87)$ \\
\hline & $p$ & $0.28(1.72)$ & $0.26(1.64)$ & $0.25(1.93)$ \\
\hline & $M S e \times 10^{-4}$ & 0.45 & 0.22 & 0.40 \\
\hline & SE & 0.007 & 0.005 & 0.006 \\
\hline & PRD & 2.55 & 2.15 & 5.85 \\
\hline & AIC & -3669 & -3251 & -2443 \\
\hline & $R^{2}$ & 0.999 & 0.999 & 0.999 \\
\hline \multirow{8}{*}{$\begin{array}{l}\text { Combination of moisture } \\
\text { related diffusion coefficient } \\
\text { and slab thickness } \\
L(X)=c_{1} X(t)+c_{2} \text {, Eq } 12 . \\
D(X)=D_{0}+b X(t)\end{array}$} & $D_{o} \times 10^{-10} \mathrm{~m}^{2} / \mathrm{s}$ & $1.00(0.47)$ & $1.49(0.45)$ & $2.57(0.45)$ \\
\hline & $b \times 10^{-11}$ & $2.57(2.48)$ & $5.28(1.81)$ & $5.20(3.04)$ \\
\hline & $p$ & $0.27(1.63)$ & $0.26(1.54)$ & $0.28(1.49)$ \\
\hline & $M S e \times 10^{-4}$ & 0.44 & 0.23 & 0.30 \\
\hline & SE & 0.007 & 0.005 & 0.005 \\
\hline & PRD & 2.50 & 2.05 & 4.45 \\
\hline & AIC & -3693 & -3283 & -2652 \\
\hline & $R^{2}$ & 0.999 & 0.999 & 0.999 \\
\hline \multirow{8}{*}{$\begin{array}{l}\text { Combination of moisture } \\
\text { related diffusion coefficient } \\
\text { and fractal slab thickness } \\
L(X) \text { : Eq } 15 \text {. } \\
D(X)=D_{0}+b X(t)\end{array}$} & $D_{o} \times 10^{-10} \mathrm{~m}^{2} / \mathrm{s}$ & $1.01(0.48)$ & $1.51(0.48)$ & $2.61(0.45)$ \\
\hline & $b \times 10^{-11}$ & $2.49(2.63)$ & $4.95(2.08)$ & $4.25(3.80)$ \\
\hline & $p$ & $0.26(1.69)$ & $0.25(1.71)$ & $0.26(1.57)$ \\
\hline & $M S e \times 10^{-4}$ & 0.46 & 0.27 & 0.32 \\
\hline & $\mathrm{SE}$ & 0.007 & 0.005 & 0.006 \\
\hline & PRD & 2.59 & 2.27 & 5.04 \\
\hline & AIC & -3631 & -3142 & -2611 \\
\hline & $R^{2}$ & 0.999 & 0.999 & 0.999 \\
\hline
\end{tabular}


The analytical expression for the diffusion in a slab as given by Crank explains the two apparent stages in the drying rate as a function of moisture ratio. These stages appear in a similar way for large infinite slabs as the smaller cubicles. The trend in these phases is strongly supported by the introduction of a sample moisture dependent thickness and diffusion coefficient in the model.

The mathematical form of the two-term approximation for Fick's diffusion equation as given in Equation 3.16 corresponds to models used in semi-empirical expressions for the drying rate (Verma et al., 1985, Henderson, 1994, Sharaf-Eldeen et al., 1980). In those models the exponential terms are only estimated parameters. It is common practice to reject or to modify the mentioned models if the model does not adequately fit to the data. Examples of modifications are discussed in the review of Erbay and Icier (2010). Instead of modifying or seeking for another model, in this work the parameters were linked to moisture dependent diffusion behavior and shrinkage, which leads more to the fundamentals of moisture transport.

This work was focused on the mass transport by diffusion. From the dynamics for heat transfer a time constant around 30 seconds was derived. Therefore, the role of variations in temperature on the very slow mechanism of moisture transport can be neglected. The product samples remained close to the dryer inlet air temperature. Product quality degradation, like vitamin $\mathrm{C}$ and color were not the focus of this work. Vitamin $\mathrm{C}$ degradation which can already occur at the applied drying temperatures in the high moisture content region needs attention in further investigation.

\subsection{Conclusion}

Crank's analytical solution of Fick's diffusion equation for slabs has been used to describe the drying behavior of yam (Dioscoreaceae rotundata cultivar Dente) in terms of moisture dependency of shrinkage and diffusivity. The analytical expression for the diffusion in a slab is also valid for the smaller cubicles, but results in a higher effective diffusion coefficient, and shows two stages in the drying rate as a function of moisture ratio. The comparative study of moisture dependent shrinkage and moisture dependent diffusivity justifies the interdependence of diffusivity and shrinkage due to water loss during drying. This study shows that this behavior for yam is best explained by a combination of fractal moisture dependent shrinkage and moisture dependent diffusion. The moisture dependent diffusion behavior can be attributed to mobility of water from the food matrix due to different moisture content in the multilayer and monolayer regimes. The results from this study challenges to investigate the drying behavior of other food products. 


\section{Nomenclature}

Symbols used for drying models

$\begin{array}{cl}a, b, c_{1}, c_{2}, n & \text { Constants } \\ C_{T}, C_{T 0} & \text { Centre thickness of sample during drying and initial centre thickness }(\mathrm{cm}) \\ D & \text { Effective diffusion coefficient }\left(\mathrm{m}^{2} / \mathrm{s}\right) \\ D_{0} & \text { Reference value for effective diffusion coefficient }\left(\mathrm{m}^{2} / \mathrm{s}\right) \\ h & \text { Height of parabolic inclination at top and bottom of sample (m) } \\ L, L(X) & \text { Thickness of yam samples and thickness as a function of moisture content } \\ & \text { (m) } \\ L_{i}, L_{0} & \text { Measured sample thickness during drying, and initial sample thickness (m) } \\ L_{c} & \text { Relative thickness (-) } \\ M R(t) & \text { Moisture ratio (-) } \\ p & \text { Second term pre-exponential coefficient of the two term diffusion equation } \\ r & \text { Radius of parabolic inclination at top and bottom of sample (m) } \\ S_{T}, S_{T 0} & \text { Side thickness of sample and initial side thickness (cm) } \\ S_{L}, S_{L 0} & \text { Side length of a sample and initial side length (cm) } \\ t & \text { Time (s) } \\ V_{i}, V_{0} & \left.\text { Measured sample volume during drying, and initial sample volume (m }{ }^{3}\right) \\ V_{c} & \text { Relative volume (-) } \\ V_{s q r}, V_{p a r} & \text { Volume of rectangular part of sample, volume of parabolic inclination at top } \\ x & \text { and bottom of sample (m) } \\ X(t) & \text { Position in the product compared to the center (m) } \\ X_{0}, X e & \text { Moisture content during drying (kg water } / \mathrm{kg} \text { dry matter) } \\ z & \text { Fritial and equilibrium moisture content (kg water/kg dry matter) } \\ & \end{array}$

Symbols used for statistics

AIC Aikaike information criterion

MSe Mean squared error

$N_{e} \quad$ Number of data points

$N_{p} \quad$ Number of parameters

$P R D \quad$ Percentage relative deviation

Residuals Not yet given

$S E \quad$ Standard error

$V(\hat{p}) \quad$ Sum of squared errors

$\bar{X} \quad$ Mean value 


\section{Chapter 4}

\section{Distributed mathematical model supporting design and construction of solar collectors for drying}

This part of thesis was published as:

E. A. Y. Amankwah, K. A. Dzisi, G. van Straten, L. G. van Willigenburg \& A. J. B. van Boxtel (2017) Distributed mathematical model supporting design and construction of solar collectors for drying, Drying Technology, 35:14, 1675-1687, DOI:

10.1080/07373937.2016.1269806 


\begin{abstract}
Coupled partial differential equations were developed to investigate which collector lengths are appropriate for drying and adsorbent regeneration under prevailing Ghanaian weather. Unlike approaches based on empirical data, the numerical model is more flexible. Effects of operational and design variables on outlet temperature and performance were systematically studied. Collector length and air speed affects performance indicators. Operational overall heat loss coefficient, an important characteristic of the collector, is not constant but varies during the day. With plausible physical parameters the model describes the experimental data well. Collector lengths of $1.5 \mathrm{~m}$ and $4.5 \mathrm{~m}$ suited drying and regeneration, respectively.
\end{abstract}




\subsection{Introduction}

Supply of hot air is important for drying agricultural products. Open air drying is currently the most widely practiced agricultural operation in the world (Fellow, 2000, Fellow, 2009, Doymaz, 2004). Long exposure to the drying temperature has adverse effects on physical and chemical content (Fellow, 2000, and Hofsetz et al., 2007). Moreover, consumers expect processed products that are not contaminated (Özcan et al., 2005) which is hard to achieve in open air drying. Therefore, various forms of drying equipment have been introduced. However, energy consumption for drying processes is generally high. It is about a quarter of national resources in the developed countries Mujumdar (1996) and less but still significant for developing countries. In addition, for quality reasons there is a desire to keep drying temperatures low, but conventional dryer systems that operate at low drying temperatures have low energy efficiencies (Atuonwu et al., 2011).

One way to overcome these difficulties is to use solar drying, especially in countries with favourable conditions, such as Ghana. Ghana is geographically located between latitude $4^{\circ}$ and $12^{\circ} \mathrm{N}$ and longitude $30^{\circ} \mathrm{W}$ and $1^{\circ} \mathrm{E}$. The country is endowed with daily hour by hour mean radiation between 0-920 W/m2 and monthly mean solar radiation between 4-6 kWh/m2-day (Akuffo, 1991 and Akuffo et al. 2003). The annual sunshine duration of Ghana is 1800-3000 hours (Edjekumhene and Atakora, 2001).

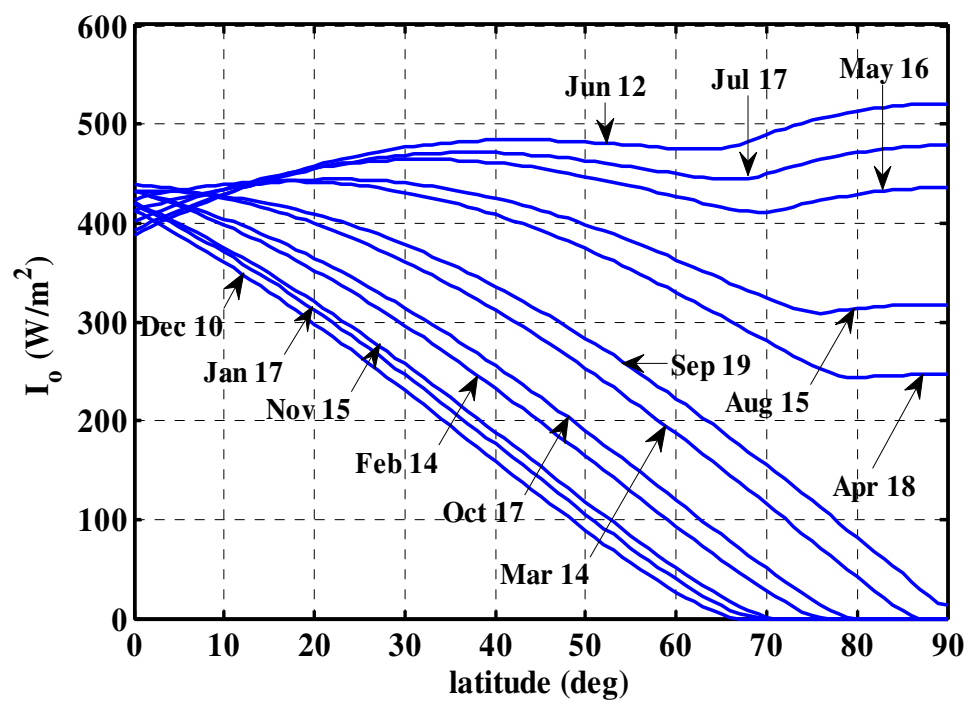

Figure 4.1. Monthly hourly mean extraterrestrial radiation on a horizontal surface for North latitude. Ghana is located between $4^{\circ}$ and $12^{\circ}$.

Thus Ghana's geographical location predisposes it to high solar radiation (see Figure 4.1). In this figure, the average monthly daily extraterrestrial radiation on a horizontal surface pointed due south, with monthly mean day numbers is shown (Akuffo, 1991). It can be observed that variation throughout the whole year is moderate for Ghana's latitude as compared to places of higher latitudes. 
This resource has not been harnessed effectively, especially for drying due to the fact that output collector air temperature is not known before construction. Food products that are usually dried in Ghana include cocoa beans, cereals, legumes, leafy vegetables, cassava, yam, cocoyam, plantain, fish, snail and shrimps etc. However, currently these are mostly dried in the open sun exposing them to contaminants.

Therefore any means by which these products could be dried effectively, quickly and hygienically to make them available during the lean season and to increase its variability of uses in product formulation without compromising on quality would be appropriate. Low temperatures are known to have minimal effect on heat sensitive components of a food product. However, improper design of collector systems may lead to over-heating or under-heating. Hence in designing a solar collector for drying purposes with the intention of maintaining nutrition value, parameters such as flow of heating medium, collector dimensions, absorber and cover plates material and surface type have to be considered.

Continuous drying at night can be possible by introducing an adsorbent (with for example silica gel) in the process. A solar adsorption dryer system (SADS) is an integrated dryer system that utilizes the sun's energy for drying and regeneration during the day and drying with dehumidified and slightly heated air drying during the night. This represents a new technology. Starting from this new technology a first essential step is a model-based design of flat plate solar collectors and investigating its suitability for drying and regeneration at varying collector length. Tomas et al. (2009) mentioned that virtual prototyping of solar collectors helps to predict the performance of a collector before manufacturing. Following this line, the goal here is to base the solar collector design on physical state-space modeling in order to investigate the collector dimensions that give low air output temperature which may lead to minimal deleterious effect on heat sensitive nutrients during drying during day time and, in addition, to investigate a collector system of dimension suitable for sorbent regeneration. Investigation of design and operational parameters on performance is also considered.

The design of solar collectors for drying find their basis in the model based work of Duffie and Beckman (1980). There are, however, several aspects of novelty in the model based approach of the current study. The earlier literature on solar collectors, such as the seminal work of Duffie and Beckman (1980) (and thus most of the subsequent work) was at the time necessarily limited to the use of analytical expressions and approximations. With numerical models the limitations of this approach can be alleviated. For instance, Duffie and Beckman (1980) mention that it is difficult to determine the spatial mean temperature of the absorber plate, which is required to obtain an overall heat loss coefficient. In the spatially distributed model as presented here this is not a problem at all. Moreover, solar collectors are often characterized by the heat removal factor that must be determined experimentally. This is obviously not of much use when the collector still has to be designed. In more recent papers on solar collector modeling, the focus is on heat gain from solar radiation and heat removal factor (Koyuncu, 2006) but surprisingly not enough on the temperature at the outlet. However, the temperature at the outlet is essential 
for drying sensitive agricultural products $\left(40-50^{\circ} \mathrm{C}\right)$, and for regeneration of adsorbents in an adsorption dryer system $\left(50-80^{\circ} \mathrm{C}\right)$. Kicsiny (2016) modeled the outlet temperatures for an existing solar collector based on experimental data for the environmental conditions, but this approach does not help to design the dimensions of the solar collector, especially solar collectors being operated under different conditions. The current work does include the collector outlet temperature, and evaluates the effect of operational factors, such as air speed, and design factors, such as collector length. In addition, the dynamics during the day can be evaluated, in contrast to several steady state analyses in the literature. Heat transfer coefficients are not constant, and change during the day and may be affected by collector length, which is another motivation for the development of a dynamic model. The heat transfer coefficients in the work of some researchers were not investigated as function of time, space and air velocity. Some researchers have reported them as parameters to be estimated (Kicsiny, 2016, Gao et al., 2007, Alvarez et al., 2010). In the dynamic model of Buzás et al. (1998) spatial distribution is not considered as the collector is considered as a mixed tank. Spatially distributed works that come close to this work are PV/water systems (Chow et al., 2006, Ji et al., 2009, Tiwari and Sodha, 2007), solar tunnel dryer Talbot et al. (2016), and solar water heater (Tiwari and Sodha, 2007). This work sought to use a model-based approach to design and construct solar collectors for low and high outlet temperatures in a solar adsorption drying system for drying agricultural products and for regeneration of the adsorbent used for night drying. The models are validated with experimental data from the constructed collector systems.

\subsection{Solar collector modeling}

On a solar collector, the incident solar energy is partially absorbed by an absorber plate and subsequently transferred to a flowing medium in an enclosure. One design uses an absorber plate and a glass cover with flowing air in between (Figure 4.2). The regime of air flow, whether laminar or turbulent, has an influence on the dynamic behavior of the system. In the present model, the rate of change of air temperature between plates is a function of absorber plate and cover temperatures, air gap, collector length and air flow rate. On the other hand the rate of change of absorber (plate) temperature is a function of the external input solar flux, plate temperature and glass temperature while the rate of change of cover plate (glass) temperature is a function of the glass, ambient and sky temperatures.

The glass cover, air stream and the absorber plate (aluminum coated black) are modeled using the following assumptions:

- Solar absorption is mainly by the absorber plate

- Air flow is in longitudinal direction only (one dimensional)

- The temperature equilibration in the directions perpendicular to the flow direction is so fast that there are no temperature gradients in these directions

- Transversal temperature gradients within the glass cover are ignored 
- Losses through the front end, back end and the convective term of the top cover are to ambient temperature while the irradiation term of the top cover is to the sky

- Longitudinal dispersion of heat is negligible

- Dust and dirt on the collector are negligible

- Shading of the absorber plate is negligible

- Convective transfer coefficients between absorber plate and air and between air and cover plate (glass) are the same

The schematic sketch (not to scale) of the solar collector system showing the incident radiation, air flow between glass and absorber plates and the heat transfer coefficients is shown in Figure 4.2 (Top), and the whole system including air boxes at the inlet and outlet end beyond the collector in Figure 4.2 (Bottom). The inlet box is to ensure an even distribution of air over the width of the collector, the outlet box collects the air for further use.

The inputs are ambient air temperature $T_{a}\left({ }^{\circ} \mathrm{C}\right)$, incident radiation $I\left(\mathrm{~W} / \mathrm{m}^{2}\right)$ while the states are glass temperature $T_{g}\left({ }^{\circ} \mathrm{C}\right)$, air temperature $T_{f}\left({ }^{\circ} \mathrm{C}\right)$ and plate temperature $T_{p}\left({ }^{\circ} \mathrm{C}\right)$ respectively.

Accumulation of heat in the absorber plate is a function of radiation received by absorber plate minus radiation heat lost to the atmosphere through the glass, minus heat transferred to the fluid, minus heat transferred to the back and edge wall as represented in

$$
\begin{gathered}
\frac{d T_{p}(x, t)}{d t}=\left[I(\mathrm{t}) \alpha_{\mathrm{p}} \tau_{g}-h_{r p g}\left(T_{p}(x, t)-T_{g}(x, t)\right)-h_{c p f}\left(T_{p}(x, t)-T_{f}(x, t)\right)\right. \\
\left.-U_{k}\left(T_{p}(x, t)-T_{a}\right)-U_{b s} \frac{2 Y_{p}}{W}\left(T_{p}(x, t)-T_{a}\right)\right] \frac{1}{Y_{p} \rho_{p} C p_{p}}
\end{gathered}
$$

The one but last term between the square brackets at the right hand side stems from the loss through the back of the plate, and the last term from the heat loss at the edges of the plate $\left(\frac{2 Y_{p}}{W}=\frac{\left.2 Y_{p} \Delta x \text { (two sided area of plate }\right)}{W \Delta x \text { (collector area })}\right)$. As only the back plate is insulated, the heat loss coefficient through insulation materials wool (ins) and wood (constr) is:

$$
U_{k}=\left[\frac{Y_{\text {ins }}}{\lambda_{\text {ins }}}+\frac{Y_{\text {Constr }}}{\lambda_{\text {constr }}}\right]^{-1}
$$



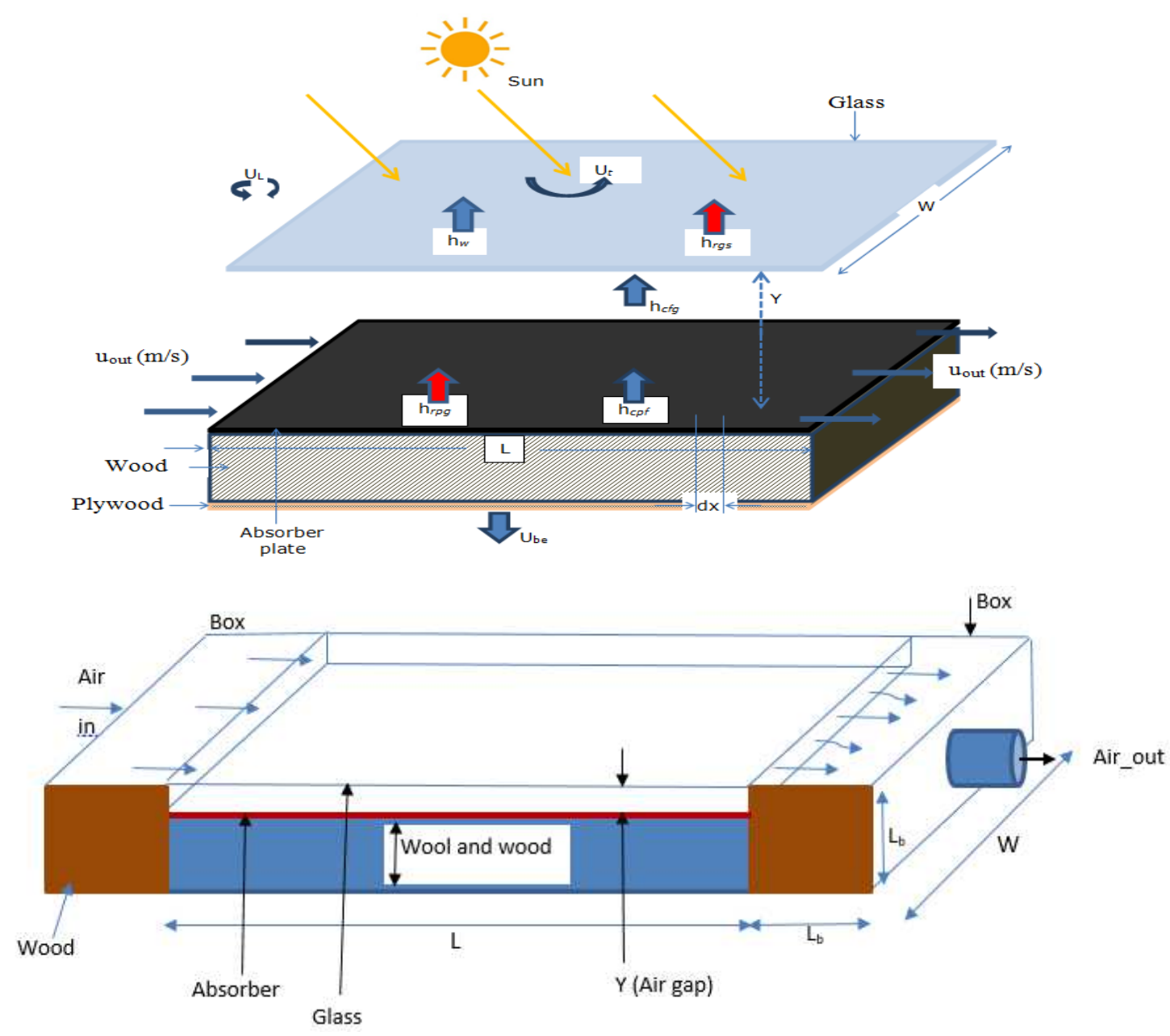

Figure 4.2 Solar collector system showing air flow, insulation and loss coefficients (Top) and air box at the inlet and outlet end beyond the collector (Bottom).

whereas for the edge of the plate we have

$$
U_{b s}=\frac{\lambda_{\text {constr }}}{Y_{\text {constr }}}
$$

For the applied symbols, see the list of symbols. Heat accumulated in the fluid is a function of heat gained in the direction of collector length plus heat gained from plate, minus heat lost to the glass and wall:

$$
\begin{gathered}
\frac{d T_{f}(x, t)}{d t}=-u \frac{\partial T_{f}(x, t)}{\partial x}+\frac{h_{c p f}\left(T_{p}(x, t)-T_{f}(x, t)\right)}{\rho_{f} C p_{f} Y}-\frac{h_{c f g}\left(T_{f}(x, t)-T_{g}(x, t)\right)}{\rho_{f} C p_{f} Y} \\
-\frac{U_{b s}(2 Y)}{W} \frac{\left(T_{f}(x, t)-T_{a}(x, t)\right)}{\rho_{f} C_{p f} Y}
\end{gathered}
$$

The heated air is collected in an end box with dimensions $L_{b} \times L_{b} \times W$. Assuming complete mixing, the outlet temperature $T_{b}$ from the box can be described by the following heat balance 
$\rho_{f} C_{p f} V_{b} \frac{d T_{b}(t)}{d t}=u W Y \rho_{f} C_{p f} T_{f}(L, t)-u \rho_{f} C_{p f} W Y T_{b}(t)-U_{w a l l} A_{b}\left(T_{b}(t)-T_{a}(t)\right)$

where $u W Y$ is the volumetric air flow rate entering and leaving the box, and the overall heat transfer coefficient $U_{\text {wall }}$ is the same as $U_{b s}$ when wood with the same thickness is used. The contact area of the box with the surrounding air is $A_{b}=2 L_{b}{ }^{2}+3 L_{b} W$, whereas the volume is $V_{b}=L_{b}^{2} W$

In principle, Equation 4.5 can be used as such, but a simplification is possible if the time constant is much smaller than the scale of variation of the outside conditions. Equation 4.5 is a first order equation with time constant

$$
\tau=\frac{L_{b}{ }^{2}}{u Y+\left(\frac{U_{w a l l} A_{b}}{\rho_{f} C_{p f} W}\right)}
$$

With the dimensions of the box and the characteristic air speed of $0.5 \mathrm{~m} / \mathrm{s}$ the time constant is less than 2 seconds, so the box can be assumed to be in quasi-steady state, which leads to

$$
T_{b}=\frac{u}{u+p} T_{f}(L, t)+\frac{p}{u+p} T_{a}(t)
$$

with $p=\frac{U_{w a l l} A_{b}}{\rho_{f} C_{p f} W Y}$.

The temperature of the glass plate is given by the solar heat absorbed by glass, and by radiation received from the plate and lost to the sky, as well as by conductive exchange with the air in the duct as well as with the atmosphere, as described by Equation 4.8.

$$
\begin{aligned}
\frac{d T_{g}(x, t)}{d t}= & \frac{h_{c f g}\left(T_{f}(x, t)-T_{g}(x, t)\right)}{\rho_{g} C p_{g} Y_{g}}+\frac{h_{r p g}\left(T_{p}(x, t)-T_{g}(x, t)\right)}{\rho_{g} C p_{g} Y_{g}}-\frac{h_{r g s}\left(T_{g}(x, t)-T_{s}\right)}{\rho_{g} C p_{g} Y_{g}} \\
& -\frac{h_{w}\left(T_{g}(x, t)-T_{a}\right)}{\rho_{g} C p_{g} Y_{g}}+\frac{\alpha_{g} I(t)}{\rho_{g} C p_{g} Y_{g}}
\end{aligned}
$$

The initial conditions at time $t_{o}=0$ are $T_{p}\left(x, t_{o}\right)=T_{f}\left(x, t_{o}\right)=T_{g}\left(x, t_{o}\right)=T_{a}\left(t_{o}\right)$. The boundary condition is $T_{f}(0, t)=T_{a, \text { in }}(t)$.

The various differential equations were discretized along the collector length $L$ using finite difference and subsequently solved in Matlab using the Euler backward method. All section lengths are equal and denoted by $d x$. The total number of sections equals $L / d x$, a typical choice is 45 .

Equations 4.1, 4.4, 4.5 and 4.8 were formulated on the assumption that solar radiation transmitted through the glass cover is absorbed by the absorber plate and heats up the plate to temperature $T_{p}$. Heat is lost to ambient at $T_{a}$ through back, $U_{k}$, box and side edge wall loss coefficients $U_{b s}$. Energy is gained from the plate by the fluid to temperature $T_{f}$ through convective heat transfer coefficient $h_{c p f}$. Energy is lost from the plate to the glass at $T_{g}$ through 
irradiation with transfer coefficient $h_{r p g}$ while energy is lost from the air to the glass through convective heat transfer with coefficient $h_{c f g}$. The glass thus loses energy to the ambient at $T_{a}$ through heat transfer coefficient $h_{w}$ which is a function of the wind speed and to the sky at $T_{s}$ through irradiation by the heat transfer coefficient $h_{r g s}$. Other researchers have used these heat transfer coefficients as estimated parameters (Kicsiny, 2016). In Equation 4.8, $\alpha_{\mathrm{g}}$ represent the proportion of incident radiation absorbed by glass (0.05). The sky temperature $T_{s}$ is computed from the ambient air temperature $T_{a}$ by the relation (Eq. 9) mentioned by Gao et al. (2007), Swinbank (1963) and cited by Hamed et al. (2014) and Wolf et al. (1981).

$$
T_{s}=0.0552\left(T_{a}+273\right)^{1.5}-273
$$

The convective heat transfer coefficient within plates are equal as shown in Equation 4.10.

$$
h_{c p f}(x, t)=h_{c f g}(x, t)=\frac{N u \lambda_{f}}{Y}
$$

The calculation of irradiation heat transfer coefficient between plate and cover glass is based on the common local linearization of the radiative flux, and is given by

$$
h_{r p g}(x, t)=\sigma\left[\frac{\left(T_{p}^{2}(x, t)+T_{g}^{2}(x, t)\right)\left(T_{p}(x, t)+T_{g}(x, t)\right)}{\frac{1}{\varepsilon_{p}}+\frac{1}{\varepsilon_{g}}-1}\right]
$$

Where $\sigma\left(\mathrm{Wm}^{-2} \mathrm{~K}^{-4}\right)$ the Stephan Boltzmann constant, $\varepsilon_{g}(-)$ the glass emissivity, and $\varepsilon_{p}(-)$ the emissivity of the absorber plate. Similarly, the radiative heat transfer coefficient between the glass and the sky (atmosphere) is

$$
h_{r g s}(x, t)=\sigma \varepsilon_{g}\left(T_{g}^{2}(x, t)+T_{s}^{2}\right)\left(T_{g}(x, t)+T_{s}\right)
$$

where $T_{p}, T_{g}$ and $T_{s}$ in Equations. 4.11 and 4.12 are temperatures expressed in Kelvin. The convective heat transfer coefficient between glass cover and atmosphere is given by McAdams (1954).

$$
h_{w}=5.7+3.8 w
$$

where $w$ is the wind speed $(\mathrm{m} / \mathrm{s})$. Although time variable wind speeds are allowable without any fundamental difficulty, for convenience a constant value of $4 \mathrm{~m} / \mathrm{s}$ is used. Equations 4.9 4.12 have also been used in the analytical solution of Gao et al. (2007).

Flow regimes in channels are developed in the initial part of a channel. As a consequence for turbulent flow in relative short channels with aspect ratio (i.e. the ratio of the collector length to hydraulic length $\left(L / D_{H}\right)$ ) of 10 the actual $N u$ number is $16 \%$ higher, while for aspect ratios 30 , the $\mathrm{Nu}$ number is $5 \%$ higher. At $L / D_{H}$ is 100 , the effect of entrance region on $N u$ is insignificant for turbulent flow. However, for laminar flow the heat transfer coefficient is significantly affected due to development of thermal and hydrodynamic boundary layer. Duffie and Beckman (1980) gave for laminar flow the following relationship between the Rayleigh 
number and Nusselt number, as suggested by Hollands et al. (1976) for solar collectors with tilt angles $\beta$ between 0 and $75^{\circ}$.

$$
N u(x, t)=\frac{1+1.4\left[1-\left(\frac{1708 \sin (1.8 \beta)^{1.6}}{R a(x, t) \cos (\beta)}\right)\right]\left[1-\left(\frac{1708}{R a(x, t) \cos (\beta)}\right)\right]^{+}+}{\left[\left(\frac{R a(x, t) \cos (\beta)}{5830}\right)^{1 / 3}-1\right]^{+}}
$$

In here $\beta$ is the collector tilt angle $\left(^{\circ}\right)$ and $R a$ the Rayleigh number (-). The plus superscript in this equation means that the term has to be set to zero when the results evaluates to a nonpositive number. The Rayleigh number and thermal diffusivity calculations are shown in Equations 4.15 and 4.16.

$$
\begin{gathered}
R a(x, t)=g \xi \frac{\Delta T_{p g}(x, t) Y^{3}}{v \alpha^{*}} \\
\alpha^{*}=\frac{v}{P r}
\end{gathered}
$$

Where $g$ is the acceleration due to gravity, $\xi$, volumetric coefficient of expansion which is the inverse of the mean air temperature $(1 / K)$ between plate and glass, $\Delta T_{p g}$ temperature $(K)$ difference between the plate and glass, $\alpha^{*}$ thermal diffusivity $\left(\mathrm{m}^{2} / \mathrm{s}\right), v$ kinematic viscosity $\left(\mathrm{m}^{2} / \mathrm{s}\right)$ and $\operatorname{Pr}$ the Prandtl number (-) which is taken constant (0.7). Note that since the temperature is a function of position and time, also $R a$ and $N u$ are functions of space and time, as well as all heat transfer coefficients in the model while Gao et al. (2007) has reported constant values in his analytical approach.

The important parameters that are key in determining the performance of a collector system are the heat loss coefficient, heat gain and the thermal efficiency. The instantaneous efficiency (i.e. the efficiency at any moment) is given by

$$
\eta(t)=\frac{Q_{u}(t)}{A_{p} I(t)}
$$

The heat gain $Q_{u}(t)$ for the heated air along the collector, is given by:

$$
Q_{u}(t)=\Phi(t) \rho_{f} C_{p f}\left[T_{f}(L, t)-T_{f}(0, t)\right]
$$

Where $T_{f}(L, t)$ is the outlet air temperature, and $T_{f}(0, t)$ the inlet air temperature, which, in this case, is equal to the ambient temperature $T_{\text {in }}(t), \Phi(t)$ is the volumetric air flow rate $\left(\mathrm{m}^{3} / \mathrm{s}\right)$.

The heat gain is also equal to the difference between heat absorbed, and heat lost to the environment:

$$
Q_{u}(t)=A_{p}\left[\alpha_{p} \tau_{g} I(t)-U_{L}(t)\left(T_{p m}(t)-T_{a}(t)\right)\right]
$$


Where $\alpha_{p} \tau_{g}$ is the combination of the solar absorption-coefficient of the plate and transmittance of the glass, $I(t)$ the solar radiation intensity as measured on a horizontal plane, and $T_{p m}(t)$ the mean plate temperature over the length of the collector, i.e.

$$
T_{p m}(t)=\frac{1}{L} \int_{0}^{L} T(x, t) d x
$$

The term $U_{L}(t)$ is the instantaneous overall heat loss coefficient, and is an important characteristic of the solar air heater. In fact, under the assumption that the rate of heat storage in the material of the collector is small as compared to the other terms, the two heat gains (Equations 4.18 and 4.19) should be equal, which provides an operational definition of the actual overall heat loss coefficient as Equation 4.21.

$$
U_{L}(t)=\frac{A_{c} \alpha_{p} \tau_{g} I(t)-\Phi(t) \rho_{f} C_{p f}\left[T_{f}(L, t)-T_{f}(0, t)\right]}{A_{p}\left(T_{p m}(t)-T_{a}(t)\right)}
$$

The overall heat loss coefficient could be a useful characteristic to compare various designs, on the basis of measurements after the units have been built. Prior to construction, when no data is available on the temperatures, the overall heat loss coefficient has little value as a design parameter.

\subsection{Results and discussion}

\subsubsection{Model-based solar collector design and analysis}

Design and analysis calculations have been performed with the default nominal parameters as given in Table 4.1 (The Engineering Toolbox), and using representative inputs and operational conditions. To solve the partial differential equations, the solar collector was discretized in 45 sections of equal length and for each section Equations 4.1, 4.4, 4.5 and 4.8 were solved in time. The calculations were performed with the differential equation solver "ode45" of Matlab.

Table 4.1. Parameter values

\begin{tabular}{lll}
\hline Symbol & Name & Value \\
\hline$C p_{f}$ & Heat capacity of air $\left(\mathrm{J} \mathrm{kg}^{-1} \mathrm{~K}^{-1}\right)$ & 1009 \\
$C p_{p}$ & Heat capacity of plate $\left(\mathrm{J} \mathrm{kg}^{-1} \mathrm{~K}^{-1}\right)$ & 910 \\
$C p_{g}$ & Heat capacity of glass $\left(\mathrm{J} \mathrm{kg}^{-1} \mathrm{~K}^{-1}\right)$ & 840 \\
$g$ & Acceleration due to gravity $\left(\mathrm{m} \mathrm{s}^{-2}\right)$ & 9.81 \\
$L b$ & Edge of box $(\mathrm{m})$ & 0.15 \\
$P r$ & Prandtl number & 0.7 \\
$u$ & Air speed $\left(\mathrm{m} \mathrm{s}^{-1}\right)$ & 0.5 \\
$W$ & Width of plate $(\mathrm{m})$ & 1.00 \\
$w$ & Wind speed, nominal value $\left(\mathrm{m} \mathrm{s}^{-1}\right)$ & 4 \\
$Y_{p}$ & Thickness of plate $(\mathrm{m})$ & 0.002 \\
$Y_{g}$ & Thickness of glass $(\mathrm{m})$ & 0.005 \\
$Y_{\text {wool }}$ & Thickness of wool $(\mathrm{m})$ & 0.07
\end{tabular}




\begin{tabular}{|c|c|c|}
\hline$Y_{\text {wood }}$ & Thickness of wood (m) & 0.03 \\
\hline$\alpha_{g}$ & Glass absorption coefficient & 0.05 \\
\hline$\alpha_{p}$ & Plate absorption coefficient & $\begin{array}{l}0.95 \text { ( } 0.88 \text { after } \\
\text { adjustment, see } \\
\text { text) }\end{array}$ \\
\hline$\beta$ & $\begin{array}{l}\text { Collector tilt angle (degrees), nominal value } \\
\text { (degree) }\end{array}$ & 25 \\
\hline$\varepsilon_{g}$ & Emittance of glass & 0.84 \\
\hline$\varepsilon_{p}$ & Emittance of plate & 0.90 \\
\hline$\lambda_{a}$ & Thermal conductivity of air $\left(\mathrm{W} \mathrm{m} \mathrm{m}^{-1} \mathrm{~K}^{-1}\right)$ & 0.029 \\
\hline$\lambda_{\text {ins }}=\lambda_{\text {wool }}$ & Thermal conductivity of wool $\left(\mathrm{W} \mathrm{m}^{-1} \mathrm{~K}^{-1}\right)$ & 0.029 \\
\hline$\lambda_{\text {constr }}=\lambda_{\text {wood }}$ & Thermal conductivity of wood $\left(\mathrm{W} \mathrm{m}{ }^{-1} \mathrm{~K}^{-1}\right)$ & 0.15 \\
\hline$\lambda_{p}$ & Thermal conductivity of aluminum plate $\left(\mathrm{W} \mathrm{m}^{-1} \mathrm{~K}^{-1}\right)$ & 205 \\
\hline$\lambda_{g}$ & Thermal conductivity of glass $\left(\mathrm{W} \mathrm{m}^{-1} \mathrm{~K}^{-1}\right)$ & 0.13 \\
\hline$\rho_{a}$ & Density of air $\left(\mathrm{kg} \mathrm{m}^{-3}\right)$ & 1.14 \\
\hline$\rho_{p}$ & Density of aluminum plate $\left(\mathrm{kg} \mathrm{m}^{-3}\right)$ & 2700 \\
\hline$\rho_{s}$ & Density of silica gel $\left(\mathrm{kg} \mathrm{m}^{-3}\right)$ & 600 \\
\hline$\rho_{g}$ & Density of glass $\left(\mathrm{kg} \mathrm{m}^{-3}\right)$ & 2600 \\
\hline$\sigma$ & Stefan Boltzmann constant $\left(\mathrm{W} \mathrm{m}^{-2} \mathrm{~K}^{-4}\right)$ & $5.7 \times 10^{-8}$ \\
\hline$\tau_{g}$ & Glass transmittance & 0.88 \\
\hline$v$ & Kinematic viscosity $\left(\mathrm{m}^{2} \mathrm{~s}^{-1}\right)$ & $2.029 \times 10^{-5}$ \\
\hline
\end{tabular}

The varying input conditions to the model are the ambient temperature $T_{a, i n}(t)$ and the radiation $I(t)$. Figure 4.3 gives an example of the variation of these inputs over the simulation time. This figure starts with the use of the system at $8.00 \mathrm{~h}$ in the morning. The simulation is stopped at around $17.00 \mathrm{~h}$. The linear air flow velocity was $0.5 \mathrm{~m} / \mathrm{s}$ and after evaluation of different air gaps, the value was set to $0.025 \mathrm{~m}$. The collector width was set to $1.0 \mathrm{~m}$. 


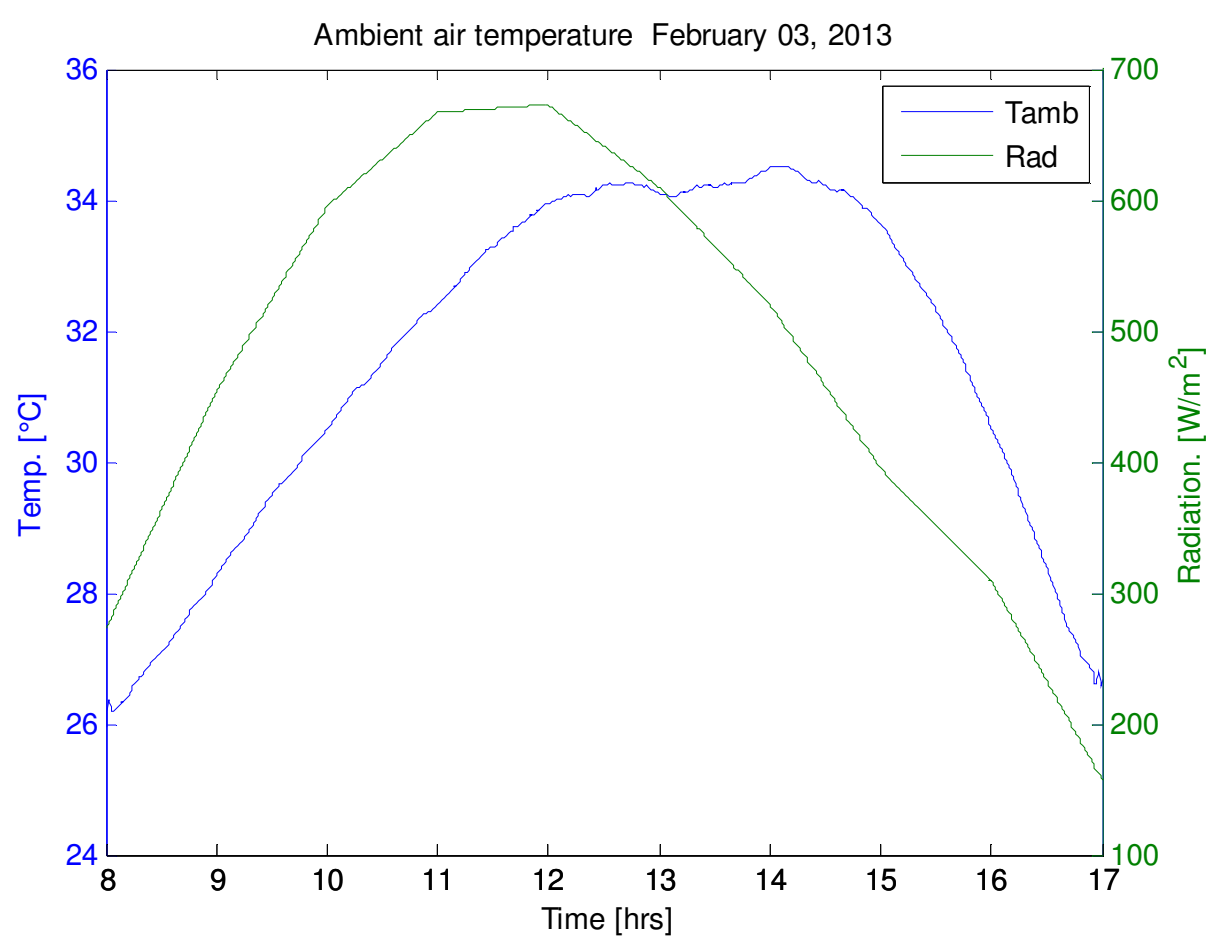

Figure 4.3. Model input ambient air temperature (Tamb) and solar radiation (Rad) for February 3, 2013).

\subsubsection{Effect of absorber surface on performance}

The surface properties of an absorber plate have some influence on the absorbed radiation as well as the energy loss (Gao et al., 2007). A selective surface can improve the efficiency of a solar thermal collector system, in that it rather emits less infra-red radiation than absorbed solar radiation. However, a non-selective surface absorbs more radiation and emits almost the same percentage of infra-red radiation. In this work a non-selective black coated absorber surface was used. The nominal values for the fraction of absorbed solar radiation $\left(\alpha_{p}\right)$ and the thermal radiation emitted $\left(\varepsilon_{p}\right)$ from the absorber plate used were set to 0.95 and 0.90 , respectively. The solar absorption coefficient is not exactly known, but as it is an important parameter, it is later adjusted on the basis of the experimental data (see section experimental verification and validation).

\subsubsection{Effect of collector length on temperature}

Figure 4.4A-C shows the 3-D plots of modeled temperature as a function of time and space with ambient air and radiation of a representative day as input (data of $3^{\text {rd }}$ February, 2013). The variation of air temperature along the collector length was higher than that of glass and absorber plate. The main gain in air temperature is achieved in the initial part of the collector (between 0 and $1.5 \mathrm{~m}$ ) and in a long solar collector (over 4.5 meter) the gain in temperature becomes marginal towards the end. It implies that increasing collector length beyond a certain value does not lead to a sufficient increase in air temperature. This information helps to determine the suitability of a particular collector length to yield a predetermined collector output air 
temperature. A temperature level between $40-50^{\circ} \mathrm{C}$ during a main part of the day was considered as sufficient for solar aided drying, and for this purpose a collector length of $1.5 \mathrm{~m}$ was appropriate.

Figure 4.4. Temperature profile of glass (A) air (B) and plate (C) at varying collector length
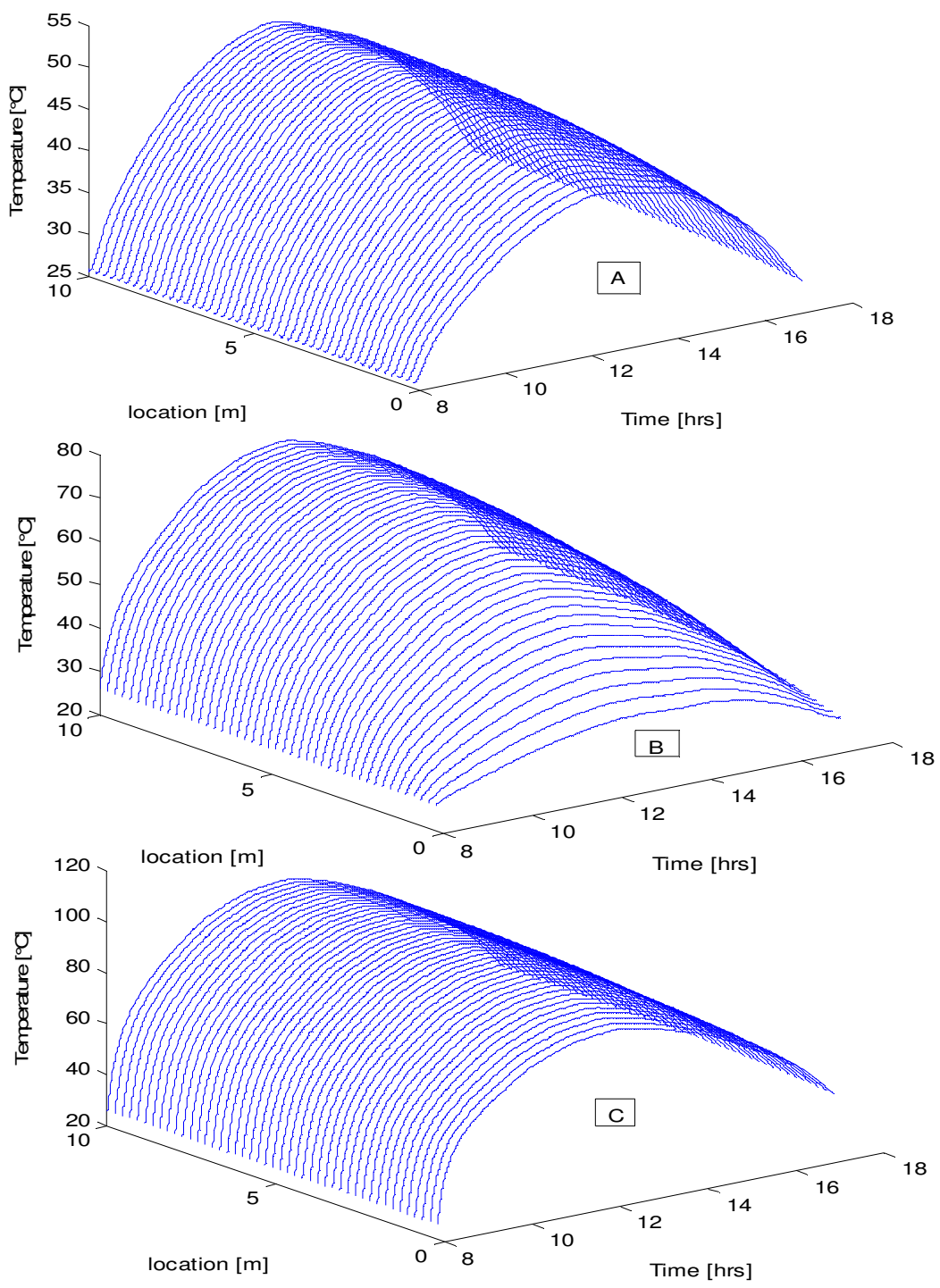

for February 3, 2013.

The water holding (adsorption) capacity of silica gel at ambient conditions $\left(25-30^{\circ} \mathrm{C}, 60-80 \%\right.$ relative humidity) is about $20 \%$ water/kg dry silica gel, while at temperatures above $50^{\circ} \mathrm{C}$ the holding capacity is below 5\% water/kg dry silica gel (Boxtel et al., 2012). These properties allow a cycle of adsorption and desorption of water to silica gel. For the cycle it is required that the solar collector is long enough to reach temperatures above $50^{\circ} \mathrm{C}$ during several hours a day. This is achieved during the main part of the day by a collector length of $4.5 \mathrm{~m}$. 


\subsubsection{Construction of Collector Equipment}

The model output indicated that collectors of lengths $1.5 \mathrm{~m}$ and $4.5 \mathrm{~m}$ were suitable for drying and regeneration respectively. The efficiency of solar collectors is influenced by the tilt angle. From the data of Perez et al. $(1987,1988)$ it was concluded that a $25^{\circ}$ tilt angle is most effective for the latitude of Ghana. Based on this information two collectors (for drying and regeneration) tilted at $25^{\circ}$ were constructed in Ghana as shown in Figure 4.5.

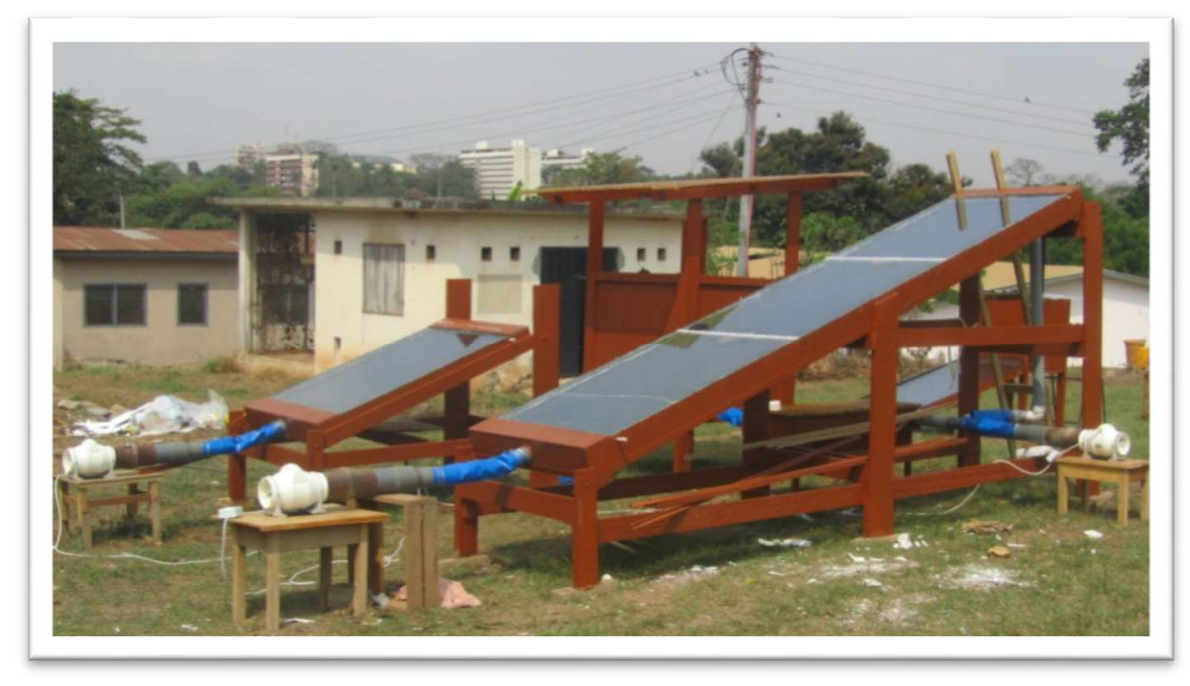

Figure 4.5. Collector systems: Photo of construction showing the position of the fans pointed due south.

\subsubsection{Effect of design decisions}

Figure 4.6 represent the simulated spatially distributed Nusselt number $(\mathrm{Nu})$, Rayleigh number $(R a)$, convective heat transfer coefficient between plates $\left(h_{c p f}\right)$, radiative heat transfer coefficient between plates $\left(h_{r p g}\right)$ and sky $\left(h_{r g s}\right)$ as a function of time for the collector length of $1.5 \mathrm{~m}$. In this figure, all the coefficients have minor variations in length and strong variations over the operational time. Hence for the design of solar collectors the temporal variations of these coefficients, due to the changing radiation input and environmental air temperatures, are more important than the spatial variations. This also implies that models that use time-invariant numbers are a gross simplification.

The radiation heat transfer coefficient values between the plates were higher than the convective heat transfer coefficient values due to the non-selective coating surface properties of the absorber. The non-selective absorber surface exhibited more thermal radiation emission than convective loss, thus making the radiative loss component dominant (Mintsa Do Ango et al., 2013) and Gao et al., 2007). Bhagoria et al. (2002) and Gao et al. (2007) propose the use of rough surfaces to improve the convective heat transfer coefficient. In the natural convection and analytical approach of Gao et al. (2007) where a flat absorbing and flat bottom plates were used as the air flow channels, constant values of $h_{r g s}, h_{r p g}$, and $h_{c p f}$ reported were respectively $12.4,5.9$ and $8.8 \mathrm{~W} / \mathrm{m}^{2} \mathrm{~K}$. These values were obtained for one set of conditions 
during a day. From the simulations in this work, the outlet $h_{r g s}, h_{r p g}$, and $h_{c p f}$ as function of day time are reported to be in the range of $4.75-5.60,1.16-3.89$ and $4.65-7.19 \mathrm{~W} / \mathrm{m}^{2} \mathrm{~K}$, respectively. So, application of values obtained by parameter estimation at one time of the day may lead to errors when applied to the daily cycle.
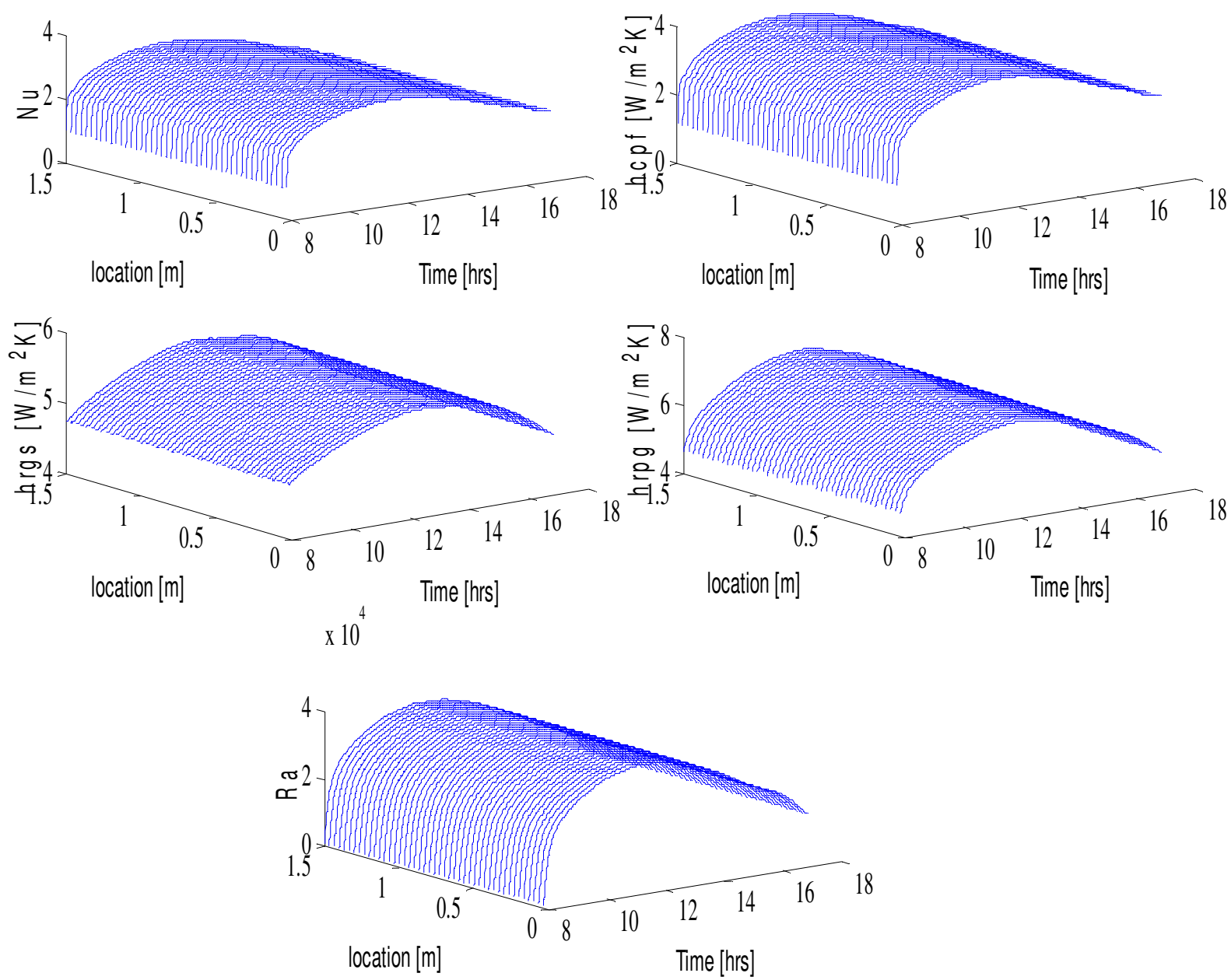

Figure 4.6. Nusselt number, Rayleigh number and heat transfer coefficients against space and time for $1.5 \mathrm{~m}$ collector length.

\subsubsection{Collector performance}

Figure 4.7 shows the thermal efficiency (top left); heat gain (top right); mean plate temperature (bottom left); and overall heat loss coefficient (bottom right), respectively. Just as the transfer coefficients these values vary over the day. Moreover, the performance is a function of the collector length. While increasing the length of the collector the incoming amount of energy increases proportionally. During the passage of the air through the collector, however, the air temperature comes closer to the plate temperature so that the driving force for heat transfer between plate and air decreases. 
As a consequence, the heat gain does not increase proportionally along the length of the collector. Therefore the efficiency decreases and the heat loss coefficient increases with the collector length. Although these findings are easy to understand from a physical point of view, several authors report heat loss coefficients or efficiencies from experimental work. From this work it can be stated that observed loss coefficients and efficiencies, though perhaps useful for comparing alternative designs, are not meaningful for collector design since they depend on the design choices. For example, the range of the overall heat loss coefficient $\left(U_{L}\right)$ at increasing collector length is between $4.3-7.7 \mathrm{~W} / \mathrm{m}^{2} \mathrm{~K}$ compared to $15-24 \mathrm{~W} / \mathrm{m}^{2} \mathrm{~K}$ by Koyuncu (2006) and $5.5 \mathrm{~W} / \mathrm{m}^{2} \mathrm{~K}$ by Santos et al. (2005). The very different values underline the unsuitability of the heat loss coefficient $\left(U_{L}\right)$ as design parameter.

It may be noted that the heat gain between the collector lengths of 1.5 and $4.5 \mathrm{~m}$, is more than between 4.5 and $10 \mathrm{~m}$ as has earlier been mentioned. Mintsa Do Ango et al. (2013) mentioned that collector length has no effect on collector performance, which is at variant with the present work.
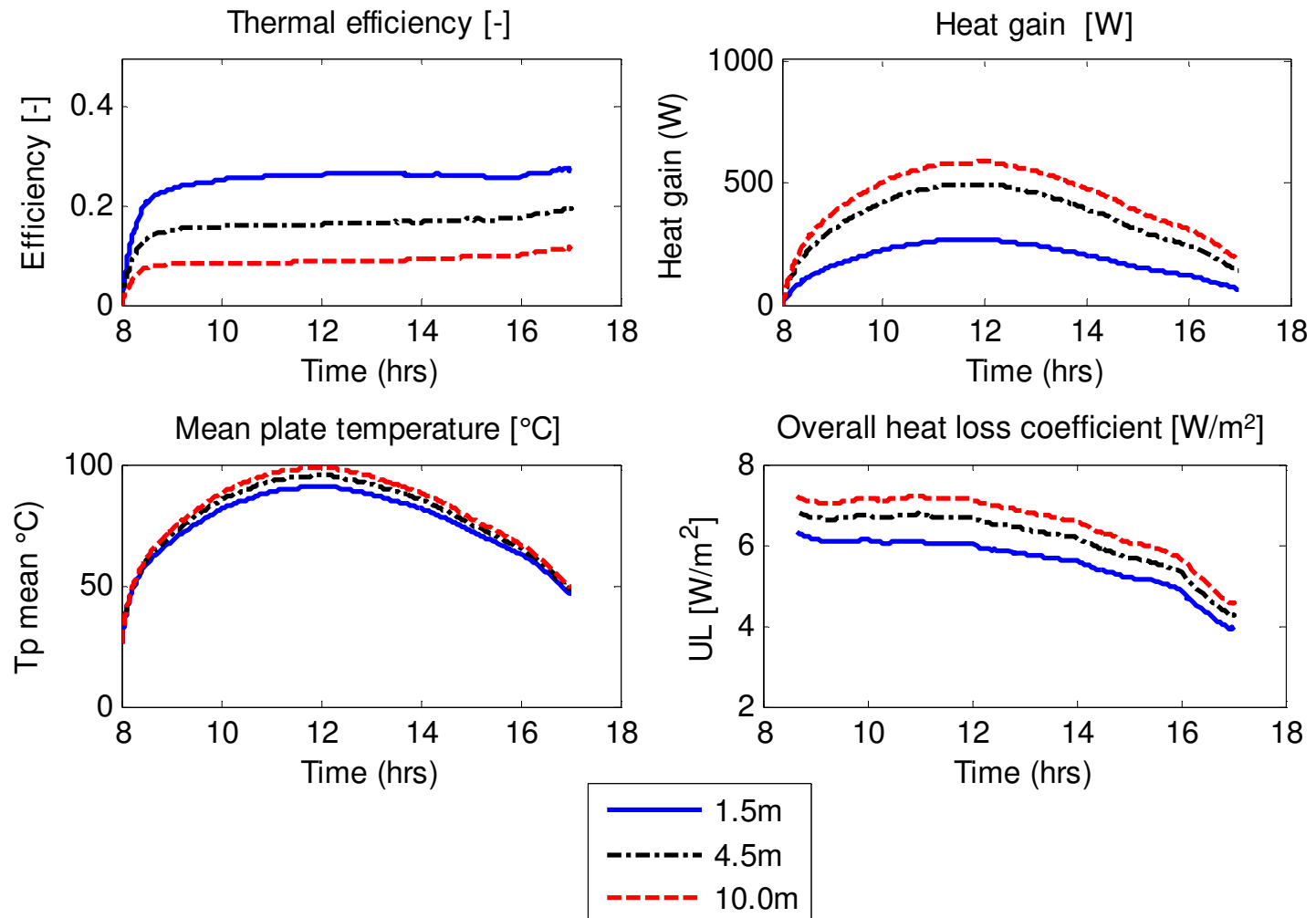

Figure 4.7. Collector performance: Efficiency (Top left); Heat gain (Top Right); Mean plate temperature (Tpmean, Bottom left); heat loss coefficient ( $\mathrm{U}_{\mathrm{L}}$, Bottom right) for 1.5, 4.5 and $10 \mathrm{~m}$ collector length.

\subsubsection{Effect of air speed on collector performance}

One of the operational parameters that affect the performance of a solar system is the flow of air. The impact of the air velocity on the mean plate, air and glass outlet temperatures for the day is investigated (see Figure 4.8). Figure 4.8 (Top) illustrates that mean plate and glass temperatures are moderately affected by the air velocity while the air temperature is strongly 
affected. The decrease of air temperature with increasing air velocity is result of heating a higher amount of air by the same amount of solar energy.
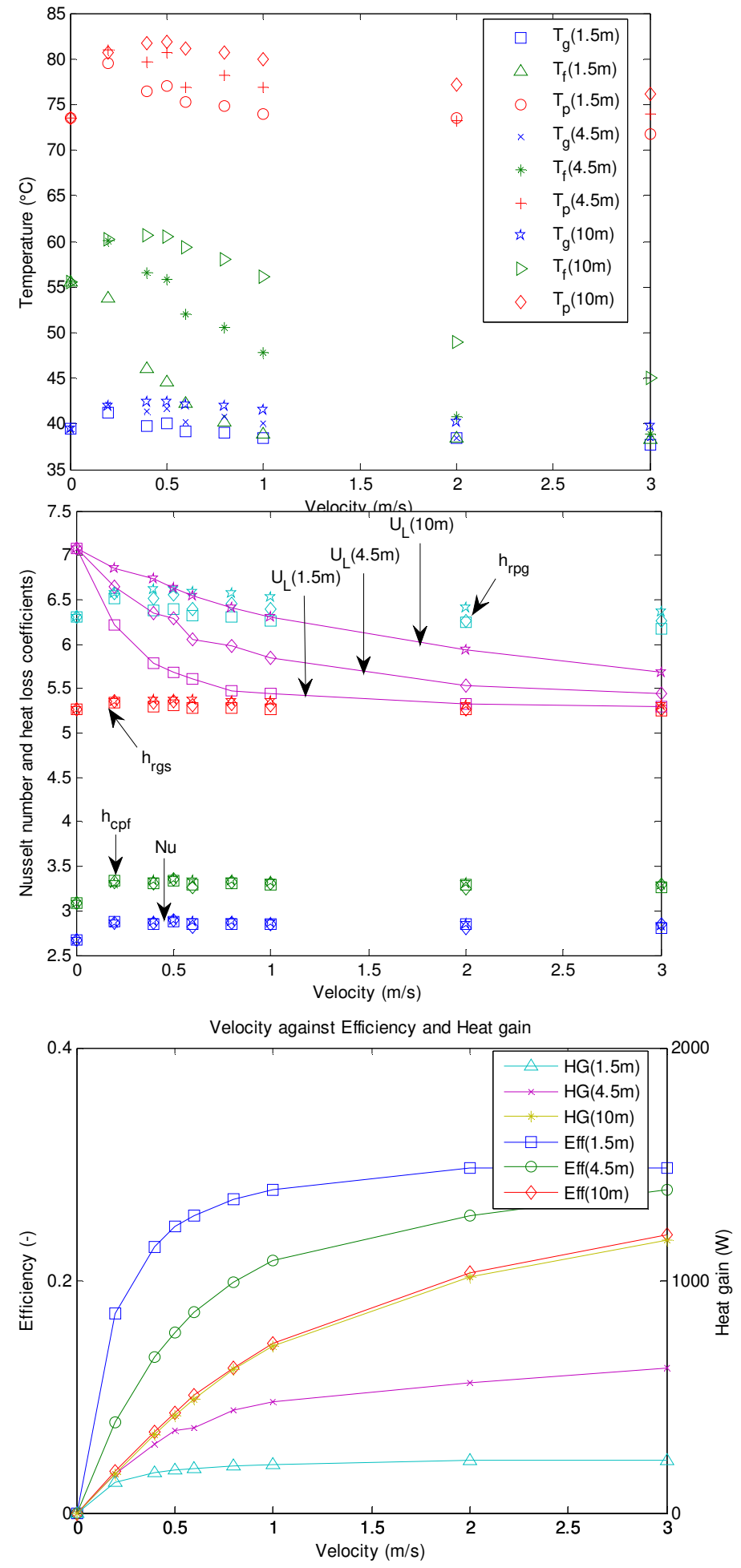

Figure 4.8 Mean outlet absorber, air and glass temperatures (Top); Mean Nusselt number, overall loss coefficient and heat transfer coefficients (Middle) and Mean heat gain and thermal efficiency (Bottom) as function of air velocity for 1.54 .5 and 10 m collector lengths. 
Lower air temperatures enhance the heat transfer from plate to the air and hence the thermal efficiency and heat gain improve and the overall loss coefficient decreases. Variable point of equilibration of efficiency/heat gain have been reported in literature due to differences in design dimensions. In the present work beyond $1 \mathrm{~m} / \mathrm{s}$ velocity equilibration starts for all parameters studied while Lin et al. (2005) reported a value of $0.6 \mathrm{~m} / \mathrm{s}$.

In addition the turbulence of air can further be improved by using a rough or corrugated surface (Gao et al., 2007) to increase the convective heat transfer coefficient between plates and if possible a high selective black coating to improve the air temperature as well as the thermal efficiency and heat gain. In the solar adsorption dryer system (SADS) that forms the motivation for this work, the dryer requires a temperature of about $40-50^{\circ} \mathrm{C}$ whereas a temperature well over $50^{\circ} \mathrm{C}$ is required for the adsorbent regeneration system. These conditions are well reached for the design flow of $0.5 \mathrm{~m} / \mathrm{s}$ with collector lengths of 1.5 and $4.5 \mathrm{~m}$, respectively.

\subsection{Experimental verification and validation}

\subsubsection{Description of the experiments}

Experiments were conducted to verify the output responses of the two collectors. The ambient inlet and the outlet temperatures for both collectors were logged during three experimental days (3-5 $5^{\text {th }}$ February, 2013 from 8:00 to 17:00h)) at 5 seconds interval using Labview as interface. The data were smoothed using a moving average method to remove high frequency measurement noise. The ambient temperature and interpolated values of the hourly radiation data for the $3^{\text {rd }}$ of February were used to test the model, and to make adjustments of the plate solar absorption coefficient. The data of 4 and 5 February served as validation data.

\subsubsection{Model verification and parameter adjustment}

Application of the model on the data of February 3, 2013 with the nominal parameters resulted in somewhat higher temperatures than really observed. Obviously, there are uncertainties in a large number of parameters, and to some extent adjustment can be made on both the gain side (solar absorption) as well as the loss side (heat loss coefficients). The data have been collected primarily with the intention to test whether predicted collector lengths were suitable for the intended purposes (drying and adsorbent regeneration). The data are rich enough for this purpose, but not rich enough for the purpose of a formal full parameter estimation. As the heat transfer coefficients have a well-established basis, it was decided to just adapt the solar absorption coefficient by the plate, as this was essentially unknown. An adjustment from the nominal value of 0.95 to 0.88 was sufficient to obtain the fit shown in Figure 4.9. The figure also shows the effect of the final collector box. On retrospect, it appears that the lack of insulation of the end box of the collector causes a considerable temperature drop. It is also observed that in the afternoon the model has slightly higher temperatures than observed in the real system. From the data there is no obvious explanation. Note that small changes in sky temperature may already have an appreciable effect on the temperature, but as no further 
information is available, this cannot be substantiated further. Overall, in view of the fact that just one parameter was adjusted, the fit is quite satisfactory.
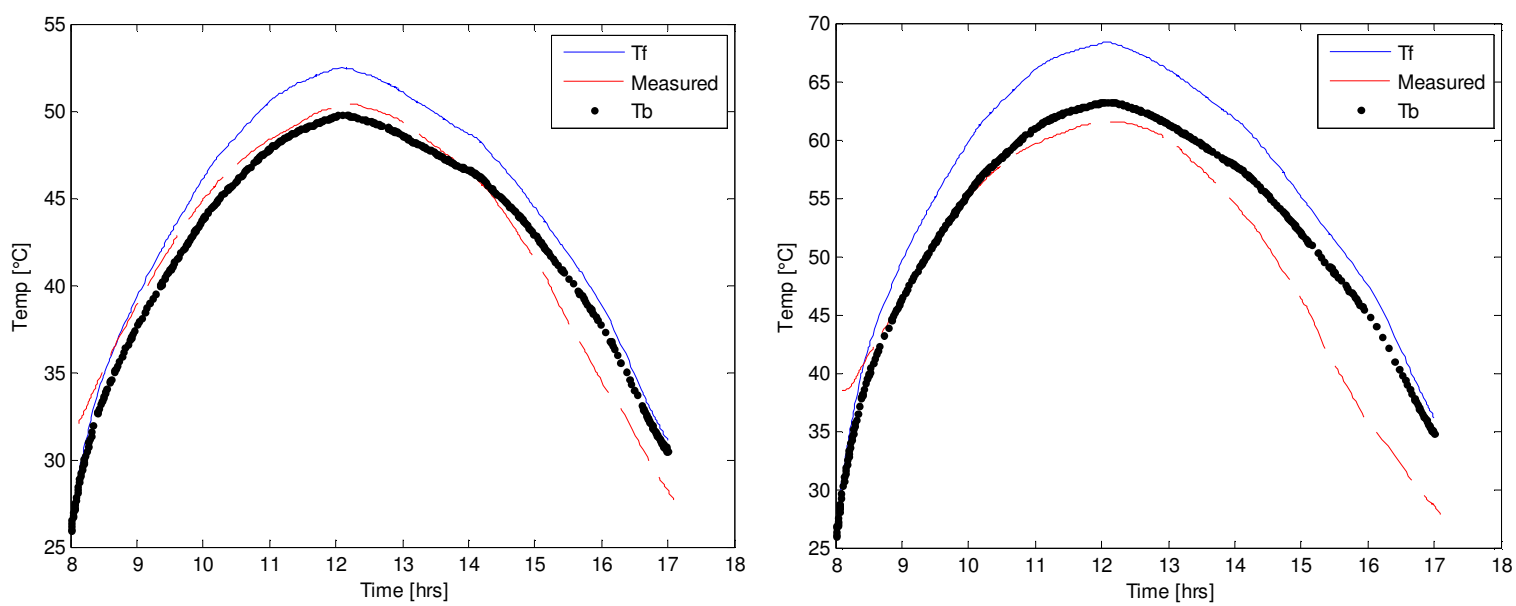

Figure 4.9 Outlet air temperatures for $1.5 \mathrm{~m}$ (Left) and $4.5 \mathrm{~m}$ (Right) lengths for temperatures just after collector (Tf), box (Tb) and experiment (measured) taken from $3^{\text {rd }}$ February, 2013.

\subsubsection{Validation}

Without further adjustment, the model was then applied to the data of February 4 and 5, 2013. The results are shown in Figure 4.10. Given the limitations, the model predicts well for both collector lengths. The main error for both collectors were obtained after 13 hours corresponding to a higher increase in the ambient temperature. It should be noted that these results were obtained by using physical parameters directly derived from the dimensions and other properties, without any further calibration except for the absorption coefficient. As impression of the quality of the fit the error index has been computed, i.e. the integral of the absolute difference between model and data relative to the integral of the measurements, expressed as percentage. The error for the $1.5 \mathrm{~m}$ collector was between $3-6 \%$, while that for the $4.5 \mathrm{~m}$ was between $8-10 \%$ for the dates $3^{\text {rd }}$ to $5^{\text {th }}$ February, 2016. 

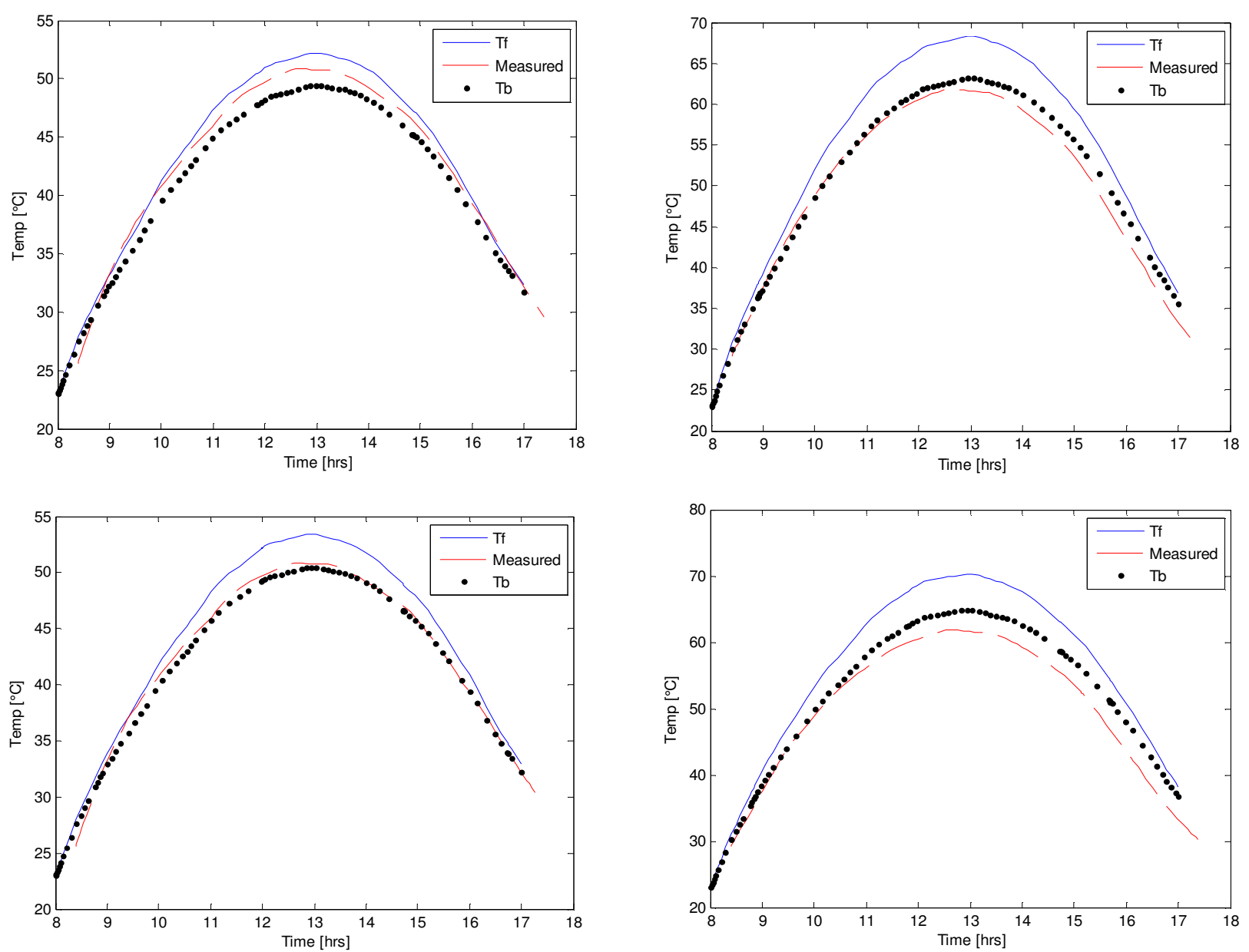

Figure 4.10 Validation of model with $\alpha_{p}=0.88$. Outlet air temperatures for $1.5 \mathrm{~m}(\mathrm{Left})$ and $4.5 \mathrm{~m}$ (Right) lengths for temperatures just after collector (Tf), box (Tb) and experiment (measured) taken from $4^{\text {th }}$ to $5^{\text {th }}$ February, 2013 (respectively top and bottom).

\subsection{Discussion}

A modeling and simulation study approach was used to construct solar collector systems suitable for drying and regeneration in a solar adsorption dryer system. The generic spatially discretized model proved to be a versatile tool to guide solar collector design and operation. The results for the temperature distribution in the given experimental set-ups suggest that a simplification of the model might be possible by spatial lumping of the glass cover and plate temperatures, but this does not hold for the air temperature along the length of the collector. On the other hand, similarly to the treatment of the box temperature, it might be acceptable to handle the spatial air temperature along the collector as being in pseudo-steady state. Such simplifications may be useful in applications where computational speed is relevant, such as formal parameter estimation or optimization studies. The experience with the current fully dynamic model however shows that for the current purpose such simplifications are unnecessary. Parameters obtained from physical knowledge already provide a good fit to experimental data. The current choice to only adapt the absorption parameter is not the only possibility, but if the goal would be to investigate details of the heat transfer, more data, in 
particular air temperatures along the collector, and distance measurements of the plate temperature, should be recommended to allow for a more formal parameter estimation.

\subsection{Conclusions}

Experiments conducted on collectors with air path lengths of 1.5 or $4.5 \mathrm{~m}$ indicated a good comparison between the model and observed data, just on the basis of physical parameters without further calibration, except for the solar absorption coefficient of the collector plate. The modeling exercise makes it clear that increasing the collector length beyond a certain limit makes it inefficient due to decreasing driving force for heat transfer between plate and air.

The findings of this work indicate that plate and glass temperatures as well as heat transfer coefficients are practically independent of the length and are weak functions of air velocity. In contrast, the overall heat loss coefficient, heat gain and efficiency are highly dependent on the operational air velocity. In addition, it was shown that heat transfer coefficients and the overall heat loss coefficient vary considerably during the day. Therefore designing a solar collector based on a general number of the heat loss coefficient is not feasible, and fixed heat loss coefficients as reported in literature have little to offer for the design of a new collector. Empirical approaches based on constant values are gross simplifications. The study shows that these limitations can be overcome by using a physical model. Finally, the primary goal, namely to know which collector lengths would be needed for drying and adsorbent regeneration, was reached. The model indicated that under conditions prevailing at the latitude of Ghana a collector length of $1.5 \mathrm{~m}$ gives drying temperatures suitable for drying of heat sensitive agricultural products at air speed of $0.5 \mathrm{~m} / \mathrm{s}$, and this was confirmed by the experiments. Likewise a collector of $4.5 \mathrm{~m}$ length at an operational air speed between $0.2-0.5 \mathrm{~ms}^{-1}$ is suitable for adsorbent (silica gel) regeneration. 


\section{NOMENCLATURE}

\section{Physical symbols}

$\begin{array}{ll}A_{c} & \text { Area of collector }\left(\mathrm{m}^{2}\right) \\ C p & \text { Specific heat capacity }\left(\mathrm{kg}^{-1} \mathrm{~K}^{-1}\right) \\ D_{H} & \text { Hydraulic diameter }(\mathrm{m}) \\ d x & \text { Discretized plate length }(\mathrm{m}) \\ g & \text { Acceleration due to gravity }\left(\mathrm{m}^{-2}\right) \\ h & \text { Heat transfer coefficient }\left(\mathrm{W} \mathrm{m}{ }^{-2} \mathrm{~K}^{-1}\right) \\ I & \text { Irradiance }\left(\mathrm{Wm}{ }^{-2}\right) \\ L & \text { Total plate length }(\mathrm{m}) \\ L_{b} & \text { Edge dimension of the receiving box }(\mathrm{m}) \\ N u & \text { Nusselt number } \\ p & \text { Combined parameter } \frac{\mathrm{U}_{\mathrm{wall}} \mathrm{A}_{\mathrm{b}}}{\rho_{\mathrm{f}} \mathrm{C}_{\mathrm{pf}} \mathrm{WY}} \\ P r & \text { Prandtl number } \\ Q u & \text { Useful heat gain }(\mathrm{W}) \\ R a & \text { Rayleigh number } \\ R_{e} & \text { Reynolds number } \\ T & \text { Temperature }(\mathrm{K}) \\ \Delta T & \text { Temperature difference }(\mathrm{K}) \\ u & \left.\text { Velocity (ms }{ }^{-1}\right) \\ U_{k} & \text { Back loss coefficient }\left(\mathrm{Wm}-{ }^{-1} \mathrm{~K}^{-1}\right) \\ U_{L} & \text { Overall loss coefficient }(\mathrm{W} \text { m } \\ \left.U_{w a l l}=U_{b s} \mathrm{~K}^{-1}\right) \\ W & \text { Box or Side wall loss coefficient }\left(\mathrm{Wm}-{ }^{-1} \mathrm{~K}^{-1}\right) \\ Y & \text { Width of plate }(\mathrm{m}) \\ Y_{g} & \text { Air gap between plate and glass cover }(\mathrm{m}) \\ & \text { Thickness of plate }(\mathrm{m}) \\ & \end{array}$

\section{Subscripts}

$\begin{array}{ll}a & \text { Ambient } \\ b & \text { Receiving air box } \\ c & \text { Convective } \\ \text { col } & \text { Collector } \\ \text { constr } & \text { Construction material (wood) } \\ e & \text { Side wall } \\ f & \text { Flowing medium, i.e. air } \\ g & \text { Glass cover } \\ \text { in } & \text { Input } \\ \text { ins } & \text { Insulation (wool) }\end{array}$


$k$

$m$

$p$

$r$

$s$

w

\section{Greek letters}

$\alpha$

$\alpha^{*}$

$\beta$

$\varepsilon$

$\eta$

$\lambda$

$\xi$

$\rho$

$\sigma$

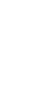

$\tau$

$v$

$\Phi$

Absorber insulation

Mean

Plate

Radiative

Sky

Wind

Absorbance of radiation(-)

Thermal diffusivity $\left(\mathrm{m}^{2} \mathrm{~s}^{-1}\right)$

Slope of plate $\left(^{\circ}\right)$

Emissivity (-)

Collector efficiency (-)

Thermal conductivity $\left(\mathrm{Wm}^{-1} \mathrm{~K}^{-1}\right)$

Volumetric coefficient of

expansion $\left(\mathrm{K}^{-1}\right)$

Density $\left(\mathrm{kgm}^{-3}\right)$

Stephan Boltzmann

constant $\left(\mathrm{Wm}^{-2} \mathrm{~K}^{-4}\right)$

Transmittance (-)

Kinematic viscosity $\left(\mathrm{m}^{2} \mathrm{~s}^{-1}\right)$

Volumetric flow rate $\left(\mathrm{m}^{3} / \mathrm{s}\right)$ 


\section{Chapter 5}

\section{Experimental verification of yam drying with Solar Adsorption Drying}

This chapter is being prepared for submission as:

E.A. Amankwah, G. Kyere, H. Kyeremateng, K.A. Dzisi, A.J.B. Boxtel. Experimental verification of yam drying with a Solar Adsorption Drying. 


\begin{abstract}
This work evaluates the yam drying performance of solar adsorption drying (SAD) compared to solar drying (SD) and open sun drying (OSD). The evaluation concerns the drying cycle for batches of yam, the effect on vitamin $\mathrm{C}$, color and composition. As SAD can be applied during the night, by using air dehumidified by passing through a bed of silica gel, the cycle time for drying batches of yam can be reduced over $20-25 \%$ compared to SD and halved compared to OSD. SAD is thereby most effective during the first nights of drying when the driving force is the highest. Composition was not affected by drying methods but did affect vitamin $\mathrm{C}$ content. Vitamin $\mathrm{C}$ retention for SD and SAD is close to each other with a preference for SD. For three yam cultivars (Pona, Lilii and Dente), Lilii dried fastest and Dente drying slowest. SAD maintained the whitish color of yam better than the other drying methods. Seasonal variations affected drying conditions and drying time. Regeneration of silica gel is realized over three successive days with air heated in a solar collector. The regeneration rate was the highest on the first day of regeneration. The highest day temperature and a good adsorbent bed loading are crucial for efficient regeneration, whereas more work on regeneration is needed for a complete systems design.
\end{abstract}




\subsection{Introduction}

Alternate energy sources which are less costly, abundant and safe will not only help to meet the energy needs of the farmer but will also help to remove potential roadblocks for processing agricultural products. Energy from the sun has been used in the drying and preservation of agricultural products for a long time. According to Berinyuy et al. (2012), most agricultural surpluses are preserved using energy from the sun. Arinze et al. (1990) reported that in developing countries over $90 \%$ of agricultural products are sun dried. Although open sun drying requires little capital and work force, it is associated with many problems and shortcomings. Beside longer drying periods and the possibility of contact with contaminants such as stones and dirt, the crops dried along roadsides stand the risk of contamination with exhaust gasses from traffic or moving vehicles, hence denaturing their nutritional value (Basuinia, 2001). El-Beltagy et al. (2007) reported that vitamin C has a high sensitivity to light and therefore the exposure to solar radiation increased the vitamin $\mathrm{C}$ loss during drying. In order to minimize or prevent the shortcomings of open air drying, the use of dryer equipment driven by solar energy has been investigated and proven to be a better alternative.

Reliable supply of energy is one of the important prerequisites for the growth of Africa's agricultural industry. Access to fossil fuels such as coal and petroleum or electricity for farm operations or crop processing is expensive and mostly unreliable, while that of fuel wood is not sustainable. Solar energy is an alternative source of energy which has an advantage over other alternative sources of energy such as wind and shale because of its abundant, inexhaustible, renewable and non-polluting nature. The method of drying affects the rate of drying and the quality of the product. Air drying in general enhances the drying rate, while direct exposure to the sun can have a deleterious effect on the quality of the dried product. Changes of vitamin $\mathrm{C}$ content during drying have been affected by drying time, drying air temperature as well as moisture content (Erenturk et al., 2005 and Davey et al., 2000). Yam in particular, contains vitamin $\mathrm{C}$ as a bioactive compound which has a strong antioxidant activity. It plays an important role in human nutrition due to free radical scavenging activities (Skrede et al., 2000 and Giovanelli et al., 2009). Vitamin C is degraded by irreversible oxidative reactions during air drying (Vega-Gálvez et al., 2009). Santos and Silva (2008) mentioned that a high oxygen concentration around the drying environment may lead to increase in vitamin $\mathrm{C}$ degradation in the dried product. It has been reported that drying methods effects final moisture content, but not on other components of yam flours (Hsu et al., 2003). Maintaining the original colour of food samples is a priority of the processor and the demand of the consumer. Yam contains phenolic compounds which are associated with oxidative browning by enzymes and oxidative browning (Okaka and Okaka., 2001). Thus any processing method that is consumer acceptability driven by maintaining either the whitish or creamer color of yam meets a great demand.

Solar drying systems, where either the product is directly dried in a glass covered chamber or indirectly by channeling hot air into a drying chamber by first heating ambient air through a 
solar collector system, improve the rate of drying as well as the food quality (Oguntola et al., 2010). In both systems, drying results in a reduced drying time and is an improvement over the open air drying method. Moreover, contamination of final product is reduced in the solar dryer drying systems (Hassan et al., 2007). Solar systems are not full proof since the sun's energy is limited to between 6-8 hours a day in the tropics and during the night rewetting of the products may occur. A solar dryer system with thermal storage was designed and constructed by Madhlopa et al. (2002) which enabled to extend drying to continue after sunset. However the intensity of the solar radiation is not always enough to sufficiently heat the thermal mass. Thus, with this system, the continuity of drying is not warranted.

An improved method is Solar Adsorption Drying (SAD) (see Figure 5.1), which is a combination of solar collector and adsorption systems. In this system night drying is made possible by utilizing dehumidified air as a result of passing ambient air through a chamber filled (packed bed) with adsorbents, while releasing adsorbent energy (latent heat) due to phase change. The saturated adsorbent is regenerated during day time by using a separate solar collector.

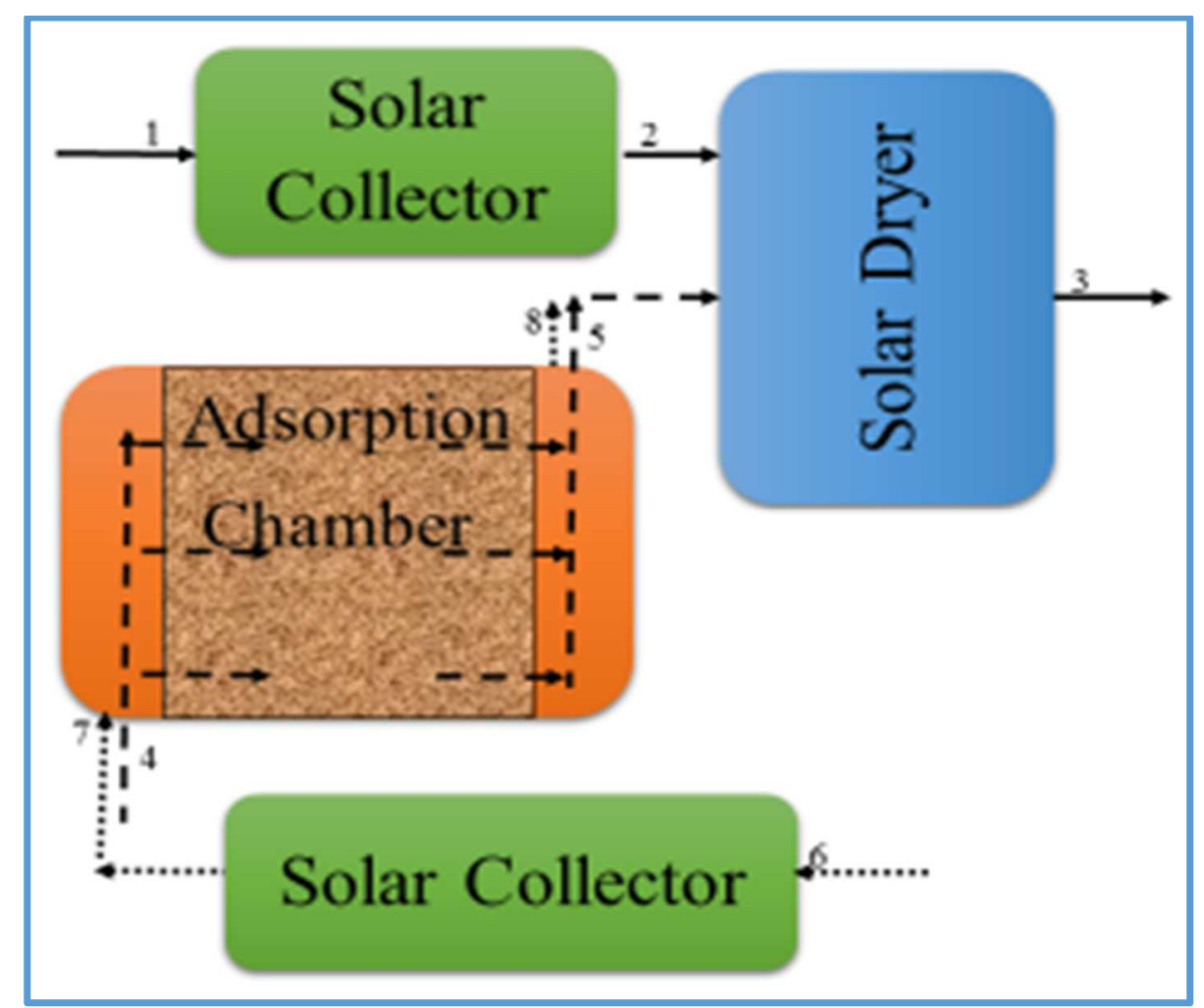

Figure 5.1 Solar-adsorbent dryer (SAD). $1 \rightarrow 2 \rightarrow 3$ : air flow during drying, $4 \rightarrow 5 \rightarrow 3$ : air flow during night drying, $6 \rightarrow 7 \rightarrow 8$ : air flow for regeneration during day time.

Silica gel has been used to dry agricultural products (example apricot, flowers and herbs) at low temperature giving excellent product quality in terms of texture, color and durability (Chua and Chou, 2003).

Regeneration of the silica gel after drying is usually done in an electric oven which comes with its own added cost. It has been reported that silica gel has an excellent capacity for adsorption 
of water on the basis of physical adsorption of water and can easily be regenerated between 50 $-90^{\circ} \mathrm{C}$ (Ng et al., 2001). Saito (1993) has reported the possibility to regenerate silica gel with solar heated air. This assertion has been confirmed by Techajunta et al. (1998). During adsorbent regeneration the dehumidification rate decreases with decrease in solar radiation but slightly increased with air flow rate. Sukhmeet and Parm (1997) investigated the regeneration of silica gel and activated alumina in a multi-shelf dehumidifier with the air temperature in the range $42-72^{\circ} \mathrm{C}$, air speed $0.175-0.55 \mathrm{~m} / \mathrm{s}$ and packed bed as control. They concluded that the regeneration time decreased with increased air temperature and bed air velocity and that this system worked better in a humid tropical climate with regeneration during the day and dehumidification of air during the night.

The first aim of this work is to quantify the yam drying performance in an SAD compared to a common solar dryer (SD) and open sun drying (OSD) and to compare with the effect on vitamin $\mathrm{C}$ retention in these three systems. The second aim is to quantify the drying performance, vitamin $\mathrm{C}$ retention and product color of different cultivars of yam for the three different drying methods. To this end, an experimental system was designed and realized according to the schematic diagram shown in Figure 5.1 (Amankwah et al., 2017). It would be beneficial if the regeneration of the adsorbent in the SAD system could be done by solar energy. Therefore, the third aim is to perform a preliminary experiment to study the solar regeneration of the adsorbent.

\subsection{Materials and methods}

\subsubsection{Description of dryer systems}

Three experimental drying methods were employed in this study: traditional open sun drying (OSD), solar drying (SD) and the solar adsorption dryer SAD as described in Figure 5.1. OSD and SD were applied during daytime, while the SAD is also applied during part of the night. The experiments on the three systems were performed in parallel in an open space near the Agricultural Engineering Department, KNUST, Kumasi, Ghana. For OSD, samples were placed in three trays next to each other in the open sun with air passing through freely. Drying for this system depends on the solar radiation, ambient temperature and humidity and air circulation along and around the trays. These conditions were subject to natural and uncontrolled variations. The SD system is made up of a solar collector system and a dryer chamber (i.e. equivalent to path 1-2-3 in Figure 5.1). The collector system consisted of glass cover, air gap, absorber plate and insulation material at the backside. The collector can achieve air temperatures up to $60^{\circ} \mathrm{C}$. Details of the collector design and the performance are given by Amankwah et al. (2017).

The SAD was organized as presented in Figure 5.1. During day time the SAD was operated as an SD, while during night drying the air passed through a bed of silica gel which was used as adsorbent. The applied solar collector was designed to reach air temperatures up to $60^{\circ} \mathrm{C}$ under Ghanaian radiation conditions. For adsorbent regeneration another solar collector is used. This 
collector was larger and could reach air temperatures of between $80-85^{\circ} \mathrm{C}$. Details about the design and performance are given by Amankwah et al. (2017). In the drying cabinet, the air flowed freely along the product particles at the wired trays by natural (OSD) or forced convection (SD and SAD). Location of temperature measurements is shown in Figure 5.2.
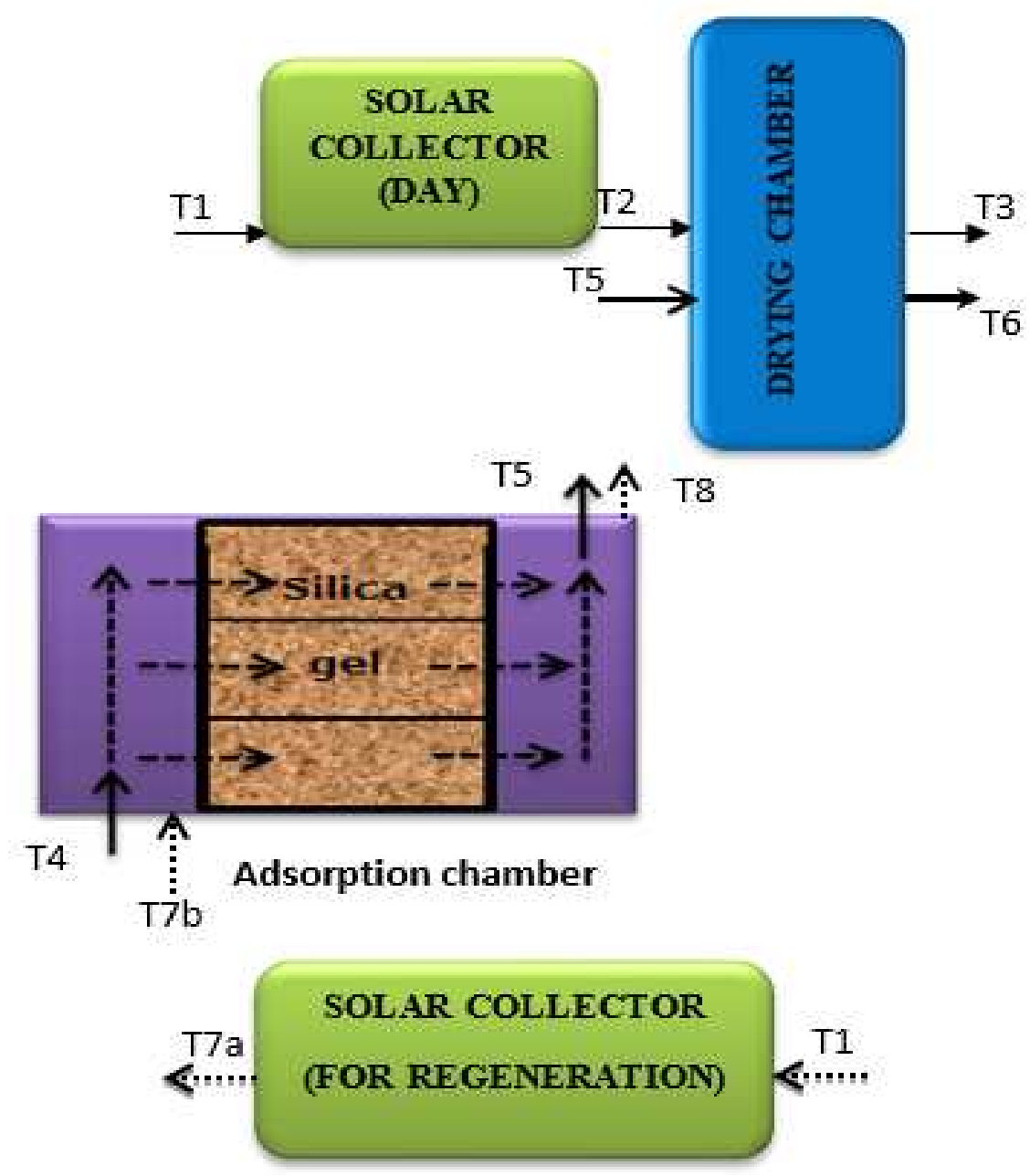

Figure 5.2 Solar-adsorbent dryer system (SADS) showing locations of K-type thermocouple for the temperature measurement (T1-T8) at input and output of each unit.

\subsubsection{Temperature, air velocity and weight measurements}

Calibrated K-type thermocouples were used to measure the inlet and outlet air temperature of all the units in Figure 5.2, logged by an Agilent (34970A, USA) data logger. An analytical balance (Ohaus, Model PA-2102, USA) with precision 0.01g was used to weigh the drying samples. This was done manually with a 30 minutes interval for the first two hours and one hour interval till the end of drying by removing the samples from the drying chamber. The samples were placed back into the drying chamber not later than five minutes to ensure continuity of the drying process. The air velocity was measured from time to time to ensure it was averagely constant with a thermal anemometer (Testo, model 425, Germany, accuracy $\pm 0.05 \mathrm{~m} / \mathrm{s}$ ) by placing the rod housing the sensor perpendicular across the direction of the airflow for both SD and SAD. Every time three measurements were performed and the values were averaged. Initially the RH was measured with a hand held sensor at all locations given in 
Figure 2. However, in the low RH range the repeatability of the measurements with the hand held sensor was not satisfactory for interpretation and therefore these measurements were no longer used.

\subsubsection{Chemical Analysis}

The AOAC protocol (1990) was followed for the determination of crude fat and fiber. Nitrogen was determined by the Kjeldahl digestion and fat by the Soxhlet method (AOAC, 1990). Crude protein content was calculated using a factor of 6.25. Moisture and ash content were determined gravimetrically in accordance with AACC methods 44-17 (AACC, 2000). Crude fiber content was determined by the digestion method (AACC, 2000). Total percentage carbohydrate was determined by the difference method. This method involves adding the total value of moisture, ash, crude protein, crude fiber component of sample and subtracting it from 100. The values determined were converted to dry basis ( $\mathrm{kg} / \mathrm{kg}$ dry matter).

\subsubsection{Vitamin C content}

The vitamin $\mathrm{C}$ was determined by visual titration of ascorbic acid with 2,6 dichlorophenolindophenol as indicator in a pH range of 1 - 3.5 (Ojukwu and Nwobi, 2017, Kumar et al., 2013). The values were reported in dry basis ( $\mathrm{mg} / \mathrm{g}$ dry matter).

\subsubsection{Instrumental determination of color}

The colour of fresh and dried yam slices was determined in terms of the tristimulus color values $L^{*}, a^{*}$ and $b^{*}$ using Minolta Chromameter, CR-300 (Minolta Co., Japan). Where, L* indicates lightness or darkness of the material; $\mathrm{L}^{*}=0$ is completely black and $\mathrm{L}^{*}=100$ is completely bright. The $\mathrm{a}^{*}$ is the color coordinate in red-green axis; positive $\mathrm{a}^{*}$ value for redness and negative for greenness. $b^{*}$ is the color coordinate in yellow-blue axis; positive for yellowness and negative blueness. The color of the yam slices was measured after calibrating the instrument with a white tile ( $\mathrm{L}^{*}$ 93.3; $\mathrm{a}^{*} 0.32$ and $\mathrm{b}^{*} 0.33$ ). Yam slices were put into a transparent petri dish and the measuring head of the meter was carefully placed on three different locations on the petri dish. The measurements were determined in triplicates and mean determined.

\subsection{Experimental procedure}

Two collector systems of the same dimension were separately used for the SAD and SD drying processes. The first experiment, hereafter called 'Performance of SAD drying', concerns the comparison of the required drying times and vitamin $\mathrm{C}$ retention of SAD relative to SD and OSD. For this experiment OSD and SD were carried out during the day time between 9am $5 \mathrm{pm}$ when enough solar radiation was available. The SAD was applied for five additional hours in the evening until 10pm, with the adsorption system in use. Full night experiments were not feasible in view of safety regulations. Before each experiment the SD and SAD were allowed to run for 30 minutes to reach steady state before loading the trays that contain the yam cubicles to be dried each day. 
About 200 grams of yam (Dente) cut $(3 \times 3 \times 1 \mathrm{~cm})$ with initial moisture content between 1.63$2.13 \mathrm{~kg}$ water $/ \mathrm{kg}$ dry matter was placed on each of the three successive trays stacked in the same chamber of external and internal dimensions $70 \times 45 \times 50 \mathrm{~cm}$ and $60 \times 45 \times 40 \mathrm{~cm}$ respectively. The air flow was in the upward direction from the bottom part of the drying chamber beneath the trays made of wire mesh. At the end of each day, the yam samples were cooled and placed in zip-lock polyethylene bags and stored at room temperature. Next day, the samples were unpacked and placed at the trays to continue drying. This process was repeated on the subsequent days until the product was sufficiently dried. At low moisture contents the benefit of air dehumidification at night becomes minor. Hence, in one experiment, after two day-night cycles, the drying was continued by the solar system only. The vitamin $\mathrm{C}$ content was measured for the dried samples.

The next experiment, herein after called 'Drying different yam cultivars', concerned the drying behavior of different cultivars and the effect of different drying methods on the composition, color and again vitamin $\mathrm{C}$. The procedure is similar as described for the first experiment. One hundred grams $(100 \mathrm{~g})$ each of yam cultivar cut $(3 \times 3 \times 1 \mathrm{~cm})$ with initial moisture content between $1.55-2.06 \mathrm{~kg}$ water $/ \mathrm{kg}$ dry matter depending on the variety were all loaded on one tray and same loaded on tray stacked below it as replicate. Yam samples from tree cultivars (Pona, Lilii and Dente) of D. Rotundata were bought from a yam farm.

The last part of this work, herein after called 'Regeneration of silica gel', concerns the regeneration of the silica gel. The regeneration commenced for saturated adsorbent after the 3 nights of drying of $D$. Rotundata (Dente). The adsorbent chamber (three holder compartments in series), that had gained weight as a result of the adsorption drying, was connected to the solar collector system designed for regeneration (Amankwah et al., 2017). The regeneration was applied during the full day, during which heated air from the collector passed through the silica gel. The silica gel was weighed before and after each day of regeneration to determine the amount of moisture removed. This process was continued for 3 days until equilibrium was reached. The day averaged regeneration rates of the silica gel were calculated from the amount of water removed over the period of regeneration and expressed as $\mathrm{kg}$ water/hour (Mehla et al., 2014). The main characteristics of the various categories of experiments are shown in Table 5.1 . 
Table 5.1 Major characteristics of experiment

\begin{tabular}{|c|c|c|c|c|c|}
\hline & Start & Duration, & $\begin{array}{l}\text { Chemical } \\
\text { analysis }\end{array}$ & $\begin{array}{l}\text { Sensors/ } \\
\text { probe }\end{array}$ & $\begin{array}{l}\text { No. of } \\
\text { cultivars }\end{array}$ \\
\hline $\begin{array}{l}\text { Performance } \\
\text { of SAD }\end{array}$ & Night & 3-5 days & $\begin{array}{l}\text { Vitamin } \mathrm{C} \text { in } \\
\text { fresh and } \\
\text { dried } \\
\text { product }\end{array}$ & $\begin{array}{l}\text { K-type } \\
\text { thermocouple }\end{array}$ & 1 \\
\hline Night & & 6 hours & & & \\
\hline Day & & 9 hours & & & \\
\hline $\begin{array}{l}\text { Drying } \\
\text { different yam } \\
\text { cultivars }\end{array}$ & Morning & 4-9 days & $\begin{array}{l}\text { Vitamin } \mathrm{C} \text { in } \\
\text { fresh and } \\
\text { dried } \\
\text { product } \\
\text { Composition }\end{array}$ & $\begin{array}{l}\text { K-type } \\
\text { thermocouple }\end{array}$ & 3 \\
\hline $\begin{array}{l}\text { Regeneration } \\
\text { of silica gel }\end{array}$ & Day & $\begin{array}{l}3 \text { days of } 6 \\
\text { hours each }\end{array}$ & & $\begin{array}{l}\text { K-type } \\
\text { thermocouple, } \\
\text { silica weight }\end{array}$ & \\
\hline
\end{tabular}

\subsection{Results and discussion}

\subsubsection{Performance of SAD drying}

This experiment started with night drying using dried silica gel as adsorbent. The adsorbent was used on the first night for 5 hours and hermetically sealed since the time for assess to the drying site was up. On the second and third night the adsorbent was used again. The adsorbent was then stored for regeneration. The performance of the system was monitored by recording the air inlet and outlet temperatures. During the night the temperature increased with $5.2^{\circ} \mathrm{C}$ by the release of latent heat of adsorption and the raise of temperature indicates active dehumidification by the adsorbent.

The operational conditions: radiation, ambient temperature, input and outlet air temperatures for SAD, SD and OSD drying systems are shown in Figure 5.3. The air temperatures that enter the drying units were significantly higher during the day than the nights, whereas the outlet temperatures were slightly lower. During the day, air temperatures increased from the morning, peaked in the afternoon and dropped towards the evening. Night temperature increased initially due to adsorption energy (see grey portion of Figure 5.3). Meanwhile air temperature related well with solar radiation. 

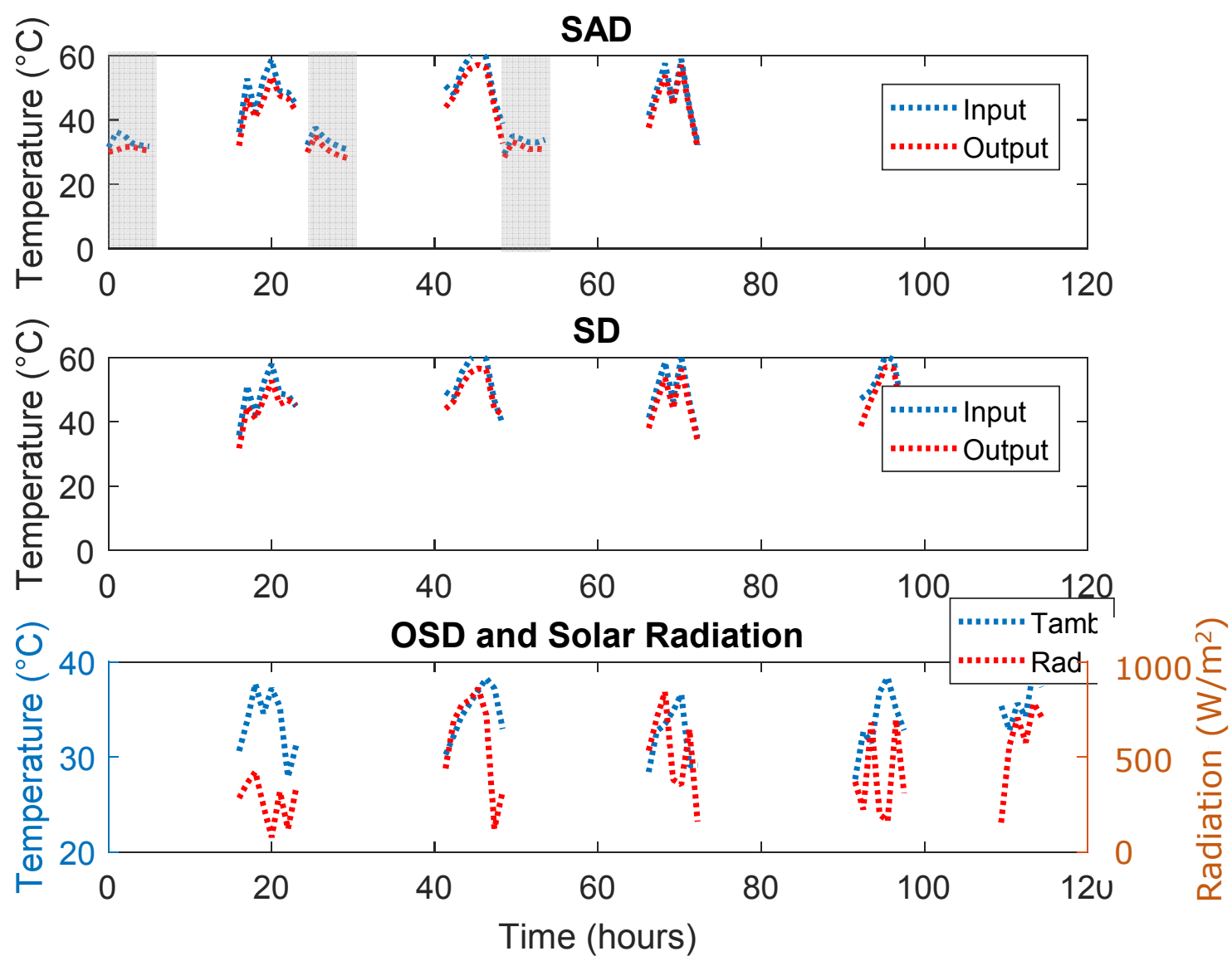

Figure 5.3 Drier cabinet input and output air temperatures T4 and T5 (night), T2 and T3 (day) for SAD (top graph), T2 and T3 (day) for SD (middle graph) and ambient temperature T1 for OSD (See Figure 5.2) and radiation (bottom graph). The grey portions represent the night drying.

The moisture content of yam particles, averaged over the three trays, is given in Figure 5.4. The product in the SAD dried immediately in the first night and the water content falls from 1.70 to $1.15 \mathrm{~kg}$ water $/ \mathrm{kg}$ dry matter over the first 5 hours of drying with dehumidified air. SAD is continued the following mornings (day 1). During night 2 SAD is still effective, but at day 3 the effectivity is no longer significant. The low drying rate during night 3 is a result of the low driving force between the nearly dry product at the temperatures realized by the dehumidification system. So, adsorption drying during the night is most effective at the early stages of drying after which elevated temperatures are required to remove water when moisture content of samples are low. 


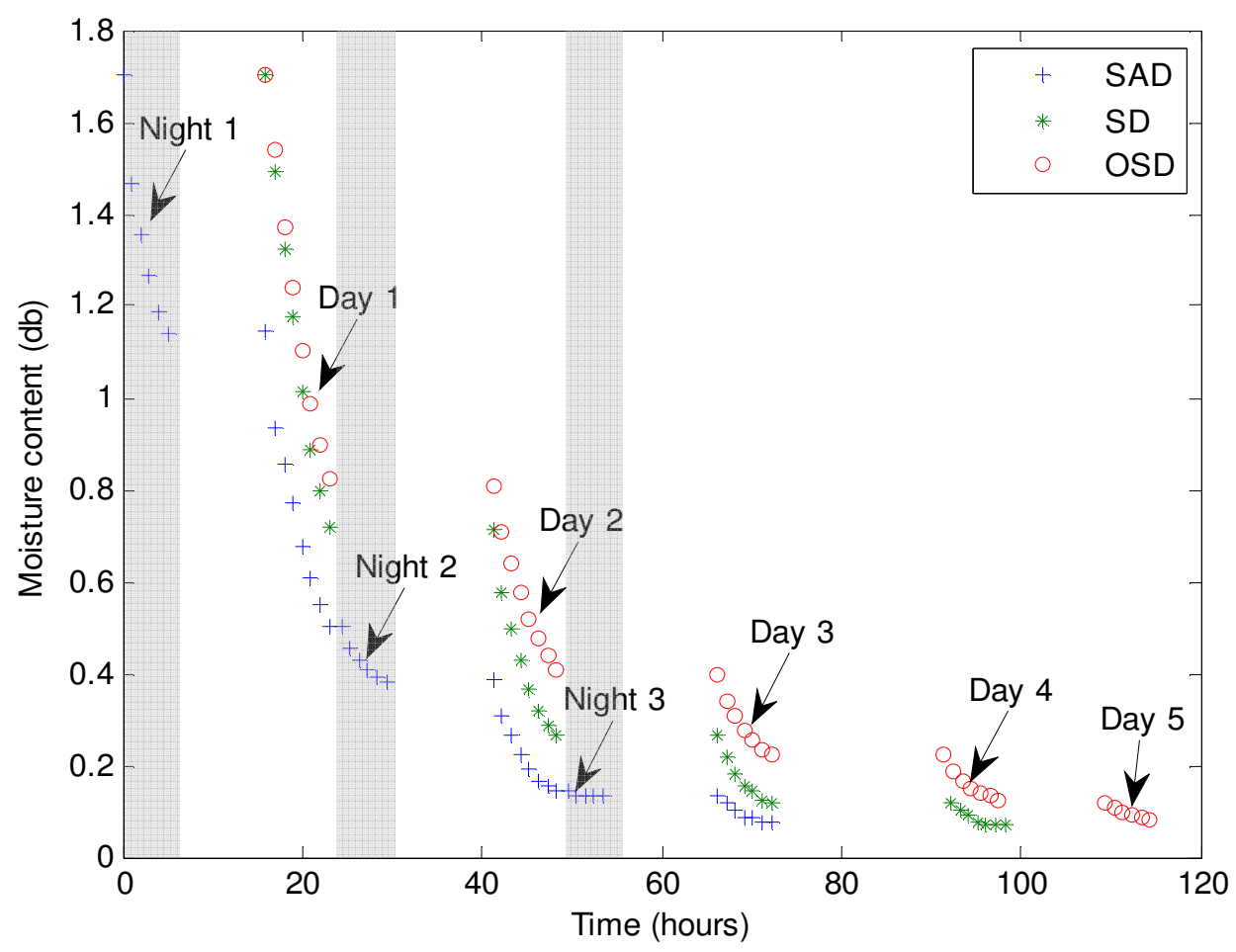

Figure 5.4 Average moisture content over all trays of yam particles (Dente) for different drying methods, SAD, SD and OSD. The grey portions represent night drying.

By the end of the second day $90.3,84.3$ and $76.2 \%$ of water was removed for SAD, SD and OSD, respectively. The total time needed for SAD to reach a final moisture content of 0.07$0.08 \mathrm{~kg}$ water $/ \mathrm{kg}$ dry matter is within three evenings and 3 days compared to 4 and 5 days for the SD and OSD respectively. This result implies that the capacity of a solar drying system increases by a $20-25 \%$ shorter time line compared to a standard solar dryer. Extension to full night drying with an adsorption system, which was not possible in this experimental setting, can further reduce the drying cycle. The moisture content of yam particles at various locations of the drying chamber as a function of time for various drying methods is shown in Figure 5.5. 
SAD

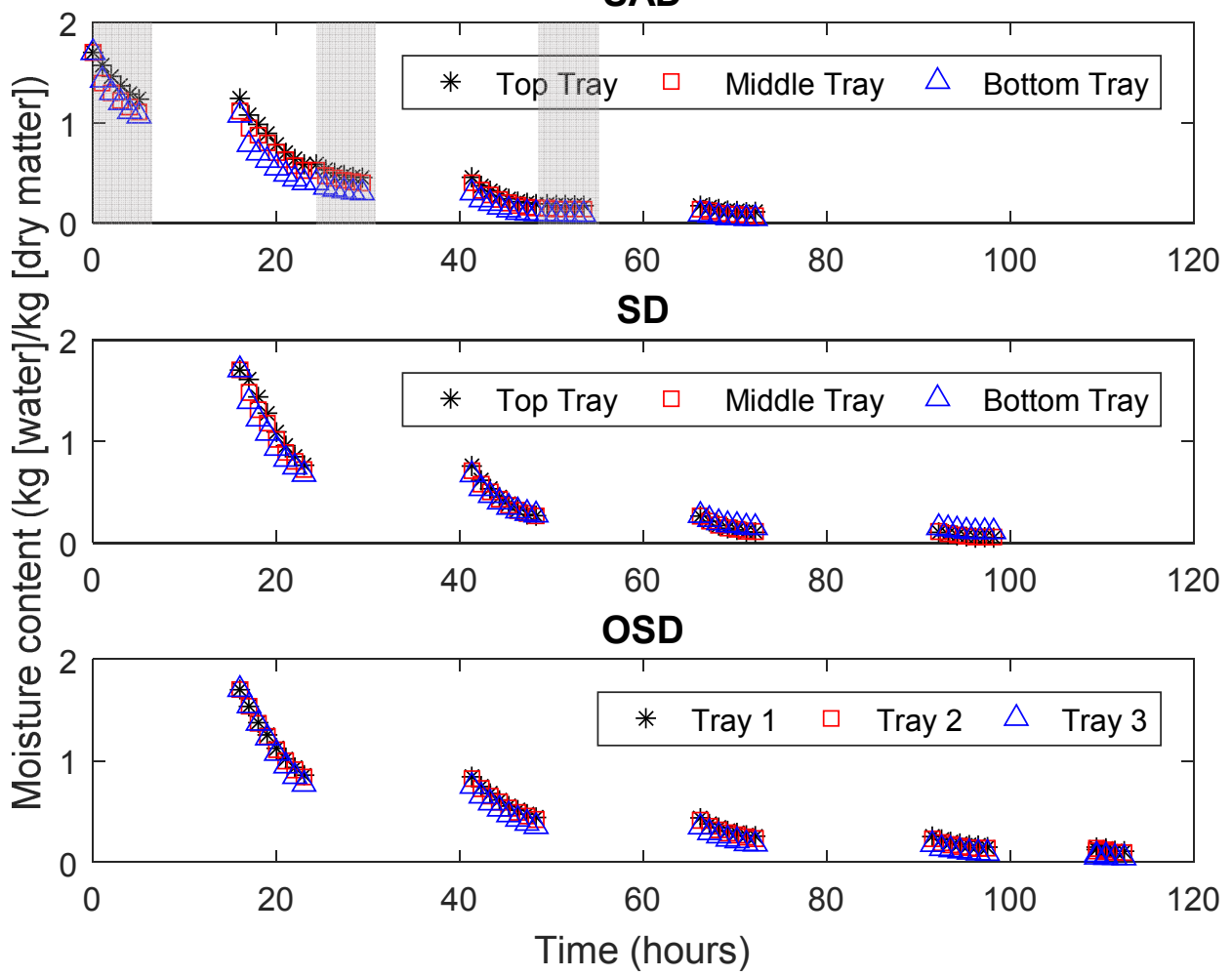

Figure 5.5 Moisture content of yam particles (Dente) at different positions in the dryers as a function of time for SAD, SD and OSD. . The grey portions represent night drying.

The trays were categorized as Top tray, Middle and Bottom trays with air flowing from below the drying chamber for the SAD and SD systems, while that of the OSD are noted as Tray 1-3. For OSD drying the trays are not stacked in a drying chamber and therefore there is no influence between the trays. The SAD system shows differences in moisture content for the three trays especially in the first night under low temperature drying with dehumidified air, while there are only minor differences for the trays in the SD dryer as corroborated by Dissa et al. (2011). The differences between the trays in SAD that arise during the first night propagate over the next days and nights.

Figure 5.6 shows the effect of different drying methods on vitamin $\mathrm{C}$ at the end of drying in Dente. The figure shows that for each drying method vitamin $\mathrm{C}$ content reduced. Solar drying (SD) retained the most vitamin $\mathrm{C}$ followed by solar adsorption drying (SAD) and open sun drying (OSD) respectively. Though adsorption drying involves also low temperatures, because it is an addition to solar drying, the longer exposure of the food samples ( 44 hours for SAD and 32 hours for SD) to air flow might have contributed to vitamin C loss in comparison with the SD system (Santos and Silva, 2008, Oyetade et al., 2012). Additionally, the loss of vitamin C might also be attributed to higher temperatures for both SAD and SD while higher rates of moisture removal by SAD than SD causing a difference between them Jin et al. (2011). During open sun drying (OSD) dried the samples retained less vitamin $\mathrm{C}$ due to exposure of food to direct sunlight (El-Beltagy, 2007) in addition to moisture removal. This explains why the SAD and SD samples retained higher concentrations of vitamin $\mathrm{C}$ compared to the OSD samples. 


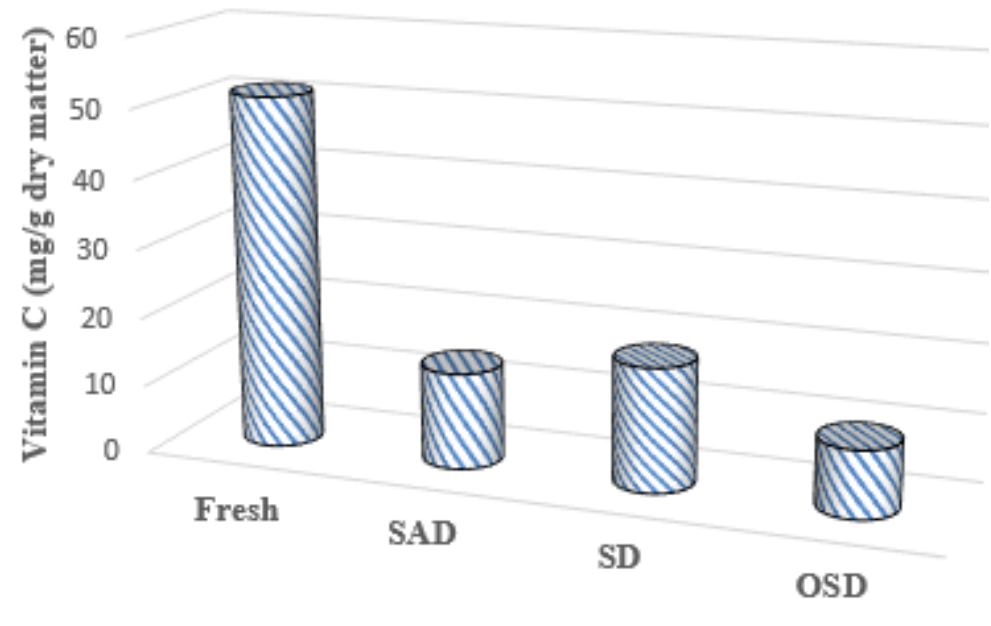

Drying method

Figure 5.6 Effect of different drying methods on vitamin C retention in Dioscorea rotundata.

\subsection{Drying different yam cultivars}

\subsubsection{Operational conditions}

The operational conditions are shown in Figure 5.7. Just as in Figure 5.2, the input and output air temperatures increased from morning and peaked in the afternoon and drops towards the evening. Again, during the night drying period, the output air temperature from the dryer cabinet were below that of the input temperature due to yam sample absorbing energy in the course of drying. Apart from the first day the solar radiation was higher compared to this experiment. As a consequence the dryer input and output temperatures and ambient temperature in this experiment were below those in the previous experiment (Figure 5.3). As a result of the lower radiation and temperatures, it took about 9 days to dry the Dente cultivar to a storable moisture content, compared to 3-5 days in the previous experiment. 

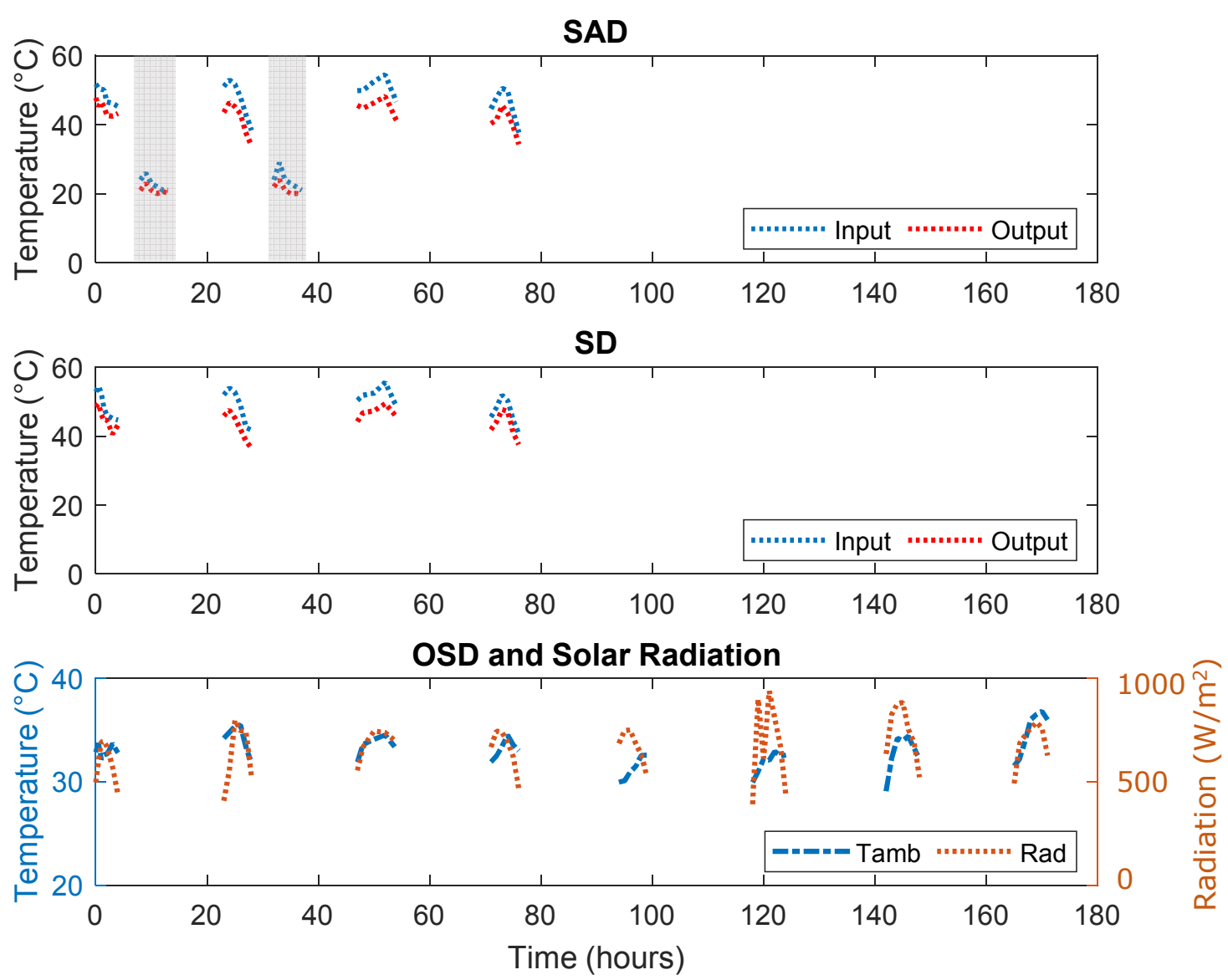

Figure 5.7 Drier cabinet input and output air temperatures T4 and T5 (night), T2 and T3 (day) for SAD (top graph), T2 and T3 (day) for SD (middle graph) and ambient temperature T1 for OSD (See Figure 5.2) and radiation (bottom graph). The grey portions represent the night drying.

Figure 5.8 shows the drying behavior of three yam cultivars (Pona, Lilii and Dente) subjected to SAD, SD and OSD. As the cultivars samples start with different initial moisture content (see Table 5.2), the drying behavior is expressed in the moisture ratio, here defined as:

$$
M R(t)=\frac{M(t)}{M_{\text {start }}}
$$

With $M R(t)$ the moisture ratio at time $t, M(t)$ the moisture content at time $t, M_{\text {start }}$ the initial moisture content. While it took 3 - 4 days to dry Pona and Lilii to a specified moisture content, it took 7 to 9 days to dry Dente to a moisture content below 10\% (wb). Lilii and Pona have large granules which lead to a lower water binding affinity, whereas Dente, has smaller granules that result in higher water binding. For all varieties $\mathrm{SAD}$, which involves night drying, reduced the drying cycle as compared to the SD. The OSD was less effective in terms of moisture removal and subsequently final moisture content. 

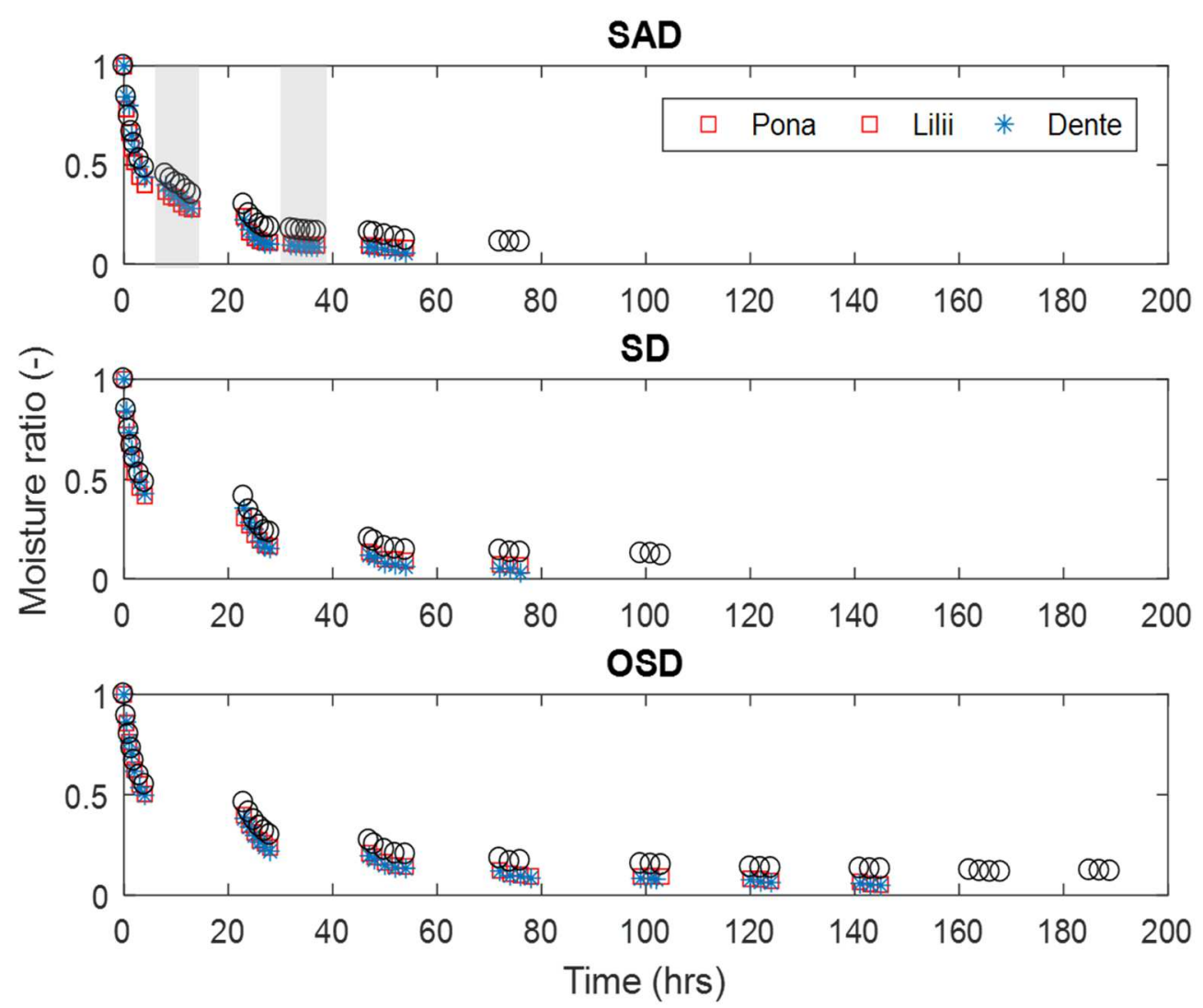

Figure 5.8 Comparison of drying methods on different varieties of yam. The grey portions represent night drying.

By the end of the third day the moisture ratio of Lilii was for the three methods between 0.0606 - 0.203 while that of Dente was between $0.133-0.224$. SAD recorded the lowest moisture ratio and the OSD the highest. It took 4 days for SD to bring the moisture ratio of Lilii to or below 0.06 while SAD needed three days. SAD had thus the shortest drying cycle compared to the other drying methods. Meanwhile, final moisture ratios of $0.111,0.116$ and 0.119 were reached after 4, 5 and 9 days using SAD, SD and OSD respectively in drying Dente. These different drying times are only partly as a consequence of the difference in initial moisture content, but mainly to the differences in food matrix. It is possible that Lilii and Pona may have large granules which lead to lower water binding affinity, whereas the converse holds for Dente.

Table 5.2 shows the composition of fresh and dried yam per dry weight basis. The moisture content of fresh yam ranged between $1.55-2.06 \mathrm{~kg} / \mathrm{kg}$ dry matter with Pona recording the least and Dente the highest. The final moisture content values of the samples using various drying methods range between $0.05-0.09 \mathrm{~kg} / \mathrm{kg}$ dry matter. These values are below $10 \%$ wet basis, which is considered as the acceptable range for well packaged dehydrated yam product.

Table 5.2 shows that, generally, the drying methods do not affect the proximate composition of samples but rather the final moisture content as mentioned by Hsu et al. (2003). Though generally there is marginal increase in fibre and decrease in protein composition between fresh 
and dried samples, there is no obvious trend in variability among the values of cultivars. Effect of drying on protein is as a result of decrease in its digestibility and biological value as mentioned by Karel (1995). Heating does not generally affect total dietary fibre content (Jones et al., 1990), however, it causes the increase of the insoluble dietary fibre content as a result of complexing of its components with protein and amino acids (Matalas et al., 2001).

Table 5.2 Composition ( $\mathrm{kg} / \mathrm{kg}$ dry matter) of the three cultivars (fresh and dried) at different drying methods

\begin{tabular}{lllllll}
\hline \multirow{2}{*}{$\begin{array}{l}\text { Method } \\
\text { Cultivar }\end{array}$} & Moisture & Ash & $\begin{array}{l}\text { Crude } \\
\text { Protein }\end{array}$ & Crude Fibre & Crude Fat & Carbohydrate \\
\cline { 2 - 7 } & \multicolumn{5}{c}{ Pona } \\
\hline Fresh & 1.549 & 0.020 & 0.053 & 0.010 & 0.003 & 0.915 \\
SAD & 0.055 & 0.038 & 0.040 & 0.011 & 0.007 & 0.906 \\
SD & 0.054 & 0.037 & 0.041 & 0.011 & 0.007 & 0.897 \\
OSD & 0.075 & 0.038 & 0.046 & 0.011 & 0.006 & 0.895 \\
\cline { 2 - 7 } & & & & Lilii & \\
\hline Fresh & 1.872 & 0.027 & 0.042 & 0.013 & 0.002 & 0.863 \\
SAD & 0.061 & 0.036 & 0.034 & 0.027 & 0.006 & 0.882 \\
SD & 0.062 & 0.038 & 0.036 & 0.027 & 0.006 & 0.885 \\
OSD & 0.073 & 0.039 & 0.041 & 0.027 & 0.006 & 0.891 \\
& & & & Dente & & \\
\hline Fresh & 2.063 & 0.020 & 0.043 & 0.011 & 0.002 & 0.856 \\
SAD & 0.054 & 0.030 & 0.042 & 0.022 & 0.006 & 0.901 \\
SD & 0.055 & 0.032 & 0.042 & 0.022 & 0.005 & 0.906 \\
OSD & 0.078 & 0.032 & 0.041 & 0.023 & 0.006 & 0.926 \\
\hline
\end{tabular}

\subsubsection{Vitamin $C$ and color of dried yam}

Vitamin $\mathrm{C}$ content, expressed in $\mathrm{mg} / \mathrm{g}$ dry matter, of the fresh and dried samples is presented in Table 5.3. All drying methods significantly affected the vitamin $\mathrm{C}$ content with the highest effect by OSD due to the direct exposure of the food to the sun. Just as in the previous experiment vitamin $\mathrm{C}$ loss for $\mathrm{SAD}$ is a bit higher than that for SD due the additional drying of samples at night. Moreover, the vitamin $\mathrm{C}$ content of Dente is about half to that of the previous experiment as a result of more drying days. Thus extra drying days, further degrades vitamin C. It is also clear that the loss in vitamin $\mathrm{C}$ after drying varies for the different cultivars. The loss in vitamin $\mathrm{C}$ content after drying is in line with what has been reported by Hassan et al. (2007) who mentioned that drying methods greatly affect micronutrients as corroborated by and Jin et al. (2011). Hodali and Bougard (2001) reported of improved quality and more economical process as a result of reduced time of drying of apricot by using solar adsorbent integrated system. 
Table 5.3 Vitamin C content (mg/g dry matter) of fresh and dried cultivars of yam at different drying methods

\begin{tabular}{lrr}
\hline Drying method & Vitamin C \\
\hline Fresh & Pona & 44.4 \\
SAD & 6.8 \\
SD & 7.1 \\
OSD & 2.4 \\
\hline & & \\
\hline Fresh & Lilii & 26.7 \\
SAD & & 4.8 \\
SD & & 5.0 \\
OSD & 1.5 \\
\hline & & \\
\hline Fresh & Dente & 60.8 \\
SAD & & 6.9 \\
SD & & 7.8 \\
OSD & 2.3 \\
\hline
\end{tabular}

The measured $\mathrm{L}^{*}$ values for fresh yam ranged between 81.83 and 83.68 . The $\mathrm{L}^{*}$ values (whiteness) for the dried samples decreased and ranged between 52.14 and 78.41 (see Table 5.4). The change in color is attributed to enzymatic browning (Okaka and Okaka, 2001) as a result of differences in phenolic compounds which is associated with oxidative browning of yam. SD and SAD dried samples are close in the $\mathrm{L}^{*}$ value, but despite the night drying periods the averaged values of the SAD dried samples show a lower change of whiteness than those for the SD dried samples. This makes the SAD system superior in terms of maintaining the white colour of dried samples. The $\mathrm{a}^{*}$ values show a slight change due to drying, while the $\mathrm{b}^{*}$ values move towards less yellowness. 
Table 5.4 Colour measurement results for both fresh and dried yam of different varieties.

\begin{tabular}{|c|c|c|c|}
\hline METHOD/ & $\mathrm{L}^{*}$ & $\mathrm{a}^{*}$ & $\mathrm{~b}^{*}$ \\
\hline & \multicolumn{3}{|c|}{ Pona } \\
\hline Fresh & 81.83 & -0.34 & +14.36 \\
\hline SAD & 76.87 & -0.49 & +7.55 \\
\hline SD & 78.41 & -0.22 & +8.38 \\
\hline \multirow[t]{2}{*}{ OSD } & 65.79 & -0.06 & 7.83 \\
\hline & \multicolumn{3}{|c|}{ Lilii } \\
\hline Fresh & 83.69 & -1.28 & +14.34 \\
\hline SAD & 76.01 & -0.26 & +5.75 \\
\hline SD & 73.30 & -0.33 & +4.92 \\
\hline \multirow[t]{2}{*}{ OSD } & 62.67 & -0.35 & +7.58 \\
\hline & \multicolumn{3}{|c|}{ Dente } \\
\hline Fresh & 83.68 & -1.300 & +14.98 \\
\hline SAD & 76.22 & -0.08 & +6.08 \\
\hline SD & 75.32 & -0.14 & +6.80 \\
\hline OSD & 62.49 & -0.74 & +7.79 \\
\hline
\end{tabular}

\subsection{Regeneration of silica gel adsorbent}

Regeneration air temperatures from the $4.5 \mathrm{~m}$ solar collector and silica chamber are shown in Table 5.5. The outlet collector air temperatures had an average of $60^{\circ} \mathrm{C}$ with peak temperatures beyond $80^{\circ} \mathrm{C}$ for all the experimental days. These realized temperatures correspond to the design conditions, and thus the collector operated according expectations. Despite the applied insulation of the PVC pipes between the solar collector and adsorbent chamber, the temperature of the hot air entering the adsorbent chamber is a few ${ }^{\circ} \mathrm{C}$ below the air temperature from the collector. To utilize the gained energy from the collector effectively, it is therefore essential to apply a high quality of insulation. 
Table 5.5 Air temperatures through solar collector for regeneration, silica gel chamber and air relative humidity during adsorbent regeneration. $\mathrm{T}_{\mathrm{ac}}$,in: collector input temperature, $\mathrm{T}_{\mathrm{ac}, \text { out }}$ : collector output temperature, $\mathrm{T}_{\mathrm{as}, \text { in }}$ : silica chamber input temperature, $\mathrm{T}_{\mathrm{as} \text {,out: }}$ silica chamber output temperature.

\begin{tabular}{lrrrrr}
\hline Date & Time(h) & $\mathrm{T}_{\text {ac,in }}$ & $\mathrm{T}_{\text {ac, out }}$ & $\mathrm{T}_{\text {as, in }}$ & $\mathrm{T}_{\text {as,out }}$ \\
Day 1 & 1 & 29.1 & 60.9 & 48.1 & 30.7 \\
& 2 & 33.2 & 72.4 & 68.0 & 54.3 \\
& 3 & 33.4 & 86.9 & 78.6 & 62.2 \\
Day 2 & 4 & 37.7 & 83.7 & 77.1 & 64.8 \\
& 5 & 45.1 & 56.1 & 53.1 & 54.4 \\
& 6 & 36.6 & 63.9 & 59.7 & 54.6 \\
& 22 & 32.5 & 83.4 & 75.6 & 52.4 \\
& 23 & 35.6 & 88.5 & 80.0 & 64.4 \\
Day 3 & 24 & 42.0 & 84.7 & 77.6 & 66.5 \\
& 25 & 46.7 & 80.5 & 75.5 & 67.7 \\
& 26 & 44.1 & 63.8 & 60.3 & 59.7 \\
& 27 & 41.1 & 58.2 & 52.6 & 48.4 \\
& 44 & 26.3 & 85.0 & 69.5 & 41.2 \\
& 45 & 31.6 & 81.4 & 74.3 & 60.3 \\
& 46 & 38.0 & 82.8 & 76.1 & 64.8 \\
& 47 & 40.9 & 72.6 & 68.0 & 63.6 \\
& 48 & 38.2 & 53.1 & 42.9 & 43.1 \\
& 49 & 36.1 & 53.5 & 40.6 & 43.2 \\
\hline & & & &
\end{tabular}

Desorption occurs when the vapor pressure of the silica gel is higher than that of the hot air. During desorption the air temperature decreases while passing the adsorbent chamber. The measured differences in input and output air temperatures over the silica chamber show that indeed energy is used to release water from the silica gel and confirm desorption. Desorption results are also shown in Table 5.6, which show that the total initial weight of the silica gel in the three adsorbent holders was $31.5 \mathrm{~kg}$. During air dehumidification in the night the weight increased to a total of $40.1 \mathrm{~kg}$, thus $8.6 \mathrm{~kg}$ water is adsorbed from the air, representing $27.3 \%$ of the original weight of adsorbent. On the first, second and third days of regeneration the total weight of silica gel were $38.8,38.65$ and $38.57 \mathrm{~kg}$ respectively. This consist of $1.30,0.15$ and $0.08 \mathrm{~kg}$ each for the three days equivalent to a total of $1.53 \mathrm{~kg}$ representing $18 \%$ of the amount of water adsorbed over the three day period (See Table 5.6). Most of the adsorbed (15\%) water is removed on the first day alone, the second and third day contribute hardly to the regeneration. 
Table 5.6 Regeneration data over three days period

\begin{tabular}{lccc}
\hline Day & $\begin{array}{c}\text { Mass of silica } \\
\text { gel }(\mathrm{kg})\end{array}$ & Water loss $(\mathrm{kg})$ & $\begin{array}{c}\text { Regeneration } \\
\text { rate }(\mathrm{kg} \text { water } / \mathrm{h})\end{array}$ \\
\hline 0 & 40.1 & 0 & 0 \\
1 (6 hours) & 38.8 & 1.3 & 0.216 \\
2 (6 hours) & 38.65 & 0.15 & 0.025 \\
3 (4 hours) & 38.57 & 0.08 & 0.020 \\
\hline
\end{tabular}

The water loading of $27.3 \%$ after night drying corresponds to the sorption isotherms for silica gel at $30^{\circ} \mathrm{C}$ and $30 \% \mathrm{RH}$ (Boxtel et al., 2012). The regeneration results, however, were below the expected values. The discrepancy is for a major part explained from the experimental data. The silica is weighed at the end of the day when silica is in equilibrium with the conditions at that moment, i.e. $40-50^{\circ} \mathrm{C}$. The silica gel sorption isotherms show that the water loading capacity of silica ( $\mathrm{kg}$ water $/ \mathrm{kg}$ silica) at $50^{\circ} \mathrm{C}$ and $30 \% \mathrm{RH}$ is around $10-12 \%$, and at $40^{\circ} \mathrm{C}$ around $18 \%$ indicating that temperature has an effect of the regeneration rate as reported by Sukhmeet and Parm (1997). The potential for water desorption is the difference between the loading after night drying and the water loading at the end of the day. The best moment to stop regeneration is achieved around the peak temperature $\left(80^{\circ} \mathrm{C}\right)$ with a water loading capacity of about $3 \%$ and thus a much larger difference with the loading at the end of the night drying. So the end of the day is not the most effective, moment to stop the regeneration. As all days end at about $40-50^{\circ} \mathrm{C}$, it is clear why the adsorbent is hardly regenerated over the second and third day.

Another reason for the discrepancy is due the role of the air-silica contact on the regeneration, which might have been impeded by the void volumes between the silica gel particles. In the experiment it was observed that in the silica gel some air channels started to appear. The resulting lower air-silica contact limits the regeneration capacity. This problem is also noted by Bhool et al. (2014) who noted that the regeneration rate was not only dependent on solar intensity (high temperature) but on other factors such as airflow rate. Moreover, Pramuang and Exell (2007) observed that the regeneration of silica gel is more strongly dependent on the air flow than on the solar radiation. Therefore further improvement in the regeneration system is required in such way that the regenerating air should flow with good contact through the bed of silica. This can be achieved by placing the silica gel in thin layers in trays and blowing the hot air from the bottom side beneath the trays.

The experiment indicates that partial regeneration of the silica gel is possible using the solar collector system though some improvements in the design of the silica gel bed, operation strategy and optimization of the stop time of regeneration are required to remove more adsorbed water. 


\subsection{Conclusion}

This work sought to quantify the yam drying performance in a solar adsorption dryer (SAD) compared to a solar dryer (SD) and open sun drying (OSD) and to validate the effect on vitamin $\mathrm{C}$ and composition retention in these three systems. The dryer performance, vitamin $\mathrm{C}$ retention and product color of different cultivars as well as the ability of the system to regenerate the adsorbent were conducted.

The SAD drying works the best in the initial period of drying. In this period the night contributes to drying and reduces the total drying cycle in terms of days due to the application of night drying. At the end of drying, the benefit of night drying is minor due to the low driving force for water transfer. At this stage, dehumidification of the air hardly helps the drying at night. In this period an elevated temperature is more effective. The drying time in the SAD is affected by seasonal variations and weather conditions.

For three cultivars, Lilii dried faster than Pona and Dente with Dente drying slowest, which results from the differences in granule shape and sizes of these cultivars. SAD helped in maintaining the original whitish color of yam better than the other drying methods. Long exposure of yam to drying conditions had more influence on the deterioration of vitamin $\mathrm{C}$, but did not affect the composition. The deterioration of vitamin $\mathrm{C}$ is the strongest for OSD, and is close for SD and SAD drying with a preference for SD.

The applied solar collector provides a sufficient high temperature for regeneration. However, the temperature at which regeneration is stopped has to be optimized towards the highest temperature at a day to remove more water from the adsorbent. Moreover, a good and equal flow pattern of air through the adsorbent bed is required for the air-adsorbent contact. 
Chapter 6

Perspectives, reflections and conclusion 


\subsection{Introduction}

Yam is an important food crop in Ghana which has many uses. Due to the high moisture content when harvested it is susceptible to spoilage and a limited shelf life. Drying is therefore required to increase the shelf life but affects some quality parameters such as vitamin $\mathrm{C}$ and color. To preserve the nutritional components, low drying temperatures and short exposure are desirable. The solar adsorption dryer system (SAD) can be used to dry yam cubicles day and night. After drying the yam is milled into powders and incorporated into other food products such as soups, weaning foods and bread. For drying and storage purposes the sorption isotherms of yam, in addition to the drying characteristics need to be studied with a focus on moisture dependent shrinkage and moisture diffusivity.

Drying requires high amounts of energy for its operation. Electricity and fossil fuel heating are cost intensive and result in unwanted $\mathrm{CO}_{2}$ exhaust. Fuel wood could be an option but leads to desertification and erosion, and this option must be rejected. The sun's energy is free and its application in terms of solar energy technology for heating agricultural products is inexpensive. Open sun drying is mostly practiced in Ghana, though solar drying in a confined chamber has no contamination from the environment and can be performed under controlled conditions and is therefore preferred for good food quality. Solar drying (SD) at night is not possible and typically leads to rewetting unless hermetically packaged. Solar adsorption drying (SAD) is a new system that can continue with night drying with humidifier air, by lowering the moisture content and boosting the temperature of the drying air by passing it over an absorber prior to entering the dryer, thus preventing rewetting and reducing the drying cycle. However, night drying requires the adsorbent to be regenerated.

A 3-dimensional drawing of the solar adsorption drying system is shown in Figure 6.1. In this thesis the principle and performance of the solar adsorption system was experimentally explored and analyzed in order to assess the feasibility of SADS for drying of yam. Investigations were centered on: the sorption properties of yam; drying kinetics of yam; design of the solar collector system; proof of principle of solar adsorption drying and comparing with solar drying and open sun drying; and the effects of solar adsorption drying on product quality. 


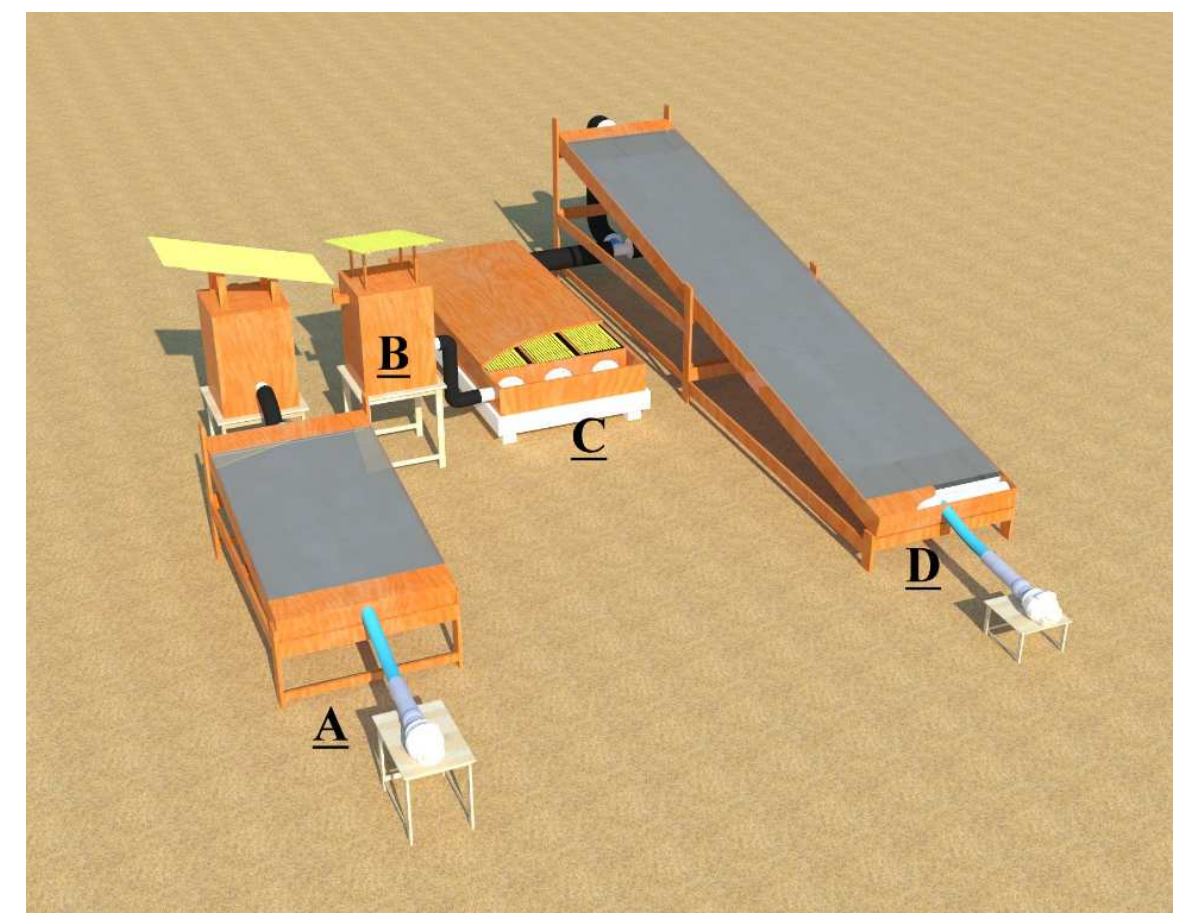

Figure 6.1 Solar adsorption and confined solar dryer system. Collector system for drying (A), drying chamber (B), adsorbent chamber (C) and Collector system for regeneration (D).

\subsection{Sorption isotherms}

Knowledge of the sorption isotherm is essential for food product storage especially when dried. The method for the sorption determination has an effect on the accuracy. Sorption curve determinations that use saturated salt solution does not provide accurate information to obtain a complete sorption curve. A Dynamic Vapour Sorption (DVS) analyzer, which is very sensitive to micro changes in weight loss during dehydration or rehydration, was used in this work. Some scanty information was available for yam which needed an update. The various models for describing the equilibrium moisture content in relation to water activity at different temperatures were extensively considered. Some works in the literature have been restricted to desorption or adsorption alone as reported in the work of Andrade et al. (2011), Montes et al. (2009) and Saad et al. (2014)). In the current work (Chapter 2) experimental equilibrium moisture isotherms for yam at temperatures of $25^{\circ} \mathrm{C}$ and $50^{\circ} \mathrm{C}$ and over a range between $0-$ 0.85 water activity, both for adsorption and desorption were observed.

Hysteresis between adsorption and desorption was observed, but it was larger at $25^{\circ} \mathrm{C}$ than at $50^{\circ} \mathrm{C}$. The occurrence of the hysteresis is that, during desorption, some solutes may supersaturate below their crystallization water activity and thus hold more water at desorption compared to adsorption (Miguel-Aguilera and Stanley, 1999, Barbosa-Canovas et al., 2007). While hyteresis depends also on shrinkage, the capillary condensation, and the swelling ability of product, the presence of capillaries in food results in considerable decrease in water activity (Raji and Ojediran, 2011). The level of supersaturation determines the level of hysteresis. Also increasing the temperature, at a constant water activity, may lead to decrease in the equilibrium 
moisture content (EMC) which is in contrast to the findings of this work where temperature did not affect EMC during desorption. The no temperature effect on EMC at constant water activity may be due to minimal change in solubility of solute, low dissociation of water and minimal enthalpy of water binding at the temperatures of $25^{\circ} \mathrm{C}$ and $50{ }^{\circ} \mathrm{C}$ for yam. Recent findings by Montes et al. (2009) on yam (Dioscorea rotundata) between temperatures of $45^{\circ} \mathrm{C}$ and $55^{\circ} \mathrm{C}$ supports this assertion.

A decrease in equilibrium moisture content for increased temperature at the same water activity (water content that does or does not support the growth of microorganisms) has been reported (Saad et 2014, Kiranoudis et al., 1993). Ronald et al. (2005) reported an insignificant difference in EMC for temperatures of 30 and $40{ }^{\circ} \mathrm{C}$ between water activity range of $0-0.4$ during desorption of Ziziphus spinachristi leaves. In the present work a change in water activity of $0.15-0.65$ results in 0.093 ( $\mathrm{kg}$ water $/ \mathrm{kg}$ dry matter) increase in moisture content. Therefore yam powders must be properly sealed during storage to avoid rewetting.

The parameters and their uncertainty range for each of the models (GuggenheimAnderson-de Boer (GAB), Henderson, Halsey, Oswin, Smith, Brunauer-Emmett-Teller (BET) and Peleg were estimated, where objective criteria were used to select the model that best describes the experimental desorption and adsorption isotherms over the relevant range of moisture contents. The Peleg, Oswin and GAB models were found to be most suitable for describing the experimental equilibrium moisture contents of yam (Dente) of both desorption and adsorption based on the standard error of prediction. The lowest Akaike Information Criterion (AIC) for sorption makes the Oswin model the most appropriate when it is needed to describe wetting of a product. Though the Peleg and GAB models had the larger number of parameters, the low AIC values at desorption make them good candidates for drying. The GAB having physiological background and fewer parameters than that of Peleg makes it preferable. On the other hand the GAB is not usually utilized beyond water activity of 0.93 (Andrade, 2011). It thus underestimates the moisture content values at high water activity $\left(a_{w}\right)$ levels $\left(a_{w}>0.93\right)$. The GAB model is made up of mono-molecular layer and multilayer adsorption layer, whereas that of the Peleg model, does not have a monolayer component. The Peleg model is deficient in explaining structural water (H-bonded water) and water which is sorbed by the hydrophilic and polar groups (polysaccharides, proteins, etc.) in foods (Mujumdar, 1980).

The present study did not consider intermediate temperatures between $25-50^{\circ} \mathrm{C}$, nor did it consider temperatures beyond $50^{\circ} \mathrm{C}$, to ascertain the temperature effect on equilibrium moisture content at constant water activity. For example, in this study the monolayer moisture constant $\mathrm{C}_{1}$ and the adsorption constants $\mathrm{C}_{2}$ and $\mathrm{C}_{3}$ which are related to the energies of interaction between the first and the further sorbed molecules at the individual sorption sites at $25^{\circ} \mathrm{C}$ and $50^{\circ} \mathrm{C}$ respectively gave values that are not temperature dependent. A vast difference exists between the parameters of the present study and that of Montes et al. (2009) for yam at $70^{\circ} \mathrm{C}$ (see Table 6.1). Since $\mathrm{C}_{2}$ and $\mathrm{C}_{3}$ are related to the enthalpies of interaction between the multilayers of sorbed molecules, it would have been appropriate to establish the relationship 
between these constants and temperature using the Arrhenius equation. However, the limitation is as a result of using only two temperatures for the work. A linear curve using the Arrheneus equation, could not be established with two points. The measurements at two temperatures, however, do satisfy for drying purposes where drying occurs at temperatures in the midrange $40-60^{\circ} \mathrm{C}$.

The sorption isotherm model of yam is a tool for designing drying equipment, and for studies on shelf-life, packaging and storage. In packaging, water activity range at a particular temperature range helps to predict the equilibrium moisture content that is suitable for long storage life. Yam floor producers and the yam floor packagers will now know at what range of relative humidity to store their products in order to expect a good equilibrium moisture content that will inhibit the growth of microorganisms.

Table 6.1 Parameters of the present work by applying the GAB model at different temperatures compared to that of Montes et al. (2009) for Yam (Deouscorea rotundata)

\begin{tabular}{ccccc}
\hline & \multicolumn{3}{c}{ Parameter } & \multirow{2}{*}{ Reference } \\
\cline { 2 - 4 } Temperature $\left({ }^{\circ} \mathrm{C}\right)$ & $\mathrm{C}_{1}$ & $\mathrm{C}_{2}$ & $\mathrm{C}_{3}$ & \\
\hline 25 & 0.0755 & 10.657 & 0.8152 & \\
50 & 0.0827 & 10.126 & 0.7578 & Amankwah et al. (2017) \\
70 & 0.136 & 0.448 & 2.111 & Montes et al. (2009) \\
\hline
\end{tabular}

\subsection{Drying kinetics of shrinking yam cubicles}

Cranks approximation of diffusion (Crank, 1975) helps to understand the drying behavior of food particles. The equation concerns a series expansion of Fick's diffusion equation for products with a uniform moisture distribution at the start of drying. The equation is often applied in semi-empirical drying models by using one term of the series expansion. Moreover, the use of the Cranks equation is limited to infinite and non-shrinking slabs. These conditions do not exist in practice since most food particles are limited in their dimension and are accompanied with shrinkage during drying. A CFD investigation in this thesis conducted on the error made by assuming finite yam cuts resulted in a higher value of effective coefficient of moisture diffusivity. Also incorporation of shrinkage with the fractal approach helped to solve this problem. The drying curves were fit, and the results were graphically evaluated by the curve of drying rate as a function of moisture ratio which is not very common. The present work is thus a significant contribution in view of literature.

Chapter 3 clearly indicates that there exist moisture content dependent shrinkage and diffusivity. It therefore suggests that empirical and semi-empirical models are a gross simplification for explaining the moisture removal of food particle during drying as practiced by other researchers (Saeed et al., 2006), Doymaz, 2005b, Yaldiz and Eterkin, 2001). This work indicates that using the drying curve alone to understand the drying behavior of food products is not only deceptive but also inaccurate. It is therefore concluded that observing both the drying curve and the drying rate curves result in a better interpretation and of the drying 
behavior. In fact, while the drying curve may show a close relationship between the observed and model data with good statistical model performance, the drying rate curve may still be showing a considerable error between them. It is therefore recommended to rather examine the drying rate as a function of moisture ratio and the drying curve for predicting the drying behavior of food particles. The present work, which is based on Fick's diffusion equation and distinct from other models (Yilbas et al., 2003; Yadollahinia and Jahangiri, 2009; Al-Muhtaseb et al., 2004; Hassini et al., 2007), opens new directions (for other food products) and for researchers to focus their attention on.

The modification of the Crank's analytical approximations of Fick's diffusion equation in moisture dependent diffusion and shrinkage of yam drying is advantageous since it has a potential for application to a wide spectrum of processing conditions (temperature, moisture, thickness, etc.). In this approach, drying of finite sized particles with fractal shrinkage is accurately described. Hitherto the conditions for validity of Crank's approximation did not allow that. This approach can be applied in a multi-purpose decision making in an industrial setting for process design. However, the current semi-analytical description does not immediately provide a suitable kinetic model that can be used in dynamic models for drying under variable conditions. Further research on how exactly this information can be used for design and optimization of SADS is needed. Probably, CFD models in 3-D with moisture dependent moisture diffusivity and particle size, for which this chapter gives solutions, may be of help.

\subsection{Solar collector}

Most researchers construct collectors and see what happens, whereas others do not link to dryers, since the output temperature of the collector has not been considered as a critical issue. To overcome these issues, a Duffie and Beckmann (1991) model based approach was used for the design and construction of the collectors for the product to be dried and the adsorbent to be regenerated. This is in contrast to empirical designs. The Duffie and Beckman model needed some assumptions and lumping of parameters to reach analytical solutions. In this work some modifications in the Duffie and Beckmann equations have been made to cancel these approximations and to solve the system numerically by applying a spatially distributed model. This model approach resulted in collector lengths of 1.5 and $4.5 \mathrm{~m}$ for drying and regeneration respectively as shown in the design schemes Figures $6.2-6.4$. Through a manual switch system (see Figure 6.5), the adsorbent - dryer system either functions as air dehumidifier at night or adsorbent regeneration system during the day by blowing ambient air through the a bed of adsorbent. In figure the insert shows an expanded form of the manual switch, where cups are used to disengage either air flow from the regenerator during the night or from ambient air during the day. 


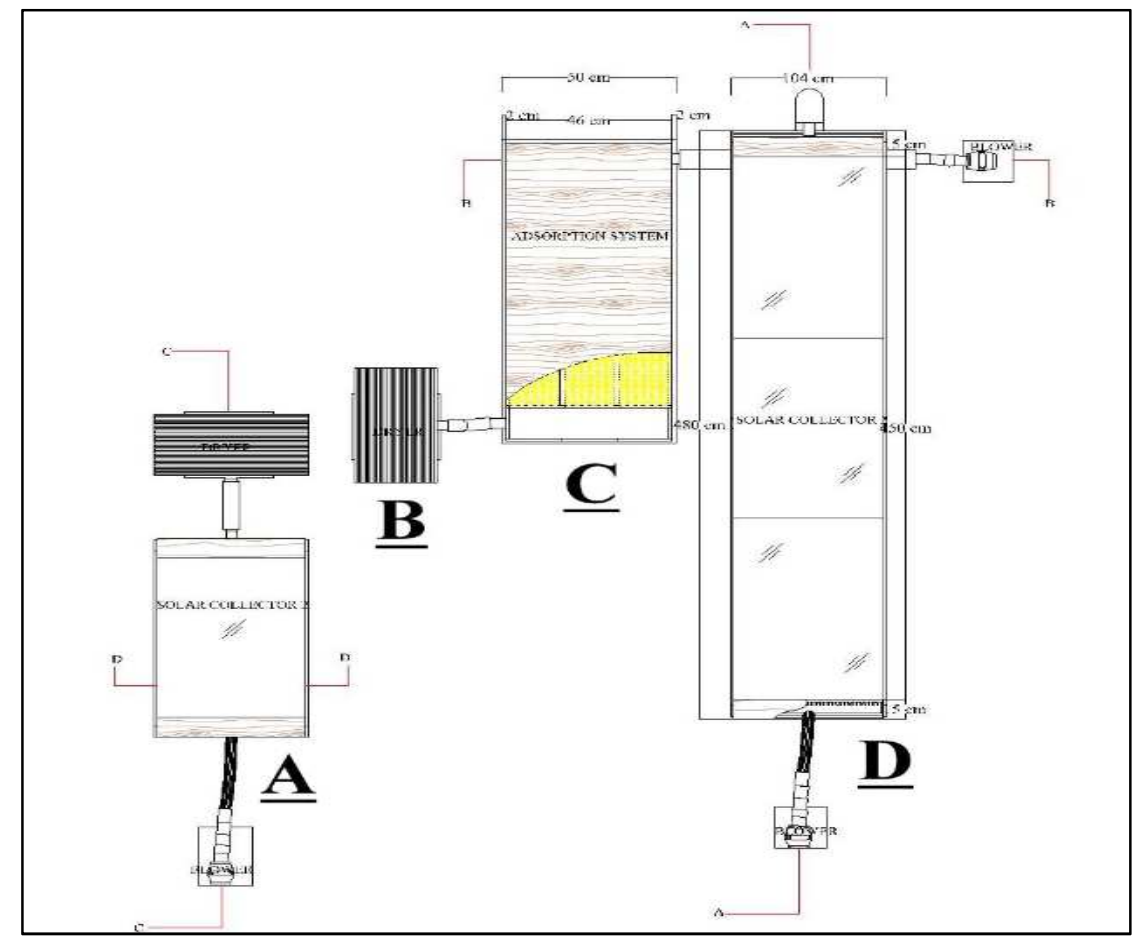

Figure 6.2 Plan of solar adsorption system. There is a solar collector for drying (A), drying cabinet (B), adsorbent holder (C) and solar collector for regeneration (D).

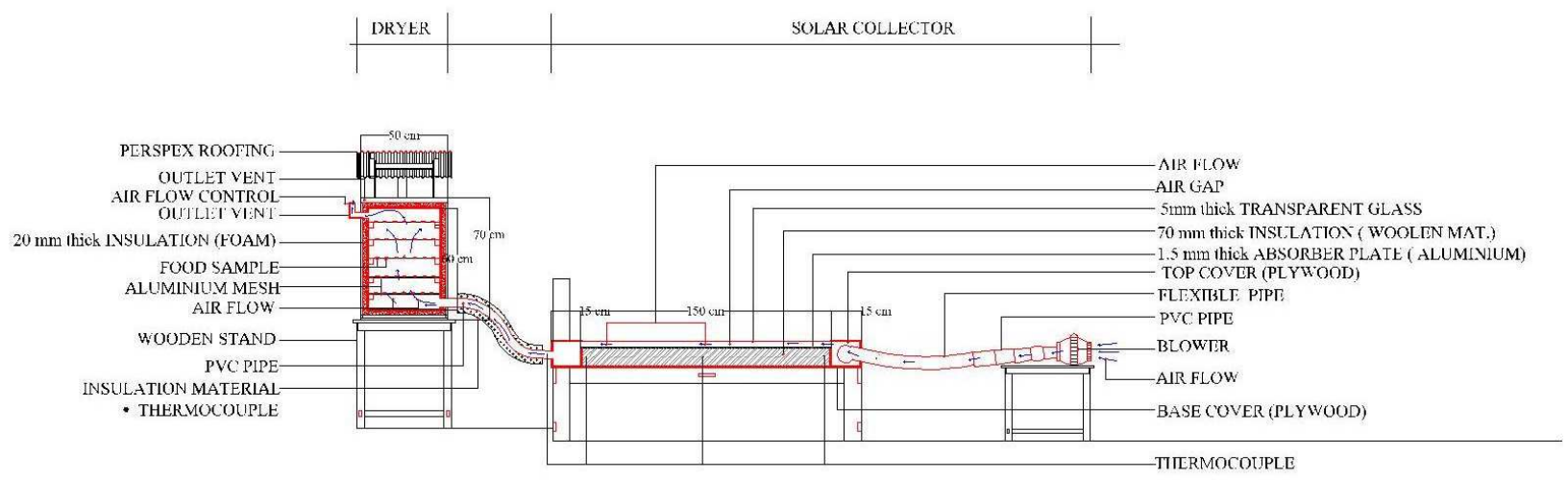

\section{SECTION C-C}

Figure 6.3 Cross sectional dimension of the collector and drying chamber. 


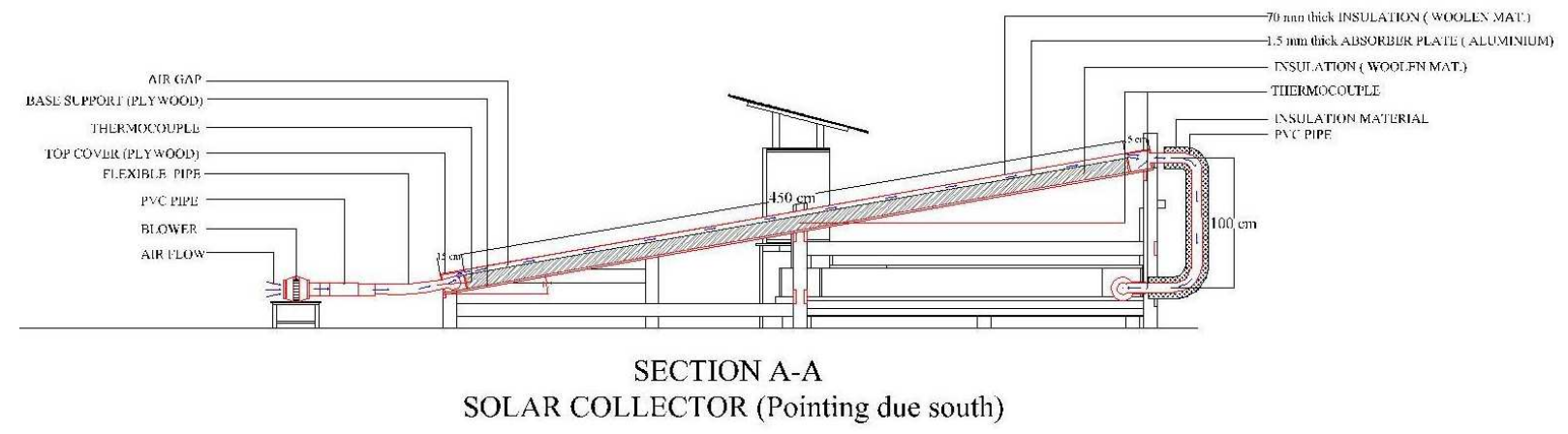

Figure 6.4 Cross sectional dimension of the collector for adsorbent regeneration.

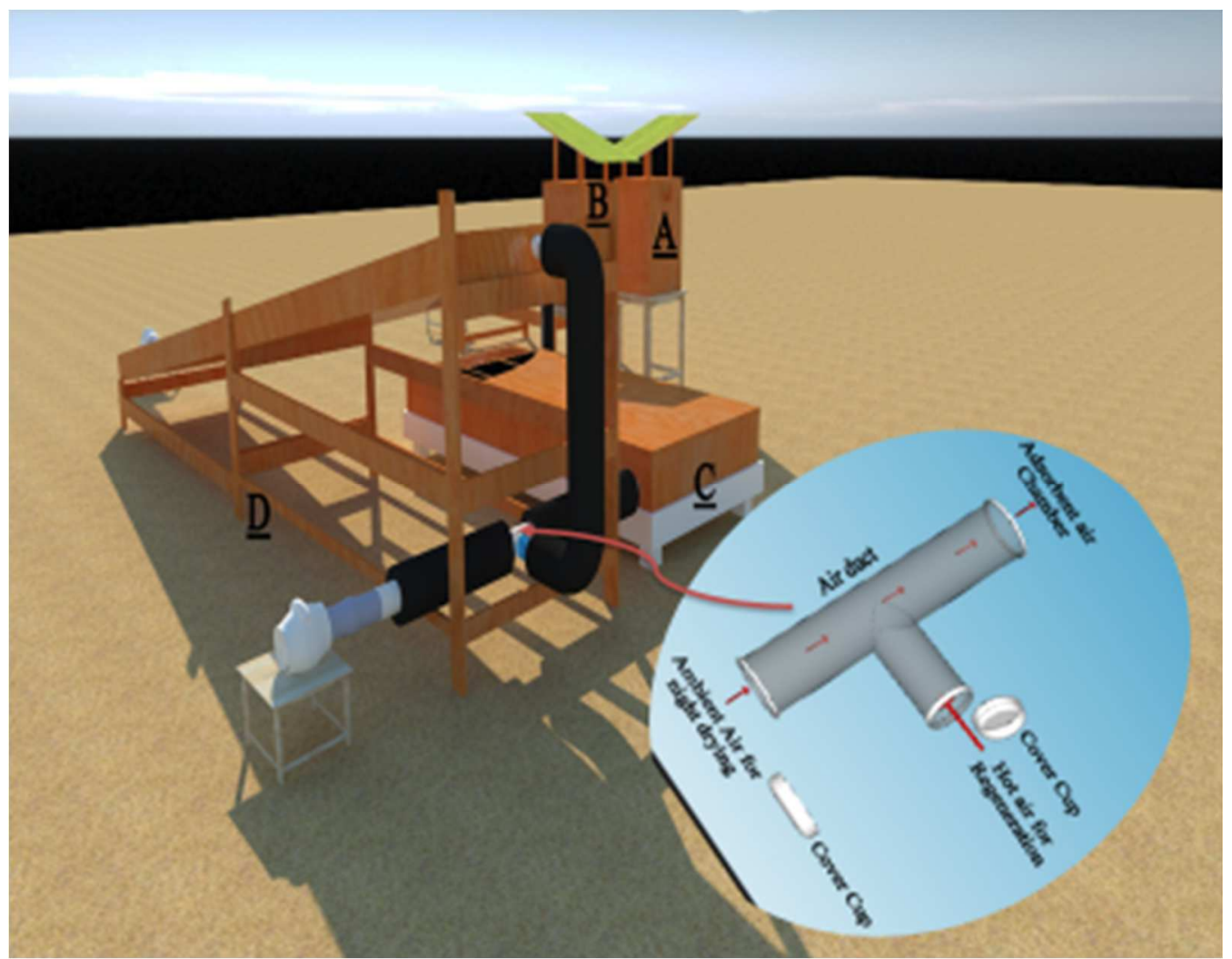

Figure 6.5 Plan of solar adsorption system. There is a solar collector for drying (A), drying cabinet (B), adsorbent holder (C) and solar collector for regeneration (D). Insert is the manual switch system.

The first step in the design of SADS was to develop a spatially distributed model of coupled partial differential equations which could find, for different dimensions of collectors and using Ghana's radiation conditions, the output air temperature which fits to the drying of agricultural products and also the temperatures needed for adsorbent regeneration (Chapter 4). This model makes it possible to determine the spatial mean temperature of the absorber plate, a requirement for obtaining the overall heat loss coefficient which was difficult in calculating in the Duffie and Beckmann approach. The study results show that the operational overall heat loss coefficient (which is a strong function of the air velocity and collector length), radiative and convective heat transfer coefficients (which are weak functions of the air velocity and collector length) vary significantly during the day in contrast to time invariant values reported by Gao 
et al. (2007). The collector performance is a function of the collector length. Though increased collector length leads to input energy, the passage of air through the collector, bring closer the air and plate temperatures decreasing the driving force of heat transfer between them. As a result, the heat gain increases disproportionately with collector length, in comparison with decreased thermal efficiency and increased overall heat loss coefficient. On the other hand the plate and glass cover temperatures vary significantly during the day but are weak functions of the collector length. It is thus recommended, that solar collectors must not be designed based on a general number of the heat loss coefficient and that constant values are gross simplifications.

There are some limitations that may need attention. Uniform air distribution on the absorber plate is difficult to ascertain, even though a T-joint pipe with perforations receives and passes the inlet air over the plate. To solve the issue of uniform airflow, the perforations could be tapered from the ends towards the middle (joint). More air will then reach the outer section over the absorber plate.

Since the collector parts are made of wood and especially the $4.5 \mathrm{~m}$ collector which is supported on an angle iron frame to prevent it from sagging, the structure of the collector system is heavy, thus exerting so much pressure on the supporting stands. This sometimes leads to total collapse of the setup and damage of the glass cover. Light materials such as aluminum moldings which is affordable and available, could be used for the main structure and frame. The weight of the structure will then drastically be reduced. More jobs will be created by diversifying the use of aluminum sheets.

The mathematical model tool is suitable for design optimization. The model also provides the required collector length for Ghana's radiation conditions, given the temperatures allowed for the product and the temperatures needed for regeneration. Specifically, a collector length of $1.5 \mathrm{~m}$ gives drying temperatures suitable for drying agricultural products at air speed of $0.5 \mathrm{~m} / \mathrm{s}$. Likewise a collector of $4.5 \mathrm{~m}$ length at an operational air speed between $0.2-0.5 \mathrm{~m} / \mathrm{s}$ is suitable for adsorbent (silica gel) regeneration. The model output is close to the experimental data in predicting the output air temperature for both 1.5 and $4.5 \mathrm{~m}$ collector lengths. Further study about heat losses and possible changes in the design is needed to reduce heat losses. All parts that are in contact with heated air must be insulated.

\subsection{Experimental verification and proof-of-principle}

Chapter 5 concerned the proof of principle of solar adsorption drying (SAD) in comparison to solar drying (SD) and open sun drying (OSD). The proof of principle concerned the duration of drying cycles, vitamin $\mathrm{C}$ retention, composition and colour and drying of three yam different cultivars. Moreover, the regeneration ability of the solar collector system was evaluated. Three type of experiments were performed: 


\section{1) Proof of principle of $S A D$ and its benefits compared to $S D$ and $O S D$}

A dryer that gives a specific final moisture content at the shortest possible time would be a better option. The findings indicate that SAD gives the shortest drying cycle but due to night drying the product is longer exposed to drying conditions whereas the OSD dried slowest and had the highest final moisture content within the allotted time. Adsorption drying is effective at the early stages of drying after which elevated temperatures which cannot be achieved during the night or longer duration of drying are required to remove water when the moisture content of the samples get gradually lower. The SAD system is thus a better option in terms time cycle. It can therefore be said that, a system that needs a longer time to reach not even the target moisture content, is inferior from the point of view of throughput.

\section{2) Effect of SADS on quality of different yam cultivars}

As a result of the longer exposure to drying conditions in SAD, vitamin C degraded slightly (not much) more compared to SD. SAD preserved the whitish color of yam better than the other methods whereas OSD gave the worst performance on vitamin $\mathrm{C}$ and color, though all the drying methods significantly affected vitamin C content. In this work between $80-90 \%$ vitamin $\mathrm{C}$ reduction occurred.

With regard to the cultivars (Pona, Lilii and Dente), Lilii dried fastest and Dente slowest across all methods which may be due to differences in the molecular structure of the different yam matrix. Generally the drying method do not affect the proximate composition (Hsu et al., 2003) though there is marginal increase in fiber and decrease in protein composition between fresh and dried samples due to an increase in insoluble dietary fiber content by complexing with protein and amino acids (Matalas et al., 2001). No obvious trend in variability among the values of cultivars is found. The two seasonal variations in weather and pre-history of yam cultivar affected the drying rate especially of Dente cultivar which dried slowest.

\section{3) Regeneration of silica gel.}

The solar collector performance was according to the design and is satisfactory for regeneration of the silica gel, but further work is needed to understand the recovery rate, and to optimize the system. Silica gel requires between $50-150^{\circ} \mathrm{C}$ for regeneration. In this work the target temperature was between $70-80^{\circ} \mathrm{C}$. In the adsorption drying experiment (rehydration of adsorbent), over three days, the sorbent adsorbed up to $27.3 \mathrm{w} \%$ of moisture per the original weight of the adsorbent. The regeneration experiment removed (desorbed) up to $18 \mathrm{w} \%$ of water adsorbed during the adsorption drying process, in three days, of which $15 \mathrm{w} \%$ occurred on the first day. On the second and third day, hardly was water removed. It is expected that more water was regenerated at the peak temperatures, but at that moment, no measurement was taken. For a typical silica gel sorption isotherm at $50^{\circ} \mathrm{C}$ and $30 \% \mathrm{RH}$ the loading capacity is between $10-12 \%$. However, at $80^{\circ} \mathrm{C}$ the water loading capacity reduces roughly to about $3 \%$. In view of this difference, and assuming that equilibrium is reached fast in the adsorber, it may perhaps be best to stop the regeneration at the highest temperature of the day. Bhool et al. (2014) and Pramuang and Exell (2007) reported that the regeneration rate is not entirely 
dependent on solar radiation but also the air flow. In the present design, the air is impeded by the small interspace between the bed of particles of silica gel making it difficult for air flow to pass and to transfer heat to adjacent particles by conduction. Redesign of the regeneration system is paramount to expose the hot air to thin layer of adsorbent.

\subsection{Perspectives of SADS (in Africa and elsewhere)}

For the farmer's use, a scale-up is necessary. The farmers who are categorized as families, groups and small and medium scale enterprises (SME) in order of financial strength, dry for home consumption, for the local market or for export, respectively. Women groups who dry unsold products of dry fruits and vegetables can take advantage of this confined solar dryer system, which produces hygienic and wholesome products - a prerequisite for the Food and Drugs Authority giving approval for samples to be consumed or exported. Also SMEs can explore this system to hygienically dry and package their produce such as processed tubers, cereals, mangoes, pineapples, bananas, ripe and unripe plantain, coconut fruit, and etcetera for the international market. The SMEs often obtain technical and financial support from government and/or non-governmental organizations and have the purchasing power even beyond $\$ 4000$ per dryer for SAD inclusive of a solar dryer house of $2.5 \times 4 \times 2.5 \mathrm{~m}$ size. With little financial and technical support, this dryer system can be maintained between 7-10 years without any major renovation. When production is to be increased several copies of same dryer system may be needed. Also a combination of direct and indirect solar dryer house system is proposed as shown below to dry cocoa, ginger, cassava, yam etc., as against the traditional method for drying in the open sun. For a direct solar dryer, the solar radiation is directly incident on the food material, whereas hot air is blown from a solar collector duct and channeled into a drying chamber for the indirect dryer system. Thus, with a combination of redesigned adsorption system, the benefit of reducing the drying cycle is achieved. The integrated approach of combined direct and indirect solar adsorption dryer system cost within the neighborhood of $\$ 5000-\$ 10000$ depending on the size between $60 \mathrm{~m}^{3}$ and $125 \mathrm{~m}^{3}$ and 2 4 tons capacity of the integrated system for a drying period of 3 to 5 days.

Thus, with some modification in the adsorption system, as mentioned above the solar adsorption dryer system can be built and operated in many agricultural farms and close to silos and warehouses in Ghana. Meanwhile, further detailed economical study would be worthwhile.

After the investigations of the sorption properties of yam, drying kinetics of yam, design of the solar collector system, proof of principle of solar adsorption drying and the effects of solar adsorption drying on product quality, some limitations have been adduced above: To this end the following are further research that need to be considered. 
- The universal application of the modified Crank equation into a moisture dependent fractal shrinkage and moisture diffusivity model for drying kinetics of other food materials.

- Use of cheaper sorbent such as clay can be investigated.

- A model-based optimization of the design, at different geographical solar conditions to simplify the equation.

- Model-based optimization of the operation of the system in an attempt to reduce the error between the model data and observed data.

- Thorough investigation to handle and to incorporate differences characteristic attributes between yam cultivars in drying equation.

\subsection{Conclusions}

The sorption isotherm model of yam is a tool for designing drying equipment, shelf-life studies, and packaging and storage investigations. From this work, the equilibrium moisture content can be predicted while monitoring storage life. This means that the close environment of stored packages can be controlled to maintain moisture content that will not support microbial growth. For the desorption isotherm, temperature had no effect on equilibrium moisture content at constant water activity which is contrary to what has been reported in literature. Yam powders must be stored well since a change in water activity between 0.15 to 0.65 leads to a significant change in equilibrium moisture content. The Peleg, Oswin and GAB models were found to best describe both desorption and adsorption processes, whereas using the Akaike Information Criterion (AIC) which takes into account, the number of parameters, makes the Oswin model the most suitable for wetting of yam. In the same way, for drying, the Peleg and GAB models were the best. They had the larger number of parameters, the lowest AIC values. In the end the GAB was preferable since it had physiological meaning and fewer parameters than that of the Peleg.

The modification of the Crank's analytical approximations of Fick's diffusion equation with moisture dependent diffusion and shrinkage has potential for application to a wide spectrum of processing conditions. Real life situational drying practices could be achieved in practice, since moisture dependent fractal shrinkage and diffusivity is factored in the modified model. Drying rate as a function of moisture ratio, establishes a better relationship between observed and modeled data. Here, a finite sized particle with fractal shrinkage is a possibility. Hitherto the conditions of Crank did not allow that. In process design in an industrial setting, a multipurpose decision can be made using this spatially distributed model.

A spatially distributed model for the solar collector is available and can be used to design and construct solar collectors for drying of agricultural products in Ghana and regeneration of adsorbent. The model can foretell the collector length that is needed to achieve the required output temperature of the collector. In combination with adsorbent system, drying is extended 
to the night preventing rewetting. In this work the mean plate temperature was estimated, a prerequisite for the determination of the overall heat loss coefficient. It has been shown in this work that outlet air temperature increases with collector length but limited to some extent. The difficulty in calculating the overall heat loss coefficient as alluded to by Duffie and Beckmann is not a problem in this model, whereas the heat removal factor, collector efficiency and heat gain could be predicted with this spatially distributed model. Hitherto experimental work was requite. Meanwhile, assuming a constant value of the overall heat transfer coefficient is over simplification and leads to inaccurate predictions. It is indicative that the plate temperature, glass temperature and radiative and convective heat loss coefficients can be lumped together as constants along the collector length. The operational air velocity affects the overall heat loss coefficient, heat gain and efficiency.

A quick removal of water especially on the first days is indeed a sure bet to maintain the original color of food product. The extent of water removed from adsorbent depends on the regeneration temperature. SAD systems helped to reduce the drying cycle compared to the SD and OSD systems. Product dried with SAD maintained the white color of the yam better than the other methods whereas its dried samples had a little lower vitamin C content than that of the SD. The OSD was worse in terms of maintaining original color and vitamin $\mathrm{C}$ content. This research showed that different cultivars of yam from the same variety ( $D$. rotundata) dried at different rate, Dente drying at the slowest rate while Lilii dried at the fastest rate. The solar collector for the regeneration operated according to the design but the measured rate of regeneration was low as a result of low temperature at end of dehydration. Therefore regeneration must end at the highest temperature of the day assuming that equilibrium is reached fast in the sorbent.

With some modification in the adsorption system the solar adsorption dryer system as investigated in this thesis can be built and operated in many agricultural farms in Ghana. The SAD hold promise to boost high throughput. 
7.0 References 
AACC (2000). Approved Methods of the AACC, 10th edn. Methods 44-17, St. Paul, MN: American Association of Cereal Chemists.

AOAC International Official methods of analysis. (1990). Gaithersburg, MD. (17) Method, 985.14.

Aguilera, J.M., and D.W. Stanley. 1999. Microstructural Principles of Food Processing and Engineering. Aspen Publishers INC. Gaithersburg Maryland.

Agunbiade, S.O., Olranlokun, J.O. and Olaofe, O.A. (2006). Quality of chips produced from rehydrated, dehydrated plantain and banana chips. Pakistan Journal of Nutrition, 5 (5): 471473.

Ah-Hen, K.,Zambra, C.E.,Aguëro, J.E.,Vega-Gálvez, A.,Lemus-Mondaca,R. (2013) Moisture diffusivity coefficient and convective drying modeling of murta (Ugni molinae Turcz): Influence of temperature and vacuum on drying kinetics. Food and Bioprocess Technology 6(4): 919-930.

Akpinar, E.K., Midilli, A., Bicer, Y. (2003b). Experimental Investigation of Drying Behaviour and Conditions of Pumpkin Slices Via A Cyclone-Type Dryer. Journal of the Science of Food and Agriculture, 83: 1480-1489.

Akuffo, F.O. (1991). Climatic data for solar and wind energy application in Ghana, Ministry of Energy, Ghana, 2, 1-22.

Akuffo, F.O., Brew-Hammond, F.O., Antonio, A., Forson, J., Edwin, F., Sunnu, I.A., Akwensivie, A., Agbeko, F., Ofori, K.E., Appiah, F.K. (2003). Solar and Wind Energy Resource Assessment (SWERA), Energy Commission, Ghana. 1-44.

Alhassan A.Y. (1994). Post-harvest aspects of yam and cassava in Ghana. Consultancy Report, MOFA/GTZ, Ghana.

Al-Muhtaseb, A.H., McMinn, W.A.M., Magee, T.R.A. (2004). Shrinkage, density and porosity variations during the convective drying of potato starch gel. In: 14th International Drying Symposium (IDS), São Paulo, Brazil, vol. C, 1604-1611. Eds. M.A. Silva, Campinas State University, Brazil.

Alvarez, A., Cebaza, O., Muñiz, M.C., Varela, L.M. (2010). Experimental and numerical investigation of a _at-plate solar collector, Energy, 35, 3707-3716.

Amankwah, E.A.Y. Dzisi, K.A. van Straten, G. van Willigenburg L.G. and van Boxtel, A.J.B. Distributed mathematical model supporting design and construction of solar collectors for drying, Drying Technology, 2017, 35(14), 1675-1687.

Amankwah E.A., Ellis W.O., Oldham J.H. (2006). Manufacture of tomato ketchup using the gravity method of concentration. Journal of Ghana Science Association, 8: 63-64. 
Andrade, P.R.D., Lemus, M.R. and Pérez., C.C.E. (2011). Models of sorption isotherms for food: uses and limitations. Vitae, Revista of the Facultad of Química Farmacéutica, 18(3): 325334.

Arata, A. and Sharma, V. (1991) Performance evaluation of solar assisted dryers for low drying temperature applications-Plant description, Renewable energy, 1(5and 6): 729-736.

Arinze, E.A., Adefila, S.S., and Eke, B.A. (1990). Experimental evaluation of various designs of free-convection solar crop dryer with and without thermal storage. Proceeding of National Conference of Nigerian Society of Agricultural Engineers, 15-19.

Asiah, N., Djaeni, M., Hii, C.L. (2017). Moisture transport mechanism and drying kinetic of fresh harvested red onions bulbs under dehumidified air. International Journal of Food Engineering, DOI:10.1515/ijfe-2016-0401.

Atuonwu, J.C., van Straten, G., van Deventer, H.C., van Boxtel, A.J.B. (2011). Improving adsorption drying energy efficiency by simultaneous optimization and heat integration. Drying Technology, 29, 1459-1471.

Atuonwu, J.C., van Straten, G., van Deventer, H.C., van Boxtel, A.J.B. (2010). Modeling and energy efficiency optimization of a low temperature adsorption based food dryer, Proceedings$17^{\text {th }}$ International Drying Symposium, Magdeburg, Germany, 423-431.

Ayensu, A., (1997) Dehydration of food Crops Using a Solar Dryer with Convective Heat Flow.

Solar Energy, 59, 121-126.

Bala, B.K., Morshed, M., and Rahman, M.F. (2009). Solar drying of mushroom using solar tunnel dryer, International Solar Food Processing Conference, Department of Farm Power and Machinery Bangladesh Agricultural University, Mymensingh 2202, Bangladesh, 1-11.

Barbosa-Canovas, G.V. Fontana, A.J., Schmidt, S. J. and Labuza, T.P., (2007). Water activity in foods, Blackwell Publishing Company, Ames, Iowa, USA.

Basuinia, M.A. and Abe, T. (2001). Design and construction of simple three shelf solar rough rice dryer. Journal of Agricultural Mechanization in Asia, Africa and Latin America, 32(3): pp. $54-55$.

Ben Haj Said, L., Najjaa, H., Farhat, A., Neffati, M. and Bellagha, S. (2015). Thin layer convective air drying of wild edible plant (Allium roseum) leaves: experimental kinetics, modeling and quality. Journal of Food Science and Technology, 52(6): 3739-3749.

Berinyuy, J.E., Tangka, J.K., and Fotso, G.M. (2012). Enhancing natural convection solar drying of high moisture vegetables with heat storage. Agricultural Engineering International: CIGR Journal, 14(1): 141-148. 
Bhagoria, J.L., Saini, J.S., Solanki, S.C. Heat transfer coefficient and friction factor correlations for rectangular solar air heater duct having transverse wedge shaped rib roughness on the absorber plate. Renewable Energy, 2002, 25(3), 341-369.

Bhool, R., Kumar, P., and Mehla, A. (2014). Performance evaluation and regeneration of activated charcoal by solar parabolic dish collector. International Journal of Science Engineering and Technology Research, 3(5): pp. 1507-1513.

Boxtel, van A.J.B, Boon, M.A., Deventer H.C. van, Bussmann P.J.Th. (2012). Zeolites for reducing drying energy usage. In Modern Drying Technology, Vol. 4, Energy Savings, Edited E. Tsotsas, A.S. Mujumdar. Wiley-VCH Verlag, Weinheim, Germany.

Brennan, J.G. (2006). Evaporation and drying. In: Handbook of Food Processing, Brennan, J.G (Ed) Wiley-VCH, Weinheim, Germany.

Buzás, J. Farkas, I. Biró, A. Németh, R. (1998). Modeling and simulation of a solar thermal system, Mathematics and Computers in Simulation, 48, 33-46.

Chayjan, R.A., Salari K, Barikloo (2012). H. Modeling moisture diffusivity, activation energy and specific energy consumption of squash seeds in a semi fluidized and fluidized bed drying Acta Sci Pol Technol Aliment., 11(2):131-48.

Chemkhi, S., Zagrouba F., and Bellagi, A. (2005). Modeling and simulation of drying phenomena with rheological behaviour. Brazilian Journal of Chem. Engineering 22 (2): 153163.

Chow, T.T., He, W., Ji, J. (2006). Hybrid photovoltaic-thermosyphon water heating system for residential application, Solar Energy, 80, 298-306.

Chua, K.J. and Chou, S.K. (2003) Low-cost drying methods for developing countries, Trends in Food Science \& Technology, Review, 14, 519-528.

Crank, J. The Mathematics of Diffusion. 1975. Oxford University Press. Oxford.

Davey, M.W., Montagu, M., Inze, D., Sanmartin, M., and Benzie, J.J. Plant L-ascorbic acid: Chemistry, function, metabolism, bioavailability and effects of processing. Journal of Science Food and Agriculture, 2000, 80: 825-860.

Dissa, A.O., Desmoreux, H. Bathiebo, J. and Koulidiatti, J. (2011). A comparative study of direct and indirect solar drying of mango, Global Journal of Pure and Applied Sciences, 17(2): 273-294.

Djaeni, M., Bartels, P., Sanders, L., van Straten, J. and van Boxtel, A.J.B. (2007). Process Integration for Food Drying with Air Dehumidified by Zeolites, Drying Technology, 25. 225239.

Doymaz I. (2004), Drying Kinetics of White Mulberry, Journal of Food Engineering, 61, 341346. 
Doymaz, I. (2005). Sun drying of figs: an experimental study. Journal of Food Engineering, 71: 403-407.

Duffie, J.A., Beckman, W.A. (1991). Solar engineering of thermal processes, John Wiley and Sons Inc. 23-41, 73-74, 95-101.

Duffie, J.A., Beckman, W.A. (1980). Solar Engineering of Thermal Processes, ed 2, John Wiley and Sons, Inc., 23, 73-74, 95-101.

Edjekumhene, I. and Atakora, S.B. (2001). Implementation of renewable energy resources opportunities and barriers, Ghana Country Study, 48.

Eka, O. U. (1985). The chemical composition of yam tubers in Advances in Yam Research. The Biochemistry and Technology of Yam tubers, Vo. 1 ed. Osuji, G. O, published by Biochemical Society of Nigeria in collaboration with ASUTECH, Enugu, pp. 51-75.

El-Beltagy, A., Gamea, G.R., and Essa, A.H.A. (2007). Solar drying characteristics of strawberry. Journal of Food Engineering. 78: 456-464.

Erbay, Z., Icier, F.A review of thin layer drying of foods: Theory, modeling, and experimental results. Critical Reviews in Food Science and Nutrition. 2010, 50:5,441-464.

Erenturk, S., Gulaboglu M.S, Gultekin S. (2005). The effects of cutting and drying medium on the vitamin C content of rosehip during drying, Journal of Food Engineering, 68, 513-518.

Esper, A, and Mühlbauer, W. (1996). Solar tunnel dryer for fruits, Plant Res Development, 44: 61-80. Exell, RHB, Kornsakoo, S. A low-cost solar rice dryer. Appropriate Technology 1978; 5: $23-24$.

Ezekoye, B.A. and Enebe O.M. (2006). Development and Performance Evaluation of Modified Integrated Passive Solar Grain Dryer. The Pacific Journal of Science and Technology Department of Physics and Astronomy, University of Nigeria, Nsukka. 7(2): Enugu State, Nigeria, 185-190.

FAO, (2005). Production Year book, Vol. 55. Collection FAO statistics no. 170. FAO, Rome Italy.

Fagunwa, A.O., Koya O.A. and Faborode M.O. (2009). Development of an Intermittent Solar Dryer for Cocoa Beans, Obafemi Awolowo University, Ile-Ife, Nigeria.

Fellow, P. (2000). Food Processing Technology-Principles and Practice, Second Edition, Wood Head Publishing Limited, Cambridge England, 330.

Fellow, P. (2009). Food Processing Technology: Principles and Practice, Wood Head Publishing Limited, Cambridge, England. 481.

Fioreze, R., and B. Morini. (2000). Yam (Dioscorea sp) drying with different cuts and temperatures: experimental and simulated results. Food Science and Technology (Ciencia e Tecnologia de Alimentos), 20(2): 262-266.

Gálvez, A.V., Aravena, E.L. and Mondaca, R.L. (2006). Isotermas de adsorción en harina de 
maíz (Zea mays L.). Food Science and Technology (Ciencia e Tecnologia de Alimentos), 26(4): 821-827.

Gao, W., Lin, W., Liu, T., Xia, C. (2007). Analytical and experimental studies on the thermal performance of cross-corrugated and flat plate solar air heaters. Applied Energy, 84( 4): 425441.

Gekas, V.; Lamberg, I. (1991). Determination of Diffusion Coefficients in Volume-Changing Systems - Application in the Case of Potato, Drying Journal of Food Engineering, 14, 317326.

Giovanelli, G., and Buratti, S. (2009). Comparison of polyphenolic composition and antioxidant activity of wild Italian blueberries and some cultivated varieties. Food Chemistry, 112(4): 903-908.

Giovanelli, G., Zanoni, B., Lavelli, V. and Nani, R. (2002). Water sorption, drying and antioxidant properties of dried tomato products, Journal of Food Engineering, 52, 135-141.

Goula, A.M., Karapantsios, T.D. Achilias, D.S. and KAdamopoulos, G. (2008). Water sorption isotherms and glass transition temperature of spray dried tomato pulp. Journal of Food Engineering. 85(1): 73-83.

Gutti, B.,Kiman, S., and Mustafa, B.G. (2012). Design and construction of forced and natural convection solar vegetable dryer with heat storage. Journal of Engineering and Applied Science, 7(10): 1213-1218.

Hamed, M., Fellah, A., Brahim, A.B. (2014). Parametric sensivity studies on the performance of a flat plate solar collector in transient behaviour. Energy Conservation and Management, 78, 938-947.

Hassan, S. W., Umar, R. A., Maishanu, H.N., Matuza, I.K., Faruk, U.Z. and Sani, A.A. (2007) The effect of drying method on nutrients and non-nutrients composition of leaves of Gynandropsis gynandra (Capparaceae), Asian Journal of Biochemistry. 2007, 2:349-353.

Hassini, L., Azzouz, S. Peczalski, R. Belghith, A. (2007). Estimation of potato moisture diffusivity from convective drying kinetics with correction for shrinkage, Journal of Food Engineering, 79, 47-56.

Henderson, S.M. Progress in developing the thin layer drying equation. (1974). Transactions of the ASAE, 17, 1167-1172.

Hodali, R. and Bougard, J. (2001). Integration of a desiccant unit in crops solar drying installation: optimization by numerical simulation, Energy Conversion and Management, 42, $1543-1558$.

Hollands, K.G.T., Unny, T.E., Raithby, G.D., Konicek, L. (1976). Free convective heat transfer across inclined air layers. Journal of Heat Transfer, 98, 189-192. 
Hofsetz K. Lopes C.C., Hubinger M.D., Mayor L., Sereno A.M. (2007), Changes in the Physical Properties of Bananas on Applying HTST Pulse During Air Drying, Journal of Food Engineering, 83, 531-540.

Hsu, C.L., Chen, W., Weng, Y.M., Tseng, C.Y., Chin-Lin, H., Wenlung, C. (2003). Chemical composition, physical properties, and antioxidant activities of yam flours as affected by different drying methods, Food Chemistry, 83, 85-92.

$\mathrm{Hu}$, S. (2007). Akaike Information Criterion. Available at: http://www4.ncsu.edu/ shu3 /Presentation/ AIC.pdf. Accessed 4 June 2018.

Igathinathane, C., Womac, A.R. Sokhansanj, S. and Pordesimo, L.O. 2005. Sorption equilibrium moisture characteristics of selected corn stover components. Transaction of the ASAE, 48(4): 1449-1460.

Jannot, Y., Talla, A., Nganhou, J., Puiggali, J.R. (2004). Modeling of banana convective drying characteristic curve (DCC) method. Drying Technology, 22, 1949-1968.

Ji, J., He, H., Chow, T., Pei, G., He, W., Liu, K. (2009). Distributed dynamic modeling and experimental study of PV evaporator in a PV/T solar-assisted heat pump, International Journal of Heat and Mass Transfer, 52, 1365-1373.

Jin X., Sman, R.G.M.van der, Boxtel A.J.B. van. (2011). Evaluation of the Free Volume Theory to predict moisture transport and quality changes during broccoli drying. Drying Technology, 29(16): 1963-1971.

Jones, G.P., Biggs, D.R., Wahlqvist, M.L., Flente. L.M. and Shiell, B.J. (1990). Dietary fibre content of Australian foods, Fruits and fruits products. Food Australia, 42(3): 143-145.

Jorge, F., Armando, C.O., (2004) Analysis of a Plate Heat Pipe Solar Collector International Conference on Sustainable Energy Technologies. Nottingham, UK, 277-283.

Kadar, A., Kashmire, R.F., Mitchel, F.G., Reid, M.S., Sommer, N.P. and Thompson, J.F. (1985). Postharvest Technology of Horticultural Crops Special Publication No. 3311. Division of Agriculuture and Natural Resources. University of Natural Resources. University of California. Davis, CA.

Karel, M. (1985). Control of lipid oxidation in dried food. In: the concentration and drying of foods, Richardson, J. and Finley, J. W. (Eds). Springer Technology and industrial arts, California, 495-512.

Karim, M.A. and Hawlader, M.N.A (2004). Mathematical modeling and experimental investigation of tropical fruits drying, International journal of heat and mass transfer, 48, 49154925.

Kenyon L., Anandajayasekeram, P. and Ochieng, C. (2006). A Synthesis/Lesson-Learning Study of the Research Carried Out on Root and Tuber Crops Commissioned through the DFIDRNRRS Research Programmes between 1995 and 2005. Available at: 
http://www.envirobase.info/PDF/Root_Tuber_research_synthesis_P1.pdf. Accessed 4 June 2018.

Kicsiny, R. (2016). Improved multiple linear regression based models for solar collectors, Renewable Energy, 91, 224-232.

Kiranoudis, C. T., Z. B. Maroulis, E. Tsami and D. Marinos-Kouris. 1993. Equilibrium moisture content and heat of desorption of some vegetables. Journal of Food Engineering, 20(1): 55-74.

Koyuncu, T. (2006). Performance of various design of solar air heaters for crop drying applications. Renewable Energy, 31, 1073-1088.

Krokida M.K., Marinos-Kouris D. (2003). Rehydration Kinetics of Dehydrated Products, Journal of Food Engineering, 57, 1-7.

Kumar, G. Vasanth, Ajay Kumar, K., Raghu Patel, G.R. and Manjappa, S. (2013). Determination of vitamin C in some fruits and vegetables in Davanagere city, (Karanataka) India, International Journal of Pharmacy \& Life Sciences, 4(3): 2489-2491.

Labuza T.P., Mizrahi, S. and Karel, M. (1972). Mathematical models for optimization of flexible film packaging of foods for storage. Transactions of the American Society of Agricultural Engineers, 15(1): 150-155.

Levine, H., and Slade, L. (1991). Water Relations in Foods. New York, United States: Plenum Press.

Lin, W., Gao W., Liu T. (2005). A parametric study on the thermal performance of cross corrugated solar air collectors. Applied Thermal Engineering, 26(10): 1043-1053.

Ljung, L. 1987. System Identification - Theory for the User. Englewood Cliffs, New Jersey: Prentice-Hall.

Madhlopa, A., Jones, S.A., Kalenga Saka, D.J. (2002). A solar air heater with compositeabsorber systems for food dehydration, Renewable Energy, 27(1): 27-37.

Matalas, A.L., Zampelas, A. and Stavrinos, J. (2001). The Mediterranean Diet, CRC Press ICC. Matuska T, Zmrhal V and Metzger J (2009) Detailed modeling of flat plate collectors with design tools 2.2, (2009) Eleventh international IBPSA conference, Glasgow, Scotland, 22892295.

McAdams, W.H. (1954). Heat transmission. New York, McGraw-Hill.

Mehla A., Kumar, P., Bhool R., Kumar P. (2014). Regeneration of Solid Desiccant by Solar Parabolic Dish Collector in India: An Experimental Analysis, International Journal of Scientific Engineering and Technology Research, 3(5): 743-723.

Miguel Aguilera, J. and Stanley, D.W. 1999, Microstructural principles of food processing and engineering, Aspen. 
Mintsa Do Ango A.C. Medale, M. Abi, C. Optimization of the design of a polymer flat plate solar collector, Solar Energy, 2013, 87, 64-67.

Montes, E., R. Torres, R. Andrade, O. Perez, J. Marimon, and I. Meza. 2009. Models of desorption isotherms of yam (Dioscorea rotundata). Dyna, 76(157): 145-152.

Maroulis, Z.B., Tsami, E., Marinos-Kouris, D. and Saravacos, G.D. (1988). Application of the GAB model to the moisture sorption isotherms for dried fruits. Journal of Food Engineering, 7(1): 63-78.

Mulet, A. Drying modeling and water diffusivity in carrots and potatoes. Journal of Food Engineering, 1994, 22, 329-348.

Myhara, R.M., Taylor, MS. Slominski, B.A. and Al-Bulush, I. (1998a.) Moisture sorption isotherms and chemical composition of Omani dates. Journal of Food Engineering, 37(4): 471479 .

Myhara, R. M., Sablani, S. S. Al-Alawi, S. M. and Taylor, M. S. (1998b). Water sorption isotherms of dates: modeling using $\mathrm{GAB}$ equation and artificial neural network approaches. LWT-Food Science and Technology, 31(7-8): 699-706.

Maroulis, Z.B., Tsami, E. Marinos-Kouris, D. and Saravacos, G.D. (1988). Application of the GAB model to the moisture sorption isotherms for dried fruits. Journal of Food Engineering, 7(1): 63-78.

Mujumdar, A.S. (1996). Innovation in drying. Drying Technology - An International Journal, $14,1459-1475$.

Mujumdar, A.S. 1980 Drying theories: Their bases and limitations as applied to foods and grains, (Ed.). Advances in Drying, Fortes M, Okos MR. 1: Washington, USA: Hemisphere Publishing Corporation; 301.

Ng, K.C., Chua, H.T., Chumg, C.Y., Loke, C.H., Kashiwagi, T., Akisawa, A., and Saha, B.B. (2001). Experimental investigation of the silica gel water adsorption isotherms. Applied Thermal Engineering, 21(16): 1631-1642.

Njomo D. (2000). Unglazed selective absorber solar air collector: Heat exchanger analysis, Journal of Heat and Mass Transfer, 36: 313-317.

Njomo, D. and Daguenet, M. (2006) Sensitivity analysis of thermal performances of flat plate Solar air heaters, Heat and mass transfer, 42.

Oduro, I. Ellis, W., Sulemana A., Oti-Boateng P. (2007). Breakfast meal from breadfruit and Soybean composite, Discovery and Innovation, 19(3), 238-242.

Oguntola, J.A, Collins, N.N.; Olayinka, A. (2010). Design and construction of a domestic passive solar food dryer, Leonardo Journal of Sciences. 16, 71-82.

Ojukwu U.P. and Nwobi S.C. (2017). Determination of ascorbic acid content of some local fruits in Nigeria. Analytical Chemistry: An Indian Journal. 17 (1): 1-5. 
Okaka, J.C. and Okaka, A.N.C. (2001). Food: Composition, Spoilage, Shelf-life Extension. OCJANKO Academic Publishers, Enugu.

Oliveira, M.M., Campos, A.R.N. Dantas, J.P. Gomes, J.P. and Silva, F.L.H.D. (2006). Desorption isotherms of passion fruit peel (Passiflora edulis Sims): experimental determination and mathematical model evaluation. Cienc Rural, 36(5): 1624-1629.

Opara L. (1999), YAMS: Post Harvest Operation, Massey University, New Zealand.

Osunde, Z. D. (2008). Minimizing postharvest losses in Yam (Dioscora sp.). Treatments and techniques. International Journal of Food Science and Technology; 12: 2-14.

Owo, H.O., Adebowale, A.A. Sobukola, O.P. Obadina, A.O. Kajihausa, O.E. Adegunwa, M.O. Sanni, L.O. and Tomlins, K. (2017). Adsorption isotherms and thermodynamics properties of water yam flour. Quality Assurance and Safety of Crops \& Foods, 9(2): 221-227.

Oyetade, O.A., Oyeleke, G.O., Adegoke, B.M., and Akintunde, A.O. (2012). Stability studies on Ascorbic acid (Vitamin C) from different sources. Journal of Applied Chemistry. 2(4): 2024.

Özcan M, Arslan D and Ünver A (2005) Effect of drying methods on the mineral content of basil (Ocimum basilicum L.). Journal of Food Engineering, 69, 375-379.

Pramuang, S., and Exell, R.H.B. (2007). The regeneration of silica gel desiccant by air from solar heater with a compound parabolic concentrator. Renewable Energy, (32): 173-182.

Perez, R., Seals, R., Ineichen, P., Stewart, R. Menicucci, D. (1987). A new simplified version of the Perez diffuse irradiance model for tilted surfaces, Solar Energy, 39: 221.

Perez, R., Stewart, R., (1988). The Development and Verification of the Perez diffuse radiation model, Sandia National Laboratories Contractors Report (SAND88-7030).Postharvest Technology of Horticultural Crops Special Publication No. 3311. Division of Agriculture and Natural Resources. University of Natural Resources. University of California. Davis, CA.

Pramuanga, S. and Exella, R.H.B. (2007). The regeneration of silica gel desiccant by air from a solar heater with a compound parabolic concentrator, Renewable Energy, 32, 173-182.

Quirijns, E.J., van Boxtel, A.J., van Loon, W.K. and van Straten, G. (2005). Sorption isotherms, GAB parameters and isosteric heat of sorption. Journal of the Science of the Food and Agriculture, 85(11): 1805-1814.

Raji, A.O. and Ojediran, J.O. (2011). Moisture sorption isotherms of two varieties of millet. Food Bioproduct Processing. Jul; 89 (3): 178-184.

Rizvi, S.S.H. 1995. Thermodynamic properties of foods in dehydration. In Engineering Properties of Foods, 2nd ed., eds. M. A. Rao and S.S.H. Rizvi, 223-309. New York: M. Dekker Inc. 
Ronald, E.W. Eric, A.D. Steven, J.S. and Peter, S. (2005). Handbook of food analytical chemistry, water, proteins, enzymes, lipids, and carbohydrates, John Wiley and Sons, Hoboken, NJ, USA.

Rubens, P. and Heremans, K. (2000). Stability diagram of rice starch as determined with FTIR, High Pressure Research, 19, 161-166.

Ruiz-Lopez. I.I., Garcia-Alvarado M.A. (2007). Analytical solution for food-drying kinetics considering shrinkage and variable diffusivity. Journal of Food Engineering, 79: 208- 216.

Saad, A., Touati, B., Draoui, B., Tabti, B., Abdenebi A., and Benaceur. S. (2014). Mathematical modeling of moisture sorption isotherms and determination of isosteric heats of sorption of Ziziphus leaves. Modeling and Simulation in Engineering, 2014: article No. 16.

Saeed, I. E., Sopian, K. and Zainol Abidin, Z. (2006). Drying kinetics of Roselle (Hibiscus sabdariffa L.): dried in constant temperature and humidity chamber. Proc. SPS 2006. Edited by Muchtar. 29th-30th August. Permata, Bangi, S.D.E., Malaysia: 143-148.

Saito, Y. (1993). Regeneration characteristics of adsorbent in the integrate desiccant/collector. Journal of Solar Engineering, 115: 169-75.

Sahin, S., and Sumnu, S.G. (2006). Physical Properties of Foods. New York, United States: Springer.

Eltief, S.A., Ruslan, M.H., Yatim B. (2007). Drying chamber performance of V-groove forced convective solar dryer. Desalination 209(1-3) 151-155.

Salunkhe, d.K., Bolin, H.r. and Reddy, N.R. (1991). Storage, Processing and Nutritional Quality of Fruits and Vegetables, 2 ed. CRC Press. Boca Roton. FL.

Samaniego-Esquerra, C. M., I. F. Boag and G. L. Robertson. (1991). Comparison of regression methods for fitting the GAB model to the moisture isotherms of some dried fruits and vegetables. Journal of Food Engineering, 13(2): 115-133.

Santos, B.M., Queiroz, M.R., Borges, T.P.F. (2005). A solar collector design procedure for crop drying. Brazilian Journal of Chemical Engineering, 22(02), 277-284.

Santos, P.H.S., and Silva, M.A. (2008). Retention of vitamin C in drying process of fruits and Vegetables - A review, Drying Technology, 26 (12): 1421-1437.

Sharaf-Eldeen, Y.I., Blaisdell, P.N., Hamdy , M.Y. A model for corn drying. Transactions of the ASAE 1980, 23, 1261-1271.

Simate, I.N. (2010) Simulation of the mixed-mode natural convection solar drying of on maize, Drying Technology. Dekker, Online publication, 1136-1154.

Siripatrawan, U., and Jantawat, P. (2006). Determination of moisture sorption isotherms of jasmine rice crackers using BET and GAB models. Food Science and Technology International, 12(6): $459-465$. 
Sjöholm, I. and Gekas, V. Apple, (1995). Shrinkage upon Drying, Journal of Food Engineering. 25, 123-130.

Skrede, G., Wrolstad, R.E. and Durst, R.W. (2000). Changes in Anthocyanins and polyphenolics during juice processing of highbush blueberries (Vaccinium corymbosum L.). Journal of Food Science, Sensory and Nutritive Qualities of Food, 2000, 65(2), 357-364.

Sreekumar, A., Manikantan, P.E. and Vijayakumar, K.P. (2008). Performance of indirect solar cabinet dryer, Energy Conversion and Management, 49, 1388-1395.

Sukhmeet, S. and Parm, P.S. (1997). Regeneration of silica gel in multi-shelf regenerator, Renewable Energy, 13(1): 105-119.

Swinbank; W.C. (1963). Long wave radiation from clear skies, Quart. J. Royal Meteorol. Soc., 89. 339-348.

Talbot, P., Lhote, M., Heilporn, C., Schubert, A., Willaert F.-X., Haut B. (2016). Ventilated tunnel solar dryers for small-scale farmers communities: Theoretical and practical aspects, Drying Technology, 1-46.

Techajunta S., Chirarattananon S. and Exell R.H.B. (1999) Experiments in a solar simulator on solid desiccant regeneration and air dehumidification for air conditioning in a tropical humid climate. Renewable Energy, 17:549-68.

Tiwari, A., Sodha, M.S. (2007). Parametric study of various configurations of hybrid PV/thermal air collectors: Experimental validation of theoretical model. Solar Energy Materials and Solar Cells, 91, 17-28.

Toğrul H., Arslan, N. (2007). Moisture sorption isotherms and thermodynamic properties of walnut kernels. Journal of Stored Products Research, 43: 252-264.

Tomas, M.; Vladimir, Z.; Juliane, M. (2009). Detailed modeling of solar flat-plate collectors with design tool kolektor 2.2, Building Simulation. Eleventh International IBPSA Conference Glasgow, Scotland, 2289-2296.

Toor, R.K. and G.P. Savage (2004). Effect of semi-drying on the antioxidant components of tomatoes, Food Chemistry, 94, 90-97.

Torres, R., Montes, E.J., Andrade, R.D., Perez, O.A., Toscano, H. (2011). Drying kinetics of two yam (Dioscoreaceae alata) varieties. Dyna., 79(171), 175-182.

Tsami, E., Marinos-Kouris, D. and Maroulis, Z.B. (1990). Water sorption isotherms of raisins, currants, figs, prunes and apricots. Journal of Food Science, 55(6): 1594-1597.

Tütüncü, M.A., Labuza, T.P. (1996).Effect of Geometry on the Effective Moisture Transfer Diffusion Coefficient, Journal of Food Engineering, 30, 433-447.

Vega-Gálvez, A., Lemus-Mondaca, R., Tello-Ireland, C., Miranda, M., and Yagnam, F. (2009).) 
Kinetic study of convective drying of blueberry variety O'Neil (Vaccinium corymbosum). Chilean Journal of Agricultural Research, 2009, 69(2): 171-178.

Vega-Mercado, H., Gongora-Nieto, M.M and Barbosa-Canovas, G. (2001). Advances in dehydration of food. Journal of Food Engineering, 49, 271-289.

Verma L.R., Bucklin R.A., Endan J.B., Wratten F.T. (1985). Effect of drying air parameters on rice drying models. Transaction of the ASAE, 28(1): 296-301.

Wolf, D., Kudish, A.I., Sembira A.N. Dynamic simulation and parametric sensitivity studies on a flat-plate solar collector. (1981). Energy. 6, 333-349.

Yadollahinia, A. Jahangiri, M. (2009). Shrinkage of potato slice during drying, Journal of Food Engineering, 94, 52-58.

Yaldiz, O. and Ertekin, C. (2001). Thin layer solar drying of some vegetables. Drying Technology, 19(3/4): 583-597.

Yilbas, B.S., Hussain, M.N. and Dincer, I. (2003). Heat and moisture diffusion in slab products to convective boundary. Heat and Mass Transfer, 39:471-476.

Young, J.H., and Nelson, G.L. (1967). Theory of hysteresis between sorption and desorption isotherms in biological material. Transaction of the ASAE, 10(2): 260-263.

Zanoni, B., Peri, C., Nani, V. and Lavelli (1999). Oxidative heat damage of tomato halves as affected by drying, Food Research International, 31, 395-401. 
Summaries 


\section{Summary}

Yam is an important food crop in Ghana. It is a delicacy that is eaten after cooking or frying the fresh sample when cut into slices. The powders of the dried yam can be incorporated into soups, baby food and bread as composite flours. However, the high moisture content of yam when harvested (about $70 \% \mathrm{wb}$ ) makes it susceptible to spoilage leading to reduced shelf life and onward rejection by the consumer. This adds to the waste basket. Drying is a worldwide postharvest method for extending the shelf life of agricultural food products such as yam. An energy source that is cheap and clean has always been from the sun. The open sun method has been utilized severally and for many years, but this is subject to various contaminants and thus reducing its quality. A confined solar drying method is a better option but the energy source is limited to the day's solar energy. Solar adsorption drying is an opportunity to dry day and night in an efficient and product conserving manner with a reduced drying cycle. Prior to this thesis work, several aspects were insufficiently known to really judge the potential. The thesis tackles some of the bottlenecks and problems: lack of knowledge about the drying properties of yam; how to design appropriate solar collectors for drying and regeneration and to share experiences with the actual implementation of the system to see its possibilities an opportunities. In this thesis the sorption properties of yam which gives an indication of the equilibrium moisture content in relation to water activity at constant temperature, but has been given less attention in literature, is studied. The analytical Crank solution to the Fick's second law has been utilized in the prediction of drying curves of many food products. However the Crank solution puts limitations on the extent to which the equation could be utilized. The limitation is that the particle of food sample to be dried must be infinite, shrinkage should not exist, while moisture diffusion coefficient must be constant. In practice, these limitations are not realistic since most biological food products go through shrinkage together with variable moisture diffusion.

Meanwhile the source of energy for drying has largely come from the sun and has led the use of the so-called open sun drying (OSD) method especially in tropical countries, for so many years. This method exposes the food to weather conditions and contaminants reducing the quality of the dried product. Recent research has shown that a confined drying system is most appropriate in terms of reduced drying time and quality of the final product. The shortcoming of the solar drying (SD) method is that, drying is limited to a time interval of 6-9 hours of the day after which the sun's energy can no more be explored. Solar adsorption drying (SAD), as an alternative drying to solar drying, is an integrated drying method that helps in drying day and night in a continuous manner. Research in solar adsorption drying systems is limited in literature, therefore its performance is yet to be explored. Solar collectors are an integral part of solar and solar adsorption dryers. However, most researchers construct collectors to see what happens or use heuristic rules, whereas others do not link to dryers. The output air temperature has an effect on the quality of the dried food product, therefore much attention must be given to the output temperature of the air that enters the dryer. On the other hand after adsorption 
drying, the adsorbent needs to be regenerated. The easiest way to regenerate the adsorbent (silica gel), which requires temperatures over $70^{\circ} \mathrm{C}$ is by conventional ovens, which is costly.

In this thesis, the condition and requirements for solar adsorption drying of yam (Dioscorea rotundata) is investigated. The approach is first to investigate the sorption properties of yam, then the drying characteristics of yam by modifying the Crank solution of the Fick's diffusion equation, subsequently the model based design and construction of solar collectors for drying and regeneration purposes, and then finally, the proof of principle of solar - adsorption for both drying and regeneration.

The first part of this thesis concerns investigating the equilibrium moisture isotherms for yam at $25^{\circ} \mathrm{C}$ and $50^{\circ} \mathrm{C}$, both for sorption and desorption, experimentally using the gravimetric method (Chapter 2). The strength of this work is that a Dynamic Vapour Sorption (DVS) analyzer, which is very sensitive to micro changes in weight loss during dehydration or rehydration, was used. A graphical presentation of equilibrium moisture content, as a function of water activity from the outcome of nonlinear regression analyses of desorption and adsorption isotherms respectively, is shown. The findings contradict most of the findings in literature. The parameters and their uncertainty range for each of the models (GAB, Henderson, Halsey, Oswin, Smith, BET and Peleg) are estimated. The strength of the statistical analysis is that an objective criteria is used to select the model that best describes the experimental desorption and adsorption isotherms over the relevant range of moisture contents. This has been presented in a table form where statiscally, the standard error $(S E)$, the percent average relative deviation $(P R D)$, Akaike Information Criterion (AIC), coefficient of performance $\left(R^{2}\right)$, and most importantly, the $2-\sigma$ bound confidence interval of the parameters, in particular those that bear the same unit as the equilibrium moisture content $\left(X_{e}\right)$, have been taken into consideration. The GAB model was selected to describe both the desorption and adsorption isotherms, because it allows a physical interpretation.

In Chapter 3, the Crank's analytical approximation to Fick's diffusion equation is used to investigate the effect of moisture dependent sample thickness and diffusivity on the drying behavior of yam (Dioscoreaceae rotundata) cubicles. Separate experiments of drying and shrinkage at constant temperatures of 30,40 and $50^{\circ} \mathrm{C}$ were conducted in a cabinet dryer. The comparative study shows an interdependence between diffusivity and shrinkage due to water loss during drying. The analytical expression for the diffusion in a slab results in non-Fickian behavior for smaller cubicles and consequently, results in a higher effective diffusion coefficient. The drying rate trajectory shows two stages as a function of moisture ratio. The drying behavior of yam is better described by observing both drying and drying rate curves concurrently. This gives good agreement between observed and model data by a combination of fractal moisture dependent shrinkage and moisture dependent diffusion. The advantage of this modified Crank's approximation is that the moisture trajectory of finite food cubicles can be predicted appropriately. 
In Chapter 4, coupled partial differential equations are developed to investigate which collector lengths are appropriate for drying and for adsorbent regeneration. The output air temperature of the model was validated with an experiment. The spatially distributed model is a powerful tool to aid in multi-purpose collector design leading to solar dryer and regeneration system construction. The advantage of this model is that, the spatial mean temperature of the absorber plate, a requirement for the determination of the overall heat loss coefficient, which hitherto is absent in the approach of Duffie and Beckmann, is no more a problem. The result shows a spatially distribution of temperature in air, absorber plate, and glass cover as functions of collector length and time (day) at constant air velocity and presented in a graphical from. While the temperature of absorber plate, glass cover and air are functions of time (day), the air temperature additionally varies directly with collector length. The study shows the operational overall heat loss coefficient, radiative and convective heat gain and efficiency as functions of the operational air velocity. There was a good agreement between the observed and the model air output temperature.

The proof of principle of solar adsorption drying (SAD) and its benefits, compared to solar drying (SD) and open sun drying (OSD) and the effects of these drying methods on the quality of different yam cultivars and regeneration of silica gel is considered in Chapter 5. The drying methods SAD, SD and OSD are compared in terms of drying cycles. The SAD had, the shortest drying cycle while maintaining the whitish colour of yam, followed by SD and OSD. However, due to the night drying, the SAD dried product is longer exposed to the drying medium (air), leading to slightly lower vitamin $\mathrm{C}$ content of dried sample compared to SD dried samples. OSD had the worst effect on vitamin C. The study shows that the different cultivars of yam dried at different rates. Drying has no effect on composition. Regeneration was possible with solar energy but more work must be done to obtain the information needed for improved designs and operation strategies for the desorption. Chapter 6 gives the perspective, impact and reflection of the whole work. The potential application of the study has also been discussed. 


\section{Twi tofa bo}

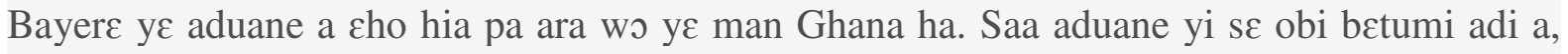
gyes $\varepsilon$ watwitwa asensene no nketenkete $\varepsilon d e$ nsuo anoa, anaas $\varepsilon$ woakye no anwa mu ansana

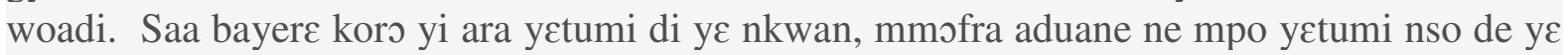

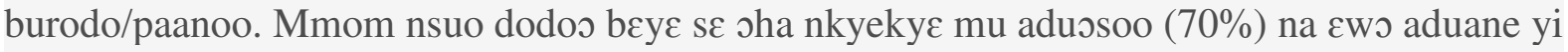

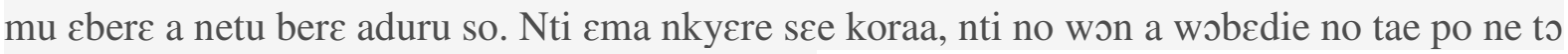
no, ma yede gu bosla so anaa nkenten a $\varepsilon$ nye mu.

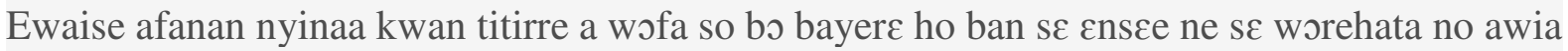
mu ama no awo kama. Esiane se anyinam ahooden a $\varepsilon$ fo na $\varepsilon$ ho te $\varepsilon$ pa ara ne sboadea awia. Mfic bebree nie na yede awia yi adi adwuma saa nanso wei tumi ma nnooma ne nyarewa bi ka

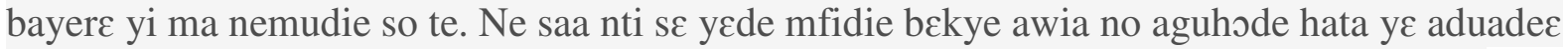

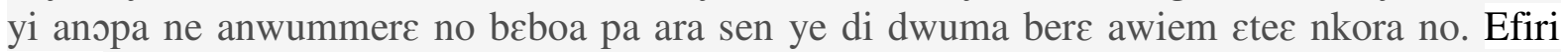

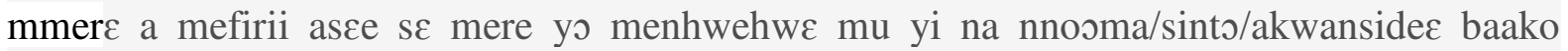
mmienu mma yentumi nhunu owiakyere (Solar system) yi ahooden ne ne dibre yie. Adwuma

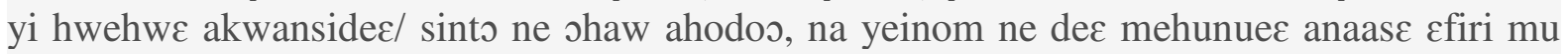

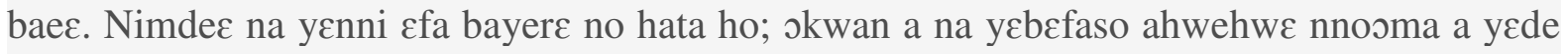
bekyere awia no na yeasisi anaa yeatimtim mfidie ne adan na yede yensua hunu atumi ahunu

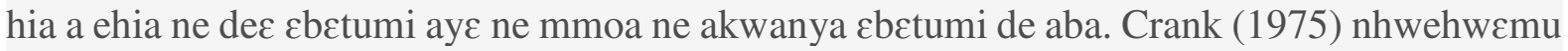

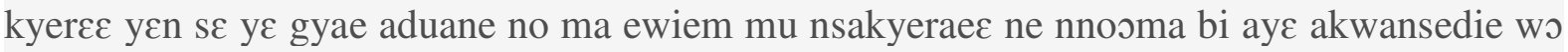

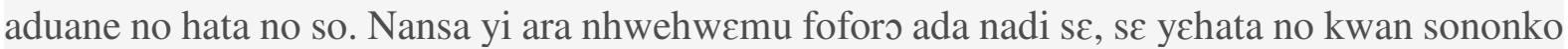

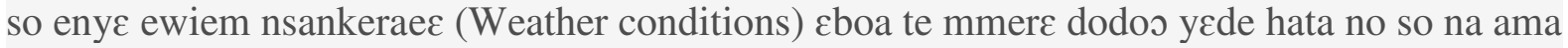

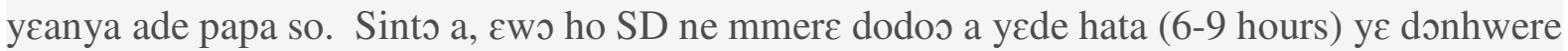
nsia - nkron wo damu no nyinaa afei awia ahoododen ntumi nye hwee bio. Solar Adsorption

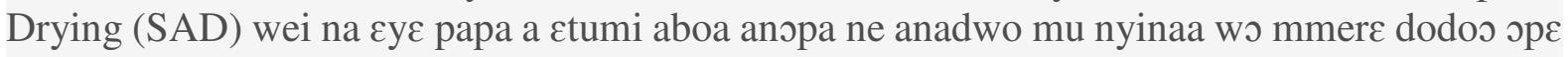

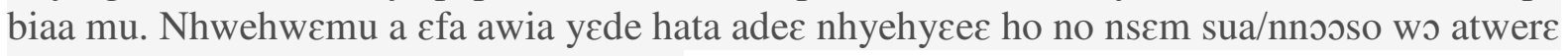
mu na mmom ne dwumadie na $\varepsilon$ bekyere.

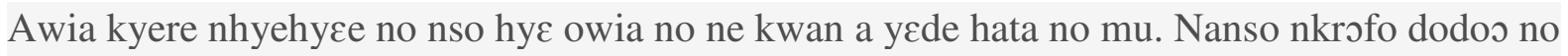

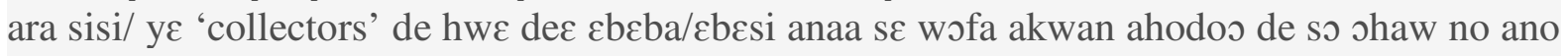

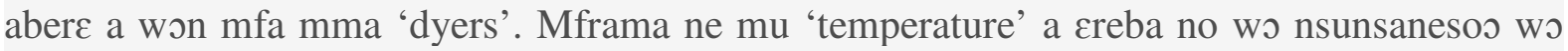

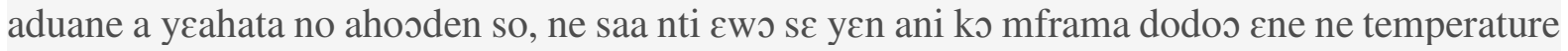

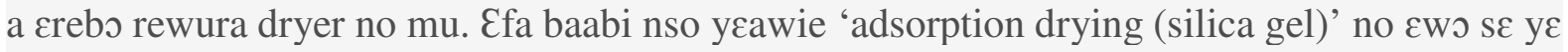
yi nsuo efiri adsorbent nemu. Jkwan a $\varepsilon f o$ koraa a yebetumi ayi nsuo yi behia enframa a

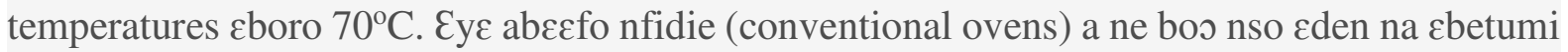

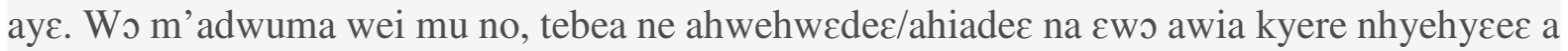

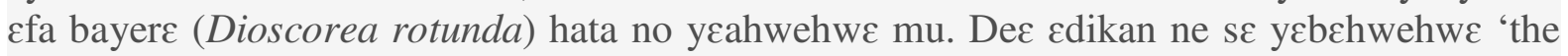

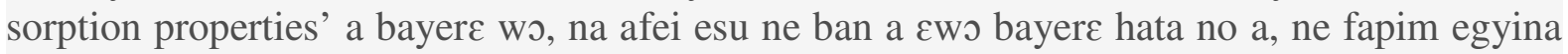
de $\varepsilon$ Owura Crank mmuae $\varepsilon$ a $\varepsilon f a$ 'Fickian diffusion equation' ne 'model based design ne

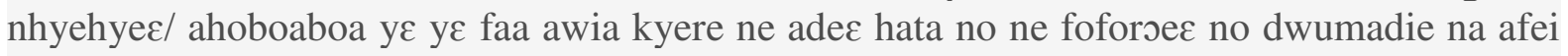

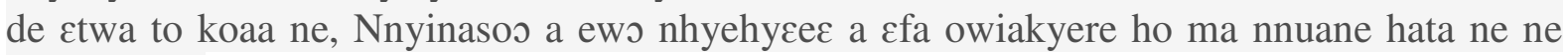
foforoe ho.

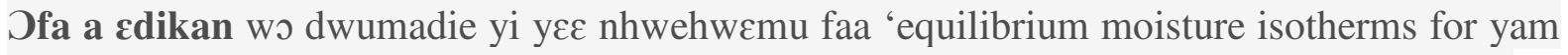
$25^{\circ} \mathrm{C}$ ne $50{ }^{\circ} \mathrm{C}$, عma adsorption ne desorption experimentally using the gravimetric method.

Ofa a Etoso mmienu, dwumadie yi ahooden gyina 'Dynamic Vapour Sorption (DVS)

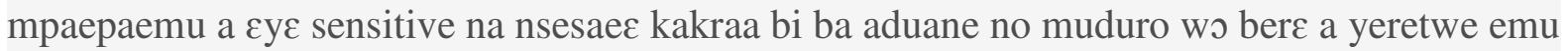

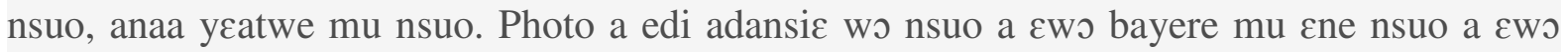
nframa mu firi 'nonlinear regression analyses of adorption' mu ne 'desorption isotherms mu

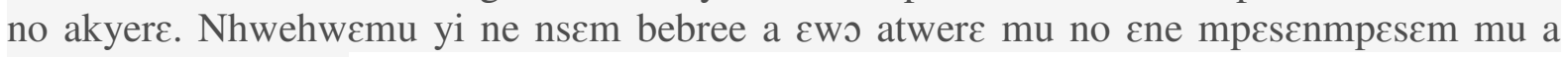
ebinom aye bo abira. 
Adwene mu kesenee ntanta ne nteasec/akyinniyegye $\varepsilon$ bi a na $\varepsilon w \supset$ won mu no ses $\varepsilon$ kakra. The parameters $\varepsilon$ ne uncertainty range ewo models (GAB, Henderson, Halsey, Oswin, Smith, BET

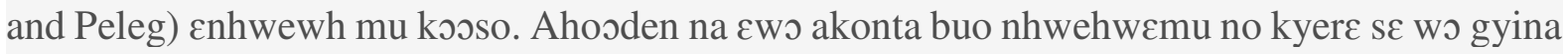

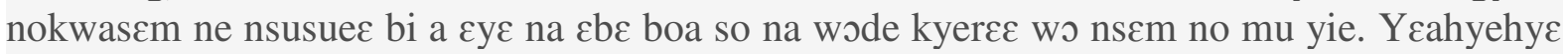
wei wo kama wo epono so a akontabuo ne nnooma nyinaa deda n'akwan mu kama.

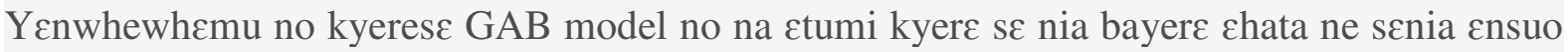
firi emu ba $\varepsilon$ ne senia $\varepsilon$ kyi nsuo. Yesii saa gyina $\varepsilon$ wei esanse GAB no wo physical interpretation.

Jfa a $\varepsilon$ toso mmiensa, Crank mpensenpensenmu a efa 'Fick diffusion equation' no na ode

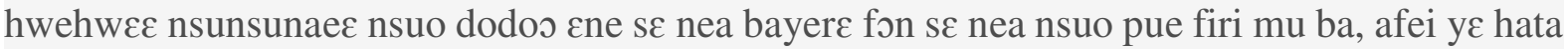

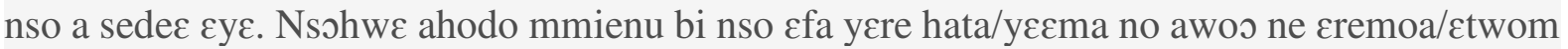
a na egyina temperatures ahoros 30, 40 ne $50{ }^{0} \mathrm{C}$ nso kos so wo kabenet draya mu. Adesua/suahunu a $\varepsilon$ firi mu bae $\varepsilon$ ne se ntease $\varepsilon$ ne ahotosoo bi wo se عremoa ne nsuo a efiri mu

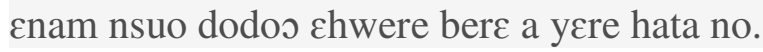

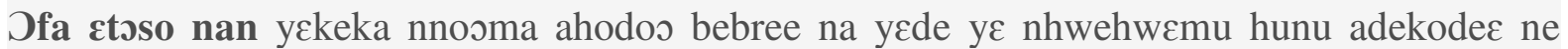

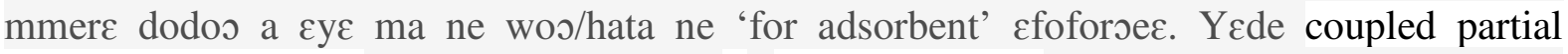
differential equations $\varepsilon$ na $\varepsilon y \varepsilon \varepsilon$ nhwehwemu s $\varepsilon$ collector tintin ben na yetumi de hata bayer $\varepsilon$ ene

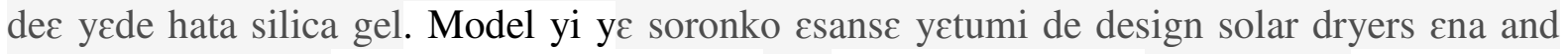
regenerators. Ebio, spatial mean temperature $\varepsilon$ ma absorber plate a yede whewhe overall heat loss coefficient $\varepsilon$ ny $\varepsilon$ chao koraa, efise overall heat loss coefficient, Duffie and Beckmann, kaas $\varepsilon$ $\varepsilon y \varepsilon$ ohao paa. The result shows a spatially distribution of temperature $\varepsilon$ wo mframa mu, absorber plate, $\varepsilon$ e glass cover as functions of collector ne tintin $\varepsilon$ ene $\varepsilon m m i r \varepsilon$ (day) at constant air velocity

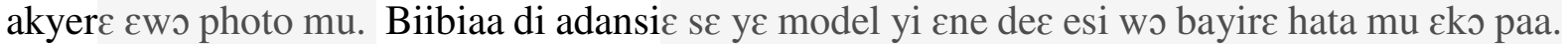

Ensonsuanso pa $\varepsilon$ ne $\varepsilon$ nsonsuanso bone a $\varepsilon$ da solar adsorption drying (SAD), solar drying (SD)

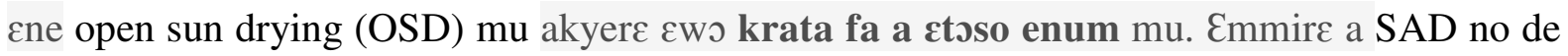

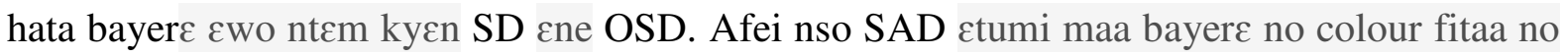

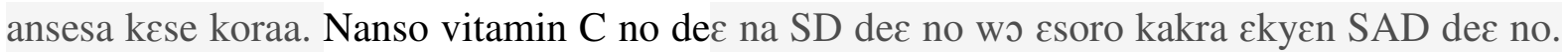

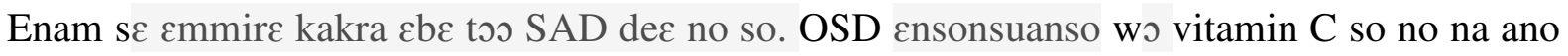

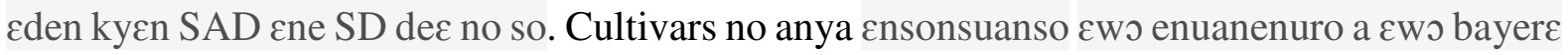

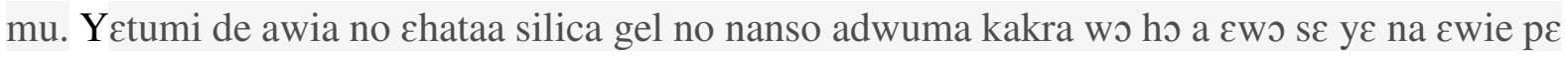

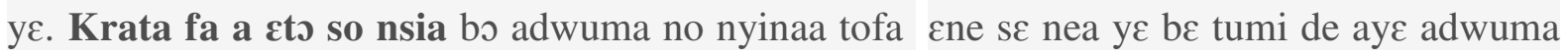
afa. 


\section{Acknowledgement}

I am most grateful to my supervisors for the wonderful support, encouragement and the various inputs made to the success of this research. Zimmerman once said "opportunity is not, it becomes". In this sense I will say "Titles are not, they become". You have proven beyond all reasonable doubt that your output justifies your titles. To Emeritus Professor Gerrit van Straten, I will say thank you so much for your meticulous scrutiny and objective comments. In fact you have always expected excellence throughout the supervision of this research. I remember you once told me that failure of one method of solution only brings a closure to that path of solution. My sincere gratitude goes to Associate professor Ton van Boxtel, who has been very instrumental to the successful end of this research. Ton the laptop you gave me is still alive and kicking. Your caring behavior is unimaginable. Professor Karel Keesman taught me physical modeling. That was the first time I was introduced to Matlab. The level of understanding of Matlab and the contributions made by my supervisors cannot be over emphasized. The contributions of Karel to the research lately, has been stunning. Dr. Rachel Ooteghem was an assistant lecturer to Karel during my Physical modeling classes. In fact she always gave an alternative solution to any challenge I was faced with. With regards to technical challenges, Kees Asselt was instrumental. In fact his technical knowledge is excellent be it new equipment, electrical gadgets, software for running control systems. My warm regards to you Kees. My regards also go to Marja for the infectious you always put on your face. It was always a delight to work with you as the secretary to the group. I thank Bitter Harry for his good and generous leadership style. I am indebted to you. This is because your intervention came in on time when I missed my flight to Las Vegas, USA, for a conference. You instructed the secretary Gerda Bos to repay for my ticket though I had lost the opportunity for the first time. I will forever remember this kind gesture you offered to me. Bitter the song we sung for you during your early days as the new chair is still fresh in my mind. In fact the composers of the song were apt. These, the cakes at coffee times and many others are the unique memories that will always linger in my mind for a long time. One person that I cannot forget is the person who initiated the discussion on my PhD with Ton, Peter Twumasi, a professor in Biochemistry, KNUST. Probably this new knowledge from these noble men of rich scientific background in Wageningen University wouldn't have materialized if you had not initiated talk on this research work with Ton. Peter I am grateful to you. My sincere thanks goes to Jos, who allowed me in his lab in performing the sorption experiment on yam. My regards to Prof Johan Sanders and Prof. Mrs. Elinor Scott for the wonderful experience we shared together especially on the chlorogenic acid (from cocoa husk) proposal we attempted soliciting for funds to undertake.

Of course there have been various contributions and concerns from people in my host country and University. First I will like to Acknowledge Professor Ibok Oduro and Professor W.O. Ellis (The former Vice Chancellor) for their support for bringing this work to a successful end. To my co-supervisor in Ghana, Prof. K.A. Dzisi, I am grateful to you for your objective 
comments and pieces of advice. Senior lecturers who have taken keen interest in my research work and want this Sandwich $\mathrm{PhD}$ work come to its logical terminating point are: Mrs F.O. Mensah, Prof. V.P. Dzogbefia (all of Biochemistry Department, KNUST) Prof J.H. Oldham, Mr. J. Barimah (all of Food Science and Technology Department, KNUST). I am most grateful to you, Mrs. F.O. Mensah, for it was you who wrote and signed the Department (KNUST) support letter for me. You are indeed a woman of genuinely good heart. I am most grateful to the MSc students, whom I supervised their thesis while using the solar adsorption dryer system (SADS) I constructed for their experimental work during this thesis work. They include: Gladys Kyere, Ama Adutwumwaa, Herbert Kyeremateng (yam drying) and Esther (Banana drying). In fact we shared so much experiences together and it was nice working with you all. Out of this sandwich $\mathrm{PhD}$ experience, a new direct and indirect solar house dryer has been constructed. I have already supervised two MSc students (Clifford Yeboah-Manson and Gabriel Annobil Bisiw) who have dried cocoa seeds with better quality characteristics compared to those dried in the open sun. I am currently supervising one MSc student (Fidaus Abdul Rahman) using the solar house dryer, in drying and extraction of Oleoresin from ginger These various experiments justifies the scientific basis for my research work. There have been numerous BSc students whom I also supervised while using various food products ranging from pepper, mangoes, coconut fruit, cassava, etc just to mention a few in the SADS.

I am most grateful to my colleague PhD students, Ellen, Xin, Jimmy, James, Nural, Sanne and Piet. It was wonderful working with you as researchers. Ellen, Sanne, Xin etc, when are you visiting Ghana? Ellen what about the mind mapping agenda?

My sincere thanks go to Henrietta Brew (Mrs,) for helping me with the architechtural drawings and Evelyn Ewuraa Ama Ennu for translation the English version of the summary to Twi (An Akan language spoken by many Ghanaians in Ghana). My profound gratitude goes to the professional carpenter, Kwaku Adu Boahen, Alias Kooko (RIP), who did all the carpentry work for this project. I thank him so much.

My family has been there for me throughout this research work since as part of the work I have to be in Netherlands for some months while the experiment is conducted in Ghana. My family has been supportive. My sincere thanks goes to my parents (James Adu Amankwah and Comfort Owusu Afriyie (Diseased)) and especially my wife Mrs. Bertha Amankwah and my children Adubofour Amankwah, Nana Adwoa Amankwah, Kufour Amankwah and Naomi Amankwah. Bertha, I appreciate your objective criticisms and financial support.

Finally, this project was funded by the Wageningen University and Research Centre (WUR), The Netherlands, and Kwame Nkrumah University of Science and Technology (KNUST), Kumasi, Ghana. The authors are grateful for this financial and in kind contribution. 


\section{About the author}

Emmanuel Yaw Adu Amankwah was born in May 13, 1968. He attended Adisadel College (both Ordinary and Advance level), Cape Coast in Ghana for his secondary education between 1981 and 1988. He received his BSc degree in Agricultural Engineering in the year 1996 and M.Sc. in Food Science \& Technology (2000) all at the Kwame Nkrumah University of Science and Technology, Kumasi, Ghana. The energy consumption (bio-fuel and agricultural input) and its efficient use on one of the largest maize farms in West Africa was studied during his B.Sc. programme. Just after the B.Sc.

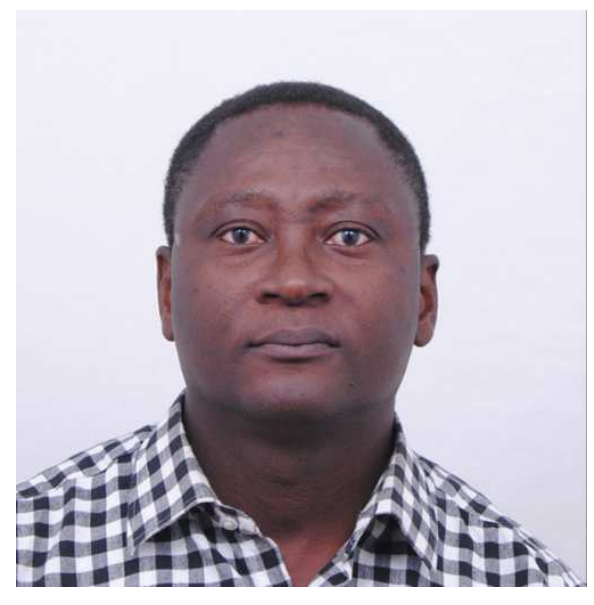
programme an offer to serve in the Agricultural Engineering Department as a teaching assistant was given. At the MSc. level, he worked on food product development/ sensory analysis and evaluation of some varieties of tomatoes in Ghana as a potential use as tomato ketchup, using the gravity method as a means of concentration. After the MSc. level an offer was also given to work as an Assistant lecturer (2001) which was upgraded to a lecturer position in 2002. As a lecturer both the BSc. and MSc. students were supervised in areas ranging from preparation of weaning foods using local materials (maize, soy bean, rice etc.), heat treatment effect of food nutrients, microbiological studies, composite fruit drinks (e.g. moringa-fruit beverages), improving efficiencies of local drying and its effect on agricultural materials, establishing the sensory and chemical stability of Wagashie (a Ghanaian local cheese), drying characteristics and physicochemical properties of two varieties of plantain, etc. Emmanuel's main areas of recent research has been in model based design and manufacture of Solar - Adsorption Drying Systems (SADS). In 2005-2006 he was the Principal Investigator in a World Bank funded project titled "Design and Manufacture of Solar and Oven Driers Using local materials to Improve Drying Operations at the Biochemistry, Biotechnology and Food Science Departments." This World Bank project was funded through Ghana Ministry of Education, Youth and Sports (MEYS), Ghana National Council for Tertiary Education (NCTE), and Ghana Education Sector Project (EDSEP). He has supervised over $30 \mathrm{MSc} / \mathrm{MPhil}$ students and numerous number of BSc students in their theses. His sandwich $\mathrm{PhD}$ research in Wageningen University Research center was begun in September 2010. It involved some few months in the Netherlands for completion of proposal, take some courses as part of the award of the degree, research conferences both within and abroad and to conduct most of the experimental work in the researcher's home country. The title of the PhD research work is "Drying of yam with solar adsorption system". Six MSc/MPhil students have been supervised the candidate in using the solar adsorption dryer equipment for their experimental work. 


\section{List of publications}

- Amankwah, E. A., K. A. Dsizi, G. van Straten, and A. J. B. van Boxtel. 2018. Modeling the equilibrium moisture content of desorption and adsorption of yam (Dente).

Agricultural Engineering International: CIGR Journal, 20(1): 184-192.

- Amankwah, Emmanuel A.; Dzisi, Komla Agbeko; Straten, Gerrit van; Boxtel, Anton J.B. van 2018. Moisture dependent diffusion and shrinkage in yam during drying, International Journal of Food Engineering, 14(7-8), ISSN 2194-5764 - 15 p.

- E. A. Y. Amankwah, K. A. Dzisi, G. van Straten, L. G. van Willigenburg \& A. J. B. van Boxtel (2017) Distributed mathematical model supporting design and construction of solar collectors for drying, Drying Technology, 35:14, 1675-1687.

\section{Conference proceedings (peer reviewed)}

- Amankwah, E.A. Dzisi, K.A. van Straten, G. and van Boxtel, A.J.B. (2014) Modeling the drying and sorption behavior of Yam (Dioscoreaceae rotundata), 3rd International Conference and Exhibition on Food Processing and Technology, July 21-23, 2014, Hampton inn, Las Vegas, USA.

- Amankwah, E.A., K.A. Dzisi, G. van Straten, A.J.B. van Boxtel, Modeling the solar collector for drying agricultural products, 18th International Drying Symposium November 11th - 15th, 2012, Vol B, Swiss International Hotel, Xiamen, China.

- Ooteghem R.J.C. van, Amankwah E.A., Boxtel, A.J.B. Recursive identification of timevariant model parameters from drying curves. IDS2016. Gifu Japan. 


\section{Completed training activities}

\section{Discipline specific activities}

Reaction kinetics in food science, VLAG, 2013

Physical modeling, SENSE, 2010

3rd International Conference and Exhibition on Food Processing and Technology, July 21-23, 2014, Hampton inn, Las Vegas, USA.

\section{General courses}

VLAG student week, Venlo, VLAG, 2010

Sustainability analysis in food and biobased production, VLAG, 2014

Scientific writing, Centa, 2012

Presentation skills, Centa, 2012

End note X4, Library, 2012

Lecturing, EDS, 2010

Conversation skills in One to one guidance, EDS, 2010

Food Structuring and rheology, WU

\section{Optional}

Writing/updating project proposal, SCO, 2010

Control engineering, SCO, 2011 
This work was performed at Wageningen University within the chair group Biobased Chemistry and Technology. The research has been financially supported by the Wageningen University Fund and Kwame Nkrumah University of Science and Technology.

Cover design: Emmanuel Peprah, Perpx Print Solutions 